University of Louisville

ThinkIR: The University of Louisville's Institutional Repository

Electronic Theses and Dissertations

$12-2011$

\title{
Analyzing common algebra-related misconceptions and errors of middle school students.
}

Sarah B. Bush

University of Louisville

Follow this and additional works at: https://ir.library.louisville.edu/etd

Part of the Algebra Commons, and the Junior High, Intermediate, Middle School Education and Teaching Commons

\section{Recommended Citation}

Bush, Sarah B., "Analyzing common algebra-related misconceptions and errors of middle school students." (2011). Electronic Theses and Dissertations. Paper 187.

https://doi.org/10.18297/etd/187

This Doctoral Dissertation is brought to you for free and open access by ThinkIR: The University of Louisville's Institutional Repository. It has been accepted for inclusion in Electronic Theses and Dissertations by an authorized administrator of ThinkIR: The University of Louisville's Institutional Repository. This title appears here courtesy of the author, who has retained all other copyrights. For more information, please contact thinkir@louisville.edu. 


\title{
ANALYZING COMMON ALGEBRA-RELATED MISCONCEPTIONS AND ERRORS OF MIDDLE SCHOOL STUDENTS
}

\author{
By \\ Sarah B. Bush \\ B.S., Indiana University Southeast, 2005 \\ M.ED., Indiana Wesleyan University, 2008 \\ A Dissertation Submitted to the Faculty of the \\ College of Education and Human Development of the University of Louisville \\ in Partial Fulfillment of the Requirements \\ for the Degree of \\ Doctor of Philosophy \\ Department of Teaching and Learning \\ University of Louisville \\ Louisville, $\mathrm{KY}$
}

December 2011 
Copyright 2011 by Sarah B. Bush

All rights reserved 


\title{
ANALYZING COMMON ALGEBRA-RELATED MISCONCEPTIONS AND ERRORS OF MIDDLE SCHOOL STUDENTS
}

\author{
By
}

Sarah B. Bush

B.S., Indiana University Southeast, 2005

M.ED., Indiana Wesleyan University, 2008

A Dissertation Approved on

October 6, 2011

By the following Dissertation Committee:

Karen Karp, Dissertation Director

Maggie McGatha

Sam Stringfield

E. Todd Brown

William Bush 


\author{
DEDICATION \\ In loving memory of my grandmother (Me-Me) \\ Lenelda June Sieg \\ a great role model who taught me the value of kindness. \\ $\&$ \\ To my dad \\ Norman Anthony Thomas Jr. \\ who taught me the value of hard work.
}




\section{ACKNOWLEDGMENTS}

This dissertation represents a milestone and stepping stone in my journey as a lifelong learner and contributor to the field of mathematics education. Without the guidance, support, patience, and critical advice given to me by those involved in my doctoral journey, this dissertation would not be complete.

I will start by thanking Dr. William Jamski, my undergraduate advisor at Indiana University Southeast, who inspired and encouraged me to pursue my doctorate in mathematics education. If it were not for him, my life would not have taken this path nor would I have been led to the University of Louisville.

Most importantly, I would like to thank Dr. Karen Karp, my advisor and dissertation chair. In addition to being a uniquely great advisor, Dr. Karp also became a wonderful role model as I observed her dedication, success, and passion for the field of mathematics education, my Ph.D. Mom, a colleague I will always feel privileged and honored to work with, and a wonderful friend. From the beginning stages of my coursework, Dr. Karp challenged me far beyond the program requirements and as a result, truly prepared me for a new career in academia through invaluable research, service, and teaching experiences. While Dr. Karp's expectations were extremely high, she provided wonderful support, coaching, and mentoring so that I could be successful. I cannot ever thank her enough for being a rigorous advisor who always took time to provide me with timely and constructive feedback so that I could reflect and grow as a teacher and learner of mathematics education. 
I would also like to thank my committee members, Drs. E. Todd Brown, William Bush, Maggie McGatha and Samuel Stringfield for their help, support, and feedback throughout my dissertation journey. Specifically, I would like to thank Dr. Brown and Dr. McGatha for their valuable guidance from the beginning as I chose my topic and for extremely helpful feedback throughout the entire process. I would like to thank Dr. Bush for his extra time and help during the initial outline phase of my proposal and for his detailed editing comments and thoughtful suggestions throughout the remainder of the journey. I would like to thank Dr. Stringfield for his significant contributions as I drafted, edited, and fine-tuned my proposal. I will forever be indebted and grateful for their participation and role in my dissertation journey.

I would like to thank the following people who helped contribute to my dissertation either through help on a specific task or through their caring support: Robert Ronau, Amy English Hunter, Ryan Higgins, Elizabeth Popelka, Christopher Rakes, Namok Choi, and Stefanie Livers.

Finally, I would like to thank my husband and best friend Sam, who was enthusiastically my biggest supporter and fan on this journey. He is always willing to support my dreams and goals, listen to my frustrations, sacrifice our time for the sake of my dissertation, celebrate in my accomplishments, and encourage me to strive for more. 


\section{ABSTRACT \\ ANALYZING COMMON ALGEBRA-RELATED MISCONCEPTIONS AND \\ ERRORS OF MIDDLE SCHOOL STUDENTS}

Sarah B. Bush

October 6, 2011

The purpose of this study was to examine common algebra-related misconceptions and errors of middle school students. In recent years, success in Algebra I is often considered the mathematics gateway to graduation from high school and success beyond. Therefore, preparation for algebra in the middle grades is essential to student success in Algebra I and high school. This study examines the following research question: What common algebra-related misconceptions and errors exist among students in grades six and eight as identified on student responses on an annual statewide standardized assessment?

In this study, qualitative document analysis of existing data was used in order to analyze sixth- and eighth-grade student responses on a statewide standardized assessment. Secondary data sources consisted of Algebra I student responses which were also analyzed qualitatively using document analysis and follow-up interviews with key informants.

The primary analysis indicated that (1) numerous misconceptions and errors identified in the review of literature were present on both the sixth- and eighth-grade 
open-responses; (2) basic computational errors with whole numbers (a secondary skill), were found consistently throughout the sixth- and eighth-grade open-responses; (3) a greater number of misconceptions and errors identified in the review of the literature were present on the eighth-grade items than were found on the sixth-grade items; (4) students often lost points for reasons other than mathematical misconceptions or errors; and (5) some refinement and reorganization of Welder's (2007) framework could prove beneficial when using the framework for data analytic purposes.

The results of this study provided information about the common misconceptions and errors students possess on prerequisite algebra skills. The findings revealed common algebra misconceptions and trends that can help guide instruction for middle school mathematics teachers. The findings have direct implications for classroom practice and further confirm the need for strong and knowledgeable teachers of mathematics at the elementary and middle grades.

The researcher suggests that schools, both in the state whose standardized assessment was examined as well as other states, use this information to help build awareness of common prerequisite algebra-related misconceptions and errors in elementary and middle grades mathematics teachers. 


\section{TABLE OF CONTENTS}

PAGE

DEDICATION .....................................................

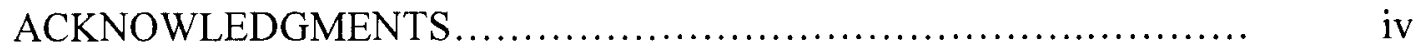

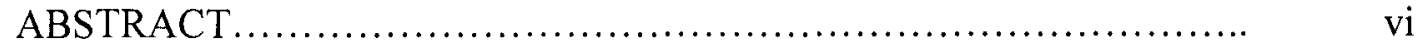

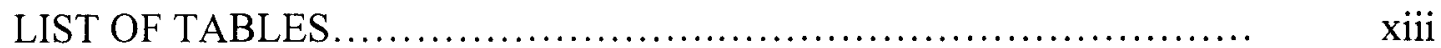

LIST OF FIGURES ................................................ xix

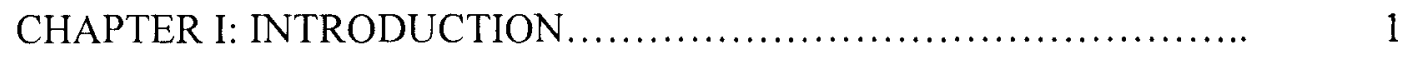

Overview......................................................

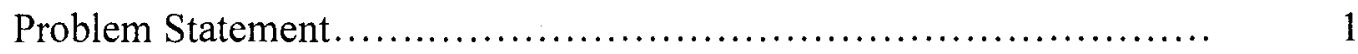

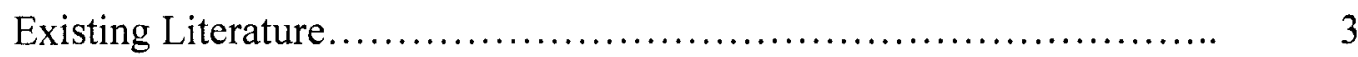

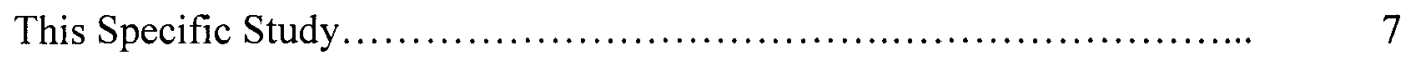

Research Question............................................. 8

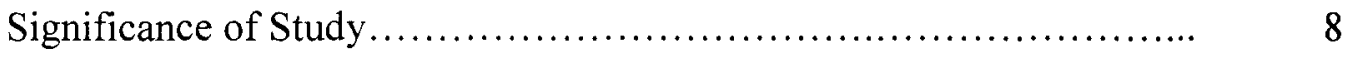

Delimitations................................................ 8

Assumptions .................................................... 9

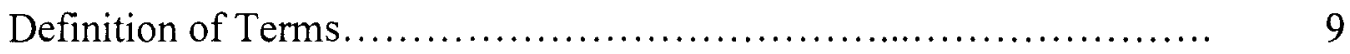

Organization of the Dissertation....................................... 10

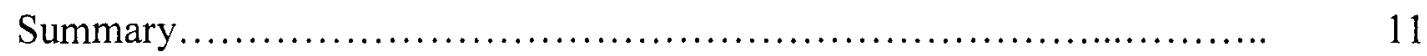

CHAPTER II: LITERATURE REVIEW ............................. 12

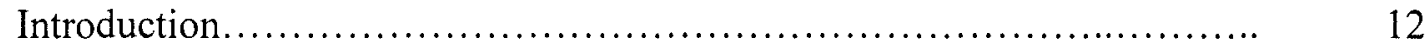

Literature Search.............................................. 13

Algebra Curriculum............................................. 14 
History of Algebra Curriculum...................................

Standards and Reform........................................... 16

Integrating Algebra Curriculum into K-8 Curriculum - Early Algebra... 20

Relevant Early Algebra Literature.................................. 21

Teacher Preparation for Teaching Algebra........................... 26

Placing Middle School Students in Algebra I........................ 29

Algebra Theoretical Construct for This Study ........................ 32

Mathematics Misconceptions...................................... 33

Misconceptions/Errors (Conceptual/Procedural)..................... 33

Mathematics Misconception Theoretical Construct for This Study....... 37

Theoretical Framework............................................ 38

Research Question.............................................. 38

Selecting a Framework........................................ 38

Framework Chosen for This Study..................................... $\quad 39$

Numbers and Numerical Operations............................... 42

Ratios and Proportions...........................................

The Order of Operations..............................................

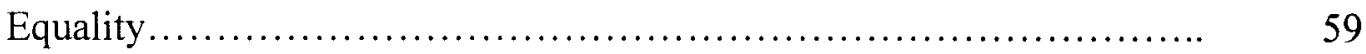

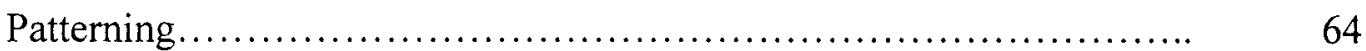

Algebra Symbolism and Letter Usage.............................

Algebraic Equations............................................

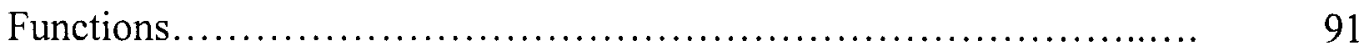

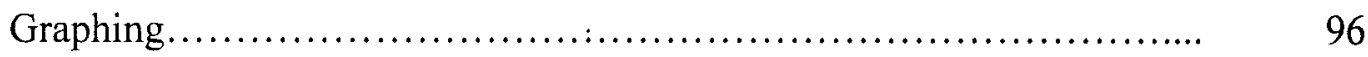


Conclusions..................................................... 101

Chapter II Summary ........................................... 101

Restatement of Research Question................................. 108

CHAPTER III: METHODOLOGY....................................... 109

Restatement of Purpose and Research Question........................ 109

Type of Research............................................ 109

Rationale for Qualitative Research................................. $\quad 110$

Appropriateness for This Study .................................... 111

Population and Sample.............................................. 112

Population.................................................... 112

Sample and Sampling Procedures................................. 112

Instrumentation...................................................... 114

Description of Instruments......................................... 114

Type of Response Categories....................................... 116

Rationale for Instruments in the Study ............................ 118

Information on Instrument Validity ................................ 119

Information on Instrument Reliability ................................. 119

How Instruments were Administered............................... $\quad 120$

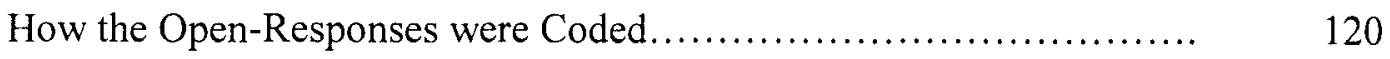

Data Collection Procedures.......................................... $\quad 124$

How Data were Collected.......................................... 124

When Data were Collected......................................... 126

Where Data were Collected........................................ $\quad 126$ 
Procedures Stated in Order of Occurrence........................... 127

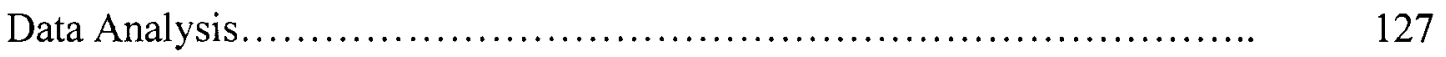

How Data Will be Reported and Displayed........................ 127

Trustworthiness of Data...................................... $\quad 128$

Methods Used to Analyze Data................................... 132

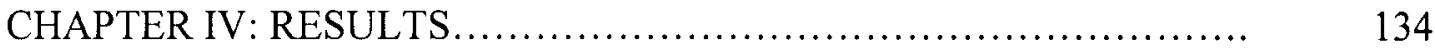

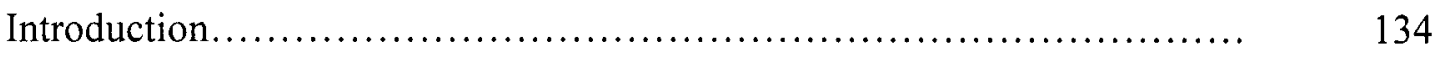

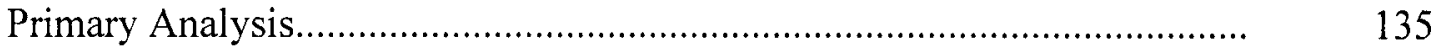

Overview..................................................... 135

Organization of Primary Analysis................................. 136

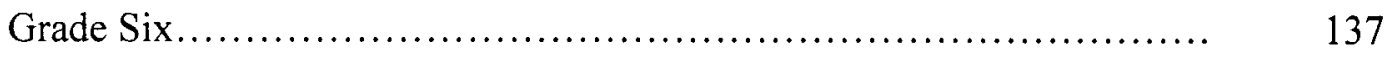

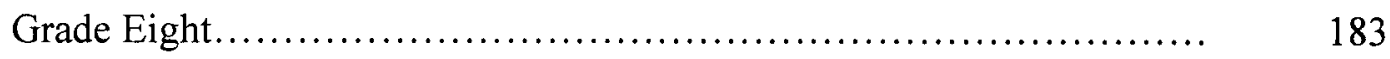

Additional Findings............................................ $\quad 242$

Summary of Primary Findings......................................

Other Primary Findings.......................................... $\quad 248$

Secondary Analysis - Connections to Algebra 1...................... 250

Overview................................................. $\quad 250$

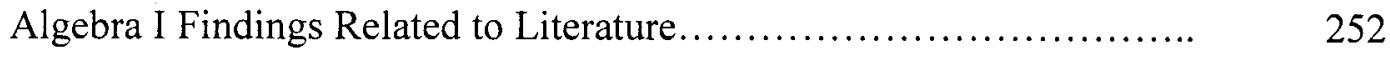

Summary of Secondary Findings................................. $\quad 258$

Secondary Analysis - Interviews with Key Informants.................. 260

Conclusion ........................................................... 266

CHAPTER V: DISCUSSION ....................................... $\quad 267$

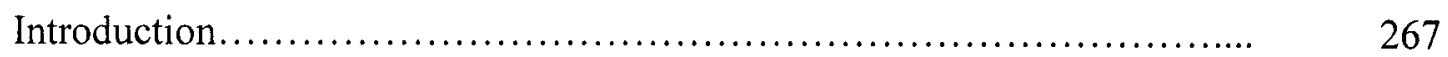


Summary of the Study ............................................ 267

Restatement of Problem Statement................................. $\quad 267$

Restatement of Purpose and Research Question....................... $\quad 269$

Review of Research Methodology.................................... $\quad 269$

Summary of Primary Findings.................................... $\quad 271$

Summary of Secondary Findings................................... $\quad 275$

Comparison of Primary and Secondary Findings...................... 277

Linking Findings to the Literature ...................................... 280

Conclusions........................................................... 282

Implications for Practice ......................................... $\quad 282$

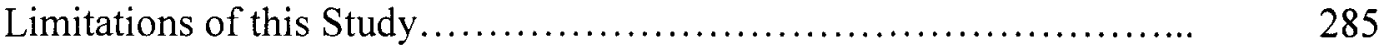

Recommendations for Future Research............................. $\quad 287$

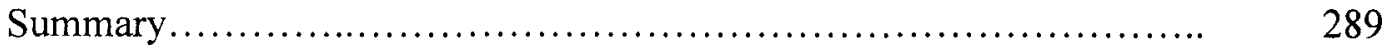

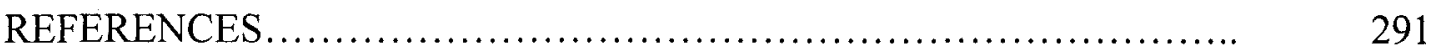

APPENDICES .................................................. 312

Appendix A: Interview Guide and Informed Consent................... 312

Appendix B: Pre-Analysis Codes from Literature........................ $\quad 320$

Appendix C: Final Coding Sheets.................................... $\quad 327$

CURRICULUM VITAE .............................................. 340 


\section{LIST OF TABLES}

TABLE

PAGE

1. NCTM Algebra Standard Expectations Grades 6-8................... 17

2. Middle School CCSS Algebra-Related Standards Grades 6-8............ 19

3. Kaput's Construct of Algebraic Reasoning........................... 32

4. Alignment of Nine Prerequisite Content Areas to Mathematics

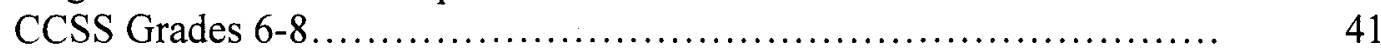

5. Ashlock's Fraction-Related Errors................................ 44

6. Ashlock's Decimal-Related Errors.................................. 46

7. Küchemann's Hierarchy of Variables............................ 74

8. Sampling Procedures by Year.................................... $\quad 114$

9. Questions Relating to Welder's Prerequisite Content Areas.............. 115

10. Inter-rater Reliability by Content Area............................. 123

11. Summary Table: Item 1, Sixth-Grade.............................. 139

12. Summary Table: Item 2, Sixth-Grade........................... 141

13. Sixth-Grade Numbers and Numerical Operations, Item $2 \ldots \ldots \ldots \ldots \ldots . \quad 142$

14. Summary Table: Item 3, Sixth-Grade............................ 144

15. Summary Table: Item 4, Sixth-Grade............................ 147

16. Sixth-Grade Ratios and Proportions, Item 4..................... 147.

17. Sixth-Grade Algebraic Symbolism and Letter Usage, Item 4.......... 147 
18. Summary Table: Item 5, Sixth-Grade..............................

19. Summary Table: Item 6 , Sixth-Grade............................... 151

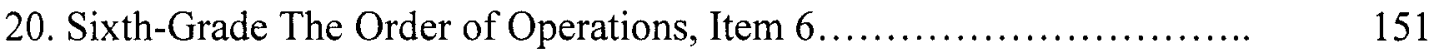

21. Sixth-Grade Algebraic Symbolism and Letter Usage, Item 6............ 152

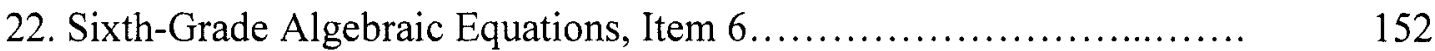

23. Summary Table: Item 7, Sixth-Grade................................ 154

24. Sixth-Grade Ratios and Proportions, Item 7 ........................ 155

25. Sixth-Grade Patterning, Item 7 ................................. 155

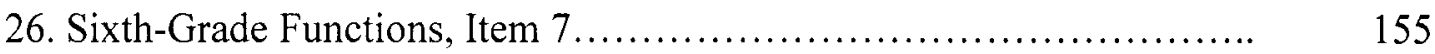

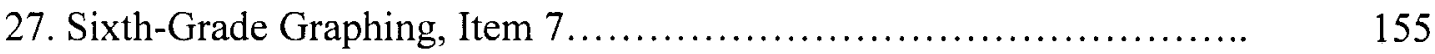

28. Summary Table: Item 8, Sixth-Grade............................... 157

29. Summary Table: Item 9, Sixth-Grade ............................... $\quad 159$

30. Summary Table: Item 10, Sixth-Grade............................... 161

31. Sixth-Grade Algebraic Symbolism and Letter Usage, Item 10.......... 161

32. Summary Table: Item 11, Sixth-Grade............................. 163

33. Sixth-Grade Numbers and Numerical Operations, Item 11............ 164

34. Summary Table: Item 12, Sixth-Grade.............................. 167

35. Sixth-Grade Numbers and Numerical Operations, Item $12 \ldots \ldots \ldots \ldots \ldots . . . .67$

36. Sixth-Grade Numbers Ratios and Proportions, Item 12............... 167

37. Summary Table: Item 13, Sixth-Grade ............................. 169

38. Sixth-Grade Functions, Item 13.................................. 169

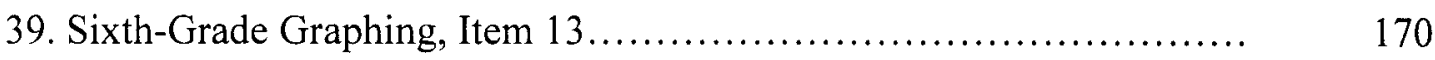

40. Summary Table: Item 14, Sixth-Grade.............................. 172 
41. Sixth-Grade Numbers and Numerical Operations, Item 14............ 172

42. Summary Table: Item 15, Sixth-Grade......................... 174

43. Summary Table: Item 16, Sixth-Grade......................... 175

44. Sixth-Grade Algebraic Symbolism and Letter Usage, Item 16......... 176

45. Summary Table: Item 17, Sixth-Grade........................ 177

46. Summary Table: Item 18, Sixth-Grade......................... 179

47. Summary Table: Item 19, Sixth-Grade.......................... 181

48. Sixth-Grade Numbers and Numerical Operations, Item 19........... 181

49. Sixth-Grade Ratios and Proportions, Item 19..................... 181

50. Summary Table: Item 20, Sixth-Grade........................ 183

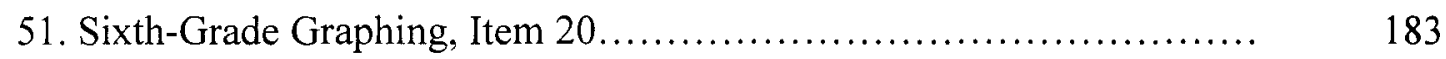

52. Summary Table: Item 1, Eighth-Grade .......................... 186

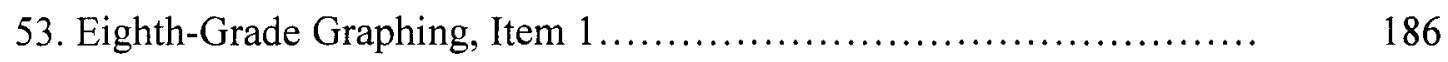

54. Summary Table: Item 2, Eighth-Grade.......................... 188

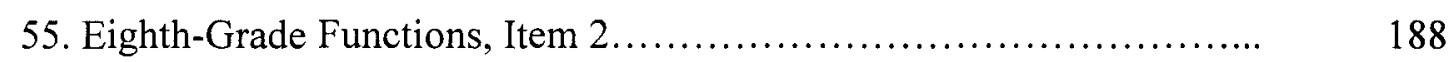

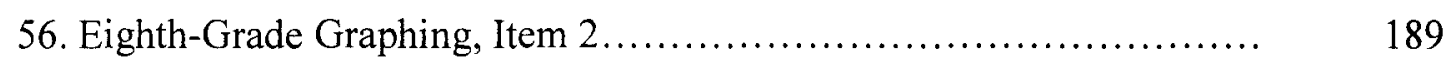

57. Summary Table: Item 3, Eighth-Grade.......................... 190

58. Eighth-Grade Numbers and Numerical Operations, Item 3............ 191

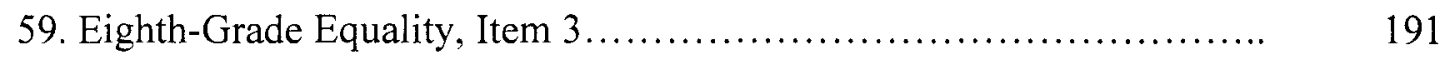

60. Eighth-Grade Algebraic Equations, Item 3....................... 191

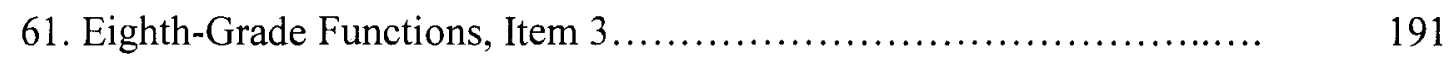

62. Summary Table: Item 4, Eighth-Grade.......................... 193

63. Eighth-Grade Numbers and Numerical Operations, Item 4........... 193 
64. Eighth-Grade Algebraic Symbolism and Letter Usage, Item 4......... 193

65. Summary Table: Item 5, Eighth-Grade......................... 195

66. Eighth-Grade The Order of Operations, Item 5.................. 196

67. Eighth-Grade Algebraic Equations, Item 5....................... 196

68. Summary Table: Item 6, Eighth-Grade......................... 198

69. Eighth-Grade Numbers and Numerical Operations, Item $6 \ldots \ldots \ldots \ldots \ldots . \quad 198$

70. Eighth-Grade The Order of Operations, Item 6................... 198

71. Summary Table: Item 7, Eighth-Grade.......................... 200

72. Eighth-Grade Numbers and Numerical Operations, Item 7........... 200

73. Eighth-Grade Ratios and Proportions, Item 7..................... 201

74. Summary Table: Item 8, Eighth-Grade......................... 202

75. Eighth-Grade Numbers and Numerical Operations, Item $8 \ldots \ldots \ldots \ldots \ldots .202$

76. Summary Table: Item 9, Eighth-Grade.......................... 204

77. Eighth-Grade Numbers and Numerical Operations, Item $9 \ldots \ldots \ldots \ldots . .205$

78. Eighth-Grade Ratios and Proportions, Item 9.................... 205

79. Summary Table: Item 10, Eighth-Grade........................ 207

80. Eighth-Grade Ratios and Proportions, Item $10 \ldots \ldots \ldots \ldots \ldots \ldots \ldots \ldots . \ldots \ldots$

81. Summary Table: Item 11, Eighth-Grade......................... 209

82. Eighth-Grade Numbers and Numerical Operations, Item $11 \ldots \ldots \ldots \ldots . .209$

83. Eighth-Grade Ratios and Proportions, Item 11.................... 210

84. Summary Table: Item 12, Eighth-Grade........................... 211

85. Eighth-Grade Numbers and Numerical Operations, Item $12 \ldots \ldots \ldots \ldots . .212$

86. Summary Table: Item 13, Eighth-Grade........................... 214 
87. Eighth-Grade Numbers and Numerical Operations, Item 13............ 214

88. Eighth-Grade Algebraic Equations, Item 13....................... 214

89. Summary Table: Item 14, Eighth-Grade ............................ 216

90. Eighth-Grade Numbers and Numerical Operations, Item 14........... 216

91. Eighth-Grade The Order of Operations, Item $14 \ldots \ldots \ldots \ldots \ldots \ldots \ldots \ldots \ldots \ldots$

92. Summary Table: Item 15, Eighth-Grade............................. 218

93. Eighth-Grade Numbers and Numerical Operations, Item 15........... 219

94. Eighth-Grade Ratios and Proportions, Item 15..................... 219

95. Eighth-Grade Algebraic Equations, Item 15....................... 219

96. Summary Table: Item 16, Eighth-Grade........................... 221

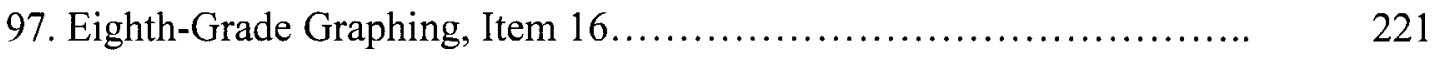

98. Summary Table: Item 17, Eighth-Grade............................ 223

99. Eighth-Grade Ratios and Proportions, Item 17..................... 223

100. Summary Table: Item 18, Eighth-Grade.......................... 225

101. Eighth-Grade Algebraic Equations, Item 18 ..................... 226

102. Summary Table: Item 19, Eighth-Grade......................... 227

103. Eighth-Grade Numbers and Numerical Operations, Item 19............ 228

104. Eighth-Grade The Order of Operations, Item 19.................. 228

105. Summary Table: Item 20, Eighth-Grade......................... 230

106. Eighth-Grade Numbers and Numerical Operations, Item $20 \ldots \ldots \ldots \ldots . \quad 231$

107. Summary Table: Item 21, Eighth-Grade.......................... 232

108. Eighth-Grade Algebraic Equations, Item $21 \ldots \ldots \ldots \ldots \ldots \ldots \ldots \ldots \ldots \ldots$

109. Summary Table: Item 22, Eighth-Grade......................... 234 


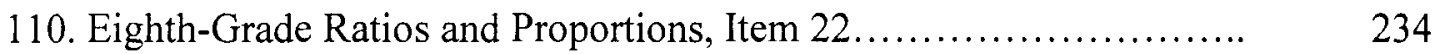

111. Summary Table: Item 23, Eighth-Grade.......................... 236

112. Eighth-Grade Numbers and Numerical Operations, Item $23 \ldots \ldots \ldots \ldots . .237$

113. Summary Table: Item 24, Eighth-Grade.......................... 238

114. Eighth-Grade Numbers and Numerical Operations, Item $24 \ldots \ldots \ldots \ldots . .239$

115. Eighth-Grade Ratios and Proportions, Item 24...................... 239

116. Summary Table: Item 25, Eighth-Grade........................... 241

117. Eighth-Grade Numbers and Numerical Operations, Item $25 \ldots \ldots \ldots \ldots . \quad 241$

118. Eighth-Grade Ratios and Proportions, Item 25..................... 242

119. Eighth-Grade The Order of Operations, Item $25 \ldots \ldots \ldots \ldots \ldots \ldots \ldots \ldots . \ldots \ldots$

120. Summary of Misconceptions and Errors Related to Welder's Nine

Prerequisite Content Areas........................................... $\quad 244$

121. Literature Connections Found in Algebra I and Sixth- and

Eighth-Grade Open-Responses...................................... $\quad 259$

122. Comparison of Findings Related to Welder's Nine Prerequisite

Content Areas..................................................... 278 


\section{LIST OF FIGURES}

\section{FIGURE}

PAGE

1. Lamon's Types of Ratios........................................ 52

2. Hierarchy of Arithmetic Operations................................ 56

3. Balance Model for Understanding of Equality ........................ 62

4. Growing Patterns Used in Radford's Study ............................. 69

5. Patterns on a Hundreds Chart....................................... 71

6. Routes from Problem Statement to Solution.......................... 84

7. Wollman's Hierarchy of Monitoring Processes....................... 87

8. One Part Response Question (0-2 points) - Grade 6................. 116

9. Multiple Part Response Question (0-2 points) - Grade 8.............. 117

10. Multiple Part Response Question (0-3 points) - Grade 8.............. 118

11. Organization of Data Analysis................................... 128

12. Item 1: Sixth-Grade .......................................... 138

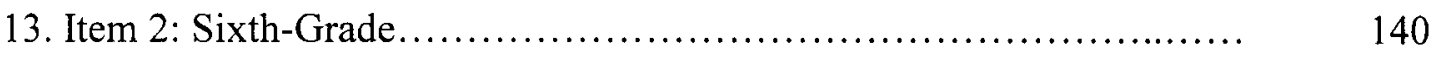

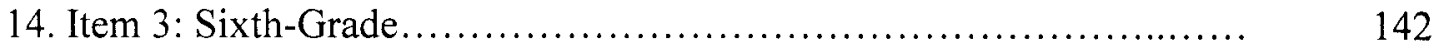

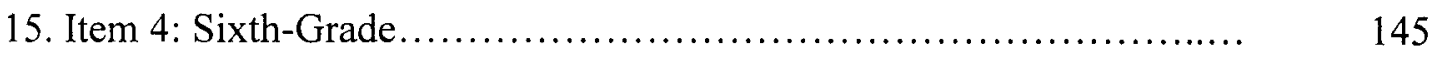

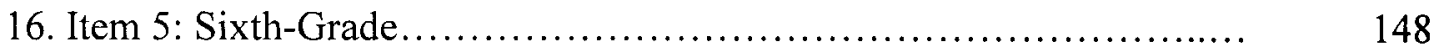

17. Item 6: Sixth-Grade .........................................

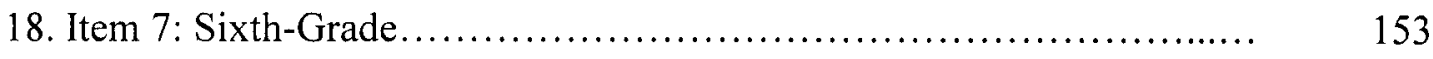




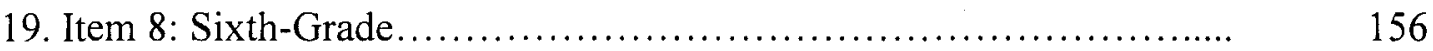

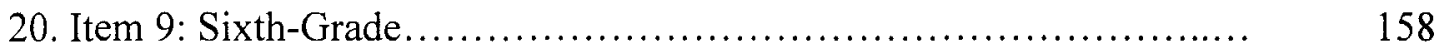

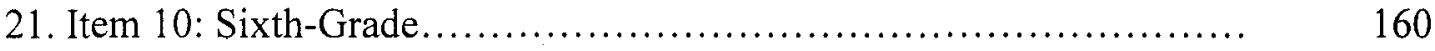

22. Item 11: Sixth-Grade............................................... 162

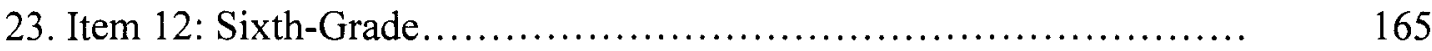

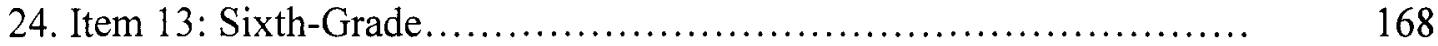

25. Item 14: Sixth-Grade.............................................. 170

26. Item 15: Sixth-Grade ............................................. 173

27. Item 16: Sixth-Grade............................................. 174

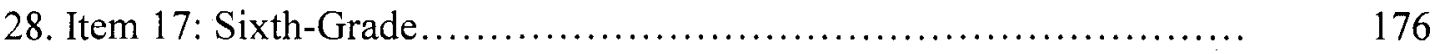

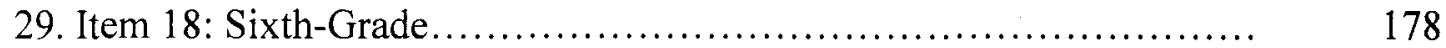

30. Item 19: Sixth-Grade.............................................. 180

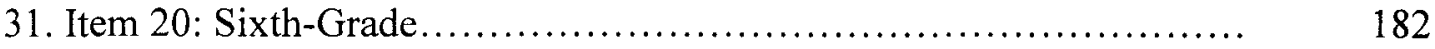

32. Item 1: Eighth-Grade ............................................. 184

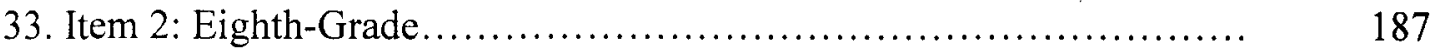

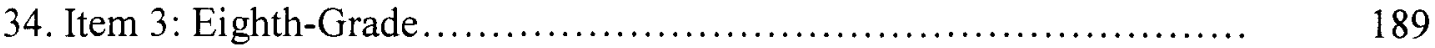

35. Item 4: Eighth-Grade ....................................... 192

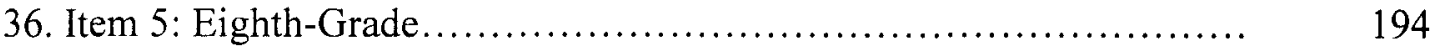

37. Item 6: Eighth-Grade......................................... 196

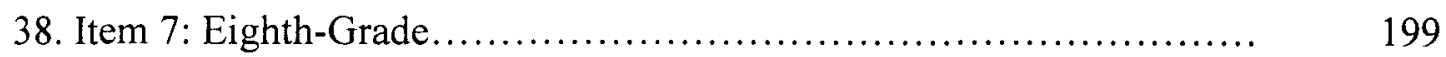

39. Item 8: Eighth-Grade.......................................... 201

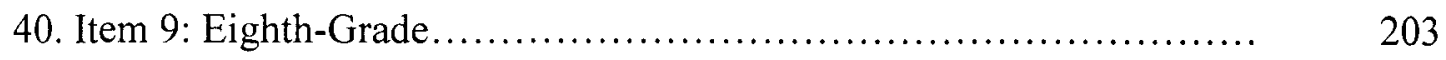

41. Item 10: Eighth-Grade......................................... 206 
42. Item 11: Eighth-Grade ........................................ 208

43. Item 12: Eighth-Grade ...................................... 210

44. Item 13: Eighth-Grade ....................................... $\quad 212$

45. Item 14: Eighth-Grade ....................................... 215

46. Item 15: Eighth-Grade........................................ $\quad 217$

47. Item 16: Eighth-Grade......................................... 220

48. Item 17: Eighth-Grade ...................................... 222

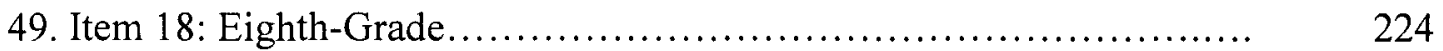

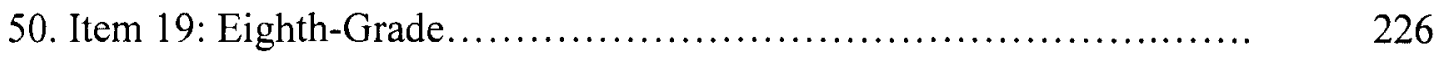

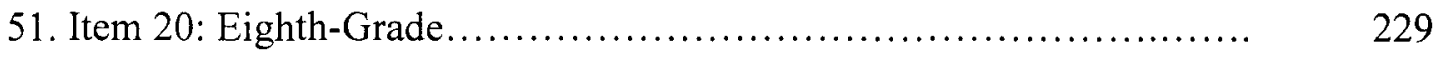

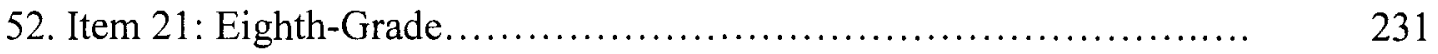

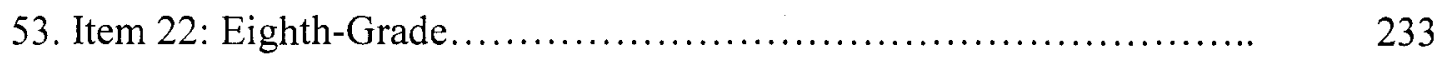

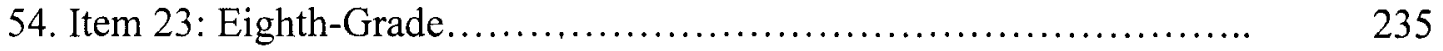

55. Item 24: Eighth-Grade ...................................... $\quad 237$

56. Item 25: Eighth-Grade ...................................... $\quad 240$ 


\section{CHAPTER I}

\section{INTRODUCTION}

\section{Overview}

This study examined algebra-related misconceptions and errors among middle school students. In recent years, many states have deemed proficiency in Algebra I the mathematics gateway to graduation from high school (Asquith, Stephens, Knuth, \& Alibali, 2007; Bottoms, 2003; Capraro \& Joffrion, 2006; Choike, 2000; Edwards, 2000; Erbas, 2005; House \& Telese, 2008; Jacobs, Franke, Carpenter, Levi, \& Battey, 2007; Kaput, 2000a; Nathan \& Koellner, 2007; Spielhagen, 2006a; Stephens, 2005; Welder, 2007; Witzel, 2005). In addition, school districts are highly encouraged to offer Algebra I to eighth- and even seventh-grade students (Fennell et al., 2007; Spielhagen, 2006a). Therefore, preparation for algebra in the middle grades is essential to student success in Algebra I and high school (Bottoms, 2003; Capraro \& Joffrion, 2006; Silver, 2000).

\section{Problem Statement}

The importance of examining algebra misconceptions and errors of middle school students stems from our nation's goal to remain mathematically competitive. High school students are encouraged to take more mathematics courses with increased difficulty (National Council of Teachers of Mathematics, 2009). Additionally, states are holding students and schools responsible by requiring students to pass graduation tests that demonstrate understanding of algebra (Bottoms, 2003). This pressure places great 
responsibility on mathematics teachers to teach algebra in ways that help all students in becoming skilled (Capraro \& Joffrion, 2006).

This increase in mathematics accountability has caused mathematics content to be "pushed down" into earlier grades. A significant movement in mathematics education suggests that one element in leading students towards a successful path in algebra is the integration of algebraic thinking skills starting in elementary school and extending into the middle grades (Asquith et al., 2007; Baroudi, 2006; Blanton \& Kaput, 2005; Capraro \& Joffrion, 2006; Carraher, Schliemann, Brizuela, \& Ernest, 2006; Erbas, 2005; Falkner, Levi, \& Carpenter, 1999; NCTM, 2000; Warren, 2009). Pre-algebra concepts are commonly a curriculum focus for sixth- and seventh-grade, while eighth-grade students often enroll in first-year algebra (Witzel, 2005).

The National Council of Teachers of Mathematics (NCTM) states that algebrarelated skills should be addressed in the middle grades as documented in their Principles and Standards for School Mathematics (2000). Specifically, this study aligns with the NCTM Algebra content standard for grades 6-8 from Principles and Standards for School Mathematics (NCTM, 2000). The NCTM (2000) supports the belief that teachers should both introduce and continuously build upon algebraic thinking concepts in early grades. For example, the NCTM Curriculum Focal Points states that students in grade six should "...write mathematical expressions and equations that correspond to given situations, they evaluate expressions, and they use expressions and formulas to solve problems" (NCTM, 2006, p. 35). By the time students finish grade eight, the Curriculum Focal Points state that students should "...use linear functions, linear equations, and 
systems of linear equations to represent, analyze, and solve a variety of problems" (NCTM, 2006, p. 39).

Similarly, the newly released Common Core State Standards (CCSS) (CCSSO/NGA, 2010) have an Expression and Equation standard for each of grades six, seven, and eight and a Functions standard for grade eight (CCSSO/NGA, 2010). The "About the Standards" tab of the CCSS website states that the standards were designed to “...define the knowledge and skills students should have within their K-12 education careers so that they will graduate high school able to succeed in entry-level, creditbearing academic college courses and in workforce training programs" (CCSSO/NGA, 2010, para.4). As of September 2011, 44 states in our nation had already adopted these newly released standards.

\section{Existing Literature}

Many studies have been conducted to examine the teaching and learning of mathematics and more specifically, algebra. For example, Richard Skemp first introduced

procedural versus conceptual knowledge in the 1970's. Skemp (1976/2006) advocated for the relational (e.g. conceptual) teaching and learning of mathematics instead of instrumental (e.g. procedural). Skemp argued that relational versus instrumental learning of mathematics were "...two kinds of knowledge (that) are so different that I think there is a strong case for regarding them as different kinds of mathematics" (Skemp, 1976/2006, p. 95).

Likewise, Hiebert et al. (2000) studied the need to teach for understanding and classroom characteristics that fostered understanding and compared U.S. classroom practices to those of other countries through analysis of Trends in International 
Mathematics and Science Study (TIMSS) video studies (Hiebert et al., 2000; Hiebert et al., 2005; Stigler \& Hiebert, 2004). More specific to algebra, Capraro and Joffrion (2006) conducted a study analyzing algebra misconceptions among 668 middle-school students. Their study focused on students' ability to form an algebraic expression or equation from written words. Although their study analyzed common student misconceptions, it focused on whether students made mistakes because of their lack of procedural or conceptual knowledge.

Moreover, other studies were conducted regarding when students should enroll in Algebra I. Spielhagen (2006a, 2006b) studied whether students should enroll in Algebra I in the eighth-grade. He concluded that Algebra I should be offered to more, if not all students, in the eighth-grade. His findings supported the notion that providing Algebra I to students in the eighth-grade can be used to close the achievement gap related to socioeconomic status (Spielhagen, 2006a, 2006b). Aligned with the idea of offering Algebra I to more eighth-grade students, The National Mathematics Advisory Panel stated in their final report that "Federal and state policies should give incentives to schools to offer an authentic Algebra I course in Grade 8..." (Fennell et al., 2007, p. 15).

TIMSS is one of the most widely known studies in school mathematics worldwide. House and Telese (2008) used TIMSS 2003 student data to examine the connections among instructional strategies, adolescent algebra achievement, and student beliefs about mathematics. They found that higher test scores in algebra were usually earned by students who believed they learned quickly in mathematics and who viewed success in mathematics as an important factor to getting accepted to a college of their choice. Nathan and Koellner (2007) also acknowledged the importance of studying these 
relationships. They reported that "to understand students' algebraic reasoning and development, we need to pay attention to classroom interactions, student preconceptions, teachers' beliefs about mathematics and learning..." (Nathan \& Koellner, 2007, p. 180).

Additionally, studies focused on algebra teaching strategies and best practices can be used to address common misconceptions. For example, Willoughby (1997) identified several strategies to help students learn about functions through use of calculators, function machines, and graphing. Hawes (2007) recommended teaching equation solving as a whole-class activity while students perform error analysis during a "pass the pen" equation solving activity. Rivera and Becker (2009) focused on helping students learn to reason algebraically through the use of patterns. They suggested that requiring students to state a hypothesis about a pattern, verify and test the hypothesis, and provide justification helped prepare students for algebra. Each of these authors worked towards understanding and developing teaching practices that foster students' understanding of algebra.

Studies also were conducted that addressed one specific type of algebra misconception or error (as found in Brown \& Quinn, 2006; Capraro \& Joffrion, 2006; Chaiklin, Lesgold, \& Pittsburgh University Learning Research and Development Center, 1984; Falkner et al., 1999; MacGregor \& Stacey, 1997; Markovits, Eylon, \& Bruckheimer, 1988; Philipp, 1992a; Schwartzman, 1996; Stacey \& MacGregor, 1997b; Steinberg, Sleeman, \& Ktorza, 1990; Wollman, 1983). Stacey and MacGregor (2000) developed a set of word problems in which students were asked to write an equation representing the problem and then find the correct answer using any method. Students' open-responses were collected from approximately 900 students from ages 13-16 in 12 secondary schools. The results revealed that only about one-third of students in year 10 
were able to write correct corresponding equations while many more students were able to obtain the correct answer through alternative methods such as logical arithmetic reasoning or guess and check. Furthermore, many students did not attempt to use algebra and had more difficulty solving problems correctly if its corresponding algebraic equation had variables on both sides of the equal sign (Stacey \& MacGregor, 2000).

Steinberg, Sleeman, and Ktorza (1990) studied equivalence of equations. Their sample consisted of 96 eighth- and ninth-grade students who had completed a unit on solving one-variable equations. Students were asked to decide if 21 pairs of equations were equivalent. The results revealed that only about one-third of the problems were solved through use of transforming equations (e.g. students recognized the second equation was correctly derived from the first, compared elements term by term, etc.) while most problems were solved through computing solutions or through methods used incorrectly. Common misconceptions identified in their analysis included students not understanding like terms, only looking at one side of the equation (not both), and using surface features to base decisions (Steinberg et al., 1990).

While many studies contributed to the knowledge base of algebra learning for middle school students; others are focused on teaching, assessment, or other areas that are not directly related to misconceptions and errors. Most studies related to algebra misconceptions and errors are often conducted on a very small scale (e.g. one classroom, 20 students) (as found in Bastable \& Schifter, 2008; Kaput, 2000b; Kaput \& Blanton, 2001) or focus on one specific skill (as found in Brown \& Quinn, 2006; Capraro \& Joffrion, 2006; Falkner et al., 1999; MacGregor \& Stacey, 1997; Stacey \& MacGregor, 1997b; Steinberg et al., 1990; Wollman, 1983). 


\section{This Specific Study}

This study was designed to address the need to increase algebra achievement through identifying student misconceptions and errors with regards to prerequisite algebra skills. For purposes of this study, misconceptions were linked to conceptual misunderstandings whereas errors were linked to procedures. Additionally, students' ability to reason was considered. Welder $(2006,2007,2010)$ identified nine prerequisite content areas in which students should be knowledgeable before entering their first formal algebra course. The nine prerequisite content areas were as follows: (1) numbers and numerical operations, (2) ratios and proportions, (3) the order of operations, (4) equality, (5) patterning, (6) algebraic symbolism and letter usage, (7) algebraic equations, (8) functions, and (9) graphing. These nine prerequisite content areas provided a framework for this study.

In this current study, Welder's (2007) nine prerequisite content areas were aligned to student response questions from a standardized assessment given to students in one Midwestern state. Responses were analyzed and the results identified common misconceptions and errors as they related to the review of literature as well as other interesting findings. Overall, this study sought to find common misconceptions and errors students possessed on the nine prerequisite algebra skills as outlined by Welder. Two secondary analyses were also conducted. The results of this study aim to provide current instructional guidance to middle school mathematics and Algebra I teachers in the state where the investigation took place as well as those that may be generalizable to other states and classrooms. 


\section{Research Question}

The purpose of this study was to examine and categorize common algebra misconceptions and errors of middle school students aligned to Welder's (2007) nine prerequisite content areas in which students should be knowledgeable before entering their first formal algebra course (Algebra I). The research question for this study was the following:

1. What common algebra-related misconceptions and errors exist among students in grades six and eight as identified on student responses on an annual statewide standardized assessment?

\section{Significance of Study}

The results of this study provided valuable information about common misconceptions and errors students possess on prerequisite algebra skills. The findings revealed common algebra misconceptions and trends that can help guide instruction for middle school mathematics teachers. Overall, the primary audience for the findings of this study was middle school mathematics teachers, first-year algebra teachers, and upper elementary teachers. The secondary audience included curriculum specialists, school administrators, and teacher educators.

\section{Delimitations}

There were several delimitations for this study. First, the student work examined in this study was taken from students in grades six and eight only. While this presents a significant task in itself, it is likely that more and different misconceptions and errors would have been revealed if the study was expanded from elementary school through college level mathematics. Second, this study focused specifically on algebra-related 
misconceptions and errors, not all areas of middle school mathematics (e.g. geometry, probability, etc.). Third, standardized assessments often test lower level mathematics skills because such skills are testable by paper exams and are considered easier to score. The assessment data used in this study is not categorized by depth of knowledge (DOK) levels. However, it is quite possible that the open-response questions from this standardized assessment reflect higher DOK levels than multiple-choice or griddedresponse (where student work is not examined) sections of the state's assessment.

Additionally, the existing data used for this study were collected from only one Midwestern state. Other states in the nation likely give similar summative tests but question types and difficulty levels vary from state to state as well as the state mathematics standards. If data were collected using a sample of other states' standardized assessments, it is likely some findings would be different.

\section{Assumptions}

The main assumption for this study was that the student responses analyzed in this study accurately reflect students' true knowledge and skill level for each question.

\section{Definition of Terms}

Error: A mistake made consistently in performing algebraic skills. This is often related to a student's ability to remember a skill or procedural knowledge.

First-year algebra: The first formal algebra course a student takes, typically in the eighth- or ninth-grade. This course is commonly called Algebra I. This course is not the first time students are introduced to algebra. 
Misconception: Refers to a student's problem or difficulty in understanding key algebraic concepts. A misconception is related to understanding and conceptual knowledge.

Open-response Question: An assessment item where students must respond to a question or task by constructing a written answer (Panasuk \& Beyranevand, 2010). Students are not given a list of answer choices. In this study, the open-response questions examined may have one or more than one part.

Reasoning: A student's ability to justify statements, relationships, and the process used to respond to an open-response question.

Standardized Assessment: High-stakes standardized assessments for students in grades 3-8. For purposes of this study, only mathematics questions on the assessment relating to Welder's (2007) nine prerequisite skills for algebra were analyzed.

\section{Organization of the Dissertation}

The organization of the remaining chapters of this dissertation is as follows:

Chapter II provides a review of literature on research-related algebra curriculum, mathematics misconceptions, and most significantly, the nine prerequisite content areas in algebra in which students should be knowledgeable before entering their first formal algebra course. Chapter III discusses the methodology for analyzing student misconceptions and errors related to the nine prerequisite content areas as outlined by Welder (2007). Chapter IV contains a description of the results of the study. Chapter V provides conclusions, discussion, limitations, and recommendations for future studies. 


\section{Summary}

Many studies have focused on the teaching and learning of school algebra. The goal of this study was to identify common misconceptions and errors students have on prerequisite algebra skills and provide a focus for algebra-related curriculum and instruction in the middle grades. While some studies provided valuable insight to specific algebra-related misconceptions and errors at various grade levels, this study examined a variety of misconceptions and errors related to Welder's (2007) nine prerequisite content areas in which students should be knowledgeable before entering their first formal algebra course. The nine prerequisite content areas were: (1) numbers and numerical operations, (2) ratios and proportions, (3) the order of operations, (4) equality, (5) patterning, (6) algebraic symbolism and letter usage, (7) algebraic equations, (8) functions, and (9) graphing (Welder, 2007).

Welder's $(2006,2007,2010)$ nine prerequisite content areas were aligned to student response questions from a standardized assessment given to students in grades six and eight in one Midwestern state. Responses were analyzed and the results identified common misconceptions and errors as well as other interesting findings. The researcher also conducted two secondary analyses which are discussed in Chapter III. 


\section{CHAPTER II \\ LITERATURE REVIEW}

\section{Introduction}

This chapter provides a literature review related to algebra in schools and algebra misconceptions and errors among students. First discussed is literature related to algebra curriculum including the following subtopics: (a) history of algebra curriculum; (b) standards and reform; (c) integrating algebra into K-8 curriculum - early algebra; (d) relevant early algebra literature; (e) teacher preparation; (f) placing middle school students in Algebra I, and a (g) algebra theoretical construct for this study. Second, literature reporting common algebra misconception and errors and a discussion of the mathematics misconception theoretical construct for this study is provided.

Third, the research question and selection of the theoretical framework for this study is discussed. Using the framework selected from Welder (2007), a review of literature was conducted related to each of the nine prerequisite content areas for success in Algebra I which includes the following: (1) numbers and numerical operations, (2) ratios and proportions, (3) the order of operations, (4) equality, (5) patterning, (6) algebraic symbolism and letter usage, (7) algebraic equations, (8) functions, and (9) graphing (Welder, 2007). Finally, the review of literature is summarized with connections to the research question.

Algebra is a topic of high interest among school districts, mathematics educators, and educational policymakers. School districts have been required by their states to place 
a greater priority on algebra. Currently, algebra proficiency is the mathematics gatekeeper for success in high school, postsecondary, and many career paths (Capraro \& Joffrion, 2006; Edwards, 2000; Erbas, 2005; Stephens, 2005). Middle school is a critical time to prepare students for Algebra I (Capraro \& Joffrion, 2006) - as they are making the transition from concrete to more abstract mathematics. In fact, many researchers advocate for more students to take Algebra I in the eighth or even in the seventh-grade (Fennell et al., 2007; Spielhagen, 2006a, 2006b; Usiskin, 1987).

\section{Literature Search}

In this review of literature, the following primary databases were used during the literature search: EBSCO Academic Search Premier, Education Resources Information Center (ERIC), Wilson Web, ProQuest Research Library, and ProQuest Digital Dissertations. Additionally, sources were obtained through search engines (such as Google Scholar), suggestions from the dissertation chair and members of the researcher's dissertation committee, the researcher's preexisting collection of literature, and through references found within collected sources. Key search terms included: algebraic thinking, algebra curriculum, algebra in elementary school, middle school Algebra I, mathematics standards, algebra reform, history of algebra, pedagogical content knowledge, algebra misconceptions, algebra errors, algebra error patterns, algebraic reasoning, algebraic equations, algebraic expressions, algebraic symbolism, algebraic variables, equality, comparing and ordering numbers, fractions, decimals, percents, integers, exponents, scientific notation, ratios, proportions, order of operations, properties of numbers, patterning, algebraic functions, and graphing. 
Literature used in this review includes peer-reviewed manuscripts from research journals, peer-reviewed manuscripts from practitioner journals, proceedings and papers from national or international level conferences, technical reports, carefully selected websites and dissertations, and books.

\section{Algebra Curriculum}

\section{History of Algebra Curriculum}

According to Katz and Barton (2007), many history of mathematics texts have described the historical development of algebra using three distinct stages.

Algebra is considered to have three stages in its historical development: the rhetorical stage, the syncopated stage, and the symbolic stage. By the rhetorical, we mean the stage where all statements and arguments are made in words and sentences. In the syncopated stage, some abbreviations are used when dealing with algebraic expression. And finally, in the symbolic stage, there is total symbolization - all numbers, operations, relationships are expressed through a set of easily recognized symbols, and manipulations on the symbols take place according to well-understood rules. (Katz \& Barton, 2007, p. 186)

Moreover, Katz and Barton (2007) argued that four conceptual stages of algebra development exist. First was the geometric stage where the concepts in algebra were geometric. Second was the static equation-solving stage where the focus was placed on finding numbers that satisfied certain conditions. The third stage was the dynamic function stage in which the underlying theme was motion. Finally, the abstract stage emerged where structure was of main concern.

Kieran (1992) discussed the development of algebraic symbolism. The first use of algebraic symbolism was by Diophantus, who first introduced the use of letters to represent unknown quantities. In his work, Diophantus had no general methods for solving a series of 189 problems in his Arithmetica - he solved each using a different 
method. Diophantus' work was translated into Latin which later led to a European scholar named Vieta who used a letter to stand for a "given", in addition to an unknown quantity. Eventually, in the centuries to follow, other mathematical ideas developed, such as the concept of function (Kieran, 1992).

As mentioned by Kieran (2007), the view of algebra as simply a tool for solving and manipulating problems is often reflected in school algebra curriculum. In her chapter, Learning and Teaching Algebra at the Middle School through College Levels, Kieran summarized the history of algebra-related research of the past century. Algebra research from the early 1900 's to the 1950 's was largely focused on the difficulties students had solving various types of problems. In the 1950's and 1960's, algebra research was often conducted by psychologists who used algebra as a means for studying skill development and memory. Later, in the 1970's, the number of algebra education researchers was on the rise and the research focus shifted towards making algebra meaningful for students as well as examining students' understanding of algebra. In the 1980's and 1990's, research was transformed by Piaget's constructivism theoretical framework. Researchers began focusing on why students made certain errors and how students think (as also mentioned in Kaput, 2008). Algebra education research today has many theories and viewpoints to draw from - along with a shifting view of school algebra.

In conclusion, the teaching, learning, and understanding of algebra have changed significantly overtime. The development of algebraic symbolism with unknowns began the use of algebra. More recently in the past century, algebra research shifted from difficulties students have with solving algebra problems to making algebra learning 
meaningful to students. Most recently, the constructivism movement shifted the focus to why students make errors and how students think.

\section{Standards and Reform}

Several national organizations in mathematics education, including NCTM and those involved in the Common Core State Standards (CCSSO/NGA, 2010) support the belief that algebra should be incorporated into K-8 curriculum. More specifically, the Algebra standard in NCTM's Principles and Standards for School Mathematics states:

Instructional programs from prekindergarten through grade 12 should enable all students to -

- understand patterns, relations, and functions;

- represent and analyze mathematical situations and structures using algebraic symbols;

- use mathematical models to represent and understand quantitative relationships; and

- analyze change in various context (NCTM, 2000, p. 37)

Furthermore, in grades six, seven, and eight, the NCTM Principles and Standards for School Mathematics specifically outlined expectations for the above listed algebra standards. See Table 1.

If states choose to not adopt the CCSS, they often become ineligible for certain federal funding - such as Race to the Top (RTTT) funds. Once adopted, a state has three years to implement the CCSS. The CCSS is supported by dozens of endorsing partners, including NCTM, Association of Teacher Educators (AMTE), and The College Board. The CCSS Initiative provides the following statement about the standards: "These standards (CCSS) define the knowledge and skills students should have within their K-12 education careers so that they will graduate high school able to succeed in entry-level, 
credit-bearing academic college courses and in workforce training programs"

(CCSSO/NGA, 2010 About the Standards, para. 4).

Table 1

NCTM Algebra Standard Expectations Grades 6-8

\begin{tabular}{|c|c|}
\hline Standard & Expectation for Grades 6-8 \\
\hline Understand patterns, relations, and functions & $\begin{array}{l}\text { Represent, analyze, and generalize a variety of } \\
\text { patterns with tables, graphs, words, and, when } \\
\text { possible, symbolic rules } \\
\text { Relate and compare different forms of } \\
\text { representation for a relationship } \\
\text { Identify functions as linear or nonlinear and } \\
\text { contrast their properties from tables, graphs, or } \\
\text { equations }\end{array}$ \\
\hline $\begin{array}{l}\text { Represent and analyze mathematical situations } \\
\text { and structures using algebraic symbols }\end{array}$ & $\begin{array}{l}\text { Develop an initial conceptual understanding of } \\
\text { different uses of variables } \\
\text { Explore relationships between symbolic } \\
\text { expressions and graphs of lines, paying } \\
\text { particular attention to the meaning of intercept } \\
\text { and slope } \\
\text { Use symbolic algebra to represent situations } \\
\text { and to solve problems, especially those that } \\
\text { involve linear relationships } \\
\text { Recognize and generate equivalent forms for } \\
\text { simple algebraic expressions and solve linear } \\
\text { equations }\end{array}$ \\
\hline $\begin{array}{l}\text { Use mathematical models to represent and } \\
\text { understand quantitative relationships }\end{array}$ & $\begin{array}{l}\text { Model and solve contextualized problems } \\
\text { using various representations, such as graphs, } \\
\text { tables, and equations }\end{array}$ \\
\hline Analyze change in various contexts & $\begin{array}{l}\text { Use graphs to analyze the nature of changes in } \\
\text { quantities in linear relationships }\end{array}$ \\
\hline
\end{tabular}

(NCTM, 2000, p. 222)

With regards to middle school mathematics, CCSS makes the following two key

points: "Having built a strong foundation K-5, students can do hands on learning in 
geometry, algebra and probability and statistics. Students who have completed 7 th grade and mastered the content and skills through the 7 th grade will be well-prepared for algebra in grade 8" and "The middle school standards are robust and provide a coherent and rich preparation for high school mathematics" (CCSSO/NGA, 2010 Key Points in Mathematics, para. $5 \&$ para. 6).

More specific to the learning of algebra, the CCSS outlines specific algebraic content that students should have at each of grades six, seven, and eight. Each of these standards at the middle school level is designed to help prepare students for Algebra I and beyond. At the secondary level, the CCSS Algebra Standard outlines that students should master the following broad topics: see structure in expressions, perform arithmetic with polynomials and rational expressions, create equations, and reason with equations and inequalities - all at a more advanced, formal, and abstract level (CCSSO/NGA, 2010). See Table 2.

Following the release of the CCSS, the mathematics education community voiced a need for a document which would guide schools, school districts, and states in the implementation of the CCSS. For many states, the implementation of the CCSS includes training teachers to teach according to the CCSS, revamping standardized assessments to address the CCSS, and realigning curriculum. NCTM addressed this need by publishing Making it Happen: A Guide for Interpreting and Implementing Common Core State Standards for Mathematics (2010). This document aligned NCTM's Principles and Standards of School Mathematics, the CCSS, and NCTM's Curricular Focal Points (CFP). 
Table 2

Middle School CCSS Algebra-Related Standards Grades 6-8

\begin{tabular}{|c|c|c|}
\hline Level & $\begin{array}{c}\text { CCSS Standards Related } \\
\text { to Algebra }\end{array}$ & Major Skills Topics \\
\hline Sixth & Expressions and Equations & $\begin{array}{l}\text { Apply and extend previous } \\
\text { understandings of arithmetic to algebraic } \\
\text { expressions } \\
\text { Reason about and solve one-variable } \\
\text { equations and inequalities } \\
\text { Represent and analyze quantitative } \\
\text { relationships between dependent and } \\
\text { independent variables }\end{array}$ \\
\hline Seventh & Expressions and Equations & $\begin{array}{l}\text { Use properties of operations to generate } \\
\text { equivalent expressions. } \\
\text { Solve real-life and mathematical } \\
\text { problems using numerical and algebraic } \\
\text { expressions and equations }\end{array}$ \\
\hline Eighth & Expressions and Equations & $\begin{array}{l}\text { Work with radicals and integer exponents } \\
\text { Understand the connections between } \\
\text { proportional relationships, lines, and } \\
\text { linear equations } \\
\text { Analyze and solve linear equations and } \\
\text { pairs of simultaneous linear equations }\end{array}$ \\
\hline & Functions & $\begin{array}{l}\text { Define, evaluate, and compare functions } \\
\text { Use functions to model relationships } \\
\text { between quantities }\end{array}$ \\
\hline
\end{tabular}

(CCSSO/NGA, 2010)

Overall, the NCTM essentially founded the mathematics standards movement. Today, other stakeholders including the National Mathematics Advisory Panel, CCSS Initiative, AMTE, and others play a critical role in developing and implementing algebra standards in efforts to keep the U.S. competitive. Most recently, the CCSS Initiative has 
created significant change - leading our nation to have common set of mathematics (and algebra) standards among all 50 states.

\section{Integrating Algebra into K-8 Curriculum - Early Algebra}

"Traditionally, algebra has been a part of the college preparatory mathematics curriculum, offered to only a fraction of students because of tracking or choices made by students, teachers, and parents" (Erbas, 2005, p. 25). However, this practice has shifted through the mathematics reform movement promoted by the NCTM in the late 1980's and 1990's. The NCTM recommended that algebra not be viewed as an isolated course. Algebra should be taught with other topics in mathematics and should be embedded into the K-8 mathematics curriculum (NCTM, 2000).

A question remains as to what is this so-called algebra that should be taught in the elementary and middle grades. Carraher, Schliemann, and Schwartz (2008) addressed this question in Early Algebra is Not the Same as Algebra Early. While "Algebra Early" means that a student enrolls in Algebra I earlier in their mathematics career, Carraher and others contend that "Early Algebra" is a different kind of algebra that is integrated into the mathematics curriculum in elementary and middle school. Furthermore, they state that Early Algebra is different from Algebra Early in three ways:

- early algebra builds on background context of problems;

- in early algebra formal notation is introduced only gradually; and

- early algebra tightly interweaves existing topics of early mathematics

(Carraher et al., 2008, pp. 236-237)

Carraher, Schliemann, Brizuela, and Ernest (2006) stated that "We would argue that the algebraic meaning of arithmetical operations is not optional 'icing on the cake' but rather an essential ingredient. In this sense, we believe that algebraic concepts and notation need 
to be regarded as integral to elementary mathematics" (p. 89). Next, literature relevant to the teaching and learning of algebraic skills in the early grades is discussed.

\section{Relevant Early Algebra Literature}

Kaput $(2000$ b 2008$)$ suggested that integrating algebra into all grade levels will

solve several deeply rooted problems in school mathematics. Most recently, Kaput stated that integrating algebra into grades K-12 addresses four major goals:

1. To add a degree of coherence, depth, and power typically missing in $\mathrm{K}-8$ mathematics.

2. To ameliorate, if not eliminate what Kaput sees as the most pernicious and alienating curricular element of today's school mathematics: late, abrupt, isolated, and superficial high school algebra courses.

3. To democratize access to powerful ideas by transforming algebra from an inadvertent engine of inequity to a deliberate engine of mathematical power.

4. To build conceptual and institutional capacity and open curricular space for new $21^{\text {st }}$-century mathematics desperately needed at the secondary level, space locked up by the $19^{\text {th }}$-century high school curriculum now in place. (Kaput, 2008, p. 6).

Mason (2008) believed our ability to think algebraically begins shortly after birth

- which supports the notion of integrating algebraic thinking into early elementary

mathematics curricula. Babies and toddlers learn to make patterned noises (before talking in words and sentences). Moreover, Mason believed that all children who can both walk and talk possess "powers" that can be used to help them develop algebraic thinking. These powers included the following: imagining and expressing, focusing and defocusing, specializing and generalizing, conjecturing and convincing, and classifying and characterizing. While young children use these powers outside of mathematics every day, their intuitive understanding can be transferred to mathematical situations (Mason, 2008). 
Carpenter, Fennema, Franke, Levi, and Empson (1999) also examined the informal knowledge children bring when they enter school. Their research focused on cognitively guided instruction (CGI), where students build upon their informal and intuitive knowledge of mathematics - rather than learning through memorization or procedures. Cognitively guided instruction seeks to understand the strategies that young children use to make sense of mathematical situations. They concluded that their research studies "...consistently demonstrate that CGI students show significant gains in problem solving... in spite of the decreased emphasis on drill and practice, there is no commensurate loss in skills" (Carpenter et al., 1999, p. 110). Such problem solving skills are essential to algebraic thinking and reasoning.

Fosnot and Jacob (2010) provided suggestions on how to incorporate algebraic thinking into the early grades. Several of these suggestions included teaching students about: patterns of factors, open number lines specifically with integers and unknowns, proving properties of numbers with pictures and diagrams, area models, equivalence activities with manipulatives such as money and Unifix cubes, and patterns in input/output tables. In their book, they discussed the incorporation of these instructional strategies with students as young as first-grade (Fosnot \& Jacob, 2010).

Bastable and Schifter (2008) provided nine case studies on how elementary school teachers have integrated algebraic thinking into their seemingly arithmetic-based lessons. Case 4 described a fourth-grade class working with consecutive square numbers (e.g. $1^{2}, 2^{2}, 3^{2}, 4^{2}, 5^{2}$, etc.). The teacher in this case assigned her students "to represent as many square numbers as possible on one piece of graph paper". The next day one student suggested that he had discovered "something amazing and it worked every time". The 
student was able to explain to the class an expression that showed the relationship between consecutive square numbers. “...consider 2 and 3 . The rule generated says add 2 plus the square of 2 plus 3 to get the square of 3 , or $2+2^{2}+3=2+4+3=9 "$ ". Through class discussion, the students in the class determined the rule worked every time (Bastable \& Schifter, 2008, p. 173).

Another interesting case study by Bastable and Schifter (2008) described an experience by a second-grade teacher. This teacher saw a great learning opportunity when her students became curious about the number of cubes that could be arranged into square shapes (e.g. an array of cubes such as $2 \times 2=4$ cubes, $3 \times 3=9$ cubes, etc.). The next day, the students explored with more square patterns up to 100 cubes and were organized into small groups and shared their ideas and discoveries about square numbers. The following is a list of several generalizations about square numbers written by this second-grade class that model deep understanding and algebraic thinking:

- 1,4 , and 9 are square numbers.

- $16,25,36,49,81$, and 100 are square numbers.

- Square numbers go odd, even, odd, even.

- If you times a square number by a square number, you get a square number (ex. 4 X $4=16$ ).

- Take any square number, add two zeros to it, and you will get another square number (ex. 4, 400).

- When you add a row at the bottom and a row to the side and make a corner, you get another square number.

- When you make a prediction for a bigger square, you always have to add a higher number than the square you just made. (Bastable \& Schifter, 2008, p. 174)

Kaput (2000a, 2000b) and Bastable and Schifter (2008) provided an example in which a third-grade teacher asked students to informally justify the commutative property of multiplication. In this example, the teacher asked her students whether writing the 
problem in reversed order would always result in the same answer (e.g. $4 \times 9$ and $9 \times 4$ ). Many students were able to take manipulatives to form two arrays and prove that 3 rows of 7 Unifix cubes was indeed the same as 7 rows of 3 Unifix cubes. Even without the formal language of properties, students were able to express and conceptualize properties in a concrete way (Bastable \& Schifter, 2008; Kaput, 2000a, 2000b).

Research by Kaput and Blanton (2000) presented a scenario where a third-grade teacher reported her experience of "algebrafying" a lesson. Students were presented with the problems $\triangle+\triangle=6,9+\triangle=12$, and $\triangle=\ldots$. Students were told that the empty triangles had to be the same number. Eventually students were able to figure out that the empty triangles must equal three and several students noticed that starting with doubles made solving the problem easier. Next, the teacher asked the students what the empty triangles could be replaced with and some students suggested a letter. The class proceeded to work more problems with larger numbers using a calculator to check. This process incorporated both the beginning use of algebraic symbolism and guided students towards thinking about patterns and making generalizations (Kaput \& Blanton, 2000).

Later, Kaput and Blanton (2001) examined the academic achievement of the students in this teacher's classroom. They administered a fourth-grade mandatory statewide exam to both this teacher's third-grade class and another teacher's third-grade class of similar student demographics to serve as a control group. The results found that this teacher's students outperformed the other class on 11 of the 14 items, with four items statistically significantly different at $\alpha=.05$. The four questions in which the control group outperformed this class were not statistically significantly different. Furthermore, this third-grade class performed statistically significantly better than the fourth-graders in 
the same district and as well as fourth-graders state-wide. With seven of the items identified as deeply algebraic, it is suggested that this teacher's practice of "algebrafying" her curriculum had been successful as documented in her students' achievement on this assessment (Kaput \& Blanton, 2001).

Overall, many researchers have evidence that suggests elementary school students can successfully engage in algebraic thinking. Asquith and others (2007), Carraher and Schliemann (2007), and Warren (2003) suggested that student success in algebra is linked to exposure to algebraic concepts in elementary and middle school. Falkner and others (1999) found that with appropriate guidance, students in first- and second-grade could make algebraic generalizations by stating that "zero added to another number equals that other number" and fourth- and fifth-graders could make generalizations about the commutative property of multiplication by stating that "when you multiply two numbers, you can change the order of the numbers" (p. 2). Likewise, Carraher and others (2006), Day and Jones (1997), Jacobs and others (2007), Kaput (2000a), and Kaput and Blanton (2001) found that elementary students as young as eight or nine could successfully engage in algebraic thinking through activities involving equality, variables, and linear modeling.

Jacobs and others (2007) conducted a study in which 89 first- through fifth-grade elementary school teachers from 19 schools voluntarily received professional development in algebraic reasoning over the course of one year. The statewide standardized assessment scores of students of these 89 teachers were compared to the scores of students from 91 control group teachers who did not take part in the professional development. The results of the study found that professional development 
on algebraic reasoning had a positive effect on both student and teacher learning. The difference in student scores between the treatment and control groups on questions related to understanding the equal sign on the equality test questions was statistically significant at $\alpha=.05$ for all grade levels. Furthermore, a sequence of student interviews found that students from the treatment group were more likely to use relational thinking than students from the control group (Jacobs et al., 2007).

To summarize, many studies have been conducted to measure the effect of learning algebraic thinking skills in the early grades (Bastable \& Schifter, 2008; Day \& Jones, 1997; Falkner et al., 1999; Kaput, 2000a). Oftentimes, lack of teacher preparation to teach such higher-level thinking skills becomes a barrier in implementing algebraic thinking curriculum at the elementary level. The next section discusses this barrier in teacher preparation.

\section{Teacher Preparation for Teaching Algebra}

In order to successfully integrate algebra into the K-8 curriculum, elementary and middle school teachers must be prepared and confident in teaching concepts related to algebra. Liston, Borko, and Whitcomb (2008) recommend the following: teachers must know in-depth the mathematics which they are teaching, researchers should look to reveal the relationship among teacher knowledge and student learning, the preparation of elementary and middle school mathematics teachers must be stronger, and pre-service mathematics teachers must be given many opportunities to learn the mathematics necessary for teaching.

Shulman (1986) suggested that the knowledge required for teaching goes beyond the knowledge base for an educated adult. In addition to subject matter content 
knowledge, Shulman argued that teachers must also possess pedagogical content knowledge and curricular content knowledge. With regards to subject matter content knowledge, Shulman stated that in addition to knowing definitions and facts, teachers must be able to explain the "whys" of their subject matter. Pedagogical content knowledge is a special set of knowledge specific to teaching which arms teachers with ways to explain, represent, discuss, and illustrate ideas to help students understand subject matter. Moreover, pedagogical content knowledge includes teachers' awareness of what students will find easy or difficult, and how to help students overcome misconceptions in learning. Finally, curricular content knowledge refers to teachers' knowledge of available resources, materials, and programs available to aid and supplement teaching. Curricular content knowledge includes knowing what students are learning simultaneously in other subject areas as well an what they learned last year and will learn next year in the same subject area (Shulman, 1986).

Ball, Thames and Phelps (2008) described the unique set of knowledge needed for teaching mathematics as the Mathematical Knowledge for Teaching (MKT). They argued that there are four components to MKT which include: (a) common content knowledge (CCK) of mathematics which includes mathematic used outside of teaching; (b) specialized content knowledge ( $\mathrm{SCK}$ ) which is a set of knowledge and skills unique to teaching; (c) knowledge of content and students (KCS) which integrates knowing about students and knowing about mathematics; and (d) knowledge of content and teaching (KCT) which integrates knowing about teaching and knowing about mathematics (Ball et al., 2008). This work by Ball et al. has built on the work of Shulman (1986) - addressing the specific need for specialized knowledge in the area of mathematics teaching. 
The National Mathematics Advisory Panel made the following recommendation

in order to improve the teaching of algebra:

Adequate preparation of students for Algebra requires their teachers to have a strong mathematics background. To this end, the Major Topics of School Algebra and the Critical Foundations of Algebra must be fundamental in the mathematics preparation of elementary and middle school teachers. Teacher education programs and licensure tests for early childhood teachers (preschool-Grade 3) should focus on the Critical Foundations of Algebra; for elementary teachers (Grades 1-5), on the Critical Foundations of Algebra and those algebra topics typically covered in an introductory Algebra course; and for middle school teachers (Grades 5-8), on the Critical Foundations of Algebra and all of the Major Topics of School Algebra. (Fennell et al., 2007, p. 15)

Elementary teachers play a critical role in "algebrafying" (Kaput, 2000b, p. 1) the

$\mathrm{K}-12$ curriculum as this process starts with students in their classes. Kaput and Blanton (2000) described three ways in which teachers must create self change in their classroom in order for this process to evolve:

- the process of building algebraic reasoning opportunities, especially generalization and progressive formalization opportunities, from available instructional materials;

- the building of teachers' "algebra eyes and ears" so they can spot opportunities for generalization and systematic expression of the generality and then act upon these as they occur;

- the process of creating classroom practice and culture to support active student generalization and formalization within the context of purposeful conjecture and argument, so that algebra opportunities occur frequently and are viable when they occur (Kaput \& Blanton, 2000, p. 8).

In her research, Ma (1999) studied the fundamental content knowledge for teaching elementary mathematics of U.S. teachers compared to teachers in China. Overall, Ma found that U.S. elementary teachers are far behind their Chinese counterparts in fundamental mathematics understanding, which would predict that U.S. students would be behind Chinese students in mathematics understanding. Chinese teachers possessed a deeper conceptual understanding of fundamental concepts and were able to 
model such concepts for their students, whereas U.S. teachers often possessed a procedural knowledge at best. Furthermore, Ma claimed that because U.S. teachers receive a low quality mathematics education they in turn provide a low quality mathematics education, thus continuing and reinforcing the cycle of low quality mathematics (Ma, 1999). This implies that U.S. teachers are at risk of passing their weak understanding of algebra to their students.

Overall, this body of research stresses the importance of teacher preparation in the development and implementation of early algebra in the K-8 curriculum. It also sheds light on the importance of mathematics content knowledge and pedagogical content knowledge in elementary and middle school teachers.

\section{Placing Middle School Students in Algebra I}

The debate regarding when students should take Algebra I has existed for decades. Usiskin (1987) argued that students should take algebra in the eighth-grade instead of in ninth-grade. Usiskin presented six reasons as to why students of average ability should take algebra in the eighth-grade:

1. For students who know sixth-grade mathematics, not much is new in the seventh- or eighth-grade.

2. Eighth-grade algebra is successful.

3. What is called "enrichment" is not a suitable alternative to eighth-grade algebra.

4. It is probably easier (and certainly no harder) to learn algebra at age thirteen than at age fourteen.

5. Our current practices with regard to placement of students in algebra are the exact opposite of reasonable logic.

6. Taking algebra in the eighth-grade reduces pressure on students in grades 912. (Usiskin, 1987, pp. 432-435)

While many of these reasons have been debated by mathematics researchers, his and others' forward-thinking approach has led us to mathematics reform that incorporates 
an "Algebra for All" expectation for districts, schools, teachers, and students. In their report, The National Mathematics Advisory Panel stated that "Federal and state polices should give incentives to schools to offer an authentic Algebra I course in Grade 8..." (Fennell et al., 2007, p. 15).

Several studies have been conducted to analyze the effects of placing eighth-grade and even seventh-grade students in Algebra 1. A study conducted by Spielhagen (2006a, 2006b) examined the mathematics course-taking trends of 2,643 eighth-grade students in a large suburban school district. Spielhagen found that students who were allowed to take Algebra I in the eighth-grade (which was based on previous performance in mathematics) scored higher than their peers on all parts of the state mathematics test. However, while the Algebra I group also scored higher on the algebra section, the range in scores was less. Overall, the students that took Algebra I in the eighth-grade tended to take more advanced mathematics courses in high school, had a greater chance of attending college, and attended better colleges. Spielhagen (2006a) concluded that, "The results of this study strongly support policies that provide algebra instruction in the eighth-grade as a means of closing the achievement gap related to the SES of school populations" (p. 39). Additionally, Spielhagen (2006a) examined one school district's criteria for placing eighth-grade students into Algebra I. He found that while the district policy stated that the decision to place an eighth-grade student in Algebra I was dependent on their mathematics standardized test scores; district teachers noted several discrepancies with this criteria. First, Spielhagen found that opportunities among elementary schools were not consistent and some school offered problem solving enrichment opportunities while others did not. The teachers interviewed acknowledged that students in these programs 
were at an advantage for entrance into eighth-grade algebra. Second, Spielhagen found that some middle school teachers decided to abandon the testing criteria and used their own subjective judgment to determine if a student should be placed in Algebra I in the eighth-grade. Finally, it was found that parents were often allowed to override the placement decision made by the teachers and school. Additionally, once a student was placed in the advanced track, some as early as third-grade, they remained in that track and were not reevaluated (Spielhagen, 2006a).

Sowder and Wearne (2006) analyzed changes in eighth-grade achievement as demonstrated from the eighth-grade National Assessment of Educational Progress (NAEP) in order to gain insight into the shift towards incorporating more algebra into eighth-grade. Sowder and Wearne found that eight-graders have shown steady gains in five mathematics content areas from 1990 to 2000 . More specifically to algebra, students appear to perform better on difficult problems relating to growing patterns - which could possibly reflect teachers' increased emphasis on algebraic thinking and reasoning skills in the elementary and middle grades. However, students still have difficulty solving equations with two variables (Sowder \& Wearne, 2006). Sowder and Wearne (2006) reported that "In 2000, 64 percent of teachers claimed placing a heavy emphasis on algebra and functions, up from 11 percent in 1992" (p. 293). In conclusion, recent research and national mathematics education leaders support the practice of eighth-grade students enrolling in Algebra I (as found in Fennell et al., 2007; Kaput, 2000b; Sowder \& Wearne, 2006; Spielhagen, 2006a, 2006b; Usiskin, 1987). 


\section{Algebra Theoretical Construct for This Study}

Kaput (2008) divided algebraic reasoning into two core aspects and three strands.

See Table 3.

Table 3

Kaput's Construct of Algebraic Reasoning

Core Aspects and Strands

The Two Core Aspects

(A) Algebra as systematically symbolizing generalizations of regularities and constraints.

(B) Algebra as syntactically guided reasoning and actions on generalizations expressed in conventional symbol systems.

Core Aspects A \& B Are Embodied in Three Strands

1. Algebra as the study of structures and systems abstracted from computation and relations, including those arising in arithmetic (algebra as generalized arithmetic) and in quantitative reasoning.

2. Algebra as the study of functions, relations, and joint variation.

3. Algebra as the application of a cluster of modeling languages both inside and outside of mathematics.

(Kaput, 2008, p. 11)

Each strand was embodied within each Core Aspect A and Core Aspect B. Kaput made several important notes about his construct of algebraic reasoning: Core Aspect $\mathrm{A}$ is believed to develop before Core Aspect B, much debate still exists as to which core aspect best defines algebra, and the core aspects and strands demonstrate how algebra is an in-depth content that is related to all areas of mathematics (as mentioned in his earlier work Kaput, 2000b).

Additionally, Kaput (2008) elaborated on each of the three strands. Strand 1 was considered by many researchers to be the easiest transition into algebra. This strand was about generalizing arithmetic from already familiar concepts, such as addition and multiplication of whole numbers, properties, counting with odds and evens. With this 
strand, both conventional and student-invented strategies can be utilized and arithmetic can be transformed to algebraic thinking when generalizations are made (e.g. two numbers multiplied together, such as $3 \times 7$ and $7 \times 3$, can be reversed and the same answer is obtained every time; the sum of two odds is always an even, etc.). Strand 2 involved moving towards the idea of functions and using equations, graphs, and tables to represent patterns. The use of symbols becomes more commonplace in Strand 2. Strand 3 includes three types of mathematical modeling: number or quantity-specific, expressing patterns and regularities in situations (inside and outside of mathematics), and generalizing from solutions. In this strand, variables are utilized and deeper constructs and relationships are analyzed (Kaput, 2008).

This study encompasses the belief that algebra is a complex web of ideas, with strands connecting and overlapping. Kaput's (2008) definition of algebra aligns with the design and framework of this study - as there are nine interweaving prerequisite content areas which will be addressed later in this chapter. Next, the idea of mathematics misconceptions and errors is discussed.

\section{Mathematics Misconceptions}

\section{Misconceptions/Errors (Conceptual/Procedural)}

Skemp (1976/2006) first brought the notion of relational understanding (conceptual) and instrumental understanding (procedural) to the forefront in 1976 in Relational Understanding and Instrumental Understanding. Skemp discussed the differences between relational understanding (knowing how to do something and why) and instrumental understanding (knowing rules without reasons). Skemp's realization that so many teachers in the 1970's advocated and practiced instrumental understanding in 
their classroom caused him to examine the advantages of teaching for instrumental understanding. While he could think of three advantages of instrumental understanding: easier to understand, more immediate rewards, and students can often get the answer faster - he was not convinced this method was best.

Instead, Skemp (1976/2006) argued that relational mathematics was more advantageous because it was adaptable to new tasks, easier to remember over time, an effective goal in and of itself, and its relational schemas foster mathematical growth. While many excuses could be given for teaching instrumentally (e.g. time restraints, difficulty, assessment), Skemp argued that instrumental understanding is not really mathematics by stating "...the two kinds of knowledge (instrumental and relational) are so different that I think there is a strong case for regarding them as different kinds of mathematics. If this distinction is accepted, then the word 'mathematics' is for many children indeed a false friend, as they find to their cost" (Skemp, 1976/2006, p. 95). Ashlock (2006) defined conceptual mathematics understanding as the understanding of both ideas and the ability to make generalizations connecting mathematics ideas. He defined procedural knowledge as the step-by-step skills and procedures to do mathematics. He believed misconceptions often occur because students overgeneralize (e.g. name a figure a triangle based on its position, use tens for regrouping even when working with mixed numbers or measurements) or overspecialize (e.g. believing the altitude of a triangle can only be found within the triangle, always finding a common denominator when working with fractions - even when multiplying or dividing), which both overgeneralizing and overspecializing related to conceptual understanding. 
"Students need a balance of conceptual (comprehension) and procedural (vocabulary) skills as they begin to develop algebraic understanding" (Capraro \& Joffrion, 2006). A benefit of having conceptual knowledge is the ability to apply existing knowledge to new and altered situations. Additionally, in order for students to be successful in algebra, they need to understand concepts and be able to perform necessary procedures (Capraro \& Joffrion, 2006). Hiebert and Grouws (2007) and Skemp (1976/2006) argued that the key to students gaining conceptual knowledge, instead of just knowing the procedures needed to "get the answer", is to focus and place a priority on the meaning of mathematical ideas and linking these ideas to other contexts in mathematics before teaching procedures.

Braswell and others (2001) in The Nation's Report Card: Mathematics 2000 described three types of mathematical knowledge and skills students must have: procedural knowledge, conceptual knowledge, and problem solving. They stated that these three mathematical abilities must overlap and exist among the five content strands of mathematics: number sense, properties, and operations; measurement; geometry and spatial sense; data analysis, statistics, and probability; and algebra and functions (Braswell et al., 2001).

The newly released CCSS stated that a key point of the mathematics standards is to:

... stress not only procedural skill but also conceptual understanding, to make sure students are learning and absorbing the critical information they need to succeed at higher levels - rather than the current practices by which many students learn enough to get by on the next test, but forget it shortly thereafter, only to review again the following year.

(CCSSO/NGA, 2010, Key Points in Mathematics, para. 4) 
Additionally, CCSS has a set of eight Standards for Mathematical Practice which address skills such as reasoning, modeling, using tools, and precision (CCSSO/NGA, 2010).

While CCSS has fewer standards overall, it focuses more on depth and understanding that equally stresses procedural fluency and conceptual understanding (Shaughnessy, 2010).

One focus of a systematic review and meta-analysis of instruction in algebra conducted by Rakes, Valentine, McGatha, and Ronau (2010) was to examine the effect sizes between studies with a learning focus on conceptual understanding compared to those with a learning focus on procedural understanding. Out of 82 studies, 25 focused on conceptual understanding and 57 focused on procedural understanding. The effect sizes for conceptual understanding ranged from -0.286 to $2.590(M=.4933)$ while procedural understanding ranged from -1.096 to $1.391(M=.2633)$. These results suggested that

A focus on the development of conceptual understanding will improve student achievement far better than the same strategy with a focus on procedural understanding. Teachers wishing to improve student achievement in their classrooms should therefore seek ways to explicitly target the meaning of important ideas in algebra and the connections between these ideas.

(Rakes et al., 2010, p. 388)

In addition to conceptual and procedural knowledge, open-response questions often challenge students' ability to reason mathematically. Algebraic reasoning often includes the ability to analyze a problem, implement a strategy, and reflect on a solution (NCTM, 2010). In this study, students' reasoning will also be considered when analyzing student open-responses.

In summary, most leaders in mathematics education today support the idea that students must have a balance of both conceptual understanding and procedural fluency in all areas of mathematics, including algebra (as found in Capraro \& Joffrion, 2006; 
CCSSO/NGA, 2010; Fennell et al., 2007; NCTM, 2000, 2006). Procedural fluency is needed for students to work efficiently and accurately while conceptual understanding is essential for students to make connections as well as justify, verify, and reason mathematically (Capraro \& Joffrion, 2006). Reasoning is also an important component of algebraic thinking (NCTM, 2010).

\section{Mathematics Misconception Theoretical Construct for this Study}

Leron and Hazzan (2009) divided mathematical thinking into four perspectives aligned to four different research communities that study mathematics: (1) mathematics (2) mathematics education (3) cognitive psychology and (4) evolutionary psychology. Further, Leron and Hazzan (2009) described how each of these four perspectives conceptualized and approached misconceptions in mathematics. The mathematics community views errors as a discrepancy between student work and the rules of mathematics. Students make errors because of their lack of mathematical knowledge, and errors can be corrected through explanations and additional practice. Most mathematics educators believe that knowledge is constructed by the learner (whereas the mathematics community believes knowledge is transmitted from teacher to student). Students are expected to make errors and making mistakes is a normal part of the learning process. Cognitive psychologists tend to believe that errors result from a clash in two systems of thinking. They normally do not focus on the educational implications but believe that students can correct misunderstandings from instruction and with motivation. Finally, evolutionary psychologists often view student errors as a clash between human nature and the rules of modern civilization. They believe that analytical skills evolve naturally through biological development. For purposes of this study, the mathematics education 
belief was adopted and it was the researchers' goal to identify the common misconceptions and errors students make with regards to the research question in this study.

\section{Theoretical Framework}

\section{Research Question}

The research question for this study was the following:

1. What common algebra-related misconceptions and errors exist among students in grades six and eight as identified on student responses on an annual statewide standardized assessment?

\section{Selecting a Framework}

In this study, it was important to identify prerequisite algebra skills for the middle grades. Varieties of frameworks exist within content areas of middle school mathematics; however, many are very specific and fit within a singular prerequisite skill for algebra. Such frameworks included Gallardo's (2002) Levels of Acceptance of Negative Numbers; Phillip's (1992a) Role of Variables; Küchemann's (1978) Variable Hierarchy; Kieran's (1992) Methods for Solving Equations; Wollman's (1983) Hierarchy of Monitoring Processes; Smith's (2008) Functional Thinking; Usiskin's (1988) Conceptions of Algebra; and others. Each of these frameworks are discussed later when prerequisite algebra skills are broken down to specific content areas. Because the purpose of this study was to examine misconceptions and errors from a variety of prerequisite Algebra I topics, other broader frameworks would better suit this study.

Better aligned to the research question in this study were frameworks which addressed the prerequisite skills necessary for learning Algebra I. The National 
Mathematics Advisory Panel (Fennell et al., 2007) identified the following areas as

"Critical Foundations" for learning algebra: fluency with whole numbers; fluency with fractions; and aspects of geometry and measurement - such as scale figures and proportions. While this framework was considered as the theoretical framework for this study, it did not include pre-algebra concepts, such as an introduction to functions, graphing, variables and symbolism, and equation solving. These concepts are a focus of middle school curriculum, both in practice and formally as outlined in both the NCTM Principles and Standards for School Mathematics and the CCSS; therefore, the researcher felt a framework that included such topics would be better suited for this study.

\section{Framework Chosen for This Study}

Welder $(2006,2007,2010)$ examined prerequisite knowledge for the learning of Algebra I as outlined by the Southern Regional Education Board (SREB). The SREB used a professional expertise panel to develop a list of 12 readiness indicators specific to the learning of algebra:

1. Read, write, compare, order, and represent in a variety of forms: integers, fractions, decimals, percents, and numbers written in scientific notation and exponential form.

2. Compute (add, subtract, multiply, and divide) fluently with integers, fractions, decimals, percents, and numbers written in scientific notation and exponential form, with and without technology.

3. Determine the greatest common factor, least common multiple, and prime factorization of numbers.

4. Write and use ratios, rates, and proportions to describe situations and solve problems.

5. Draw with appropriate tools and classify different types of geometric figures using their properties.

6. Measure length with appropriate tools and find perimeter, area, surface area, and volume using appropriate units, techniques, formulas, and levels of accuracy. 
7. Understand and use the Pythagorean relationship to solve problems.

8. Gather, organize, display, and interpret data.

9. Determine the number of ways events can occur and the associated probabilities.

10. Write, simplify, and solve algebraic equations suing substitution, the order of operations, the properties of operations, and the properties of equality.

11 . Represent, analyze, extend, and generalize a variety of patterns.

12. Understand and represent functions algebraically and graphically.

(Bottoms, 2003, p. 11; Welder, 2006, pp. 4-5)

Welder argued that while the 12 readiness indictors were derived by a group of mathematics education experts - the results were not based on research (Bottoms, 2003; Welder, 2006, 2007). Bottoms (2003) confirmed Welder's belief in his report Getting Students Ready for Algebra I: What Middle Grades Students Need to Know and Be Able to Do. In this report, Bottoms discussed that the readiness indicators were developed through the opinions of the mathematics education expert panel. Nowhere does he mention the use of research by the panel to create the SREB Algebra I Readiness Indicators.

To address this issue, Welder $(2006,2007)$ conducted a review of literature to determine which (if not all) of the 12 readiness indictors were directly related to prerequisite knowledge for algebra learning. She found that "eight of the 12 Readiness Indicators, namely numbers $1,2,3,4,8,10,11,12$, were at least partially, if not fully, supported by her research-based literature review" (p. 20). Next, she synthesized these findings and developed her own framework for content-specific prerequisite algebra skills.

As a result, Welder (2007) identified nine prerequisite content areas in which students should be knowledgeable before entering their first formal algebra course. The nine prerequisite content areas were as follows: (1) numbers and numerical operations, 
(2) ratios and proportions, (3) the order of operations, (4) equality, (5) patterning, (6) algebraic symbolism and letter usage, (7) algebraic equations, (8) functions, and (9) graphing (Welder, 2007). These nine prerequisite content areas provide a framework for this study.

It should be noted that the nine prerequisite content areas align well to the mathematics CCSS for grades six, seven, and eight. See Table 4 for alignment of nine prerequisite content areas to the CCSS. As seen in Table 4, patterning is not explicitly discussed in the table but it can be argued that patterning is embedded in standards which are addressed. A review of literature relating to these concepts and student misconceptions and errors for each content area are now discussed.

Table 4

Alignment of Nine Prerequisite Content Areas to Mathematics CCSS Grades 6-8

\begin{tabular}{|l|l|}
\hline \multicolumn{1}{|c|}{ Prerequisite Content Area } & \multicolumn{1}{c|}{ Grades Addressed in CCSS } \\
\hline 1. Number and Numerical Operations & Six, Seven, Eight \\
\hline 2. Ratios and Proportions & Six, Seven, Eight \\
\hline 3. The Order of Operations & Six, Seven, Eight \\
\hline 4. Equality & Six, Seven, Eight \\
\hline 5. Patterning & Mathematical Practice \#7 \\
\hline 6. Algebraic Symbolism and Letter Usage & Six, Seven, Eight \\
\hline 7. Algebraic Equations & Six, Seven, Eight \\
\hline 8. Functions & Eight \\
\hline 9. Graphing & Six, Seven, Eight \\
\hline
\end{tabular}

(CCSSO/NGA, 2010) 


\section{Numbers and Numerical Operations}

Comparing and ordering. Comparing and ordering numbers involves students' ability to place numbers on a continuum from least to greatest. This skill includes placing numbers in a variety of different forms, such as fractions, decimals, percents, mixed numbers, numbers in power form, and integers all on the same continuum. In doing so, students possess conceptual understanding of inequality - the ability to recognize that the value of one number is greater or less than the value of another number. In algebra, it is common for students to be asked questions such as: Which equation has the greater solution? What is the greatest common factor? What is the domain and range of the function from least to greatest?

Thorpe (1989), Bottoms (2003), and Stacey and MacGregor (1997a) agreed that students should be able to comfortably compare any two real number values to determine which one is greater (e.g. -1.2 or $-3.4,3 / 7$ or $5 / 9$, etc.). Bottoms suggested that this knowledge should be considered a basic prerequisite algebra skill which helps students determine if a solution is relevant and makes sense (Bottoms, 2003). Specific misconceptions about comparing and ordering will be addressed within the context of fractions, decimals, etc. - which are listed below.

Fractions. Understanding the meaning of fractions and computing with fractions have long been difficult for teachers to teach and students to learn. Additionally, numerous researchers and curriculum developers have dedicated much time and resources for many years in efforts to improve instruction in fraction proficiency (as found in Brown \& Quinn, 2006; Fosnot \& Dolk, 2002; Lamon, 1999; Ma, 1999; NCTM, 2000; Van de Walle, Karp, \& Bay-Williams, 2010). Choike (2000) argued that to help all 
students be successful in algebra, teachers should eliminate distracter numbers, namely fractions, when introducing new concepts. However, students' ability to understand and compute with fractions is an essential prerequisite algebra skill because fractions are commonplace in algebra. To eliminate them would be to display an inaccurate description of algebra itself. Fractions can be found as (1) coefficients, constants, and solutions in equations (Wu, 2001); (2) slope (e.g. rise/run) (Wu, 2001); and (3) proportions in algebra are written in fraction form, completing the square (e.g. $\left.(b / 2)^{2}\right)$, etc. Additionally, students must be fluent in converting fractions to decimals (Bottoms, 2003; Silver, 2000; Stacey \& MacGregor, 1997a), graphing fractional points on a coordinate plane (e.g. an ordered pair such as $(1 / 2,3 / 4))$, plotting on a number line (Darley, 2009; Stacey \& MacGregor, 1997a; Wu, 2005), and understanding the value of fractions (Darley, 2009; Wu, 2001, 2005) in order to determine if a solution makes sense. Ashlock (2006), in his book Error Patterns in Computation: Using Error Patterns to Improve Instruction, dedicated three chapters to analyzing student work relating to fractions. Table 5 below displays common errors as found by Ashlock in his chapters dedicated to fractions.

Brown and Quinn (2006) administered a 25-question test to 143 Algebra I students in five classes at the same school. The test, developed using questions from reviewed literature, consisted of six categories: (1) algorithm applications (e.g., the four basic operations, reducing, rewriting improper fraction as mixed number); (2) word problems; (3) elementary algebraic concepts (e.g. 1-step equations and proportions involving fractions); (4) arithmetic skills specific to algebra (e.g. reduce $(3+4) / 2) ;(5)$ comparing, estimating, ordering; and (6) computational fluency (e.g. such as 7/(3/5)). 
Table 5

Ashlock's Fraction-Related Errors

\begin{tabular}{|c|c|}
\hline Concept & Errors \\
\hline $\begin{array}{l}\text { Writing a fraction to } \\
\text { represent the shaded part of } \\
\text { a figure }\end{array}$ & $\begin{array}{l}\text { 1. Writing part (shaded)/part (not shaded) relationship instead of } \\
\text { part/whole } \\
\text { 2. Students failed to realize all parts must be of equal size }\end{array}$ \\
\hline $\begin{array}{l}\text { Simplifying fractions to } \\
\text { lowest terms }\end{array}$ & $\begin{array}{l}\text { 1. Students attempted to simplify even when they could not by } \\
\text { reducing to the closest number possible (e.g. } 3 / 8 \text { to } 1 / 4 \text {-because you } \\
\text { cannot divide } 3 \text { by } 2 \text { students estimated it to } 1 \text { ) } \\
\text { 2. Students reduced the numerator but not the denominator }\end{array}$ \\
\hline $\begin{array}{l}\text { Addition and subtraction of } \\
\text { fractions }\end{array}$ & $\begin{array}{l}\text { 1. Simply adding/subtracting the numerators and } \\
\text { adding/subtracting the denominators (with no attempt to get } \\
\text { common denominator first) } \\
\text { 2. Getting a common denominator but failing to change the } \\
\text { fractions into equivalent form - thus not resulting in different } \\
\text { numerators } \\
\text { 3. Incorrectly subtracting mixed numbers by failing to regroup } \\
\text { when needed and instead oversimplify by subtracting the smaller } \\
\text { number from the larger - not realizing that subtraction is not } \\
\text { commutative } \\
\text { 4. Incorrect regrouping - either by incorrectly using base ten or } \\
\text { making some other mistake }\end{array}$ \\
\hline $\begin{array}{l}\text { Multiplication and division } \\
\text { of fractions }\end{array}$ & $\begin{array}{l}\text { 1. Incorrect cross-multiplying (as if solving a proportion) and then } \\
\text { applying an invented algorithm to get the answers (such as adding } \\
\text { the sum of the two cross multiplications) } \\
\text { 2. Seeing a whole number, such as } 6 \text {, as } 6 / 6 \text { and multiplying both } \\
\text { the numerator and denominator by six - instead of just the } \\
\text { numerator } \\
\text { 3. Incorrectly dividing fractions by dividing the numerators and } \\
\text { then dividing the denominators (similar to what is correct for } \\
\text { multiplication) } \\
\text { 4. Only applying part of the "invert and multiply" algorithm - } \\
\text { student may remember to multiply but forget to invert the second } \\
\text { fraction }\end{array}$ \\
\hline
\end{tabular}

(Ashlock, 2006) 
The results of this study indicated that students had some fragmented understanding of fraction concepts and their operations. However, students had several common misconceptions. Students often applied the wrong algorithm when adding, subtracting, multiplying, or dividing fractions. Students tended to select an algorithm and use it - they rarely drew pictures or diagrams to help answer questions. When solving word problems, some students used the wrong operations (such as multiplication instead of division). Other errors included students misusing the algorithm by cross-multiplying instead of multiplying fractions straight across, students failed to use inverse operations to solve the equations from category 3 , and on the most difficult problems - namely in category 6 - many students failed to attempt the problems (Brown \& Quinn, 2006).

Decimals and percents. Decimals are an important prerequisite skill for algebra because students need to compute with decimals and percents fluently (Bottoms, 2003; Silver, 2000; Stacey \& MacGregor, 1997a); convert between decimals, fractions, and percents (Bottoms, 2003; Silver, 2000; Stacey \& MacGregor, 1997a); understand the value of a specific decimal or percent (Silver, 2000); and place decimals on a number line or graph (Bottoms, 2003; Stacey \& MacGregor, 1997a). The importance of decimal computation and representations are further advocated in Adding it up: Helping Children Learn Mathematics authored by Kilpatrick, Swafford, and Findell (2001).

Ashlock (2006) addressed common errors made by students when working with decimals. These errors are outlined in Table 6. Determining which decimal is greater based on the number of digits and other difficulties ordering decimals were also outlined by Desmet, Grégoire, and Mussolin (2010) and Steinle and Stacey (2004). Thorpe (1989) argued that the use of decimal representation would help students develop number sense 
because it is easier to compare decimals. Additionally, Thorpe indicated that it is easier to compute with decimals. However, others support the belief that because both decimals and fractions exist in real-life contexts and in many different subtopics in algebra, students must be able to work fluently with both decimals and fractions (Bottoms, 2003; Silver, 2000; Stacey \& MacGregor, 1997a).

Table 6

Ashlock's Decimal-Related Errors

\begin{tabular}{|c|c|}
\hline Concept & Error \\
\hline Comparing decimals & $\begin{array}{l}\text { 1. Determined which decimal was greater } \\
\text { simply by the number of digits }\end{array}$ \\
\hline Adding and subtracting decimals & $\begin{array}{l}\text { 1. Not using place value concept to put the } \\
\text { decimal in the correct place in the answer } \\
\text { 2. When subtracting - not regrouping but } \\
\text { instead taking the smaller number subtract } \\
\text { the larger (reversing order) }\end{array}$ \\
\hline Multiplying and dividing decimals & $\begin{array}{l}\text { 1. Placing the decimal point in the } \\
\text { incorrect place when multiplying - } \\
\text { multiple reasons } \\
\text { 2. Placing the decimal point in the } \\
\text { incorrect place when dividing - multiple } \\
\text { reasons }\end{array}$ \\
\hline
\end{tabular}

(Ashlock, 2006, pp. 136-150)

Integers. Many agree that conceptual understanding and procedural fluency of integers is key to success in algebra (Bottoms, 2003; Darley, 2009; Gallardo, 2002; Kieran, 2007; Peled \& Carraher, 2008; Thorpe, 1989). Pelled and Carraher (2008) noted that it is not easy to find everyday situations to represent problems such as $3-6=$ or $5-(-8)=\ldots$. Through their investigation, they have found that most teachers use money/debt scenarios to provide a real-life context and some use problems involving 
height or temperature. Furthermore, they suggested that using open number lines and diagrams help teach students about negative numbers.

Students often try to work problems in ways that avoid using negative numbers (Gallardo, 2002; Peled \& Carraher, 2008). Gallardo (2002) conducted a study in which he interviewed 15 students aged 12 and 13 about solving word problems involving integers. He found that, while some students verbally or in writing solved the problems using integers, other students used the negative number as a subtrahend (subtraction sign) and avoided using integer notation - to intentionally avoid thinking of the integer as a negative number. Overall, students' ability to use subtrahend, isolated negatives, and formal negatives represented their acceptance of negative numbers on the first three of four levels of negative number acceptance as identified by Gallardo through historical literature. The four levels of negative number acceptance included: interpreting negative numbers as subtrahends (level 1); relative or directed numbers (level 2); isolated numbers (level 3); and formal negative numbers (level 4). Because students reached level 3, Gallardo believed students have a sense of negative numbers before they formally learn about negative numbers.

Vlassis (2008) used interviews in order to analyze students' understanding of integers. In his study, he interviewed 17 eighth-graders in eight different classrooms from two different schools. He asked each student to solve a series of simple one-step equations involving integers (such as $-32=-8 y$ and $-x=7$ ). Overall, Vlassis found that students often had difficulty in problems involving a subtraction sign followed directly by a negative sign (e.g. such as $5-(-7)$ ) when checking their answer by substituting the solution back into the equation. For example, many students had trouble with the 
equation $4-x=5$ because when they tried to check their solution of $x=-1$ by substituting -1 back into the equation they were perturbed by $4--1$. Additionally, Vlassis found that students omitted negative signs when rearranging the equation. He noticed some students took the equation $12-x=7$ and changed it to $x=7-12$. They failed to carry through the negative coefficient on the variable.

Ashlock (2006) found similar errors and misconceptions among students involving integers - which he addressed in a chapter on error patterns in integers. Ashlock pointed out that many errors students make with computing integers included the following: knowing to subtract when finding the sum of a positive and negative but not knowing what sign to make the sum; making the sum of two negatives a positive (possibly confused with multiplication); and other incorrect uses of signs. Ashlock suggested that to help students correct these misconceptions and errors, number lines and set models should be used to teach for conceptual understanding.

Exponents and scientific notation. Understanding exponents and scientific notation is also essential to success in algebra (Bottoms, 2003) because exponents and the laws of exponents are used to factor, solve quadratic equations, simplify radical and rational expressions, and identify the shapes of functions (e.g. $x^{2}$ is quadratic, $x^{3}$ is cubic, etc.). Thorpe (1989) pointed out that understanding of exponents and the concept of very large numbers - often written in scientific notation - are critical to the understanding of exponential functions representing real-life situations such as growth and decay.

Slavit (2006) conducted an interview study of pairs of students in order to examine their sense-making skills in problem solving on topics related to algebra. He interviewed 15 pairs of seventh- and eighth-grade students who came from a rural, 
medium SES school. One task he asked pairs of students was: "What digit is in the one's place of the answer to: $2^{9 \cdot} 3^{4} \cdot 5^{6 \text { " }}$ (Slavit, 2006, p. 6). The results indicated that students tended to use a computational approach to solve this problem instead of looking for a generalizable pattern in each power.

A study conducted by Pinchback (1991) further confirmed a lack of understanding that algebra students have regarding exponents. Pinchback's study examined errors demonstrated by a two intermediate college algebra classes composed of mostly college freshman. She found that students often did not interpret expressions such as $(z-4)^{2}$ correctly and instead interpreted it as $(z-4)(z+4)$ or they tried to do other incorrect procedures such as attempting to factor $(z-4)^{2}$ to $(z+2)(z-2)$. While this study was conducted on older students, it reveals the deeply-rooted lack of understanding students have with exponents beyond the basics of $2^{2}=4,3^{3}=27$, etc.

In conclusion, the numbers and numerical operations prerequisite content area includes a variety of skills involving working proficiently, converting among, and understanding the following: comparing and ordering numbers, fractions, decimals and percents, integers, and exponents and scientific notation. Each of these representations are used in algebra.

\section{Ratios and Proportions}

Proportional reasoning is often regarded as one of the major components of formal thought and that, if acquired during adolescence, will help students in the disciplines of science and mathematics as well as in life (Hoffer, 1988; Post, Behr, \& Lesh, 1988; Silver, 2000). Post, Behr, and Lesh (1988) defined proportional reasoning as "...one form of mathematical reasoning. It involves a sense of co-variation, multiple 
comparisons, and the ability to mentally store and process several pieces of information" (p. 79). Post et al. (1988) argued that simply teaching students to set up and solve generic proportions provides a very limited understanding and that teaching proportional reasoning should extend far beyond the cross multiply algorithm. Additionally, proportional reasoning is not only mathematical, as described by $y=m x+b$, but also psychological. In order to reason proportionally, students must be able to think multiplicatively. That is, they must have a good concept of rational numbers, equivalence, understand the parts of a ratio, and decide whether an answer is reasonable and makes sense (Post et al., 1988).

Ratios and proportions are used in many ways. People encounter ratios and proportions through shopping, money exchanges, following recipes, completing home projects, driving automobiles (e.g. $\mathrm{mph}, \mathrm{mpg}$ ), and more. Additionally, proportions are used in a variety of different contexts including changing units, scale maps and diagrams, geometry (e.g. pi), probability, and graphing (Hoffer, 1988). Silver (2000) pointed out that proportional reasoning is important in algebra through linear equations and functional relationships.

Ratios and proportions may confuse students because they often appear in the form of a fraction. While a fraction represents a part/whole relationship, a ratio can represent a part/whole, part/part, or even a whole/part relationship. Additionally, ratios can have zero as a denominator and can contain different units whereas fractions cannot. For example, in a ratio for a scale map it is correct to have one inch: 50 miles, but with a fraction the same units must be used in both the numerator and the denominator. Another confusing aspect regarding ratios is the number of different ways a ratio can be written. 
For example, the ratio of 12 girls in a class of 20 students could be written as 12/20, 12:20, or 12 to 20 if writing as a part/whole ratio. However, if asked to compare the number of girls to boys in the class, the ratio could be written as $12 / 18,12: 18$ or 12 to 18 . Additionally, ratios can be written as a single number (e.g. $55 \mathrm{mpg}$, pi) and students may be asked to simplify ratios (e.g. 6:14 to 3:7) (Hoffer, 1988). Kilpatrick et al. (2001) also discussed the confusion associated with the multiple ways to write a ratio.

Another critical difference between fractions and ratios involves combining two ratios (or fractions). Hoffer (1988) provided the following example: " 2 hits out of 5 atbats followed by 3 hits out of 7 at-bats yields 5 hits out of 12 at-bats" (p. 289). Here it is logical and correct to add the numerators and add the denominators. However, if this were a fraction problem $(2 / 5+3 / 7)$ the correct process would include first finding a common denominator and following the correct procedure for adding fractions. Overall, the numerous ways students might be asked to write or represent situations using ratios and proportions can be a challenge in itself as noted by the comparison of fractions to ratios and the variety of ways to write a ratio. Additionally, students have difficulty understanding that with fractions the portions are always equal sized whereas that is not always the case with proportions (Labato \& Ellis, 2010).

Lamon (1999) also recognized the confusion associated with ratios written as fractions. Lamon believed that students are often taught to use fractions (e.g. 3/4) only to demonstrate a part-whole relationship and this oversimplified and rigid understanding causes students to be inflexible in moving back and forth between fractions, such as $3 / 4$, meaning a part/whole relationship and meaning something different, such as a part/part 
relationship. "Instruction needs to provide children the opportunity to build a broad base of meaning for fraction symbols..." (Lamon, 1999, p. 4).

Lamon (1999) defined a ratio as “...a comparison of any two quantities" (p. 164). She used the following diagram to summarize the different types of ratios.

Figure 1

\section{Lamon's Types of Ratios}

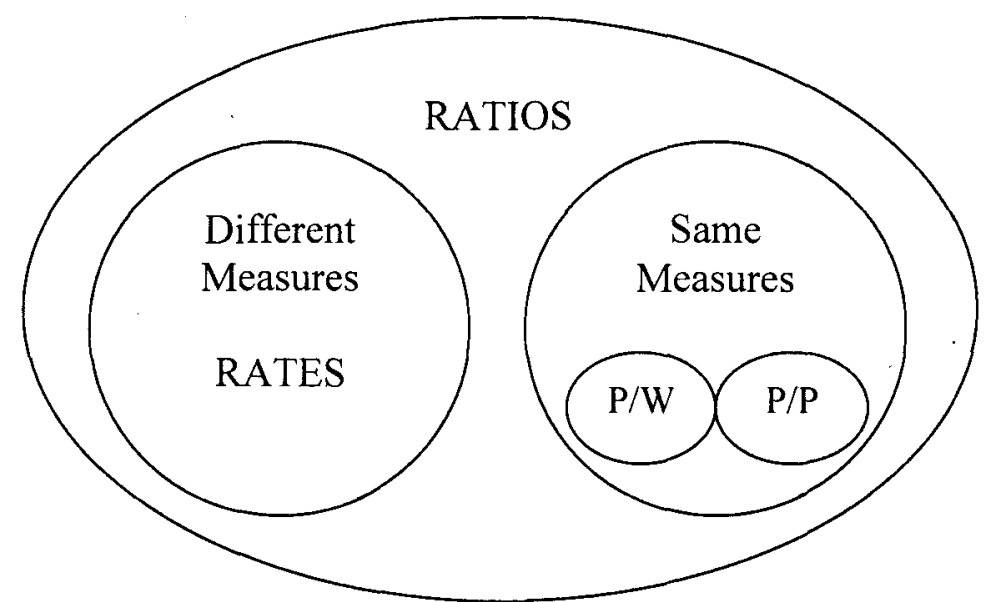

(Lamon, 1999, p. 165)

Proportional reasoning is a prerequisite algebra-related skill that can easily be incorporated into traditional middle school mathematics curricula because of its connection to multiple topics such as probability, geometry, graphs, decimals, fractions, percents, measurement, and area and is easily assisted through use of a calculator - so students are not hindered by tedious calculations and can instead focus on conceptual understanding (Hoffer, 1988). Additionally, some students have difficulty understanding the size of a ratio (Kilpatrick et al., 2001).

A study conducted by De Bock, Van Dooren, Verschaffel, and Janssens (2002) used a five-phase interview to examine students' understanding of proportionality when asked to find the area of an irregular figure. At each phase, if a student did not answer the 
question correctly, the interviewer moved to the next phase providing more information and clues - continuing until either the student arrived at the correct answer or had completed all five phases in the exercise. The results revealed that of 20 students aged 12 and 13 , none of the students answered correctly at phase one, one at phase two, seven at phase three, five at phase four, three at phase five, and four students never arrived at the correct answer. The overarching misconception found in this study was that students rigidly applied the procedure of linear proportionality to solve the problem (involving two-dimensions) and only multiplied by three (because $56 \times 3=168$ for the height, students claimed that $6 \times 3=18 \mathrm{ml}$ of paint). Students failed to realize that not only did they need to multiply the height of the irregular figure, by a factor of three, but also the width.

A study conducted by Singh (2000) used clinical interviews with two sixth-grade female students. These two students were asked to answer three types of questions which required proportional reasoning: a question about money, a question about sharing pizza with a number of people, and a question about similar figures. Student A was known as an exceptionally bright "A" student and Student B was known as a hard worker who was good at mathematics (but not as good as Student A). It should also be noted that Student A's class (advanced) had been taught the unit method (e.g. finding the rate for one unit then multiplying to get the rate of the desired number of units) of solving proportions whereas Student B's class had not. Interestingly, the results showed that Student B had a conceptual understanding of proportions while Student A had only a procedural understanding (Singh, 2000). Behr, Harrel, Post, and Lesh (1992) also discussed the difficulty students have with unitizing. 
In conclusion, Singh (2000) stated that "Student B was able to unitize the units in a composite and furthermore was able to deal meaningfully with composite units. In short, she was able to take a ratio as a composite unit and maintain the ratio unit of its element" (p. 282). Conversely,

Student A's conceptualization in proportional reasoning is solely based on the unit method, a memorized procedure rather than a conceptual one. She was able to use the unit method to solve various tasks to get the answer. However, she was not able to describe her reasoning in a meaningful way, other than describing the procedures she used. (Singh, 2000, p. 288)

The results of Singh's study suggest that teaching students to use the unit method procedure to solve proportions as a main approach may be counterproductive in students' development of proportional reasoning.

Overall, proportional reasoning is considered a skill that is essential yet understandably difficulty for students (Hoffer, 1988; Lamon, 1999). Additionally, proportional reasoning is very complex with different meanings for fractions, ratios, proportions (Hoffer, 1988; Lamon, 1999). Proportional reasoning is highly conceptual rather than procedural and a skill that develops gradually (Singh, 2000).

\section{The Order of Operations}

Order of operations. The correct use of the order of operations with whole numbers, fractions, and decimals is a basic skill needed in algebra (Bottoms, 2003). Operational sense as defined by Warren (2003) is "the ability to use operations on at least one set of mathematical objects, for example, to add positive numbers" (p. 124). Using the order of operations extends on this definition because not only do students need to know how to perform individual operations; they also make decisions about the order in which to perform said operations. 
Linchevski (1995) suggested that the pre-algebra curriculum should include activities in which students have the opportunity to see that using the order of operations correctly will provide an answer different from incorrect use. Additionally, students should practice problems and begin justifying their work. A study conducted by Linchevski and Livneh (1999) interviewed 53 students in four classes. The students were around 12 years of age, and approximately half of the students were from Canada and half were from Israel. In their study, Linchevski and Livneh asked students to solve the following problems:

1. $5+6 \times 10=$ ?

2. $\quad 17-3 \times 5=$ ?

3. $8 \times(5+7)=$ ?

4. $27-5+3=$ ?

5. $24 \div 3 \times 2=$ ?

They found that, on questions 1 and 2, the majority of students performed addition first instead of multiplication. All students got question 3 correct, which suggested that students knew to simplify the parentheses first. On questions 4 and 5, although the majority of students correctly solved from left to right, some students believed they should add before subtract or multiply before divide (instead of in order from left to right). Overall, only $26 \%$ of students answered all five questions correctly (Linchevski \& Livneh, 1999).

Additionally, Booth (1988) pointed out that students often do not use parentheses because they believe that a written sequence of operations is performed in order from left to right. While this misconception hinders students in algebra, it is really arithmetical in nature. Furthermore, in a report from a two-year project, Strategies and Errors in 
Secondary Mathematics, which analyzed student errors in mathematics, Booth concluded that:

Children ignore the use of grouping symbols, mainly because they consider them unnecessary. This belief is largely founded upon the view that:

- the context of the problem determines the order of operations;

- in the absence of a specific context, operations are performed from left to right; and

- the same value will in any case be obtained regardless of the order of calculation.(Booth, 1984, p. 86)

In order to alleviate misunderstandings about the order of operations,

Schwartzman (1996) suggested that instead of teaching commonly known statements like Please Excuse My Dear Aunt Sally (PEMDAS), students should be taught that the order of operations is a hierarchy of operations. Because multiplication and division are repeated addition and subtraction, Schwartzman recommends that students learn that the more complicated operations come first. He used the following table in his trigonometry course:

Figure 2

Hierarchy of Arithmetic Operations

\begin{tabular}{|c|c|c|}
\hline Level 1 & Level 2 & Level 3 \\
\hline+ & $x$ & $x^{n}$ \\
\hline- & $\div$ & $\sqrt[n]{x}$ \\
\hline
\end{tabular}

(Schwartzman, 1996, p. 172)

Properties. Understanding properties of numbers helps build a strong foundation for algebra (Baroudi, 2006; Bottoms, 2003; Carpenter, Levi, \& Farnsworth, 2000; Stacey \& MacGregor, 1997a; Warren, 2003). Stacey and MacGregor (1997a) stated that "One of the most frequent algebraic acts is manipulation - changing an expression into an 
equivalent expression that has the same value, for example, replacing $3 y+6$ by $3(y+2)$ "' (p. 256). Algebraic manipulations such as this one require students to have an intuitive sense of the properties of numbers.

Schifter and others (2008) examined elementary students' understanding of the commutative, associative, and distributive properties. They found that with the commutative property, students realized they would get the same answer if the order of the numbers were reversed. However, students tended to focus on the numbers themselves and not the operations in the problem. This focus is troublesome because if students know that the answer is the same when the numbers are in either order, they may fail to realize that this is only true for addition and multiplication, and not for subtraction and division. They found that this is not the case with the associative property and that students do focus on the operations (Schifter et al., 2008).

Warren (2003) administered a written test to 672 students ranging from age 11 to 14, with most students being 12 or 13 . The students attended six different schools, and all of the students were in the seventh- or eighth-grade. Two tasks on this written test aimed to gauge students' understanding of both the commutative and associative properties. Students were asked to identify if the commutative and associative properties were true for each addition, subtraction, multiplication, and division. With the commutative property, almost all students correctly identified it being true for both addition and multiplication. However, $16 \%$ and $18 \%$ of students also identified the commutative property as true for subtraction and division, respectively. When asked about the associative property, more students had incorrect responses. Only $80 \%$ and $78 \%$ of students identified the associative property as true for addition and multiplication while 
$76 \%$ and $76 \%$ of students correctly identified the associative property as false for subtraction and division. Furthermore, when asked to provide examples demonstrating the truth or falsehood of these two properties, only $73 \%$ of students were able to provide examples for the commutative property and $58 \%$ for the associative property. Of those that did provide examples, many students only used numbers in their explanation, and some students provided incorrect responses (Warren, 2003).

Several researchers in mathematics education believe that having students justify and prove the properties of numbers will help students retain their knowledge and build conceptual understanding. Carpenter and others (2000) suggested that having students in grades as low as third- and fourth-grade model the commutative property by using arrays to justify that values such as $8 \times 5$ is the same as $5 \times 8$ will help students develop the generalization that the answer will always be the same, regardless of what numbers are used. Warren (2003) suggested that students may have misconceptions regarding properties of numbers because they do not have enough time to explore and make their own conjectures in the early elementary grades and that mathematics is taught in a noncalculator environment - when in fact calculators would be valuable in exploring why particular properties do not work for subtraction and division.

Understanding of the order of operations and properties of numbers is a key element in performing sequences of steps in the correct order throughout many types of algebra problems. This review of literature suggests that memorizing rules (such as PEMDAS) is not the best way for students to retain knowledge of the order of operations and the properties of numbers (Carpenter et al., 2000; Schifter et al., 2008; Warren, 2003). Instead, students should learn about the order of operations and properties of 
numbers through practice, modeling with manipulatives, and justifying steps (Carpenter et al., 2000; Schifter et al., 2008; Warren, 2003).

\section{Equality}

Students' misunderstanding of equality begins in elementary school. In arithmetic, students often hold the misconception that the equals sign means "and the answer is" (Ball et al., 2008; Baroudi, 2006; Cathcart, Pothier, Vance, \& Bezuk, 2003; Falkner et al., 1999; Jacobs et al., 2007; Kieran, 1980, 1981; Van de Walle et al., 2010; Van Dooren, Verschaffel, \& Onghena, 2002; Welder, 2007). Through their work in elementary school classrooms, Falkner and others stated the following:

We had assumed that kindergarten children would have little experience with the equals sign and would not yet have formed the misconceptions about equality demonstrated by older children. Even kindergarten children, however, appear to have enduring misconceptions about the meaning of the equals sign that are not eliminated with one or two examples or a simple explanation. This incident also illustrates that children as young as kindergarten age may have an appropriate understanding of equality relations involving collections of objects but have difficulty relating this understanding to symbolic representations involving the equals sign. (Falkner et al., 1999, p. 232)

Stacey and McGregor (1997a) stated that this incorrect understanding of equality can be noted when students commonly work out a string of unequal problems such as $3 \mathrm{x}$ $(14+36)$ as $14+36=50 \times 3=150$. Likewise, in a multiple case study research project, Linchevski and Herscovics (1996) discovered that some participants used extra equals signs to show that two equations were equivalent by writings such as $17 n+12 n+36=$ $210=29 n+36=210($ p. 50$)$.

Elementary students rarely understand that the equals sign serves as a balance and the total value on both sides must be the same. Falkner and others (1999) found that while students struggle to solve a problem such as $4+5=[]+6$ abstractly, they often 
have few problems modeling the correct answer using manipulatives. Baroudi (2006) asked 27 eighth-grade students in a class to write their definition of the equals sign. He found that nine of these 27 students gave a definition that viewed the equals sign as that "the answer is" or "the answer is coming" although the true meaning of the equals sign had previously been discussed in that class.

Understanding equality should begin in elementary school, before abstract variables are introduced. Teaching elementary students that the equals sign really means "the same as" will prepare them for solving equations abstractly in middle school (Stacey \& MacGregor, 1997b). In students' progression of learning algebra, they must eventually become proficient in solving time consuming multi-step equations and inequalities. If a student can visualize an equation as a balance and understand the concept of equality, they will more likely understand inverse operations used to solve a missing value equation (Falkner et al., 1999). Likewise, Asquith and others (2007) stated that it is critical for students to have a relational understanding of the equals sign in order to realize the importance of preserving equivalence when performing inverse operations.

"To make algebra the rich experience that it should be, teachers must realize that students have a tendency to lose sight of equivalence" (Van Dyke \& Craine, 1997, p. 616).

As a result of their interview research addressing students' understanding of equality, Behr, Erlwanger, and Nichols $(1976,1980)$ provided a comprehensive summary of their findings:

As an operator symbol, = would be a "do something signal". As a relational symbol, $=$ suggests a comparison of the two members of an equality sentence. These interviews suggest that children consider the symbol = as a "do something signal". There is strong tendency among all of the children to view the $=$ symbol as being acceptable in a sentence only when one (or more) operation signs (+, -, 
etc.) precede it. Some children, in fact, tell us that the answer must come after the equal sign. We observe in the children's behavior an extreme rigidity about written sentences, an insistence that statements be written in a particular form, and a tendency to perform actions (e.g. add) rather than to reflect, make judgments, and infer meanings. Moreover, we have some evidence to suggest that children do not change in their thinking about equality as they get older.

(Behr et al., 1980, p. 15)

Linchevski and Herscovics (1996) conducted six case studies in an attempt to address students' concept of equality. Students were shown the following equation on a balance: $5 n+3 n+11=5 n+11+39$. Students were then asked if they noticed any equal terms that were on both sides and if they thought those terms could be taken away. Next, students were asked to solve the remaining equation, $3 n=39$. Once the equation was solved, $n=13$, students were asked if this solution was also true for the original equation, $5 n+3 n+11=5 n+11+39$. Some students were not confident that the solution was also true for the original equation and had to check by substituting $n=13$ back into the original equation. This finding suggests that students still struggle with the notion of equivalence.

Similarly, Vlassis (2002) studied equality through use of the balance model. In this study, 40 eighth-grade students were asked to solve equations with both variables on one side of the equal sign and equations with variables on both sides of the equals sign. They found that many students actually used the drawing of the balance to cancel out equivalent terms on each side of the balance. Next, some students copied down the simplified remaining equation and solved it. In conclusion, Vlassis stated that the balance model "provides a mental picture of the manipulations to be carried out and the associated concepts (the meaning of equality and expressions, the properties of equality)..." (Vlassis, 2002, p. 355). See Figure 3. 
Figure 3

Balance Model for Understanding of Equality

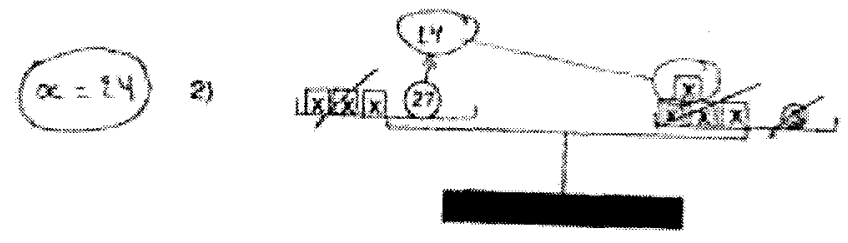

(Vlassis, 2002, p. 346)

Kieran (as found in 1980, 1981, 1988, 1999, 2008) conducted extensive research on students' understanding of equality. In one study (Kieran, 1981), she examined the concept of equality for students in preschool through college level. At preschool, students' understanding of equality is often limited to two sets being the "same", which is represented by the students' ability to count two different sets and compare the total items in each set. In elementary school and middle school, students often view the equals sign as the "do something signal" and believe that equations are written backwards if equations are written as $3=2+1$ instead of $2+1=3$. Kieran believed that around age 13 is the time when students may begin to shift from thinking of the equals sign as a symbol "prompting the answer" to understanding the notion that the equals sign represents equivalence. However, through examination of student work, Kieran suggested the errors students continue to make in high school may reveal the fact that students still do not truly understand equality and revert back to incorrectly using the equals sign as a symbol "prompting the answer" (Kieran, 1981).

A study conducted by Steinberg, Sleeman, and Ktorza (1990) sought to examine students' understanding of equivalence. A total of 96 eighth- and ninth-grade students of 
middle and high ability levels from four different classes participated in the study. Each student was presented with a written test with 21 pairs of equations and the students were asked to determine if each pair of equations were equivalent. For example, one pair of equations was $x+2=5$ and $x+2-5=0$. Analysis of student work found that most students fell into one of three groups: (a) they computed solutions to determine equivalence; (b) they based answers on reasons on transformations of equations; or (c) they had other incorrect reasons. The results found that students who transformed equations had more correct answers than those students who calculated solutions. Some main incorrect reasons used to judge equivalence suggested the following - misconceptions: students lacked knowledge of basic algebra procedures for solving equations, students did not fully understand the difference between expressions such as $5 x$ and $5+x$, students only looked at one side of each equation instead of both, and students attempted to rely on surface clues (Steinberg et al., 1990).

In order to address the misconception that the equals sign means "the answer is", Kieran (1980) suggested first expanding the notion of the equals sign by having students construct number sentences with operations on both sides. She recommended using arithmetic equalities such as:

1. $2 \times 6=4 \times 3$

2. $2 \times 6=10+2$

and then 3. $7 \times 2+3-2=5 \times 2-1+6($ Kieran, 1980, p. 4)

Placing operations on both sides of the equals sign may help students when they are asked to solve equations with variables on both sides - when the "guess and check" method becomes too complicated and properties of equality must be used. After students grasp the concept of equality with arithmetic equalities as mentioned above, then 
equations can be introduced. The concept of variable should be introduced by first covering up a number, then by replacing the number with a box, and finally by using a letter for the variable (Kieran, 1980).

Bottoms (2003) stated that students in the middle grades should learn the properties of equality and use them to solve one variable equations. He suggested having students practice writing equivalent equations and work with algebra manipulatives (e.g. algebra tiles and mats) in order to further build understanding of equivalence (Bottoms, 2003).

In conclusion, the underlying issue with students' misunderstanding of equality originates from their first experiences with equations. Too often at the elementary level, students are continually presented with equations in the same "order" and develop the notion that the equals sign means "and the answer is" (Ball et al., 2008; Baroudi, 2006; Cathcart, Pothier, Vance, \& Bezuk, 2003; Falkner et al., 1999; Jacobs et al., 2007; Kieran, 1980, 1981; Van de Walle et al., 2010; Van Dooren, Verschaffel, \& Onghena, 2002; Welder, 2007). Researchers have suggested that teachers should reverse the order of equations often in order to help students become more flexible and develop a deeper understanding of equality (Kieran, 1981; Van de Walle et al., 2010). Additionally, many students who lack understanding of equality reach a significant barrier when they are introduced to equations with variables on both sides (Kieran, 1980).

\section{Patterning}

By examining patterns on a hundreds chart, students can begin making generalizations through patterns in elementary school (Van de Walle et al., 2010). "The study of patterns in the middle grades should progress from patterns with pictures or 
simple number sequences to patterns that relate to linear functions" (Bottoms, 2003, p. 39). Additionally, students should move toward written algebraic expressions to represent patterns, instead of stating or writing patterns informally. Students should work with a variety of patterns resulting from different operations including multiplying, dividing, increasing, decreasing, and represented by pictures, tables, puzzles, etc. (Bottoms, 2003). In her book, Algebra and the Elementary Classroom: Transforming Thinking, Transforming Practice, Blanton (2008) presented pictorial patterns for students to analyze and had students create a table of values to organize patterns in an effort to foster students' algebraic understanding of functions. Using patterns to form generalizations and then justifying those generalizations provides a means for the beginning of proof (Kieran, 2007). Booth and Watson (1990) stated that "Encouraging students to see that the same pattern can be represented by different rules helps them develop flexibility in switching from one viewpoint to another, and furthermore paves the way for ideas of equivalence in expression, and algebraic simplification" (p. 13). Furthermore, Usiskin (1995) stated that algebra itself is a language of patterns for describing rules and generalizations.

The use of patterns fosters students' development in writing expressions and equations that represent the pattern in a generalized way. Pictorial patterns are one way which students can look for a pattern, describe how to continue the pattern, and then make a generalization that would work for any extension of the pattern (Mason, 2008). Lannin (2003) stated that having students make generalizations from numeric situations helps students make connections between numbers and operations and algebra and work 
in a context in which they are already familiar. Kaput (2000a) defines generalization of patterns in the following way:

Generalization involves deliberately extending the range of reasoning or communication beyond the case or cases considered, explicitly identifying and exposing commonality across cases, or lifting the reasoning or communication to a level where the focus is no longer on the cases or situations themselves, but rather on the patterns, procedures, structures, or the relations across and among them (which, in turn, become new, higher level objects of reasoning or communication). But expressing generalizations means rendering them into some language, whether it is a formal language, or, for young children, in intonation and gesture. (Kaput, 2000a, p. 6)

While using patterns to engage students in algebraic thinking can be a nonintimidating way to incorporate algebra into the middle school mathematics curriculum, it takes time for students to learn how to make algebraic generalizations (Kieran, 2008). Day and Jones (1997) indicated that, "The key is the development of students' patternbuilding capabilities through appropriate problems and questions designed to build a bridge from arithmetical to algebraic thinking" (p. 212). Kaput (2000b) believed that having students generalize patterns helps them focus on the "structure of the computation rather than its result" (p. 11). Furthermore, he suggested having students work with picture patterns to create their own rules to represent the pattern and then moving forward towards non-pictorial (more abstract) generalizations. He provided an example of this with even and odd number patterns in which students were asked to explore and generalize the pattern when taking the sum of two evens (always even), two odds (always even), and one odd and one even (always odd) (Kaput, 2000b). Blanton (2008) extended the idea of the even/odd number patterns by asking students what would happen if you add three odd numbers? Four odd numbers? How do you know your answer is always 
true? What if you subtract instead of add (even subtract odd, even subtract even, odd subtract odd, etc.)? What if you multiplied?

A. case study conducted by Blanton and Kaput (2005) sought to observe a thirdgrade teachers' use of algebraic reasoning in her classroom. Their case study included a combination of field notes, observations, reflections, and student work collected from a total of 38 classroom visits. The use of pattern diagrams in order to help students write algebraic expressions to generalize a pattern was used to help students describe relationships. By the use of pictures, students were able to see the patterns and verbally express them. With guidance, students began to work with variables and writing formal expressions to represent the patterns (Blanton \& Kaput, 2005).

Rivera and Becker (2009) conducted a study to determine the effects of using patterns as a way to strengthen student understanding of integers, equation solving, increasing patterns, decreasing patterns, and polynomials among middle school students. They found that through using pattern generalizations they could require students to state assumptions, form hypotheses, test and verify hypotheses, and justify responses - all skills that are essential for success in learning algebra (Rivera \& Becker, 2009).

Koellner, Pittman, and Frykholm (2008) observed four eighth-grade girls in an algebra class and their experience making a generalization from a pattern. The girls were asked the following questions given the task of painting the outside surface of a $3 \times 3 \times 3$ cube: "How many cubes would be painted on only one face? On two faces? On three faces?" (Koellner et al., 2008, p. 306). They found that all four girls were engaged in solving this problem, and each girl had developed their own ideas and found ways to justify their solution. Although errors in counting caused confusion among the group, 
overall the group kept moving forward together in order to answer each of the questions. Eventually the girls were able to answer the questions for a $4 \times 4 \times 4$ and a $5 \times 5 \times 5$ cube. In conclusion, the authors listed the following guidelines which they believed were essential features of problems which promoted algebraic generalizations: problems must be open-ended, tasks should be multi-faceted, teachers must provide ample time and opportunities for student to work together and share ideas, and teachers must thoughtfully select the questions they present to their students (Koellner et al., 2008).

Stacey (1989) sought to answer the following questions in her study about patterns and generalizations:

- What generalizations do students make and how do they vary with increased schooling?

- How do students explain the patterns they find and the generalizations they use?

- How consistent are students in their choice of generalizing rule (i.e. mathematical model)?

- How do the responses of students who have had some experience in generalizing questions differ from inexperienced students?

(Stacey, 1989, p. 148)

Stacey examined responses from students aged 9 to 13 on pictorial patterns with ladders and Christmas trees (number of lights) and numerical patterns with blanks where students were to fill in the next terms. Her study found that children in all age groups struggled to make generalizations. Students were also found to be inconsistent in their methods of generalizing patterns. It should also be noted that students with a previous course in problem solving were able to use a linear model more frequently and consistently and appeared to better understand the relationship between the numbers or diagram and the generalization (Stacey, 1989). 
Radford (2000) observed eighth-graders working together to solve the growing pattern shown in Figure 4. Students found questions $a$ and $b$ to be much easier to answer than question $c$. Additionally, all students were able to contribute to the problem and could informally express generalizations. Only some students were able to express generalizations using symbolic algebra. Other students expressed generalizations through very detailed written messages or through sequential steps. In conclusion, Radford stated that:

The varied forms taken by the students' algebraic thinking in the mathematical activity about patterns are seen as evidence of a complex process in which the students mesh personal and impersonal tones within the limits of the contextual possibilities to actualize the mathematical practices. (Radford, 2000, p. 260)

\section{Figure 4}

\section{Growing Pattern Used in Radford's Study}

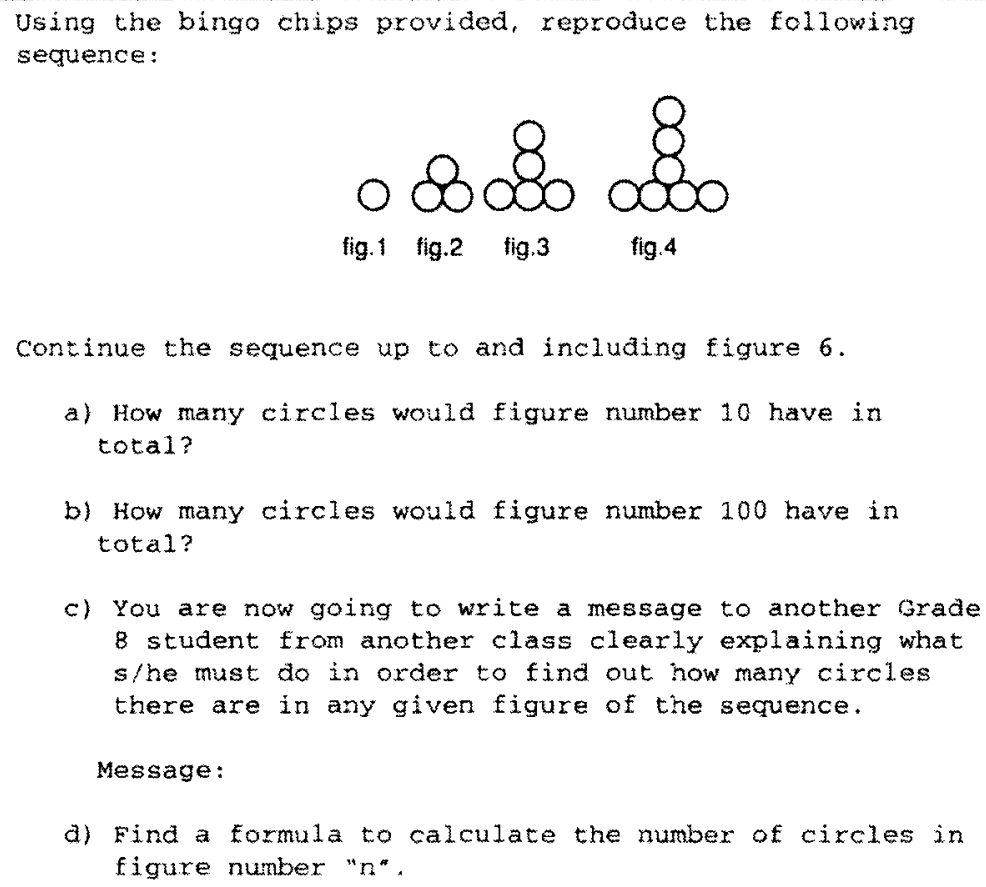

(Radford, 2000, p. 245) 
Ainley, Bills, and Wilson (2004) conducted a study in which students used spreadsheets to find patterns. Five classes of students aged 11-12 from two different schools participated. Each class worked on the task for 2-3 lessons. This task involving patterns asked students to take a $3 \times 3$ cross on a hundreds chart and compare the total of the values for each the three horizontal numbers and the three vertical numbers. Students were asked to explain to their classmates what they had found. Most students were able to explain that the total would be the same both vertically and horizontally. For example, if you look at a section of a hundreds chart, such as the one in Figure 5, both $22+23+24=$ 69 and $13+23+33=69$. Next, students moved to a $5 \times 5$ cross on the hundreds chart and were eventually convinced the horizontal and vertical numbers will always have the same sum. Additionally, students were able to state reasons why the sums were the same (e.g. the lower number and higher number cancel each other out, etc.) (Ainley et al., 2004). Fennell (2010) also discussed using a hundreds chart to examine patterns but encouraged the incorporation of decimals in the hundreds chart to help students understand that the patterns work for multiple types of numbers, not just whole numbers. 
Figure 5

Patterns on a Hundreds Chart

\begin{tabular}{|l|l|l|l|l|}
\hline 1 & 2 & 3 & 4 & 5 \\
\hline 11 & 12 & 13 & 14 & 15 \\
\hline 21 & 22 & 23 & 24 & 25 \\
\hline 31 & 32 & 33 & 34 & 35 \\
\hline 41 & 42 & 43 & 44 & 45 \\
\hline
\end{tabular}

A multiple case study conducted by Healy and Hoyles (1999) focused on students' understanding of patterns using a spreadsheet and Logo software. Students looked at one-operation and two-operation linear sequences as well as quadratic sequences in multiple forms using pictures of arrows, tiles, squares, triangles, etc. At the beginning of the study, students were able to correctly use arithmetic to make basic generalizations but struggled to translate the patterns into an algebra language and with justifying and making connections. However, by the end of the study nearly all students were able to create formal algebraic expressions. This study suggested that the use of pictorial patterns can help students begin to generalize functions and write expressions to represent patterns (Healy \& Hoyles, 1999). Using spreadsheets to form generalizations helps students shift from arithmetic to algebraic thinking without experiencing the same gaps that traditionally occur (Tabach, Arcavi, \& Hershkowitz, 2008).

In summary, many mathematics education experts support the practice of using various types of patterns in order to bridge students from viewing patterns in an arithmetic fashion to using patterns to help students learn to make generalizations (Ainley 
et al., 2004, Blanton, 2008; Day \& Jones, 1997; Fennell, 2010; Healy \& Hoyles, 1999; Kaput, 2000b; Mason, 2008; Stacey, 1989). As evident in this review of literature, teaching students to think algebraically through the use of patterns can be done through numerous types of patterns including number patterns, geometric patterns, growing patterns, chart patterns, arrays, 3-D figures, spreadsheets, and other technology.

The first five algebra prerequisite content areas (e.g. number and numerical operations, ratios and proportions, the order of operations, equality, and patterning) all focus on skills that address algebraic thinking in an informal way. The next four prerequisite content areas (e.g. algebraic symbolism and letter usage, algebraic equations, functions, and graphing) move students from informal algebraic thinking towards representing algebraic concepts formally with variables, symbolism, and equations. These four content areas are often addressed in the one or two years before a student takes Algebra I and are considered pre-algebra concepts.

\section{Algebra Symbolism and Letter Usage}

Variables. Very early in the history of mathematics, people have solved problems for unknown quantities. Diophantus was the first to designate an unknown quantity using a symbol - thus creating the capability for unknowns to be treated as known values which makes finding a solution much more efficient (Fosnot \& Jacob, 2010; Kieran, 1992; Vlassis, 2008). Substantial documentation about students' misconceptions regarding variables currently exists (Asquith et al., 2007; Clement, 1982; MacGregor \& Stacey, 1997; Philipp, 1992a; Rivera \& Becker, 2009; Stephens, 2005; Swan, 2000; Warren, 2003). Misconceptions students have include: viewing variables as labels (Asquith et al., 2007; Clement, 1982; Stacey \& MacGregor, 1997b; Usiskin, 1988); the idea that two 
different variables (e.g. $\mathrm{x}, \mathrm{y}$ ) in the same equation cannot represent the same value (Stephens, 2005; Swan, 2000); believing the value of a variable has something to do with its position in the alphabet (Asquith et al., 2007; Herscovics \& Kieran, 1980; MacGregor \& Stacey, 1997); and the inability to understand variables as varying quantities rather than a missing value (Asquith et al., 2007; Stacey \& MacGregor, 2000; Stephens, 2005; Usiskin, 1988). Phillip (1992a) found that, "Much of the difficulty students encounter with variables may be related to their inability to recognize the correct role of the variable" (p. 560). Furthermore, Phillip also noted that variables can take the following roles in algebra: labels, constants, unknowns, generalized numbers, varying quantities, parameters, and abstract symbols.

From his work with interpreting children's' understanding of variables, Küchemann (1978) noted that variables can be used in multiple ways. Table 7 discusses each way and is hierarchical in nature. That is, students typically find the types of variables appearing near the top of the table less challenging than the types of variables at the bottom of the table. 
Table 7

Küchemann's Hierarchy of Variables

\begin{tabular}{|c|c|}
\hline Name & Example \\
\hline Letter EVALUATED & $\begin{array}{l}\text { The letter is directly evaluated } \\
\begin{array}{l}\text { Ex. } x+6=12 \\
\quad x=?\end{array}\end{array}$ \\
\hline Letter IGNORED & $\begin{array}{l}\text { Technically do not have to evaluate - can ignore the letters } \\
\text { altogether and just add } 2 \text { to } 43, a+b+2=45 \\
\text { Ex. } a+b=43 \\
\quad a+b+2=\text { ? }\end{array}$ \\
\hline Letter as OBJECT & $\begin{array}{l}\text { Letters stand as names or labels, such as in geometry } \\
\text { Ex. } p=\text { perimeter, } a=\text { area }\end{array}$ \\
\hline $\begin{array}{l}\text { Letter as SPECIFIC } \\
\text { UNKNOWN }\end{array}$ & $\begin{array}{l}\text { Letters stand for an unknown quantity that cannot be evaluated. } \\
\text { Ex. Mary is } 3 \text { inches taller than Bob. Bob's height is denoted } \\
\text { by } b \text {. Therefore, Mary's height is } b+3 \text {. }\end{array}$ \\
\hline $\begin{array}{l}\text { Letter as } \\
\text { GENERALIZED } \\
\text { NUMBER }\end{array}$ & $\begin{array}{l}\text { Letters can represent a set of numbers, instead of one specific } \\
\text { number. } \\
\text { Ex. } x+y<20 \\
\qquad \begin{array}{l}x>y \\
y=?\end{array}\end{array}$ \\
\hline Letter as VARIABLE & $\begin{array}{l}\text { The relationship varies } \\
\text { Ex. Which is larger, } 2 n \text { or } n+2 \text { ? } \\
\text { In this case, it depends on what } n \text { equals. If } n=0 \text {, then } n+2 \text { is } \\
\text { greater. If } n=3,2 n \text { is greater. }\end{array}$ \\
\hline
\end{tabular}

(Küchemann, 1978, p. 23)

Booth (1984) found that some misconceptions students have with variables may be a result of their learning experiences. He suggested that students struggle to see variables as a varying quantity because they are often introduced and taught that variables represent a specific unknown, such as in one-variable equations.

When students are presented with mathematical tasks in which they could use variables to efficiently obtain a solution, they often choose to draw pictures or create lists 
instead (Stephens, 2005). Linchevski (1995) suggested using number patterns and allowing students to make up their own algebraic expression examples helps students build understanding. Darley (2009) noted that "When students possess a deep understanding of numbers and the connection between numbers and variables, they should be able to make a smooth transition from one to the other" (p. 458). MacGregor and Stacey (1997), in their study on student reactions to variables, examined the following research questions:

1. How do students who have not learned any algebra interpret letters and try to write expressions? Do they come to algebra with preconceptions about the use of letters?

2. How do students' interpretations of letters and simple algebraic expressions change over three years of school algebra learning?

3 . What are the roots of specific errors and misunderstandings?

(MacGregor \& Stacey, 1997, p. 4)

McGregor and Stacey asked three questions in which students had to form onestep expressions $(h+10, y-1,3 x)$, one question which formed a two-step expressions ( $2 x$ +18 ), and one question which formed an expression with the use of the distributive property $(3(n+5))$. With regards to Question 1, MacGregor and Stacey found that students “...frequently base their interpretation of letters and algebraic expressions on intuition and guessing, on analogies with other symbol systems they know, or on false foundation created by misleading teaching materials" (p. 15). The results from Question 2 suggested that students perform better as they get older; however, even students in grade 10 struggled as a whole on most questions. As one may assume, students across all grade levels performed better on the one-step expressions than on the two-step expressions or expressions involving the use of the distributive property. Ding and $\mathrm{Li}(2010)$ further confirm the difficulty students have when working with the distributive property. In their 
findings, MacGregor and Stacey suggested that the root of the misconceptions and errors often lie in teachers' instructional styles and the materials they select. Students often do not understand that the use of variables can help them solve problems accurately and efficiently - which is essential for student success in learning algebra (MacGregor \& Stacey, 1997).

Students also struggle with algebra notation and symbolism (Kieran, 1980; Novotna \& Hoch, 2008; Stacey \& MacGregor, 1997b; Warren, 2003; Welder, 2007; Witzel, 2005). Algebra notation serves as a language of its own. Students find algebra challenging because they are required to learn the syntax of symbolic representation as well as abandon previous meanings and practices associated with arithmetic (Novotna \& Hoch, 2008; Tabach et al., 2008). Nathan and Koedinger (2000) found that students scored lower on symbolic algebra equations than on both algebra word problems and algebra story problems.

Stacey and McGregor (1997b) found that using algebra notation as often as possible, reviewing arithmetic, and emphasizing that letters in algebraic expressions stand for numbers (not items), better prepared middle school students for algebra. For example, if students solved a word problem involving airplanes, the teacher should clearly explain that " $a$ " (or another letter or symbol) would stand for the number of airplanes and not just airplanes (Stacey \& MacGregor, 1997b). To counteract the misconceptions of algebra notation and symbolism, teachers should look for misunderstandings and address them immediately. Teachers must use algebra notation often and integrate it into other mathematics topics in a precise and practical way (Stacey \& MacGregor, 1997b). Student 
confusion about algebra notation and symbolism causes students' entire view of algebra to be unclear.

Asquith and others (2007) found that teachers often overestimated students' understanding of variables. The teachers in Asquith's study predicted that the students had a better conceptual understanding than was actually demonstrated on student test results. Additionally, the study suggested that using opportunities to engage students in algebraic reasoning in the elementary grades helped students grasp the concepts of variables when they reach middle and high school (Asquith et al., 2007).

Algebraic Expressions. Booth and Watson (1990), Booth (1986), Kilpatrick et al. (2001), and Stacey and MacGregor (1997b) found that students (1) struggle with algebraic expressions because they do not conceptually understand what the variables mean, especially with terms like $7 a b$, and (2) struggle to understand why an answer can be something other than a number (e.g. an expression, factor, etc). Kieran (1992) noted that, in addition to understanding what expressions mean, students struggle to simplify expressions correctly - meaning they struggle with the procedures. For example, students attempt to simplify $30 x-5$ to $25 x$ or they do not correctly carry out the distributive property when necessary.

Dede (2004) further confirmed the finding claiming that students often incorrectly simplify expressions such as $2+5 x$ to $7 x$. Another common misconception mentioned by Capraro and Joffrion (2006) happened when students were asked to write an expression involving subtraction. Students often wrote "four less than a number" as 4 $-n$ instead of $n-4$ 
Helping students understand that variables can be used to form algebraic expressions to generalize a situation for any amount can be challenging. In the article, Early Algebra is Not the Same as Algebra Early, Carraher and others (2008) showed how one teacher helped his students with this process. The teacher wrote the following on the board: "John has three candies fewer than Mary" (Carraher et al., 2008, p. 244). While the teacher introduced to his class that the number of candies John has could be $N$ candies, meaning any amount, he let the students figure out how many candies Mary has. At first, the students guessed that Mary also has $N$ candies, and the teacher helped them realize that would mean that John and Mary have the same amount. He then asked his class who had·fewer candies and the students responded "John". Eventually two students stated that Mary had $N+3$ candies, thus creating an algebraic expression (Carraher et al., 2008).

Van Amerom (2003) reported a similar classroom dialogue in which students were given a deck of cards and asked to form algebraic expressions using the numbers and letters (variables) in the decks of cards. Stacey and MacGregor (1997b) asked students the following question: "David is $10 \mathrm{~cm}$ taller than Con. Con is $h \mathrm{~cm}$ tall. What can you write for David's height?" (p. 111). They found that only about $50 \%$ of first-year algebra students and $75 \%$ of third- or fourth-year algebra students could write a correct expression representing David's height (e.g. $h+10$ or equivalent) (Stacey \& MacGregor, 1997b). These percentages are alarming because students were already in their first year of formal algebra and beyond.

Weinberg and others (2004) administered a written assessment on algebraic expressions to sixth-, seventh-, and eighth-graders at one middle school. They also 
interviewed 31 of the sixth-graders. Two of the questions on the written assessment are below:

Question 1: The following questions are about this expression: $2 n+3$

a) The arrow above points to a symbol. What does the symbol stand for?

b) Could the symbol stand for the number 4? Please explain your answer.

c) Could the symbol stand for the number 37? Please explain your answer.

d) Could the symbol stand for the expression $3 r+2$ ? Please explain your answer.

$$
\text { (Weinberg, et al., 2004, p. 3) }
$$

Question 2: $\quad$ Cakes cost $c$ dollars each and brownies cost $b$ dollars each. Suppose I buy 4 cakes and 3 brownies. What does $4 c+3 b$ stand for?

(Weinberg, et al., 2004, p. 4)

The results from Question 1 showed that, fewer students answered "yes" for part $\mathrm{d}$ than for part $\mathrm{b}$ or $\mathrm{c}$. This result was not surprising considering students often perceive a variable to represent an object or one number, which they do not view as an expression meeting this criterion. Additionally, eighth-graders had higher percentages than sixth- or seventh-graders and the seventh-graders scored better than the sixth- graders. On Question 2 , several students $(22 \%, 37 \%$, and $27 \%$ percent in grades $6,7,8$ respectively) incorrectly stated that $4 c+3 b$ meant 4 cakes and 3 brownies. This suggested that the students incorrectly viewed the variables as labels - with $c$ meaning cakes instead of "times the cost of a cake" and $b$ meaning brownies instead of "times the cost of brownies" (as also found in a similiar problem in Swan, 2000). The interview portion of the study revealed a wide range of responses, and no apparent patterns emerged (Weinberg et al., 2004).

Graham and Thomas (2000) had students use graphing calculators to practice using letters as specified values, generalized numbers, and variables. They used the 
graphing calculators to store the letters A and B in each of these ways and then analyze a series of expressions. Using a pre/post test design, their results suggested that the graphing calculator helped students build a versatile view of the different uses of letters. Additionally, students enjoyed learning with the graphing calculator and seemed motivated by the use of technology (Graham \& Thomas, 2000).

Swan (2000) suggested the following methods for helping students understand algebraic expressions: "Comparing equivalent mathematical representations: Mathematical concepts have many representations, from conventionally accepted notations to informal mental representations. This type of activity involves sharing, interpreting, comparing, and classifying representations" (p. 16). Swan also encouraged the use of table and area models to represent algebraic expressions. Kieran and Sfard (1999), Day and Jones (1997), Briggs, Demana and Osborne (1986), and Bottoms (2003) suggested teaching students that expressions represent situations by having students match expressions with both a table and graph. This way, they can make connections between the different representations and begin work with functions. Kieran (2008) pointed out that algebraic expressions lay the groundwork for equations and that the understanding of expressions, variables, and equivalence are essential when working with equations.

In conclusion, algebraic symbolism is a difficult concept for students to grasp for several reasons. First, students often struggle with the multiple meanings and uses of variables (Asquith et al., 2007; Booth, 1984; Küchemann, 1978; Philipp, 1992a; Stacey \& MacGregor, 2000; Stephens, 2005; Swan, 2000; Usiskin, 1988). Second, students have difficulty with the syntax of algebraic notation (Novotna \& Hoch, 2008; Stacey \& 
MacGregor, 1997b; Warren, 2003; Welder, 2007; Witzel, 2005). Finally, students find algebraic expressions challenging because they do not conceptually understand what terms (e.g. 7ab) and expressions mean (Booth, 1986; Booth \& Watson, 1990; Carraher et al., 2008; Stacey \& MacGregor, 1997b; Van Amerom, 2003).

\section{Algebraic Equations}

In her article Algebra With Numbers and Arithmetic With Letters: A Definition of Pre-Algebra, Linchevski (1995) organized pre-algebra curriculum into four categories:

- developing the notion of a solution through opportunities to experience substitution of numbers for letters (numerical verification);

- dealing with equivalent equations through substitution;

- building cognitive schemes through the reflective activity that allows students to use their own spontaneous procedures; and

- practicing forming equations as a complementary activity to solving equations. (Linchevski, 1995, p. 117)

The fact that all four areas are directly related to algebraic equations suggests the importance of incorporating algebraic equations into the middle school mathematics curriculum. Specifically, Bottoms (2003) stated that solving one- and two-step equations with one variable, as well as writing one-variable equations from word problems, is basic prerequisite knowledge for algebra while proficient prerequisite knowledge of algebra includes solving equations in two variables algebraically and graphically.

Several researchers agreed that equation solving becomes significantly more difficult for students when they encounter one-variable equations with variables on both sides (Herscovics \& Linchevski, 1994; Kieran, 1980). Students can no longer rely on arithmetic in order to solve equations, as they were previously able to do with equations such as $2 x+4=8$ (Herscovics \& Linchevski, 1994). With variables on both sides, students must make use of algebraic properties (e.g. properties of equality, distributive 
property, etc.) and have a solid understanding of equivalence to become good equation solvers.

Kieran and Sfard (1999) provided an example of dialogue between a teacher and a student in which the student knows the rules for simplifying equations but has no conceptual understanding as to why such rules exist. The student believed that the rules (in this case distributive property) exist simply so everyone would solve the equation in the same way - thus creating a uniform approach. Unfortunately, this is not an isolated case. Some students may understand the concepts of solving equations but are bogged down by the computation - usually with negative numbers, decimals, or fractions $(\mathrm{Wu}$, 2001). On the other hand, some students may have superficial knowledge of solving equations but can make no connections and establish no meaning to the equations which they are solving (as also found in Capraro \& Joffrion, 2006; Kalchman \& Koedinger, 2005; Kieran, 1992).

Kieran and Sfard (1999), Kalchman and Koedinger (2005), and Carraher and others (2006) suggested that equations should be taught alongside with tables and graphs in such a way students must always connect an equation, table, and graph together. Additionally, they believe that story problems should also be linked to tables and graphs immediately so students can see differences between linear and nonlinear equations (Kieran \& Sfard, 1999). Moreover, students need the opportunity to visualize the variables in equations as varying quantities and not specific unknowns. Capraro and Joffrion (2006) found that the

...mere knowledge of procedural skills caused students an inability to apply methods for solving the problems. The procedural approach of translating from 
mathematical words to symbolic representations did not help students succeed on the items that required students to apply this skill.

(Capraro \& Joffrion, 2006, p. 162).

The learning and teaching of algebraic equations, both writing and solving, can be challenging because of the multiple interpretations, representations, and methods for solving. Due to this complexity, it is not surprising that students have misconceptions and make many different types of errors when formulating and solving equations. Stacey and MacGregor (2000) shed light on this complexity through the following diagram, Figure 6, describing the possible paths beginning with the reading of a problem statement.

Likewise, Kieran (1992) listed the following methods for solving equations:

(a) use of number facts;

(b) use of counting techniques;

(c) cover-up;

(d) undoing (or working backwards);

(e) trial-and-error substitution;

(f) transposing (that is, Change Side - Change Sign); and

(g) performing the same operation on both sides.

(Kieran, 1992, p. 400)

The last two methods, transposing and performing the same operation on both sides, are considered the formal methods of solving equations. However, Herscovics and Kieran (1980) and Capraro and Joffrion (2006) favor performing the same operation on both sides because it promotes and fosters the meaning of equivalence. 
Figure 6

Routes from Problem Statement to Solution

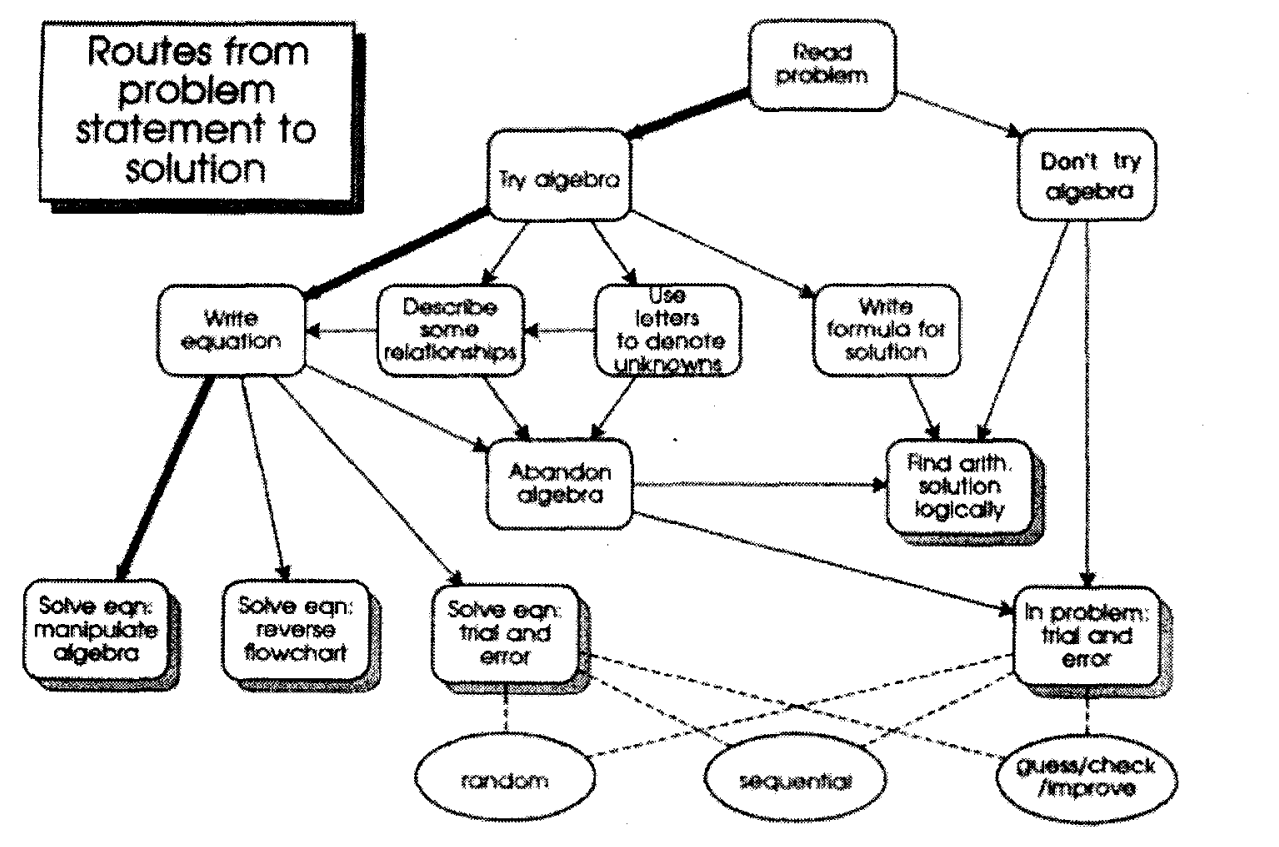

(Stacey \& MacGregor, 2000, p. 155)

Perrenet and Wolters (1994) argued that while many studies focus on how

students solve linear equations, research is lacking on how and if students are checking their solutions. Therefore, they conducted a study in which 83 eighth-grade students from two high schools completed a pencil and paper task in order to examine the behavior of solution checking. They found that, of the 83 students, 29 did not check at all, and only 10 students were consistently correct in checking. Fourteen students who checked but had errors in checking were chosen for interviews. Interestingly, researchers found that some students write down every single detail, including their errors while other students make errors because they do not write down enough steps. The first group of students tended to lack the conceptual knowledge whereas the students that skipped steps understood the 
process of checking and could easily find and correct mistakes (Perrenet \& Wolters, 1994).

Equation solving can take on many forms including story problems, wordequation problems, and symbol-equation problems. In order for teachers to help students overcome misconceptions and errors it is important for teachers to know specifically what students find challenging (Shulman, 1986). Nathan and Koedinger (2000) conducted a study in which a group of teachers and researchers ranked the difficulty of different types of equation solving problems. They found that teachers and researchers mainly ranked the story problems and word-equation problems as more difficult when in fact Algebra I and Geometry student participants performed best on story problems, followed by word-equation problems, and struggled the most with symbolic-equation problems (as also suggested by Booth, 1984). This finding suggested that a greater focus should be placed on symbolic representation and understanding at the middle school level (Nathan \& Koedinger, 2000).

Perhaps the most well known problem presented to examine students' understanding of writing an equation from a word problem is the "Students and Professors" problem. The Students and Professor problem was:

Write an equation using the variables $S$ and $P$ to represent the following statement: There are six times as many students as professors at this university. Use $S$ for the number of students and $P$ for the number of professors.

(Clement, Lochhead, \& Monk, 1981)

While the original study was conducted on college undergraduates, numerous authors have revisited and presented the Students and Professors problem to students ranging from middle school through college (Abouchedid \& Nasser, 2000; Clement, 
1982; Clement, Narode, \& Rosnick, 1981; Fisher, 1988; Philipp, 1992b; Rosnick \& Clement, 1980; Swan, 2000; Wollman, 1983). The error most commonly found with this problem is the "reversal error" in which students will write that $6 S=P$ instead of correctly writing $S=6 P$. Unfortunately, this error was found even in science-oriented college students (Clement, Narode et al., 1981). Additionally, the error still existed when studies were conducted with changed notation and the incorporation of pictures, diagrams, or tables (Clement, 1982; Fisher, 1988; Rosnick \& Clement, 1980).

With regards to the Students and Professors problem, Lochhead and Mestre (1988) described two main errors that students made.

First students exhibit a strong proclivity towards performing a left-to-right wordorder match...thus the common error, $6 S=P$. Second, students often confuse the distinction between variables and labels. The symbols " $S$ " and " $P$ " are often interpreted as labels for "students" and "professors," rather than as variables that represent the "number of students" and the "number of professors".

(Lockhead \& Mestre, 1988, pp. 129-130)

Wollman (1983) attributed the sources of error to working quickly, not checking the equation, failure to connect the equation to the meaning of the sentence, and the use of non-algebraic symbols. Furthermore, Wollman provided a diagram (Figure 7) of the hierarchy of monitoring processes which is applicable to formulating equations to represent situations. 
Figure 7

Wollman's Hierarchy of Monitoring Processes

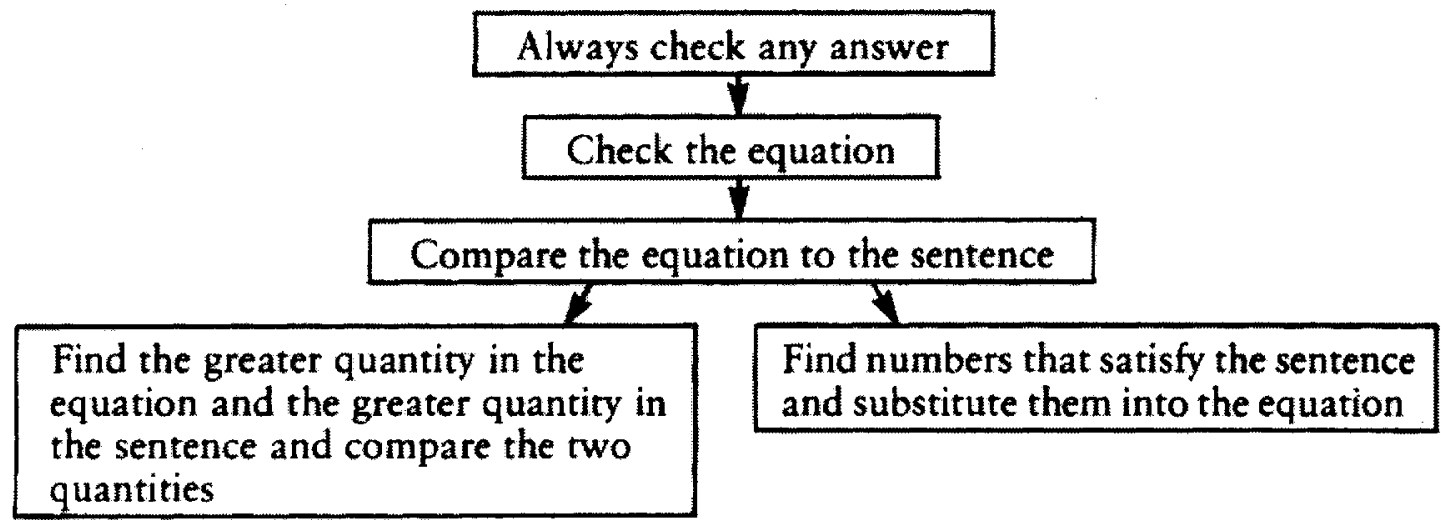

(Wollman, 1983, p. 180)

A pretest/posttest design study by Linchevski and Herscovics (1996) on a classroom of seventh-grade students sought to analyze students' difficulties with solving one-variable equations with both variables on one side and on both sides. The results of the study found that students had difficulty canceling (using inverse operations) within equations. For example, given the equation $12 n+30=13 n+19$, students rewrote the equation as $12 n+30=12 n+1 n+19$ and were thus able to simplify to $30=1 n+19$ and then solve the resulting equation.

Ashlock (2006) suggested that students made errors when solving equations because they incorrectly combined (or not combine) like terms, they performed the inverse operations incorrectly, and they did not correctly use the distributive property.

A study conducted by Swafford and Langrall (2000) interviewed 10 medium to high ability sixth-grade students from one elementary school classroom located in a Midwestern town. The students were presented with six problem tasks and were asked to: 
verbally describe the case, describe the case symbolically with variables in written form, and take their symbolic representation to solve the case. All students in the study had no previous formal instruction in algebra. Each task involved a familiar context (e.g. concert hall seats, paper folding, money, etc.) and addressed proportionality, linear and exponential functions, sequences, and inverse variation. To provide an example, the proportionality task was the following:

In some states, a deposit is charged on aluminum pop cans and is refunded when the cans are returned. In New York, the deposit is 5 cents a can.

a) What would be the refund for returning 6 (10 or 12) cans?

b) Describe how the store owner would figure the amount of refund for any number of returned cans.

c) Let $R$ represent the amount of refund and let $C$ represent the number of cans returned; write an equation for the amount of refund.

d) Can you use your equation to find out how many cans would have to be returned to get a refund of $\$ 3.00$ ? How much refund would you get for 100 cans? (Swafford \& Langrall, 2000, pp. 17-18)

Overall, Swafford and Langrall (2000) found that the sixth-grade students in the study were very successful in generalizing the task situations by verbally describing the relationships and by writing accurate equations using variables. However, they also found that students' notation was sometimes nonstandard as compared to how equations are normally written in formal algebra. Overall, more students were able to describe the relationships verbally than were able to write them symbolically. Finally, only a few students were able to take their equations and use them to answer related problems. It should also be noted that students had difficulty numerically solving the inverse variation task. They were only able to formulate an answer when asked about finding "half" and struggled to solve with other inverse values such as one-third, one-fourth, etc. (Swafford \& Langrall, 2000). 
Vlassis's (2008) study examined students' difficulties in using the subtract and negative sign while solving equations in order to better grasp students' understanding of negative numbers. Vlassis interviewed 17 eighth-graders who were asked to solve six equations, three of which resulted in a positive number solution and three in a negative number solution. Vlassis found no trend in which types of equations students answered correctly more often (meaning whether the solution was positive or negative). For example, one equation presented to the students was $4-x=5$. Vlassis found that students had three main difficulties with this equation. First, some students tried to find a number that could be substituted into the equation (e.g. guess and check) and could not arrive at an answer because the lowest number they would consider was zero (did not consider using negatives). Second, several students who originally obtained the solution of $x=-1$ became confused when they checked their solution by plugging $x=-1$ back into the original equation: $4-(-1)=5$. These students believed that it was not possible to have two "subtraction" signs placed side by side. A final difficultly students had with this equation was that they simply omitted the negative sign. After subtracting four from both sides of the equation instead of simplifying to $-x=1$ they simplified to $x=1$, resulting in an incorrect solution (Vlassis, 2008).

In Vlassis's (2008) study, the equation with the least number of correct answers was $-6 x=24$. Some mistakes students made were as follows: students attempted to use the substitution (guess and check) method and incorrectly obtained the answer $x=4$ and because of the negative sign, some students viewed $-6 x$ as $-6+x$ (sum) or $-6-x$ (difference). In his discussion, Vlassis suggested that the use of brackets helps students 
see the difference between the roles of "_" as a subtract sign and a negative sign (Vlassis, 2008).

To help students in evaluating equations, several authors have made suggestions in order to build conceptual understanding. Van de Walle and others (2010) recommended having students use algebraic balance scales to conceptually examine solving equations. Swan (2000) suggested that students should engage in an "always, sometimes, or never" activity. During this activity students are presented with numerous equations, such as $2 t-3=3-2 t$ and $x^{\wedge} 2=5 x$, and were asked to sort the equations into the three piles - always true, sometimes true, and never true. Swan found that during this activity students changed their minds many times and were forced to use justification to validate their placement of each equation. Additionally, students were required to "test" their decisions with decimal and fraction solutions.

Hawes (2007) recommended having students engage in a whole class "pass the pen" activity as a way to both help students become proficient in solving equation and to help teachers identify student misconceptions and errors. In this activity students completed one step of the equation on the board then "passed the pen" to another student. When a question was asked, the person with the pen must answer or call on another student for help. Additionally, all students must have a turn before starting over. This method built accountability but did not put all of the pressure on one student. Afterwards, Hawes asked her students to complete journal entries in order to reflect on the common errors made (Hawes, 2007). With this activity, error analysis was not only the responsibility of the teacher, but also of the students. 
Overall, students appear to have a variety of difficulties with solving and writing algebraic equations. The research suggested that students struggle with the following: checking their solution (Perrenet \& Wolters, 1994); symbolic notation (Nathan \& Koedinger, 2000; Swafford \& Langrall, 2000); reversal order error (Abouchedid \& Nasser, 2000; Clement, 1982; Clement, Lochhead et al., 1981; Fisher, 1988; Philipp, 1992b; Rosnick \& Clement, 1980; Swan, 2000); combining (or not combining) like terms (Ashlock, 2006); inverse operations (Ashlock, 2006); distributive property (Ashlock, 2006); negative numbers (Vlassis, 2008; Wu, 2001); and fractions and decimals (Wu, 2001). It is recommended that a conceptual approach to teaching algebraic equations, such as always linking an equation to a table and graph, helps foster students understanding of this complex topic (Carraher et al., 2006; Kalchman \& Koedinger, 2005; Kieran \& Sfard, 1999).

\section{Functions}

"The function concept is perhaps as important as any concept in mathematics. It permeates all of mathematics, from first-year algebra through calculus and beyond, as well as most applications of mathematics" (Willoughby, 1997, p. 215). Likewise, Thorpe (1989) and Peled and Carraher (2008) agreed that the concept of function is one of the most important topics in mathematics. Kilpatrick et al. (2001) also stressed the difficulty students have with interpreting functions and sometimes have difficulty plotting points, often reversing the $x$ - and $y$-coordinates. Young students begin learning about functions using a simple four-function calculator by repeating operations (Thorpe, 1989; Willoughby, 1997) or through geometric and number patterns (Blanton, 2008; Blanton \& Kaput, 2005; Carraher \& Schliemann, 2007). Another common way to represent 
functions is to use a "function machine" where students must input the independent variable and their calculated output is the dependent variable.

In middle school, students progress from learning about patterns through pictures and number sequences to learning about patterns in the form of functions. Bottoms (2003) suggested that determining outputs given inputs is basic prerequisite knowledge for algebra while exploring functions using formulas, exploring rates of change, and exploring non-linear functions are proficient prerequisite knowledge for algebra. In middle school, the focus is often placed on linear functions. Simply put, linear functions grow in a constant or linear pattern and can be easily seen on a graph (Van de Walle et al., 2010). Van de Walle et al. (2010) recommended that students compare the graphs of two functions, such as a perimeter and area formula, to discover that the perimeter function has a constant rate of change while the area function is quadratic in nature, thus varying in the rate of change.

Smith (2008) provided a framework for functional thinking. In his framework, he provided six activities that form the construction of functions. The following is his framework:

Engaging in a Problematic Within a Functional Situation

1. Engaging in some type of physical or conceptual activity.

2. Identifying two or more quantities that vary in the course of this activity and focusing one's attention on the relationship between these two variables.

Creating a Record

3. Making a record of corresponding values of these quantities, typically tabular, graphical or iconic.

4. Identifying patterns in these records.

5. Coordinating the identified patterns with the actions involved in carrying out the activity. 
6. Using this coordination to create a representation of the identified pattern in the relationship.(Smith, 2008, pp. 143-144)

Students must see the connections between functions written as an equation, shown on a table, and graphed on a coordinate plane (Van Dyke \& Craine, 1997). Through their work with lower grade secondary students, Markovits, Eylon, and Bruckheimer (1988) found that students usually manage and work better with functions presented in graph form because they can visually see the function. However, they also found that functions are usually introduced in algebraic form and recommend curricular work in the area of function to transform towards introducing functions graphically.

Related to functions, students must realize that algebra is a tool used to analyze rates of change (Van Dyke \& Craine, 1997). At the middle school level, by helping students understand ratios, they will have a better understanding of functions (Ellis, 2009). Davidenko (1997), Kaput (2000b), and Van de Walle et al. (2010) indicated that rate of change or variation is a very real context for students because it involves situations they are familiar with such as: speed, gas mileage, profits and expenses, and hourly wages. Kaput provides an example in which fourth-grade students were able to analyze rates of change of a function relating to a plant's height over time. Because of the familiar context and the ability to represent the function graphically, even students in the elementary grades engaged in meaningful discussions of functions (Kaput, 2000a, 2000b).

More specific to function is the concept of slope. Slope represents the change in $y$ divided by the change in $x$. Van de Walle and others (2010) also mentioned that the slope 
of horizontal lines (zero slope) and the slope of vertical lines (no slope or undefined slope) should also be addressed conceptually in the middle grades.

A common misunderstanding among both students and adults lies in the proportionality (or non-proportionality) of linear functions. It is easy to believe that linear functions are proportional because they increase (or decrease) at a constant rate. A common misunderstanding is that all linear functions are proportional. However, this is not the case as discussed by both Van de Walle and others (2010) and Pugalee (2010). Van de Walle and others pointed out that in order for a linear function to be proportional it has to pass through the $y$-intercept at the origin. Essentially, the function must take the form $y=m x$. Furthermore, they stress the importance of introducing proportional linear functions before exploring non-proportional linear functions that have an additive component.

Usiskin (1988) wrote of four conceptions of algebra. They included the following:

- Algebra as generalized arithmetic;

- Algebra as a study of procedures for solving certain kinds of problems;

- Algebra as a study of relationships among quantities; and

- Algebra as the study of structures. (Usiskin, 1988, pp. 11-15)

One of these conceptions, algebra as the study of relationships among quantities, is directly related to the concept of function. Perhaps the reason functions are so challenging for students lies in this conception - where variables must represent varying quantities (as also mentioned in Kieran, 1992). With functions, independent and dependent variables are examined. Usiskin stated that the difficulty in understanding the algebraic form of a function lies with the confusion with having so many letters in the equation $y=m x+b$. In this equation, $m$ and $b$ are both different constants, which change 
from function to function. Also, $x$ and $y$ are no longer specific value variables, but varying quantities that represent an infinite number of ordered pairs (Usiskin, 1988). When examined this way, it is easy to imagine the difficulty students find with linear functions, particularly those in the algebraic form, $y=m x+b$.

With the teaching of functions, Kalchman and Koedinger (2005) argued that students need to develop both conceptual and procedural fluency. Conceptually, students need a deep understanding of independent and dependent variables and be able to verbally explain what the slope means, with regards to the independent and dependent variable, in a given situation. Procedurally, students need to move between representations of functions, such as equations, tables, and graphs. Students need efficiency in locating slopes and $y$-intercepts on graphs and in creating tables and writing function equations from tables and graphs (Kalchman \& Koedinger, 2005). Students often have difficulty graphing the slope of a line (Labato \& Ellis, 2010).

A study conducted by Brenner and others (1995) examined the learning of functions in pre-algebra students. Using a pretest/posttest design, they developed a 20day curriculum on functions that placed an emphasis on multiple representations including tables, graphs, equations, and words. The focus of the lessons was to integrate ways functions could be represented instead of teaching them as isolated skills. The control group was taught with traditional curriculum that was more procedurally based focusing on manipulation skills. The participants consisted of students in seven prealgebra classrooms at three different schools. The results comparing the pretest to posttest for both the experimental and control group revealed no significant difference in the gains in one group compared to the other. However, the experimental group did use more 
representations of functions when solving word problems than the control group (Brenner, et al., 1995):

Ellis (2009) made the following suggestions when introducing the idea of functions to middle grades students. First, teachers must select problems carefully in order to ensure students understand the context of the problem. Second, carefully guiding classroom discussion is key in helping students shape ideas about functions. Providing discussion that helps students support reasoning quantitatively through ratios will help them with linear functions.

In conclusion, many stakeholders in mathematics education deem the concept of function to be one of the most important in mathematics (Peled \& Carraher, 2008; Thorpe, 1989; Willoughby, 1997). Students are gradually introduced to functions when they shift from learning about patterns through number patterns and geometric patterns (Blanton, 2008; Blanton \& Kaput, 2005; Carraher \& Schliemann, 2007) to learning about patterns in functions (Bottoms, 2003). Difficulties students have with the concept of functions often involves slope (Van de Walle et al., 2010) and proportionality (Pugalee, 2010; Van de Walle et al., 2010). As previously mentioned, it is recommended that functions be taught by connecting an equation with both a table and a graph (Brenner et al., 1995; Markovits et al., 1988; Van Dyke \& Craine, 1997).

\section{Graphing}

Graphing is an integral part of algebra as it relates to the concept of functions. Van de Walle and others (2010) stated that "Functions can be represented in any of five ways: (1) the pattern itself, which we can refer to as the context; (2) the table; (3) the verbal description; (4) the symbolic equation; and (5) the graph" (Van de Walle et al., 
2010 , p. 278). Students must be able to work with the five representations, make the connection between the five representations, and realize that each of the five represent the same relationship. The NCTM's Principles and Standards for School Mathematics stated that:

By the middle grades, students should be able to understand the relationship among tables, graphs, and symbols and to judge the advantages and disadvantages of each way of representing relationships for practical purposes. As they work with multiple representations of functions - including numeric, graphic, and symbolic - they will develop a more comprehensive understanding of functions. (NCTM, 2000, p. 38)

Bottoms (2003) categorized the ability to graph functions from tables and patterns as basic prerequisite knowledge for algebra and Kilpatrick et al. (2001) noted that students sometimes have difficulty interpreting graphs. Additionally, students often have difficulty graphing the slope of a line (Labato \& Ellis, 2010).

Students must have experiences working with functions using multiple representations from the beginning (Kalchman \& Koedinger, 2005; Kieran, 2007). Kalchman and Koedinger (2005) found that not teaching about functions by relating tables, graphs, and equations can lead to a detached understanding, one in which students can accurately plot the ordered pairs from a table onto a graph but fail to internalize the characteristic of linearity or the patterns in the function. It should also be noted that sometimes students have difficulty when plotting ordered pairs and reverse the $x$ - and $y$ coordinates or they have difficulty interpreting the scale of a graph (Hadjidemetriou \& Williams, 2001). Research suggested that teaching functions in an integrated fashion, where multiple representations are used consistently helps students use multiple representations and methods to solve problems involving functions (Brenner et al., 1995). 
Oftentimes, graphical representations of functions are the easiest for students to understand because students can interpret and visually see the pattern. Additionally, Stephens (2005) pointed out that graphs present a great opportunity to show students that two variables in the same equation can indeed take on the same value at some point. Even in the earlier grades, students can interpret and compare the graphs of two functions without being bogged down by the symbolic representation or even by specific values. At this stage, students can focus on overall trends, such as which function has the steeper slope, etc. (Kaput, 2000a). Graphing is an easy and meaningful way for students to compare functions (Peled \& Carraher, 2008).

Additionally, with the advancement and availability of technology in the past several decades, representing functions graphically has become much more efficient because it can easily be done on graphing calculators and through spreadsheet databases. Tables of values can be quickly created in a spreadsheet and represented graphically (Davidenko, 1997; Kieran, 2007; Saunders \& DeBlassio, 1988; Van de Walle et al., 2010). Moreover, technology can easily help students plot several translated functions on the same graph in order to make comparisons and understand transformation trends (Saunders \& DeBlassio, 1988).

Teachers often ask students to write words, draw pictures, and use numbers to explain their reasoning or answer to a problem. Scheuermann and van Garderen (2008) examined student errors, misconceptions, and ability to make meaningful and relevant graphs when solving problems. They posed three key questions that should be asked when examining the degree to which an individual student can create a graphical representation that can actually be useful in solving a problem. The three questions were: 
"Does the representation relate to the problem? If so, what type of representation was generated? How complete is the representation?" (Scheuermann \& van Garderen, 2008, p. 472).

Furthermore, Scheuermann and van Garderen (2008) believed teachers can find students' misconceptions through examining graphs and pictorial representations created by students. In order for a student to display complete understanding of a problem, the representation has to be relevant, schematic, and all relationships in the problem have to be accurately represented. Otherwise, students may possess the following misconceptions or deficiencies: difficulty accurately representing a problem using graphic notation or they do not understand the purpose of representation; difficulty using graphic notation; or difficulty depicting key aspects and relationships. Furthermore, two case study analyses conducted by Scheuermann and van Garderen further confirmed that students struggle with creating graphical representations, and teachers can benefit from analyzing such student work (Scheuermann \& van Garderen, 2008).

Post, Behr, and Lesh (1988) stated that the use of graphs can help students overcome misconceptions and visualize the concept of proportionality. By plotting ordered pairs on a graph to represent a proportional function, that is one in the form $y=$ $m x$ (intercepting the origin), provides a good opportunity to discuss why a line must cross through the origin (rather than another point on the $y$-axis) in order for the function to be proportional (Post et al., 1988).

Kieran and Sfard (1999) designed a 30-day module in order to teach functions in a visual way through graphing representations using a "graphs-before-algebra" mindset. Moreover, they used graphing technology whenever possible. Their 30-day module was 
used with three seventh-grade classes and included the five areas of introducing algebra: (1) Introducing Cartesian Graphs, (2) Algebraic Expressions and the Notation of Function, (3) Exploring Functions, (4) Operating on Functions: Equivalence of Expressions, and (5) Comparing Functions: Equations and Inequalities (p. 4). All five areas were taught using graphic representations before symbolic representations. Some activities included matching expressions with their related table and graph as well as matching story problems to their related table. At the conclusion of their study, Kieran and Sfard found that the graphical approach worked for some students and made the introduction to the five areas in the module more meaningful. Disappointingly, they also found that some students forgot what they had learned just after a short time and reverted back to procedures and rules they did not truly understand (Kieran \& Sfard, 1999).

Pugalee (2010) demonstrated how tables can be used as a powerful tool to capture student misunderstandings about proportional functions. He found that students often looked for the wrong patterns (co-variation) instead of proportionality in order to determine if a function is proportional. While it is important for students to analyze the co-variation in a function, that is the difference in input values and the difference in output values, students must also learn to look at the pattern between the independent (often $x$ ) and dependent (often $y$ ) variables (Blanton, 2008). When they begin to look at this pattern, they can begin to explore different types of functions such as linear, quadratic, and absolute value. Additionally, students can examine the idea of proportional functions (those in the form $y=m x$ ).

In conclusion, graphing provides a visual for functions - and the ability to connect functions with graphs and tables is considered an important concept in algebra (Bottoms, 
2003; NCTM, 2000; Van de Walle et al., 2010). Additionally, the visual that graphing provides students is particularly useful for students when they are introduced to patterns and functions (Brenner et al., 1995; Stephens, 2005). Scheuermann and van Garderen (2008) found that common misconceptions student hold regarding graphing included the following: difficulty with graphing notation, not grasping the purpose behind graphing, and understanding relationships graphically. Post and others (1988) stated that graphing can help students understand the concept of proportionality. Disappointingly, Kieran and Sfard (1999) found that while graphing aids students in understanding the concept of function at the time of instruction, overtime students eventually revert back to procedures which they do not conceptually understand.

\section{Conclusions}

\section{Chapter II Summary}

In summary, this literature review discussed algebra curriculum including the following subtopics: (a) history of algebra curriculum; (b) standards and reform; (c) integrating algebra into K-8 curriculum - early algebra; (d) relevant early algebra literature; (e) teacher preparation; (f) placing middle school students in Algebra I; and an (g) algebra theoretical construct for this study. Next, mathematics misconceptions with theoretical construct considerations were addressed and finally, literature related to the nine prerequisite content areas found in the theoretical framework for this study. What follows is a brief summary of the literature discussed in each of these areas.

Algebra curriculum. The first use of algebraic symbolism began with the concept of a variable representing an unknown quantity and later progressed to the idea of functions (Kieran, 1992). Over time, algebra-related research shifted significantly, 
most recently focused on student understanding (Kieran, 2007). Additionally, current reform movements have advocated for the incorporation of algebraic thinking $\mathrm{K}-12$, prealgebra concepts in grades six-eight, and student enrollment in Algebra I in the eighth- or even seventh-grade (CCSSO/NGA, 2010; Fennell et al., 2007; NCTM, 2000, 2006).

The incorporation of algebraic thinking into the elementary grades is called early algebra (Carraher et al., 2008). Kaput stated that integrating algebra into the early grades will address four major goals:

1. To add a degree of coherence, depth, and power typically missing in $\mathrm{K}-8$ mathematics.

2. To ameliorate, if not eliminate what Kaput sees as the most pernicious and alienating curricular element of today's school mathematics: late, abrupt, isolated, and superficial high school algebra courses.

3. To democratize access to powerful ideas by transforming algebra from an inadvertent engine of inequity to a deliberate engine of mathematical power.

4. To build conceptual and institutional capacity and open curricular space for new $21^{\text {st }}$-century mathematics desperately needed at the secondary level, space locked up by the $19^{\text {th }}$-century high school curriculum now in place. (Kaput, 2008, p. 6)

Fosnot and Jacob (2010), Bastable and Schifter (2008), Kaput (2000b), Carraher and others (2006), and other researchers have provided many examples of how algebraic thinking can be incorporated into the elementary grades - often through using patterns to make generalizations.

Another discussion related to algebra education involves when students should enroll in Algebra I. In summary, most reform movements advocate for more and more students to enroll in Algebra I in the eighth-grade (Fennell et al., 2007; Spielhagen, 2006a; Usiskin, 1987). 
Mathematics misconceptions. Skemp (1976/2006) first distinguished between relational (conceptual, "whys") understanding and instrumental (procedural, "hows") understanding of mathematics. Today, many mathematics education researchers are interested in the conceptual understanding of mathematics. For purposes of this study, conceptual understanding is related to misconceptions and procedural understanding is related more to errors. Students' ability to reason mathematically is also of interest. Generally, several beliefs are held in the mathematics education community. First, concepts should be taught before procedures are introduced whenever possible (Hiebert \& Grouws, 2007; Skemp, 1976/2006). Second, success in mathematics requires both conceptual understanding and procedural fluency (Braswell et al., 2001; Capraro \& Joffrion, 2006; CCSSO/NGA, 2010). Furthermore, students make mistakes and mistakes are part of the learning process (Leron \& Hazzan, 2009).

Welder's nine prerequisite content areas. Welder's (2007) nine prerequisite content areas served as the theoretical framework for this study and were as follows: (1) numbers and numerical operations, (2) ratios and proportions, (3) the order of operations, (4) equality, (5) patterning, (6) algebraic symbolism and letter usage, (7) algebraic equations, (8) functions, and (9) graphing. With regards to (1) numbers and operations, there are many reasons why students must be able to work efficiently with fractions for success in algebra (Bottoms, 2003; Darley, 2009; Silver, 2000; Stacey \& MacGregor, 1997a; Wu, 2001). Many common errors students make with fractions were outlined by Ashlock (2006) and were further confirmed by Brown and Quinn (2006). Similarly, students must be able to convert between fractions, decimals, and percents and compute efficiently with decimals (Ashlock, 2006; Bottoms, 2003; Silver, 2000; Stacey \& 
MacGregor, 1997a). Regarding integers, this literature review discussed that students often try to avoid working with negative numbers (Gallardo, 2002; Peled \& Carraher, 2008). When working with negative numbers, student often omit negative signs (Vlassis, 2008), compute negative numbers incorrectly (mix up the algorithms) (Ashlock, 2006), or have trouble checking solutions with negatives (Vlassis, 2008). Research conducted on exponents suggested that the lack of understanding students have about exponents do not disappear as students get older. Instead, they hinder students in working with factoring, quadratics, etc. (Pinchback, 1991).

A review of literature about (2) ratios and proportions found that ratios and proportions are difficult for students to understand because of the multiple ways to write ratios and proportions, the multiple representations of ratios and proportions, and because of the ways ratios and proportions differ from fractions (Hoffer, 1988; Lamon, 1999; Post et al., 1988). De Bock et al. (2002) and Singh (2000) suggested that while learning procedures to solve proportions is not all that difficult, students struggle to understand indepth concepts - causing them much difficulty when they must apply what they know to new situations involving proportions.

Reviewing student understanding of (3) the order of operations found that students often have the following misconceptions and errors: belief that addition always comes before subtraction and multiplication always before division (Linchevski \& Livneh, 1999); parentheses are not needed because numbers are already "in order" (Booth, 1984); and that there is no reason why the order of operations must be followed (Booth, 1984). When working with the properties of operations (e.g. commutative, associative, etc.) students often struggle with conceptually understanding the properties 
and why the commutative and associative properties work for addition and multiplication but not for subtraction and division (Carpenter et al., 2000; Schifter et al., 2008; Stacey \& MacGregor, 1997a; Warren, 2003).

Next, student understanding of (4) equality was examined. The main misconception students had with equality is the notion that the equals sign means "and the answer is" (Ball et al., 2008; Van de Walle et al., 2010). Many studies have confirmed this belief (Asquith et al., 2007; Baroudi, 2006; Behr et al., 1980; Falkner et al., 1999; Linchevski \& Herscovics, 1996; Stacey \& MacGregor, 1997a, 1997b; Steinberg et al., 1990; Van Dyke \& Craine, 1997; Vlassis, 2002) and some offer suggestions to help correct this misconception.

A discussion on (5) patterning found that patterns are an important way to help students engage in algebraic thinking and to begin making generalizations (Blanton, 2008; Booth \& Watson, 1990; Day \& Jones, 1997; Kaput, 2000a, 2000b; Kieran, 2008; Lannin, 2003; Mason, 2008; Van de Walle et al., 2010). The main focus on patterning research was on how to help students develop a deeper understanding of patterns and how teaching through patterns can help foster algebraic development (Blanton \& Kaput, 2005; Healy \& Hoyles, 1999; Koellner et al., 2008; Radford, 2000; Rivera \& Becker, 2009; Stacey, 1989).

With regards to (6) algebraic symbolism and letter usage, the misconceptions students have include viewing variables as labels (Asquith et al., 2007; Clement, 1982; Kieran, 1980; Stacey \& MacGregor, 1997b; Usiskin, 1988; Weinberg et al., 2004), the idea that two different variables (e.g. $x, y$ ) in the same equation cannot represent the same value (Stephens, 2005; Swan, 2000), believing the value of a variable has something to 
do with its position in the alphabet (Asquith et al., 2007; Herscovics \& Kieran, 1980; MacGregor \& Stacey, 1997), and the inability to understand variables as varying quantities rather than a missing value (Asquith et al., 2007; Stacey \& MacGregor, 2000; Stephens, 2005; Usiskin, 1988). Furthermore, Küchemann (1978) developed a list of six different ways in which variables can be used. He noted that the multiple uses of variables cause much confusion among students. Common misconceptions and errors found when students worked with algebraic expressions involved not understanding the concept of like terms (Kieran, 1992), difficulty in writing algebraic expressions to represent a situation (Stacey \& MacGregor, 1997b; Van Amerom, 2003), and the misunderstanding that variables stand for an item instead of the quantity of that item (Swan 2000; Weinberg et al., 2004).

Next, (7) algebraic equations were discussed. Solving one- and two-step equations is part of middle school mathematics curriculum and students are often successful in solving such basic equations. Many researchers noted that the real difficulty begins when students must solve equations with variables on both sides of the equals sign. At this point, students can no longer use "guess and check" methods and must possess a deeper understanding of equivalence and the properties of equality (Herscovics \& Linchevski, 1994; Kieran, 1980). Studies conducted on algebraic equations found that some students struggled more with the concepts while others with the procedures (Perrenet $\&$ Wolters, 1994); students often struggle with the symbolic representation involved in writing equations (Booth, 1984; Nathan \& Koedinger, 2000); the reversal order error (Abouchedid \& Nasser, 2000; Clement, 1982; Clement, Narode, \& Rosnick, 1981; Fisher, 1988; Philipp, 1992b; Rosnick \& Clement, 1980; Swan, 2000; Wollman, 1983); 
working hastily (Wollman, 1983); not correctly using properties of operations (Ashlock, 2006); and solving equations with negative numbers (Vlassis, 2008).

The next to last prerequisite content area discussed was (8) functions. It is agreed by several researchers that the concept of functions is one of the most important concepts in mathematics (Peled \& Carraher, 2008; Thorpe, 1989; Willoughby, 1997). In order for students to understand functions, they must make the connection between a function as an equation, table of values, and a graph (Van Dyke \& Craine, 1997). The concept of slope and proportionality of functions have been identified as two difficult concepts for students to understand (Van de Walle et al., 2010). Studies conducted on the understanding of functions have found that students need both conceptual and procedural understanding to work with functions (Kalchman \& Koedinger, 2005) and that teaching functions using an integrated approach with multiple representations fosters student understanding of the function concept (Brenner et al., 1995).

The last of Welder's (2007) prerequisite content areas addressed was (9) graphing. The literature on graphing greatly overlaps with the concept of function because in algebra, graphing usually involves the graphing of functions. Research on graphing stated that teaching students about functions through graphs first can help students visualize and conceptually understand functions (Kieran \& Sfard, 1999). Additionally, tables, graphs, and pictures can be used to help capture student misunderstandings of story problems as well as proportionality, slope, and other concepts (Post et al., 1988; Pugalee, 2010; Scheuermann \& van Garderen, 2008). 


\section{Restatement of Research Question}

The research question for this study was the following:

1. What common algebra-related misconceptions and errors exist among students in grades six and eight as identified on student responses on an annual statewide standardized assessment? 


\section{CHAPTER III}

\section{METHODOLOGY}

\section{Restatement of Purpose and Research Question}

The purpose of this study was to examine common algebra-related misconceptions and errors of middle school students. The catalogue of misconceptions were aligned to Welder's (2007) nine prerequisite content areas which students should know before entering their first formal algebra course (Algebra I). The nine prerequisite content areas are: (1) numbers and numerical operations, (2) ratios and proportions, (3) the order of operations, (4) equality, (5) patterning, (6) algebraic symbolism and letter usage, (7) algebraic equations, (8) functions, and (9) graphing (Welder, 2007). The research question for this study was the following:

1. What common algebra-related misconceptions and errors exist among students in grades six and eight as identified on student responses on an annual statewide standardized assessment?

\section{Type of Research}

The type of research in this study was classified as basic qualitative research. Merriam (2009) described basic qualitative research as the type of research commonly found in educational settings and whose primary goal is to uncover and interpret the meaning of data. In basic qualitative research, the researcher uses interviews, observations, and/or documents analysis in order to "...identify reoccurring patterns that characterize the data. Findings are these reoccurring patterns or themes supported by the 
data from which they were derived" (Merriam, 2009, p. 23). For this study, document analysis was used as the main data source followed by interviews with key informants.

\section{Rationale for Qualitative Research}

Many studies have contributed to the knowledge base of algebra learning for middle school students; however, they focus on teaching, assessment, or other areas that are not directly related to misconceptions and errors. Most studies which are related to the prerequisite algebra content areas as outlined by Welder (2007) are conducted on a very small scale (e.g. one classroom) (as found in Bastable \& Schifter, 2008; Kaput, 2000; Kaput \& Blanton, 2001 and others) or focus on one specific skill (as found in Brown \& Quinn, 2006; Capraro \& Joffrion, 2006; Falkner et al., 1999; MacGregor \& Stacey, 1997; Stacey \& MacGregor, 1997b; Steinberg et al., 1990; Wollman, 1983 and others).

As mentioned, many studies have addressed one specific type of algebra misconception or error (as found in Brown \& Quinn, 2006; Capraro \& Joffrion, 2006; Falkner et al., 1999; MacGregor \& Stacey, 1997; Markovits et al., 1988; Philipp, 1992a;

Schwartzman, 1996; Stacey \& MacGregor, 1997b; Steinberg et al., 1990; Wollman, 1983 and others). For example, Stacey and MacGregor (2000) developed a set of problems in which students were asked to write an equation representing the problem and also find the correct answer using any method. Students' open-responses were collected from approximately 900 students from ages $13-16$ in 12 secondary schools. Steinberg, Sleeman, and Ktorza (1990) conducted a study involving equivalence of equations with a sample of 96 eighth- and ninth-grade students who had completed a unit on solving onevariable equations. 
Additionally, several studies focused on a very small sample of students in order to gain specific insight (as found in Bastable \& Schifter, 2008; Kaput, 2000; Kaput \& Blanton, 2001 and others). For example, Vlassis (2008) examined students' understanding of the negative sign and computation with negative numbers by having students solve six equations, three of which produced negative solutions and three positive solutions. While Vlassis did make an effort to make his study generalizable by including students in eight different classes from two different schools in his study, his sample only consisted of 17 students, all from the eighth-grade. De Bock et al. (2002) examined proportional reasoning by looking at one question through interviews with 20 students. Additionally, case studies by researchers such as Blanton and Kaput (2005) and Swafford and Langrall (2000) have provided specific insight into areas of prerequisite algebra knowledge.

This study used qualitative document analysis to gain insight into the misconceptions and errors students demonstrate on a wide variety of prerequisite algebra tasks. Overall, this study looked for patterns and themes in the qualitative data in order to make generalizations about the algebra-related misconceptions and errors revealed by middle grades students. While the design of the study was qualitative, the sample size included documents of student work from numerous open-response questions. This was possible because the researcher chose to use document analysis as the primary source of data.

\section{Appropriateness for this study}

Document analysis qualitative research was an appropriate choice for this study because the methodology required an in-depth review of student work in order to gain a 
clear picture of student misconceptions and errors. Qualitative research, in this case primarily analyzing student response work and interviews, lends itself to in-depth analysis (Merriam, 2009; Miles \& Huberman, 1994; Patton, 2002). Conversely, analysis of only multiple-choice or gridded-response items would be limiting because the focus is on questions students got correct or incorrect - and would fail to explain why and how students arrived at the answer they chose.

\section{Population and Sample}

\section{Population}

The population for this study was middle school students in one Midwestern state (it was agreed upon that the identity of the state remain confidential with the use of this data). The students had taken the state's annual standardized assessment in 2007 and 2008. Approximately $98 \%$ of all students in each of these grades take the assessment each year. Students who do not take this assessment are students with severe learning disabilities and are classified by their school as the $2 \%$ of students chosen to be exempt from the assessment.

\section{Sample and Sampling Procedures}

The sample in this study consisted of training papers obtained from the state's Department of Education. Training papers (also called scorer papers) are a set of actual student responses from the 2007 and 2008 testing administrations for each question. These training papers are used by the Department of Education to train scorers on the various levels of performance (including correct responses). In addition to informing scorers on the point value to award diverse responses, the training papers provide scorers with the possible errors that could potentially exist on student work. Through discussion 
with the state's Department of Education and through conference calls with both the state's Department of Education Director of Assessment and staff from the testing publisher, the researcher was informed that the training papers accurately represent the range of responses, including both correct responses and common errors and mistakes, students make on each question so that the scorers can score tests efficiently and accurately. While the range or responses were represented, this does not mean the frequency (or the number of times each response occurred) was proportionally represented. Representatives from the testing publisher and the state's department of education carefully select the sample of real student responses for each open-response question.

Training papers were requested for years 2007 and 2008 for grades six and eight because of availability and the high number of open-response questions on the standardized assessment for each of these years. Between 10 to 13 questions for each grade for each year related to Welder's framework of prerequisite algebra skills. For each question, 20 total training papers which aligned to scores of 0,1 , or 2 or $0,1,2$, or 3 were obtained. In other words, there were 20 training papers for each question that represented both correct responses and different misconceptions and errors made by students on each specific question. All training papers had student work present; there were no blank training papers. Training papers were ordered directly from the state's Department of Education and the publisher of the standardized assessment. The training papers were provided in electronic format. See Table 8 for an outline of the sampling procedures by year, grade, questions, and quantity of training papers. 
Table 8

Sampling Procedures by Year

Distribution of Sample

\begin{tabular}{|c|c|c|c|}
\hline $\mathbf{2 0 0 7}$ & $\mathbf{2 0 0 7}$ & $\mathbf{2 0 0 8}$ & $\mathbf{2 0 0 8}$ \\
\hline Grade 6 & Grade 8 & Grade 6 & Grade 8 \\
\hline 10 Questions & 12 Questions & 10 Questions & 13 Questions \\
\hline 20 & 20 & 20 & 20 \\
Training & Training & Training & Training \\
Papers for & Papers for & Papers for & Papers for \\
Each of the & Each of the & Each of the & Each of the \\
10 Questions & 12 Questions & 10 Questions & 12 Questions \\
\hline
\end{tabular}

\section{Instrumentation}

\section{Description of Instruments}

The student-level open-response data in this study consisted of selected questions from a portion of an annual statewide standardized assessment. In its entirety, the instrument is composed of multiple sections of mathematics, language arts, and in some grades science and social studies each year. For purposes of this study, the researcher was only interested in the open-response mathematics portions. Stiggins, Arter, Chappuis, and Chappuis (2006) stated that open-response questions often require students to respond by comparing, analyzing, interpreting, solving, or describing. The open-response test sections do not contain multiple-choice or gridded-response questions. Gridded-response items are formatted so that students must write their answer in a grid, but they are not given possible answers to choose from. In gridded-response items, student work is not examined. Based on the grade level, the number of questions related to Welder's (2007) framework for each open-response test section for 2007 and 2008 consisted of 10 to 13 questions per year, as mentioned in the sampling procedures. As shown previously in 
Table 8, a total of 20 sixth-grade and 25 eighth-grade questions aligned to Welder's framework for 2007 and 2008.

The 45 open-response questions were selected in the following way. Each openresponse question on the four tests (2007 grade 6, 2007 grade 8, 2008 grade 6, 2008 grade 8) was examined. It was determined which, if any, of Welder's nine prerequisite algebra content areas the question assessed. Some questions assessed more than one of the nine prerequisite content areas (overlapping areas). Additionally, not all nine of Welder's content areas were adequately addressed on both the sixth- and eighth-grade tests. Table 9 describes the number of questions at each grade level as they related to Welder's (2007) nine prerequisite content areas for success in Algebra I. It should be noted that no questions related to the patterning prerequisite content area were found on either eighth-grade test. Additionally, the total on the table exceeds the total number of questions (45) because many questions assessed more than one of the nine prerequisite content areas.

Table 9

Questions Relating to Welder's Prerequisite Content Areas

\begin{tabular}{|c|c|c|c|c|c|c|c|c|c|}
\hline $\begin{array}{c}\text { Content } \\
\text { Area } \\
\text { Grade }\end{array}$ & $\begin{array}{c}\text { Number/ } \\
\text { Operation }\end{array}$ & $\begin{array}{l}\text { Ratio/ } \\
\text { Prop. }\end{array}$ & $\begin{array}{l}\text { Order } \\
\text { of Op. }\end{array}$ & Equality & Pattern & \begin{tabular}{|c|} 
Alg. \\
Sym.
\end{tabular} & $\begin{array}{l}\text { Alg. } \\
\text { Equ. }\end{array}$ & Function & Graph \\
\hline 6 & 19 & 5 & 4 & 1 & 2 & 10 & 1 & 2 & 3 \\
\hline 8 & 23 & 9 & 13 & 5 & 0 & 11 & 7 & 2 & 4 \\
\hline
\end{tabular}




\section{Type of Response Categories}

For purposes of this study, only open-response questions were examined. Each of these open-response questions were scored on a scale of 0,1 , or 2 points or $0,1,2$, or 3 points. Some questions had more than one part. The following examples provide clarification on the construction of a $0-2$ point question that had one part, more than one part, and a question worth 0-3 points total. Questions worth $0-2$ points may have one or more than one part. Questions with 0-2 points which have more than one part were usually broken down into steps for students to follow. Questions worth 0-3 points were typically questions considered to assess problem-solving ability and involve multiple steps where students were not prompted step-by-step. See Figures 8, 9, and 10.

Figure 8

One Part Response Question (0-2 points): Grade 6

The grid below contains 100 squares. Shade $\frac{3}{5}$ of the grid.

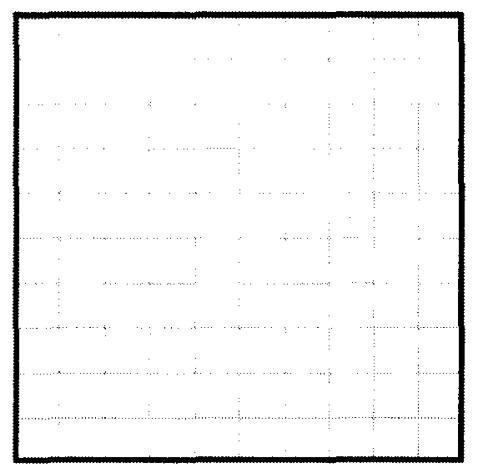

What PERCENT of the grid did you shade?

Answer

(Department of Education, 2007) 
Figure 9

Multiple Part Response Question (0-2 points): Grade 8

Sherry tutors children in computer skills for $\$ 12$ per hour. After spending $\$ 21$ of the money she earned on Monday, she had $\$ 27$ left to put in her savings account.

On the line below, write a linear equation that can be used to determine how many hours $(h)$ Sherry tutored on Monday.

\section{Equation}

Now solve the equation you wrote to determine how many hours Sherry tutored on Monday.

Answer hours

(Department of Education, 2008) 
Figure 10:

Multiple Part Response Question (0-3 points): Grade 8

A diagram of Kayla's backyard is shown below.

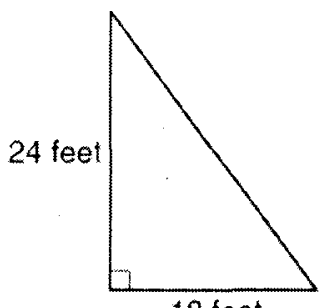

Kayla wants to put a fence around her backyard. A 6-foot section of pre-assembled fencing costs $\$ 19.97$ with tax included.

What is the cost of the fencing Kayla needs to fence her entire backyard?

Show All Work

Answer \$

(Department of Education, 2007)

\section{Rationale for Instruments in the Study}

Open-response questions on a state standardized assessment, as opposed to multiple-choice or gridded-response, were appropriate for this study. Open-response questions were needed to gain an in-depth understanding of the specific processes involved in errors and misconceptions students demonstrated when responding to mathematics questions examined. Miles and Huberman (1994) noted that such qualitative data lent themselves to a rich and complex view of the topic researched. 
This instrument was appropriate for this study because standardized assessments are a vital part of classrooms, schools, and school districts. It makes sense to use an instrument that would reveal typical responses to questions on such a test. Additionally, the items used from the open-response test sections were appropriate with regards to grade level, aligned to mathematics academic standards, and fit the framework for this study.

\section{Information on Instrument Validity}

The following information was found in the program manual for these standardized assessments. The program manual stated that content validity for the entire mathematics portion was established in this statewide standardized assessment through alignment to the state's academic content standards through a table of specifications. Additionally, an expert panel was used to read and approve the content validity of the items to ensure that each item aligned to the academic standards and was free of bias. Confirmatory and exploratory factor analyses were conducted to support the validity of the instrument as it related to the total population and to subgroups. Analysis of eigenvalues and scree plots indicated that for each grade, content area, and subgroup the tests were one-dimensional (Department of Education, 2009).

\section{Information on Instrument Reliability}

The most recent reliability information for the open-response portion of the test was obtained from the program manual. The intraclass correlations for the mathematics portions ranged from .79 to 1.00 with a mean of .94 . Additionally, a Kappa statistic mean of .87 was reported. The most recent internal consistency reliability documentation for sixth-grade mathematics, based on a sample of over 7000 student scores, was .92 . With a 
similar sample size, the internal consistency reliability coefficient was .94 for eighthgrade (Department of Education, 2009). According to Urbina (2004), reliability coefficients of .90 or above are considered very high.

\section{How Instruments were Administered}

The student response questions sampled in this study consisted of existing data. The actual standardized assessment was administered in fall 2007 and fall 2008. As this is the statewide standardized assessment used in this state to determine Annual Yearly Progress (AYP) and school ranking, the testing administration procedures are closely monitored in schools throughout this Midwestern state. During testing, classrooms must be free of posters that could provide help to students, students are not allowed to have textbooks in testing rooms, and a quiet and orderly classroom must be maintained. Additionally, each section of the assessment is timed and teachers must precisely follow the scripted directions for administering each section of the assessment. The interviews with key informants were conducted by the researcher. The interview with the mathematics content specialist at the state's Department of Education and the eighthgrade mathematics teacher were conducted over the telephone and the interview with the sixth-grade mathematics teacher was conducted in person.

\section{How the Open-Responses were Coded}

Inter-rater Reliability of Tests. Reliability in qualitative research means that the researcher's approach to analyzing the data remained consistent throughout the study (Creswell, 2009). Prior to obtaining the training papers, the researcher categorized each of the 45 questions into one or more of the nine prerequisite content areas of Welder's framework. To verify the credibility of this categorization, the researcher had two 
colleagues in mathematics education double-code this categorization. Inconsistencies were discussed and final placement was agreed upon by both the researcher and colleagues. Originally, the researcher categorized the 45 questions into the nine prerequisite content areas a total of 109 times - some questions fell into more than one category. When the researcher met with the first double-coder (double-coder \#1) there were nine total disagreements, double-coder \#1 wanted to remove one placement and add eight. Therefore, to obtain the inter-rater reliability percentage, the researcher took their own original 109 placements plus the double-coder \#1's eight additions for a total of 117 placements. The researcher and double-coder $\# 1$ agreed on $108 / 117$ of the total question placements for an inter-rater reliability of $92 \%$. The researcher and double-coder \#1 came to a final agreement on the placement of questions into the nine categories.

Next, the researcher met with double-coder $\# 2$. At this point the researcher now had the 45 questions placed in the nine categories a total of 116 times. When the researcher met with double-coder \#2 there were 10 total disagreements, double-coder \#2 wanted to remove one placement and add nine. Therefore, to obtain the inter-rater reliability percentage, the researcher took their 116 placements plus double-coder \#2's nine additions for a total of 125 placements. The researcher and double-coder \#2 agreed on $115 / 125$ of the total question placements for inter-rater reliability of $92 \%$. The researcher and double-coder $\# 2$ came to a final agreement on the placement of all questions into the nine categories. The final placement of the 45 questions into the nine categories consisted of a total of 121 placements.

In this study, inter-rater agreement was also established by consistently categorizing the misconceptions and errors found in the open-responses. Inter-rater 
reliability can be established through double-coding data (Creswell, 2009; Maruyama \& Deno, 1992; Roberts, 2004). For this study, inter-rater reliability was established by having both the researcher and two middle school mathematics educators who were also doctoral students code a small sample of the open-responses. After both the researcher and the two experts coded the same sample, the results were compared. The goal was for results of the coding between the researcher and each of the two coders to be at least $80 \%$ the same. The researcher and Coder $\# 1$ had an overall inter-rater reliability of $87 \%$. The researcher and Coder $\# 2$ had an overall inter-rater reliability of $88 \%$. This process is discussed in further detail below.

Criteria for judging competence. Competence of the experts to be used to establish inter-rater reliability was determined by the researcher and agreed upon by the dissertation chair. The experts for the double-coding were both mathematics education doctoral candidates with strong backgrounds in middle school mathematics education.

How agreements will be assessed. In efforts to establish reliability in coding, the researcher discussed any differences in the double-coding sample with the experts that took part in the double-coding process. Agreements were made through this discussion. This exercise provided additional clarity to the researcher about the organization and themes of the coding.

Percentage of data checked for agreement. Due to the large variety of student responses to be coded, 20 open-responses from each of the nine prerequisite content areas (except where missing) were double-coded for each grade six and eight. As previously mentioned, the 45 questions were organized into the nine content areas a total of 121 placements. Twenty open-responses from each of the nine prerequisite content areas were 
double-coded in grade six and twenty open-responses from eight of the nine prerequisite content areas (no patterning) were double-coded in grade eight. Therefore, 17/121 total placements were double-coded, for an overall double-coding rate $14 \%$. As a result, double-coding occurred on eight questions from grade six and on nine questions from grade eight and spanned across Welder's (2007) nine prerequisite content areas for success in Algebra I. By double-coding across grade levels and Welder's nine prerequisite content areas, the researcher gained the most clarity for coding. As mentioned above, the researcher and Coder \#1 had an overall inter-rater reliability of approximately $87 \%$ and the researcher and Coder $\# 2$ had an overall inter-rater reliability of approximately $88 \%$. See Table 10 for mean inter-rater reliability percentages organized by the nine prerequisite content areas.

Table 10

Inter-rater Reliability by Content Area

\begin{tabular}{|l|c|}
\hline \multicolumn{1}{|c|}{ Welder's Prerequisite Content Area } & $\begin{array}{c}\text { Mean Inter-rater } \\
\text { Reliability Percentage }\end{array}$ \\
\hline Numbers and Numerical Operations & $87.50 \%$ \\
\hline Ratios and Proportions & $80.00 \%$ \\
\hline The Order of Operations & $88.75 \%$ \\
\hline Equality & $82.50 \%$ \\
\hline Patterning & $82.50 \%$ \\
\hline Algebraic Symbolism and Letter Usage & $95.00 \%$ \\
\hline Algebraic Equations & $86.25 \%$ \\
\hline Functions & $95.00 \%$ \\
\hline Graphing & $87.50 \%$ \\
\hline
\end{tabular}




\section{Data Collection Procedures}

\section{How Data were Collected}

The primary data collected in this study were existing student work on openresponse questions (note that these items are all released online and are not confidential). The sample was obtained from the state's Department of Education. The researcher contacted the Director of Assessment at the state's Department of Education in August 2010. In September 2010, the researcher met with the Director of Assessment and provided the Director of Assessment with an excel spreadsheet of questions which aligned to Welder's framework for grades six, seven, and eight for years 2007 and 2008. At this time, the researcher requested that a systematic random sample of student responses be extracted from numerous urban middle schools throughout the state in order to obtain a sample representative to the population of students in grades six, seven, and eight in this Midwestern state. At the end of September 2010, the Director of Assessment took this request to the publisher of the standardized assessment. The testing publisher worked on a cost analysis through the months of October 2010 and November 2010. In November 2010, the testing publisher indicated it would be extremely costly to extract the sample as requested.

As a result, a conference call was conducted between the researcher, the state's Director of Assessment, and testing publisher representatives in order to determine the next steps. During the conference call it was agreed that the researcher would send a more detailed sampling procedure to the testing publisher, which was completed in early December 2010. In January 2011, the researcher was informed that the most current 
sampling procedure submitted in December 2010 would cost between $\$ 5,000$ and $\$ 10,000$.

A second conference call took place in early January 2011. This call included the state's Director of Assessment, the researcher, and the researcher's dissertation chair. During this call it was determined that training papers would be used instead of extracting a systematic sample through the publisher. Training papers would be used instead because they cost significantly less than extracting a systematic random sample. Shortly after the conference call, the researcher requested training papers for grades six, seven, and eight for years 2005-2010. In early February 2011, the researcher was notified that this request would cost $\$ 8437$ - which far exceeded the researcher's budget. In summary, it was determined that the researcher would request training papers for grades six and eight for 2007 and 2008 . The total cost for an electronic copy of the training papers for grades six and eight for 2007 and 2008 was $\$ 1872$. The researcher had a grant of $\$ 1000$ to help offset this cost.

Moreover, the state's Department of Education agreed to provide the researcher with training papers for the Algebra I standardized assessment used in this Midwestern state. These training papers were from a different testing publisher who could provide a portable document format (pdf.) version of the training papers at no charge. The researcher was interested in these training papers because of their potential to examine whether students still have the same misconceptions and errors in Algebra I as was found in the student responses for grades six and eight. They were used as a secondary analysis.

In addition to the training papers, the state's Department of Education agreed to an interview by the researcher. The researcher interviewed a mathematics content 
specialist who worked at the Department of Education. Additionally, the researcher interviewed a sixth-grade mathematics teacher and an eighth-grade mathematics teacher. The interview guide and informed consent documents can be found in Appendix A. The interviews and Algebra I training papers were considered secondary data sources for this study and were used for follow-up analyses.

\section{When Data were Collected}

Institutional Review Board (IRB) approval was obtained in December 2010 for the collection of existing data with all student identifiers removed. The IRB was approved under exempt status. An amendment was submitted in June 2011, which requested permission to conduct the interviews. The IRB was again approved under exempt status in June 2011. The researcher made the final request for the sixth- and eighth-grade training papers for 2007 and 2008 to the state's Department of Education in February 2011. After a confidentiality agreement and purchase order were completed in May 2011, the data were officially ordered. Both the sixth- and eighth- grade training papers and the Algebra I training papers were received by the researcher in July 2011. The researcher began the process of scheduling and conducting the interviews in August 2011.

\section{Where Data were Collected}

Data were collected from the state's Department of Education and the assessment publisher. The data used in this study were existing student data. The primary source of data collected were the training papers for the sixth- and eighth-grade for 2007 and 2008 testing administrations. Secondary sources of data included the Algebra I training papers and interviews with representatives from the state's Department of Education and two 
middle grades teachers (one from sixth-grade and one from eighth-grade). Both sets of training papers were received electronically. No on-site data collection of the student responses took place during this study. Interviews were conducted by phone with the state's mathematics content specialist and the eighth-grade mathematics teacher. The interview with the sixth-grade mathematics teacher was conducted in person.

\section{Procedures Stated in Order of Occurrence}

The final data request for the sixth- and eighth-grade training papers and the

Algebra I training papers was submitted to the Director of Assessment in February 2011. A contract agreement was signed and payment was made in early May 2011. Both sets of training papers were delivered in July 2011. The interviews were conducted in August and September of 2011.

\section{Data Analysis}

\section{How Data Will be Reported and Displayed}

The qualitative data in this study are organized and displayed in Chapter IV. The data are categorized by grade six and eight and by each of Welder's nine prerequisite content areas for success in Algebra I. For each grade, a misconception and error analysis of each question is linked to the literature review and organized by the nine prerequisite content areas. Additionally, Algebra I training papers and interviews served as a followup source of data. See Figure 11 for organization of results in Chapter IV. 
Figure 11

Organization of Data Analysis by Welder's Prerequisite Content Areas

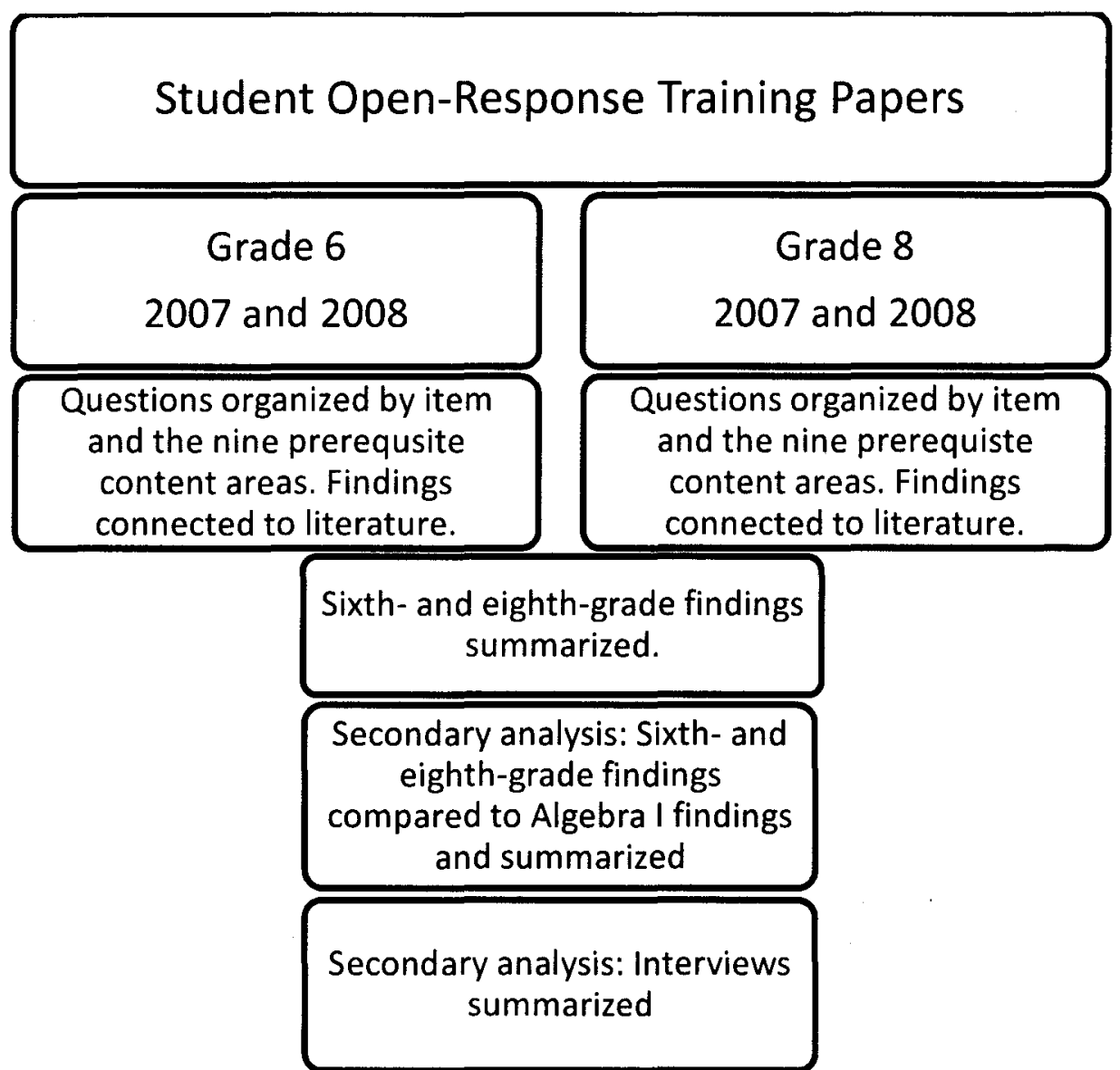

Trustworthiness of Data

Reliability. Reliability in qualitative research means that the researcher's approach to analyzing the data has remained consistent throughout the study (Creswell, 2009). The researcher addressed the reliability of the coding methods used by reviewing each open-response a final time and through the double-coding of both the questions categorized into the nine prerequisite content areas and the categorization of misconceptions and errors for each question as previously mentioned in Chapter III. At this time, any necessary changes to the coding of the data were made. This was 
completed for each student response for each training paper for each question in both grades six and eight for 2007 and 2008.

Validity. Additional methods were used to establish trustworthiness. The researcher used peer debriefing through frequent discussion of findings with fellow mathematics education doctoral students and members of the dissertation committee. The process of peer debriefing involves having a person ask the researcher questions about their study in order for the researcher to gain new and clarified interpretations of data (Creswell, 2009; Tashakkori \& Teddlie, 1998). In this study, those used for peer debriefing had a strong background in middle school mathematics education and/or algebra education. Peer debriefing conversations occurred with fellow doctoral students at least five times before the student response data were obtained. During each conversation, items of discussion included coding schemes, issues with coding, and potential findings. Once the researcher obtained the data at the end of July 2011 , the researcher had frequent conversations about the coding process and findings with two fellow mathematics education doctoral students. Additionally, the researcher had frequent conversations with the chair of the dissertation committee concerning the findings and to finalize the questions for the follow-up interviews.

Creswell (2009) suggested clarifying researcher bias as a means of establishing validity of qualitative studies. The researcher in this study had been both a middle school mathematics and Algebra I teacher. Therefore, the researcher had many beliefs, insights, and preconceptions about student misconceptions that were based solely on practice. While this provided the researcher with practitioner knowledge about student 
misconceptions and errors, it was important for the researcher to be aware that such bias existed.

Referential adequacy can also be used to establish trustworthiness (Tashakkori \& Teddlie, 1998). The researcher electronically stored copies of all student responses from the sample in a secure location which could be accessed when needed for recall and reanalysis purposes. The researcher kept an electronic and paper copy of all training papers. This allowed for the availability of reanalysis by the researcher and other investigators if needed. Additionally, any physical copies of training papers which were printed by the researcher were stored in a secure location at the researcher's residence.

It is suggested that a reflexive journal maintained by the researcher further maintains credibility, transferability, dependability, and confirmability throughout the study (Tashakkori \& Teddlie, 1998). Lincoln and Guba (1985) described a reflexive journal as "... a kind of diary in which the investigator on a daily basis, or as needed, records a variety of information about self... and the method. With respect to the method, the journal provides information about the methodologies and decisions made and the reasons for making them..." (as cited in Tashakkori \& Teddlie, 1998, p. 93). The researcher kept such a journal to maintain organization and clarity of methods and interpretations used throughout the data analysis. More specifically, the researcher kept notes during each stage of the coding. These notes included comments regarding decisions made during the coding process and reminders in order to maintain consistency. Additionally, triangulation of qualitative data sources was used in this study. The primary source of data was the student response training papers for grades six and eight. There were two secondary sources of data - the Algebra I training papers and the 
interviews. This provided the researcher with a total of three qualitative data sources. Patton (2002) stated that "Studies that use only one method are more vulnerable to errors linked with that particular method (e.g., loaded interview questions, biased or untrue responses) than studies that use multiple methods in which different types of data provide cross-data consistency checks" (p. 556).

Finally, the interviews served as an alternative to conducting member checks. Study participants could not be interviewed because existing data was used. As a substitute, the researcher chose to interview a representative from the state's Department of Education, a sixth-grade mathematics teacher, and an eighth-grade mathematics teacher on their views of the misconceptions and errors students have as they relate to Welder's framework. Creswell (2009) stated that conducting member checks with participants helps to "...determine the accuracy of the qualitative findings through taking a final report or specific descriptions or themes back to participants and determining whether these participants feel they are accurate" (p. 191). Because the primary data source of this study was existing data, there were no active student participants in a traditional sense. Therefore, the researcher chose to interview people directly involved in the development, scoring, or teaching the content related to the sixth- and eighth-grade standardized assessment. The researcher reviewed the main points taken from each interview with the respective interviewee. The main points taken from each interview were reviewed for accuracy by the interviewees. 


\section{Methods Used to Analyze Data}

Basic qualitative data analysis was used in this study in order to look for patterns in the open-responses. The following is a list of steps used in order to categorize and organize data in this study.

Step 1: Prior to examining the open-responses, the researcher developed an initial coding list for each of the nine prerequisite content areas based on the literature review from Chapter II. The lists of initial codes can be found in Appendix B. The researcher then read a sample of the collected open-responses for each of Welder's nine prerequisite content areas and made comparisons to the initial coding list and added to the list as needed. Main themes and trends in student work were documented for each question. Corbin and Strauss (2008) refer to this step as open coding. At this stage the researcher brainstormed and attempted to conceptualize the essence of the data in light of the expectations of previous research. The researcher examined evidence of misconceptions and errors in student work for each question separately. Once patterns started to emerge, the researcher sorted and grouped the responses into categories for each individual question and for each of the nine prerequisite content areas.

Step 2: A final coding list was created. As the remaining open-responses were analyzed, they were categorized according to the established coding list. As student responses that were different from any already identified codes emerged, additions were made to the master coding list. As previously mentioned, samples of open-responses were double-coded at the end of this stage to establish inter-rater reliability.

Step 3: After all open-responses were read and coded for each question, the researcher revisited the coding list and looked for ways to best group/categorize 
according to Welder's (2007) framework in order to streamline, reorganize, and prioritize the coded data. Any needed modifications were made at this time.

Step 4: Once all data were organized, the researcher revisited each open-response a final time to make certain that the main themes and patterns in the coded data set were consistent with the student work in the open-responses.

Step 5: The final copy of the coded data set was analyzed and connected to the research question and literature review for this study. This was organized by grade level and by the nine prerequisite content areas for success in Algebra I.

Step 6: Results from grades six and eight were compared to each other in order to look for differences in misconceptions and errors found between the two grade levels. Other findings were also discussed at this time.

Step 7: In efforts to triangulate data, a follow-up analysis included comparison of results from the sixth- and eighth-grade open-responses to findings from the Algebra I training papers and interviews. Interviews were summarized and responses from the three interviewees were compared to each other based on their similarities, differences, and emphasis placed on the nine prerequisite content areas. Additionally, responses from the three interviews were compared to the actual findings from the sixth-grade, eighth-grade, and Algebra I items. 


\section{CHAPTER IV}

\section{RESULTS}

Chapter IV presents the qualitative analysis of sixth- and eighth-grade student responses from selected questions on an annual statewide standardized assessment. Through document analysis, patterns were identified and themes of misconceptions and errors were categorized by Welder's (2007) nine prerequisite content areas for success in Algebra I. In addition, secondary analyses included connecting the primary findings to student responses on an Algebra I statewide standardized assessment and interviews with key informants. This chapter is divided into five sections: (a) introduction, (b) primary analysis of student responses on a statewide standardized assessment for grades six and eight on prerequisite algebra skills, (c) secondary analysis of Algebra I open-responses from a statewide standardized assessment, (d) secondary analysis using interviews with key informants, and (e) conclusion.

\section{Introduction}

The purpose of this study was to examine common algebra-related misconceptions and errors among middle school students. The errors and catalogue of misconceptions were aligned to Welder's (2007) nine prerequisite content areas which students should know before entering their first formal algebra course (Algebra I). The nine prerequisite content areas are: (1) numbers and numerical operations, (2) ratios and proportions, (3) the order of operations, (4) equality, (5) patterning, (6) algebraic symbolism and letter usage, (7) algebraic equations, (8) functions, and (9) graphing. 
The research question for this study was the following:

1. What common algebra-related misconceptions and errors exist among students in grades six and eight as identified on student responses on an annual statewide standardized assessment?

To answer this question, the researcher used qualitative document analysis on existing state-level student data. The sample in this study consisted of training papers obtained from the state's Department of Education. Training papers (also called scorer papers) are a collection of actual student responses for each open-response question. For this study, the researcher used training papers from the 2007 and 2008 testing administrations from both grades six and eight. The researcher then conducted secondary analyses using student responses from an Algebra I standardized assessment and interviews with key informants.

As outlined in Chapter III, a total of 20 questions from grade six and 25 questions from grade eight were analyzed. These were chosen because they fit into one or more of Welder's nine prerequisite content areas. Twenty papers from each of the 45 items were obtained. None of the open-responses obtained were blank.

\section{Primary Analysis}

\section{Overview}

The analysis of student responses on the sixth- and eighth-grade statewide standardized assessment serves as the primary data source for this study. As discussed in Chapter III, a total of 20 questions from grade six and 25 questions from grade eight for the 2007 and 2008 testing administrations were determined relevant for this study because of their alignment to the nine prerequisite content areas. Next, it was determined 
that the 45 questions (20 sixth-grade and 25 eighth-grade) aligned to these nine prerequisite content areas a total of 121 times. Many of the 45 questions fit into more than one of the nine prerequisite content areas. For this analysis, only the prerequisite content areas with identified misconceptions and errors are discussed for each item.

\section{Organization of the Primary Analysis}

The primary analyses proceed item by item. The 20 sixth-grade items are discussed first, followed by the 25 eighth-grade items. For each item, a figure showing the item is provided. This is followed by a descriptive narrative discussing the process necessary to complete the item and a discussion of the identified student misconceptions and errors. Third, a summary table which examines the overall performance of the item from the sample which was received is shown. The researcher was informed by a representative of the state's Department of Education that the open-responses received were representative of the range (but not the frequency) of student responses on each item. This table is provided in order to help with the interpretation of the amount of misconceptions and errors which were found for each item. Fourth, where applicable, a percentage table(s) related to each of the nine prerequisite content areas for which identified misconceptions and errors are present is provided.

The coding of student responses appears slightly differently for each prerequisite content area. This is because the researcher was looking for different errors and misconceptions depending on which content areas were being examined. All connections to the review of literature can be found within each prerequisite content area table. Additional codes were developed when the researcher noticed repeated patterns. After establishing inter-rater reliability as discussed in Chapter III, more fine-tuning was 
needed and additional codes were created. Occasionally, the same codes are worded in somewhat different ways as directed towards that question in order to provide the reader as much clarity and information about the open-responses as possible.

Three additional, clarifying points are necessary. First, if a code is specific just to one item, it may not be included on the coding sheet(s) found in Appendix C. Second, the researcher was told that the student response training papers were representative of the range of responses made by students on each item. A copy of the final coding sheets for the nine prerequisite content areas can be found in Appendix C.

\section{Grade Six}

Twenty sixth-grade items were coded and analyzed as they related to Welder's (2007) nine prerequisite content areas. First, a figure showing the item is provided. Second, descriptive narrative discussing the process necessary to complete the item and a discussion of the identified student misconceptions and errors is provided. Third, a summary table which examines the overall performance of the item from the sample which was received is shown. Fourth, percentage table(s) related to each of the nine prerequisite content areas for which identified misconceptions and errors are present are provided (where applicable). 
Figure 12

Item 1: Sixth-Grade

6 Anne's spelling scores for the first 4 months of the school year are shown in the table below.

Anne's Scores

\begin{tabular}{|l|c|c|c|c|c|c|}
\hline Month & Sep & Oct & Nov & Dec & Jan & Feb \\
\hline Score & 81 & 98 & 95 & 98 & & \\
\hline
\end{tabular}

On the lines below, write two scores that Anne could get in January and February to make her mean score 93 for all six months.

Show All Work

Answer and

(Department of Education, 2007)

On this item, students were given a set of four out of six scores. Students were asked to write a fifth and sixth score that would make the mean score 93 . In this question, most students used the concept of mean (or average) to calculate two final scores which would give the overall data set the requested mean score of 93 . There is more than one possible solution to this problem because the question consists of two unknown amounts. Table 11 provides a summary of response types. On this item, 15\% of students made computational errors with whole numbers when finding the sum of the test scores, $40 \%$ had the correct answer and correct process, and $25 \%$ had the correct answer but the work shown did not clearly lead to the correct answer. For the remaining $20 \%$ of the student responses, the researcher did not find a repeating misconception or error but did find 
different responses. On one response, the student did not show any work and answered with two test scores (95 and 93) which made the mean round to 93, but not exactly 93 . It is possible that this student had a good understanding of the concept of mean but did not realize the answer had to be exactly 93. Another open-response showed work which used subtraction in order to find two test scores which would work. This open-response had 95 and 98 as answers, giving a mean close to 94 . A third student response had no work shown and chose 82 and 84 as their answers, resulting in a mean of approximately 89. Because there was no work shown, it is unclear as to why those two answers were chosen. A fourth student response showed work in which the student found that the mean of the four given test scores was 93. However, no other work was shown and the student chose 93 and 84 as their answers for the fifth and sixth test scores, resulting in an overall mean which was too low. This response does show that the student understood how to calculate the mean (they did so with the first four given values).

Table 11

Summary Table: Item 1, Sixth-Grade

\begin{tabular}{|l|c|}
\hline \multicolumn{1}{|c|}{ Response } & Percent of Responses \\
\hline Correct answer and correct process & $40 \%$ \\
\hline $\begin{array}{l}\text { Correct answer but work shown did not } \\
\text { clearly lead to the correct answer }\end{array}$ & $25 \%$ \\
\hline Incorrect answer & $35 \%$ \\
\hline
\end{tabular}


Figure 13

Item 2: Sixth-Grade

2 Cole has $\$ 9.16$ and is given $\$ 2.25$ more. Steven has $\$ 13.64$ and spends $\$ 2.28$ at the store.

Compare the amount of money Cole and Steven now have by using the symbol for less than $(<)$, equals $(=)$, or greater than $(>)$.

Show All Work

Answer \$ $\$$

(Department of Education, 2008)

This item involved relationships of quantities through the context of money and decimals. In this question, students were asked to add two decimal amounts in dollars and cents. They were also asked to find the difference of two other decimal amounts. After calculating the sum and difference of the two sets of decimals, students were asked to write an inequality using the greater than, less than, or equal to symbol in order to compare the two amounts. Table 12 provides a summary of response types. On this item, students seemed to have the most difficulty with the computation involved in adding or subtracting the decimals, not showing their work, or transcribing the numbers correctly when working the addition or subtraction problems. Overall, $5 \%$ of student responses added both sets of numbers instead of adding the first set and subtracting the second set, $20 \%$ of student responses had both the correct answer and correct process, and $10 \%$ of responses had the correct answer but no work shown. Another $30 \%$ of the student 
responses had errors in transcription. All transcription errors occurred because the student copied one digit of one of the original decimal value incorrectly. Additionally, $10 \%$ of the student responses compared the two original amounts (did not add the 2.25 or subtract the 2.28 ) and on $5 \%$ of the student responses the computation was correct but the student then compared the amount of the sum with the original amount for the difference set (without the 2.28 subtracted). No student displayed a misunderstanding with the relationship of greater than, less than, or equal to. See Table 13 for connections made to the literature as it relates to the prerequisite content area of numbers and numerical operations. The percentages outlined in Table 13 represent the percentages out of the total number of all responses (not out of the total number of incorrect responses).

Table 12

Summary Table: Item 2, Sixth-Grade

\begin{tabular}{|l|c|}
\hline \multicolumn{1}{|c|}{ Response } & Percent of Responses \\
\hline Correct answer and correct process & $20 \%$ \\
\hline Correct answer but no work shown & $10 \%$ \\
\hline Incorrect answer & $70 \%$ \\
\hline
\end{tabular}


Table 13

Common Errors and Misconceptions: Sixth-Grade Numbers and Numerical Operations,

Item 2

\begin{tabular}{|l|l|l|}
\hline \multicolumn{1}{|c|}{ Error/Misconception } & Percent of Responses & Corresponding Reference \\
\hline $\begin{array}{l}\text { Computational error with } \\
\text { addition/subtraction of } \\
\text { decimals (10\% with }\end{array}$ & & $\begin{array}{l}\text { Ashlock, 2006; Kilpatrick et } \\
\text { al., 2001 } \\
\text { subtraction, 5\% with } \\
\text { addition, and 5\% with both) }\end{array}$ \\
\hline
\end{tabular}

Figure 14

Item 3: Sixth-Grade

4 Chelsea built a sandbox. The sandbox consists of 2 rectangles, as shown in the figure below.

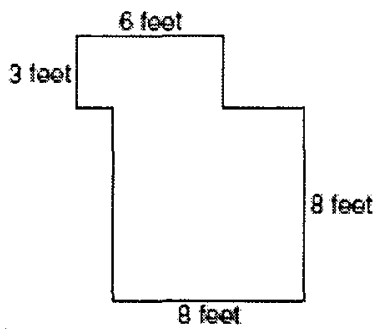

What is the area, in square teet, of the sandbox?

$$
\begin{aligned}
\text { Area of rectangle } & =\text { liw } \\
& =\text { length } * \text { widh }
\end{aligned}
$$

\section{Show All Work}

(Department of Education, 2008) 
On this item, students were given an irregular figure consisting of two combined rectangles. Students were asked to find the area of the figure and were given the formula for the area of a rectangle but were required to decompose the figure. Therefore, students were asked to find the area of both rectangles and then add the area of both rectangles in order to find the total area of the irregular figure. Table 14 provides a summary of response types. The most commonly noted difficulties students possessed on this problem included computational errors, typically in their basic multiplication facts (e.g. $8 \times 8)$ or when adding the areas of both rectangles in order to find the total area of the irregular figure. Also, some students incorrectly used the area formula when finding the area of the rectangle - instead they added the length and width or they found the perimeter of the rectangle. Overall, $40 \%$ of student responses displayed computational errors with whole numbers ( $20 \%$ when multiplying to find the area of a rectangle, and $20 \%$ when adding the two areas), $25 \%$ had the correct answer and correct process, and $5 \%$ had the correct answer but no work shown. Additionally, $5 \%$ multiplied the two areas instead of adding, and $15 \%$ added the length and width instead of multiplying when finding the area of each rectangle. Other responses included $5 \%$ which only found the area of the bigger rectangle and $5 \%$ which found the area of both rectangles but said the overall area was the area of the smaller rectangle. All students correctly broke the figure into two rectangles. 
Table 14

Summary Table: Item 3, Sixth-Grade

\begin{tabular}{|l|c|}
\hline \multicolumn{1}{|c|}{ Response } & Percent of Responses \\
\hline Correct answer and correct process & $25 \%$ \\
\hline Correct answer but no work shown & $5 \%$ \\
\hline Incorrect answer & $70 \%$ \\
\hline
\end{tabular}


Figure 15

\section{Item 4: Sixth-Grade}

5 An ice-cream partor is giving away 2 tree scoops of ice cream to each adult and 1 free scoop of ice cream to each child during a one-hour event. The ice-cream parlor collected the data shown in the table below during the event.

Ice-Cream Event

\begin{tabular}{|c|c|c|}
\hline Time & $\begin{array}{c}\text { Number of } \\
\text { Adults }\end{array}$ & $\begin{array}{c}\text { Number of } \\
\text { Chlldren }\end{array}$ \\
\hline 9.00 AM-9:15 A.M. & 9 & 11 \\
\hline $9: 16$ AM-9:30 A.M. & 6 & 8 \\
\hline $9: 31$ A.M $-9: 45$ A.M. & 11 & 13 \\
\hline $9: 46$ AM-10:00 A.M. & 13 & 15 \\
\hline
\end{tabular}

Use the expression $2 a+1 c$, where a represents the number of adufts and $\mathrm{c}$ represents the number of children that took part in the event, to find the number of free scoops given away from 9:16 A.M. until $9: 30 \mathrm{~A} . \mathrm{M}$.

\section{Show All Work}

Answer scoops

If each free scoop of ice cream weighed 4 ounces, how many POUNDS of lce cream were given away from 9:16 A.M. 10 9:30 A.M.?

$$
16 \text { ounces }=1 \text { pound }
$$

\section{Show All Work}

Answer pounds

(Department of Education, 2008) 
On this item, students were given a table of values about the number of ice cream scoops given away to adults and children at certain times of the day. They were then asked to substitute specific values from the table into a two variable expression and then simplify the expression in order to answer the first part of the item. The second part of the item asked students to convert their answer from scoops to ounces to pounds of ice cream. Students were given both conversion scales in the problem. Table 15 provides a summary of response types. When examining student responses to this item, the researcher found that while some students made computational errors, no other common patterns existed between other errors and misconceptions. Overall, $35 \%$ of students made computational errors with whole numbers. Of these computational errors, $10 \%$ were with multiplication in part one, $10 \%$ were with addition in part one, $5 \%$ multiplication in part two, and $10 \%$ division in part two. Additionally, $5 \%$ of student responses multiplied the terms instead of adding them in the expression on part one, $10 \%$ had the correct answer and correct process (both parts), $5 \%$ had the correct answer but no work shown (both parts), and $10 \%$ had the correct answer but the work shown did not clearly lead to the correct answer (both parts). Additionally, $15 \%$ of the items had other errors including doubling the number of adults twice $(5 \%$; once in the expression and again after simplifying the expression in part one), and $10 \%$ did not use the expression but simply added the number of adults and children $(6+8)$ in part one. See Tables 16 and 17 for misconceptions and errors of student responses for this item as they relate to the prerequisite content areas of ratios and proportions and algebraic symbolism and letter usage. Note that the overall percentage total for this item is more than $100 \%$ because several items displayed more than one misconception or error. The percentages outlined 
in Tables 16 and 17 represent the percentages out of the total number of all responses (not out of the total number of incorrect responses).

Table 15

Summary Table: Item 4, Sixth-Grade

\begin{tabular}{|l|c|}
\hline \multicolumn{1}{|c|}{ Response } & Percent of Responses \\
\hline Correct answer and correct process & $10 \%$ \\
\hline Correct answer but no work shown & $5 \%$ \\
\hline $\begin{array}{l}\text { Correct answer but work shown did not } \\
\text { clearly lead to the correct answer }\end{array}$ & $10 \%$ \\
\hline Incorrect answer & $75 \%$ \\
\hline
\end{tabular}

Table 16

Common Errors and Misconceptions: Sixth-Grade Ratios and Proportions, Item 4

\begin{tabular}{|l|r|l|}
\hline \multicolumn{1}{|c|}{ Error/Misconception } & Percent of Responses & \multicolumn{1}{c|}{ Corresponding Reference } \\
\hline $\begin{array}{l}\text { Inability to unitize (when } \\
\text { converting in part 2) }\end{array}$ & $25 \%$ & $\begin{array}{l}\text { Behr et al., 1992; Singh, } \\
2000\end{array}$ \\
\hline
\end{tabular}

Table 17

Common Errors and Misconceptions: Sixth-Grade Algebraic Symbolism and Letter

Usage, Item 4

\begin{tabular}{|l|c|c|}
\hline \multicolumn{1}{|c|}{ Error/Misconception } & Percent of Responses & Corresponding Reference \\
\hline $\begin{array}{l}\text { Substituting the wrong } \\
\text { value into the equation or } \\
\text { expression (in part 1) }\end{array}$ & & \\
\hline
\end{tabular}


Figure 16

Item 5: Sixth-Grade

2 The parallelogram shown below is a diagram of a city block.

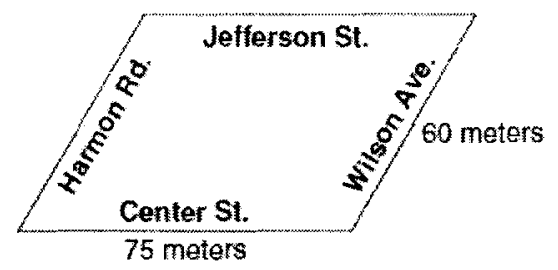

What is the perimeter, in meters, of the city block?

Show All Work

Answer meters

(Department of Education, 2007)

On this item, students were given a diagram of a parallelogram and asked to find the perimeter. Lengths were given on two non-parallel sides of the parallelogram. No formula was given. Therefore, students had to know that sets of parallel sides in a parallelogram are equal in length and that the lengths of all four sides are added in order to obtain the perimeter. Some students chose to compute the perimeter by adding the four sides while other chose to multiply the two given side lengths by two and then add their sums. Table 18 provides a summary of response types. Overall, $25 \%$ of student responses displayed computational errors with whole numbers ( $20 \%$ with addition and $5 \%$ with multiplication), 30\% had the correct answer and correct process, and 5\% had the correct answer but no work shown. Transcription errors accounted for $15 \%$ of wrong answers - 
$10 \%$ in writing their answer and $5 \%$ in writing values from the problem to do work.

Other student misunderstandings included the following: only adding two sides to calculate the perimeter (5\%), multiplying the two given measurements (using the area formula incorrectly) (5\%), multiplying all four side measurements instead of adding $(5 \%)$, multiplying the sum of widths and lengths instead of adding them $(5 \%)$, and one student response provided an answer of 130 - which is not the sum or product of the values ( $5 \%$; no work was shown).

Table 18

Summary Table: Item 5, Sixth-Grade

\begin{tabular}{|l|c|}
\hline \multicolumn{1}{|c|}{ Response } & Percent of Responses \\
\hline Correct answer and correct process & $30 \%$ \\
\hline Correct answer but no work shown & $5 \%$ \\
\hline Incorrect answer & $65 \%$ \\
\hline
\end{tabular}


Figure 17

Item 6: Sixth-Grade

1 Read the following phrase.

three more than twice $n$

On the line below, write an expression to represent the phrase.

Expression

On the line below, evaluate the expression you wrote when $n=31$.

Answer

(Department of Education, 2008)

On this item, students were given a phrase involving multiplication and addition and were first asked to write an algebraic expression to represent the phrase. Students were then asked to evaluate their expression given a value for the variable. Table 19 provides a summary of response types. Overall, it was generally found that if a student could correctly represent the phrase algebraically, then they were able to evaluate the expression for the given value. Some students were still able to correctly evaluate the expression even though they had difficulty with the symbolic representation of the expression. Students often incorrectly represented the expression symbolically by using incorrect operations and they evaluated their expression incorrectly if they had an incorrect expression or if they did not follow the order of operations. Student responses expressed the following difficulties: wrong operation used in expression such as $2 n \times 3$ or $3 n+2(40 \%)$, used words instead of symbols to write the expression (5\%), could not use 
write the expression algebraically (using only numbers and operations) (10\%), used the wrong order of operations when solving (5\%), left the expression line blank (5\%), wrote an equation instead of an expression (15\%), wrote a single number instead of an algebraic expression (5\%), omitted the multiply by two (10\%), and omitted the add three $(5 \%)$. These errors only accounted for $80 \%$ of the open-responses because four open-responses had two errors. Correct answer and correct expression accounted for $20 \%$ of the student responses. Also, $40 \%$ of open-responses had the correct answer (65) - 20\% which were included in the correct answer and correct expression and another $20 \%$ which did not have the correct expression. See Tables 20,21, and 22 for misconceptions and errors of student responses for this item as they relate to the prerequisite content areas of the order of operations, algebraic symbolism and letter usage, and algebraic equations.

Table 19

Summary Table: Item 6, Sixth-Grade

\begin{tabular}{|l|c|}
\hline \multicolumn{1}{|c|}{ Response } & Percent of Responses \\
\hline Correct answer and correct expression & $20 \%$ \\
\hline Correct answer but incorrect expression & $20 \%$ \\
\hline Incorrect answer & $60 \%$ \\
\hline
\end{tabular}

Table 20

Common Errors and Misconceptions: Sixth-Grade The Order of Operations, Item 6

\begin{tabular}{|l|l|l|}
\hline \multicolumn{1}{|c|}{ Error/Misconception } & Percent of Responses & Corresponding Reference \\
\hline $\begin{array}{l}\text { Performing operations in } \\
\text { order from left to right } \\
\text { instead of using order of } \\
\text { operations }\end{array}$ & $5 \%$ & $\begin{array}{l}\text { Linchevski and Livnch, } \\
1999\end{array}$ \\
\hline
\end{tabular}


Table 21

Common Errors and Misconceptions: Sixth-Grade Algebraic Symbolism and Letter

Usage, Item 6

\begin{tabular}{|l|r|l|}
\hline \multicolumn{1}{|c|}{ Error/Misconception } & Percent of Responses & \multicolumn{1}{c|}{ Corresponding Reference } \\
\hline $\begin{array}{l}\text { Inability to write a correct } \\
\text { algebraic expression for a } \\
\text { given situation }\end{array}$ & $75 \%$ & $\begin{array}{l}\text { MacGregor and Stacey, } \\
1997\end{array}$ \\
\hline $\begin{array}{l}\text { The belief that an answer } \\
\text { can only be a number rather } \\
\text { than an expression }\end{array}$ & $5 \%$ & $\begin{array}{l}\text { Booth and Watson, 1990; } \\
\text { Booth, 1986; Kilpatrick et } \\
\text { al., 2001; Stacey and } \\
\text { MacGregor, 1997b }\end{array}$ \\
\hline
\end{tabular}

Table 22 .

Common Errors and Misconceptions: Sixth-Grade Algebraic Equations, Item 6

\begin{tabular}{|c|c|l|}
\hline \multicolumn{1}{|c|}{ Error/Misconception } & Percent of Responses & Corresponding Reference \\
\hline $\begin{array}{l}\text { Difficulty with the symbolic } \\
\text { representation of a scenario } \\
\text { (equation research) }\end{array}$ & $80 \%$ & $\begin{array}{l}\text { Booth, 1984; Nathan and } \\
\text { Koedinger, 2000 }\end{array}$ \\
\hline
\end{tabular}


Figure 18

Item 7: Sixth-Grade

5 The Smith family is fillng their new pool. The graph below shows how the depth of water in the pool changes over time.

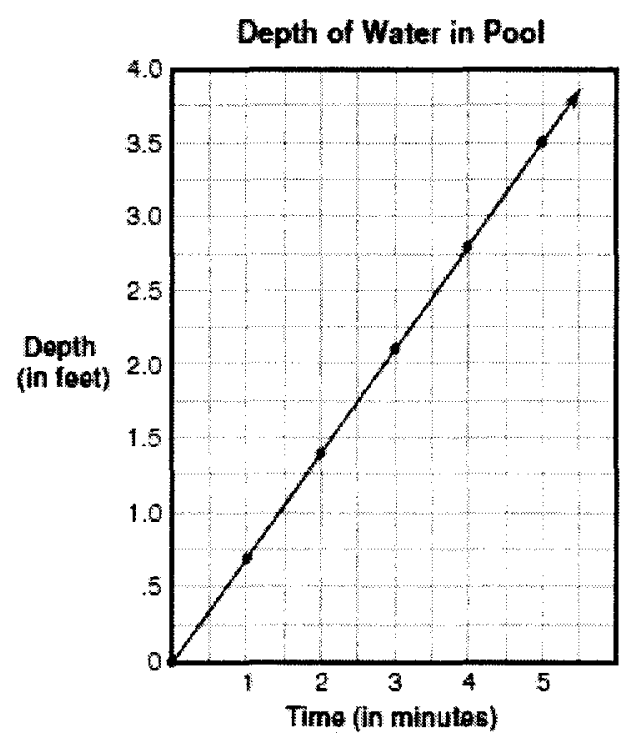

ESTIMATE how much the water level rises, in teet between 1 minute and 4 minutes.

Estimate fert

Atter 3 minutes, the pool is $25 \%$ full. On the lines below, explain how you woutd estimate the total depth of the water when the pool is full.

(Department of Education, 2007)

On this item, students were given a graph of a linear function in a context and were asked to interpret the graph to estimate a value in-between the gridlines (decimal value) and then use reasoning to predict a value of the linear function that was outside of the area shown on the graph. Table 23 provides a summary of response types. Overall, 
$35 \%$ of student responses had the correct answer and correct explanation and $5 \%$ had the correct answer but not a clear explanation. Additionally, $5 \%$ had difficulty unitizing in their explanation by not thinking proportionally. With regards to the patterns in the graph, $5 \%$ had an error in counting with patterns, $15 \%$ had difficulty making generalizations from the graph, $5 \%$ did not make consistent generalizations from the graph (comparing estimate with explanation), and 5\% used incorrect symbolism in their explanation. All other errors and misconceptions related to the interpreting and predicting of the function/graph including: errors in estimating the feet $(25 \%)$, not answering the question that was asked for the explanation (10\%), and predicting in the explanation (20\%). Errors in interpreting and predicting of the graph accounted for $50 \%$ of the open-responses overall (one open-response had two errors). Overall, the total is more than $100 \%$ because some open-responses displayed more than one mistake. See Tables 24, 25, 26, and 27 for misconceptions and errors of student responses for this item as they relate to the prerequisite content areas of ratios and proportions, patterning, functions, and graphing. Table 23

Summary Table: Item 7, Sixth-Grade

\begin{tabular}{|l|c|}
\hline \multicolumn{1}{|c|}{ Response } & Percent of Responses \\
\hline Correct answer and correct explanation & $35 \%$ \\
\hline Correct answer but not a clear explanation & $5 \%$ \\
\hline Incorrect answer & $60 \%$ \\
\hline
\end{tabular}


Table 24

Common Errors and Misconceptions: Sixth-Grade Ratios and Proportions, Item 7

\begin{tabular}{|l|r|l|}
\hline \multicolumn{1}{|c|}{ Error/Misconception } & Percent of Responses & Corresponding Reference \\
\hline Inability to unitize & $5 \%$ & $\begin{array}{l}\text { Behr et al., 1992; Singh, } \\
2000\end{array}$ \\
\hline
\end{tabular}

Table 25

Common Errors and Misconceptions: Sixth-Grade Patterning, Item 7

\begin{tabular}{|l|r|l|}
\hline \multicolumn{1}{|c|}{ Error/Misconception } & Percent of Responses & Corresponding Reference \\
\hline $\begin{array}{l}\text { Errors in counting with } \\
\text { patterns (from a graph) }\end{array}$ & $5 \%$ & Koellner et al., 2008 \\
\hline $\begin{array}{l}\text { Difficulty making a } \\
\text { generalization (from a } \\
\text { graph) }\end{array}$ & $15 \%$ & Stacey, 1989 \\
\hline $\begin{array}{l}\text { Not making consistent } \\
\text { generalizations (from a } \\
\text { graph) }\end{array}$ & $5 \%$ & Stacey, 1989 \\
\hline $\begin{array}{l}\text { Difficulty expressing } \\
\text { pattern symbolically (on } \\
\text { explanation) }\end{array}$ & $5 \%$ & $\begin{array}{l}\text { Healy and Hoyles, 1999; } \\
\text { Radford, 2000 }\end{array}$ \\
\hline
\end{tabular}

Table 26

Common Errors and Misconceptions: Sixth-Grade Functions, Item 7

\begin{tabular}{|l|r|l|}
\hline \multicolumn{1}{|c|}{ Error/Misconception } & Percent of Responses & Corresponding Reference \\
\hline $\begin{array}{l}\text { Incorrectly interpreting } \\
\text { function }\end{array}$ & $50 \%$ & Kilpatrick et al., 2001 \\
\hline
\end{tabular}

Table 27

Common Errors and Misconceptions: Sixth-Grade Graphing, Item 7

\begin{tabular}{|l|r|c|}
\hline \multicolumn{1}{|c|}{ Error/Misconception } & Percent of Responses & Corresponding Reference \\
\hline $\begin{array}{l}\text { Incorrectly interpreting } \\
\text { graph }\end{array}$ & $50 \%$ & Kilpatrick et al., 2001 \\
\hline
\end{tabular}


Figure 19

Item 8: Sixth-Grade

5 An arena has 990 seats. There are 78 events scheduled at the arena this year. Bert used the following calculation to estimate the number of tickets the arena will sell this year if every event is sold out.

$900 \times 70=63,000$

On the lines below, identify whether Bert's estimate is reasonable and explain how you determined your answer.

What is the ACTUAL number of tickets that will be sold this year if every event is sold out?

Show All Work

Answer __ tickets

(Department of Education, 2008)

On this item, students were given a multiplicative problem situation where a fictional student rounded two numbers, 990 and 78 , to 900 and 70 in order to quickly estimate a product. The item asks students to determine if the student's estimate is reasonable and to explain their answer. Then students are asked to find the actual (exact) answer. Table 28 provides a summary of response types. For the first part, it was found that most students were able to determine that the fictional student's rounding did not produce a reasonable estimate. However, a few students believed the estimate was 
accurate because the numbers were "close". More students had difficulty with the second part of the question where they were asked to find the actual (exact) answer by finding the product of 990 and 78 . The two errors students made included computational errors in multiplying or not multiplying the actual amounts. Instead, some students multiplied their chosen rounded numbers, $1000 \times 80$, or a hybrid of rounded and actual numbers, such as $990 \times 80$. Additionally, some students failed to show their work when calculating the actual answer which was required. Overall, $15 \%$ of student responses incorrectly stated that the estimate was reasonable, $20 \%$ of student responses multiplied rounded numbers instead of actual numbers, $20 \%$ had computational errors with the multiplication of correct (actual) whole numbers, 35\% had the correct answer and correct process, and $20 \%$ had the correct answer but no work shown. The total is more than $100 \%$ because several responses had more than one misconception or error.

Table 28

Summary Table: Item 8, Sixth-Grade

\begin{tabular}{|l|c|}
\hline \multicolumn{1}{|c|}{ Response } & Percent of Responses \\
\hline Correct answer and correct process & $35 \%$ \\
\hline Correct answer but no work shown & $20 \%$ \\
\hline Incorrect answer & $45 \%$ \\
\hline
\end{tabular}


Figure 20

Item 9: Sixth-Grade

4 What is the volume, in cubic feet. of the rectangular prism shown below?

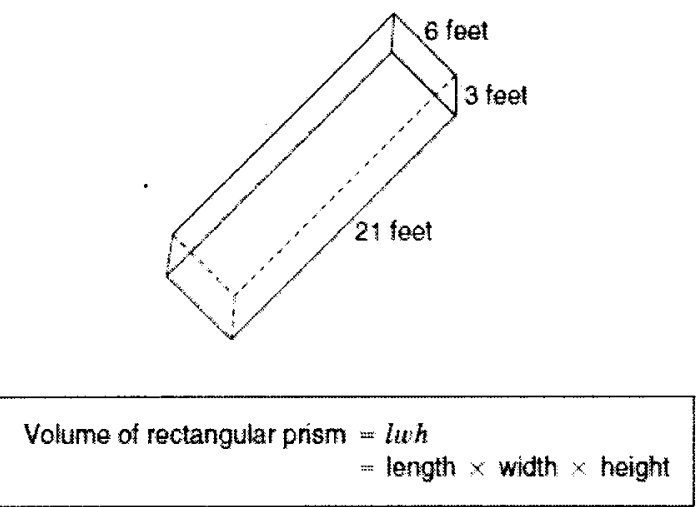

Show All Work

Answer__ cubic teet

(Department of Education, 2008)

On this item, students were given a diagram of a rectangular prism with dimensions for the length, width, and height. Students were asked to find the volume and were given the formula $V=l w h$. Table 29 provides a summary of response types. While many student responses had correct solutions, some students did not show any work. If the answer was incorrect, the most common error was a computational error when multiplying - meaning the student still understood how to use the volume formula. Overall, $30 \%$ of open-responses had computational errors. The distribution of the computational errors included 5\% when multiplying $21 \times 6,10 \%$ when multiplying $6 \times 3$, 
$5 \%$ when multiplying $63 \times 6$, and $10 \%$ when multiplying $126 \times 3$. Also, $40 \%$ of the openresponses had the correct answer and correct process and 10\% had the correct answer but no work shown. Of the remaining responses, $5 \%$ multiplied by 6 twice, $5 \%$ added the three values instead of multiplying them, and $5 \%$ added each value twice $(6+6+3+3+$ $21+21$ ) possibly confusing it with perimeter. Additionally, $5 \%$ had a transcription error because they copied their correct answer onto the answer line incorrectly.

Table 29

Summary Table: Item 9, Sixth-Grade

\begin{tabular}{|l|c|}
\hline \multicolumn{1}{|c|}{ Response } & Percent of Responses \\
\hline Correct answer and correct process & $40 \%$ \\
\hline Correct answer but no work shown & $10 \%$ \\
\hline Incorrect answer & $50 \%$ \\
\hline
\end{tabular}


Figure 21

Item 10: Sixth-Grade

1 Katie sold 12 tickets to a school play. Katie's total sales, $t$, for the tickets is given by the formula

$$
12 \times c=t
$$

where $c$ is the cost per ticket.

What were Katie's total sales if the cost of each ticket is $\$ 5$ ?

Show All Work

Answer $\$$

(Department of Education, 2008)

On this item, students were given a situation and a two-variable algebraic equation representing the situation. Students are then told the value of one variable and must substitute it into the equation in order to find the value of the other variable. No inverse operation was required in order to find the solution. Table 30 provides a summary of response types. Student difficulties on this item included the following: computational errors in basic multiplication, substituting the wrong value in for the variable in the equation, using the wrong operation (addition or division instead of multiplication), and others. Overall, $15 \%$ of open-responses substituted 12 into the equation for $c$ instead of 5 . Additionally, $35 \%$ made computational errors with the multiplication of whole numbers, $25 \%$ had the correct answer and correct process, and $5 \%$ had the correct answer but no 
work shown. Additionally, $10 \%$ used the wrong operation ( $5 \%$ added and $5 \%$ divided).

Other misconceptions and errors included multiplying by 50 then dividing by $12(5 \%)$

and multiplying by 12 twice (5\%). See Table 31 for misconceptions and errors of student responses for this item as they relate to the prerequisite content area of algebraic

symbolism and letter usage.

Table 30

Summary Table: Item 10, Sixth-Grade

\begin{tabular}{|l|c|}
\hline \multicolumn{1}{|c|}{ Response } & Percent of Responses \\
\hline Correct answer and correct process & $25 \%$ \\
\hline Correct answer but no work shown & $5 \%$ \\
\hline Incorrect answer & $70 \%$ \\
\hline
\end{tabular}

Table 31

Common Errors and Misconceptions: Sixth-Grade Algebraic Symbolism and Letter

Usage, Item 10

\begin{tabular}{|l|c|c|}
\hline \multicolumn{1}{|c|}{ Error/Misconception } & Percent of Responses & Corresponding Reference \\
\hline $\begin{array}{l}\text { Substituting the wrong } \\
\text { value into the equation or } \\
\text { expression }\end{array}$ & & \\
\hline
\end{tabular}


Figure 22

Item 11: Sixth-Grade

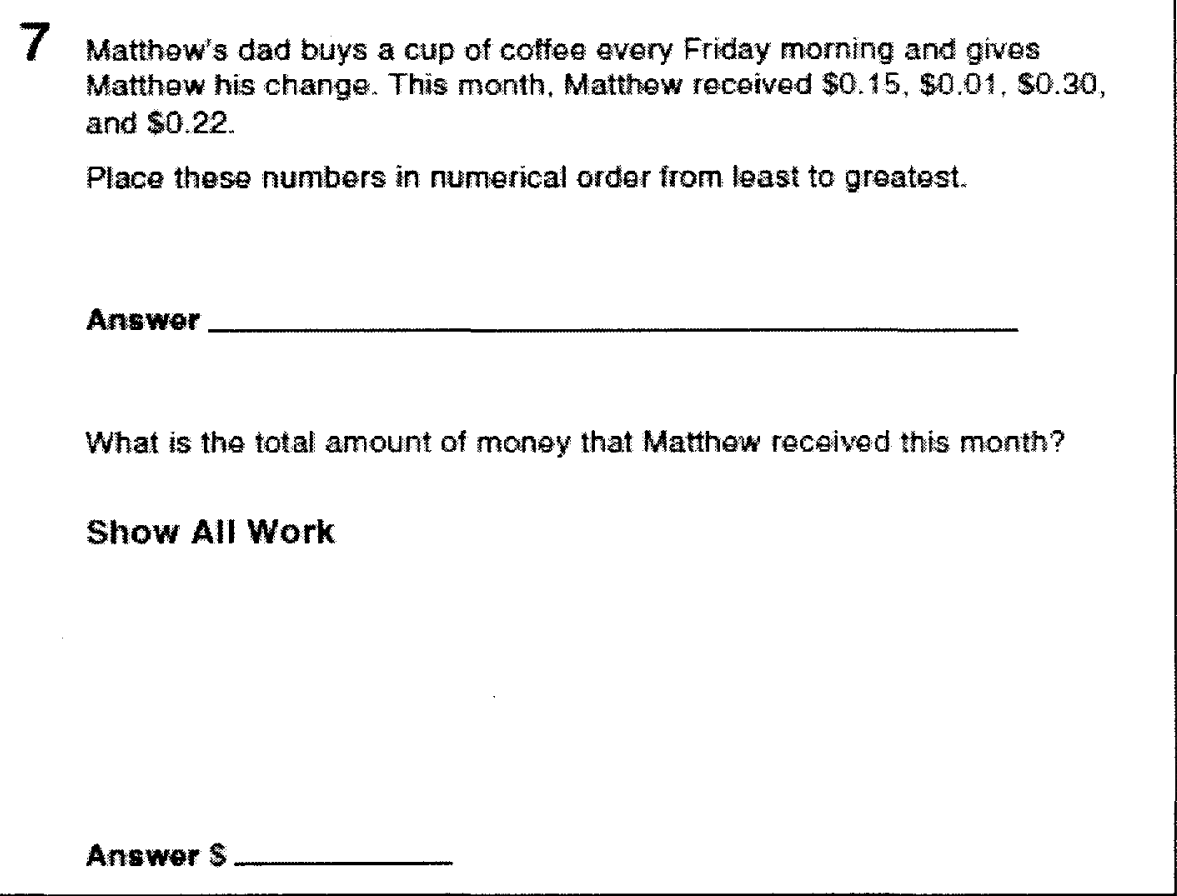

(Department of Education, 2008)

On this item, students are given four amounts of change, ranging from $\$ 0.01$ to $\$ 0.30$. Students are first asked to place these amounts in order from least to greatest. Then, students are asked to find the total amount of money, or sum, of the four amounts. Table 32 provides a summary of response types. The student responses contained a variety of different errors including: determining which decimal was greater simply by the number of digits, symbolically representing the answer incorrectly by omitting the decimal point or writing the solution as a decimal number with a cents symbol (instead of dollar symbol) (as mentioned in Kilpatrick et al., 2001), making computational errors when adding the decimals, or omitting one of the values when ordering or adding the decimals. If a student omitted one of the values they always omitted the last value in the 
list, the one followed by the word "and", which was separated from the other values. Overall, $20 \%$ of student responses omitted the decimal point or used it incorrectly symbolically, $10 \%$ omitted a decimal value, $30 \%$ had the correct answer and correct process, and 5\% had the correct answer but no work shown. Moreover, some misconceptions and errors identified in the literature were also present on this item. See Table 33 for misconceptions and errors of student responses for this item as they relate to the prerequisite content area of numbers and numerical operations. The total percentage for this item is more than $100 \%$ because several items had more than one misconception or error.

Table 32

Summary Table: Item 11, Sixth-Grade

\begin{tabular}{|l|c|}
\hline \multicolumn{1}{|c|}{ Response } & Percent of Responses \\
\hline Correct answer and correct process & $30 \%$ \\
\hline Correct answer but no work shown & $5 \%$ \\
\hline Incorrect answer & $65 \%$ \\
\hline
\end{tabular}


Table 33

Common Errors and Misconceptions: Sixth-Grade Numbers and Numerical Operations,

Item 11

\begin{tabular}{|l|r|l|}
\hline \multicolumn{1}{|c|}{ Error/Misconception } & Percent of Responses & \multicolumn{1}{|c|}{ Corresponding Reference } \\
\hline $\begin{array}{l}\text { Determined which decimal } \\
\text { was greater based on the } \\
\text { number of digits }\end{array}$ & $10 \%$ & $\begin{array}{l}\text { Ashlock, 2006; Desmet et } \\
\text { al., 2010; Steinle and } \\
\text { Stacey, 2004 }\end{array}$ \\
\hline $\begin{array}{l}\text { Computational error with } \\
\text { addition/subtraction of } \\
\text { decimals }\end{array}$ & $20 \%$ & $\begin{array}{l}\text { Ashlock, 2006; Kilpatrick et } \\
\text { al., 2001 }\end{array}$ \\
\hline $\begin{array}{l}\text { Difficulty ordering decimals } \\
\text { (incorrect, but not by } \\
\text { number of digits) }\end{array}$ & $15 \%$ & $\begin{array}{l}\text { Desmet et al., 2010; Steinle } \\
\text { and Stacey, 2004 }\end{array}$ \\
\hline
\end{tabular}


Figure 23

Item 12 - Sixth-Grade

6 Greg conducted a survey of 100 classmates to determine their favorite fruits. The results of the survey are shown in the circle graph below.

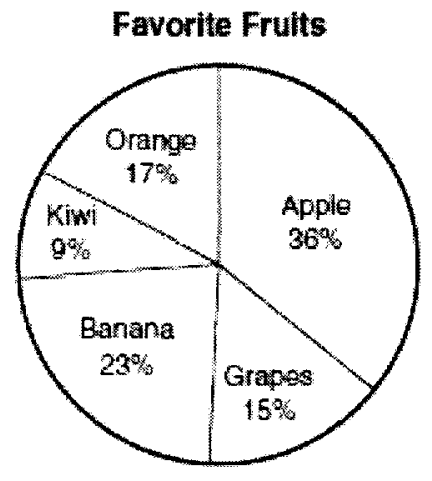

Which two fruits represent $\frac{2}{5}$ of the students' favorites?

Show All Work

Answer and

(Department of Education, 2008)

On this item, students are given a circle graph that included classmates' favorite fruits. The name of the fruit and the percentage of classmates that picked that fruit were typed in each section of the circle graph. Students were asked to find which two sections represented $2 / 5$ of the classmates' favorite fruits. Therefore, students had to understand that $2 / 5$ converts to $40 \%$ and then add to find the two fruits whose percentage totaled $40 \%$. Table 34 provides a summary of response types. Most students obtained the correct 
answer on this item, but some failed to show work that demonstrated how they arrived at the correct answer or did not show any work.

One interesting finding was that some students found the two fruits whose sum was approximately $25 \%$ (grapes and kiwi) or $50 \%$ (apples and grapes) of the total. Perhaps this meant that they believed that $25 \%$ or $50 \%$ was equivalent to $2 / 5$. This was categorized as not understanding the value of a fraction and not understanding the size of a ratio. Other interesting responses included multiplying two percents instead of adding or using non-precise rounding (rounding both $17 \%$ and $15 \%$ up to $20 \%$ and then adding to get $40 \%$ ). Both of these errors were categorized as a student applying a learned procedure. In addition, $30 \%$ of open-responses had the correct answer and correct process, $5 \%$ had the correct answer but no work shown, and 35\% had the correct answer but the work shown did not clearly lead to the correct answer. No trend was found where students selected two adjoining pieces, thinking that pieces had to be adjacent. Moreover, some misconceptions and errors identified in the literature were also present on this item. See Tables 35 and 36 for misconceptions and errors of student responses for this item as they relate to the prerequisite content areas of numbers and numerical operations and ratio and proportions. The total percentage for this item is more than $100 \%$ because several items had more than one misconception or error. 
Table 34

Summary Table: Item 12, Sixth-Grade

\begin{tabular}{|l|c|}
\hline \multicolumn{1}{|c|}{ Response } & Percent of Responses \\
\hline Correct answer and correct process & $30 \%$ \\
\hline Correct answer but no work shown & $5 \%$ \\
\hline $\begin{array}{l}\text { Correct answer but work shown did not } \\
\text { clearly lead to the correct answer }\end{array}$ & $35 \%$ \\
\hline Incorrect answer & $30 \%$ \\
\hline
\end{tabular}

Table 35

Common Errors and Misconceptions: Sixth-Grade Numbers and Numerical Operations,

Item 12

\begin{tabular}{|c|c|c|}
\hline Error/Misconception & Percent of Responses & Corresponding Reference \\
\hline $\begin{array}{l}\text { Not understanding value of } \\
\text { fraction - Belief that } 2 / 5 \\
\text { represents a percentage } \\
\text { other than } 40 \% \text { (either } 50 \% \\
\text { or } 25 \% \text { ). }\end{array}$ & $15 \%$ & $\begin{array}{l}\text { Darley, 2009; Wu, 2001, } \\
2005\end{array}$ \\
\hline
\end{tabular}

Table 36

Common Errors and Misconceptions: Sixth-Grade Ratios and Proportions, Item 12

\begin{tabular}{|l|r|l|}
\hline \multicolumn{1}{|c|}{ Error/Misconception } & Percent of Responses & Corresponding Reference \\
\hline $\begin{array}{l}\text { Student applies learned } \\
\text { procedure instead of } \\
\text { adjusting to the scenario }\end{array}$ & $10 \%$ & De Bock et al., 2002 \\
\hline $\begin{array}{l}\text { Not understanding size of } \\
\text { ratio }\end{array}$ & $15 \%$ & Kilpatrick et al., 2001 \\
\hline
\end{tabular}


Figure 24

Item 13: Sixth-Grade

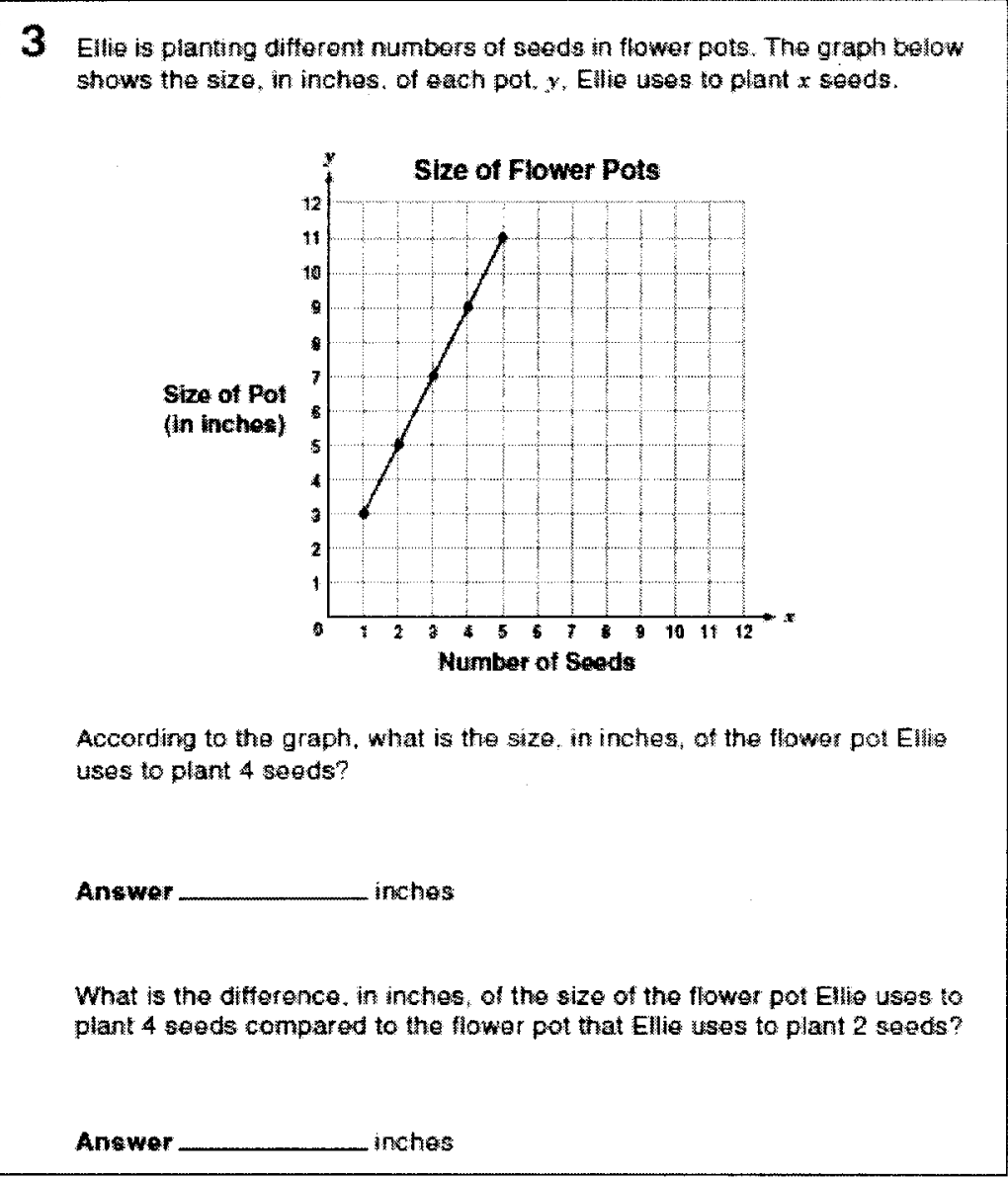

(Department of Education, 2008)

On this item, students were presented with a linear function on a graph. They were asked to interpret the graph to find a value (no calculation needed) and then use the graph to find the difference between the $y$-values of two points. Table 37 provides a summary of response types. Although a few students made computational errors in the simple one-digit subtraction, students' main misunderstanding was in the interpretation of the graph. It appeared as if students could not interpret the graph or could not interpret what the question was asking in order to provide a correct answer. More specifically, 
students made a variety of errors including: multiplying the $x$ - and $y$-coordinate to get the number of inches $(5 \%)$, subtracting the $y$-values in the second part $(5 \%)$, selecting the last point plotted (10\%), multiplying the $y$-values $9 \times 7 \times 5 \times 3(5 \%)$, providing an answer off by one value possibly just looking at the graph wrong (5\%), reversing the $x$ - and $y$ coordinates (5\%), subtracting the $x$-values instead of the $y$-values $(5 \%)$, and answers of 1 , $7,31,32,35$ with unclear reasons $(25 \%)$. Therefore, the total percentage of misconceptions and errors due to misinterpreting the graph was $65 \%$. Other responses included computational errors in finding the difference of whole numbers $(10 \%)$ and correct answer on both parts (25\%). See Tables 38 and 39 for misconceptions and errors of student responses for this item as they relate to the prerequisite content areas of functions and graphing.

Table 37

Summary Table: Item 13, Sixth-Grade

\begin{tabular}{|l|c|}
\hline \multicolumn{1}{|c|}{ Response } & Percent of Responses \\
\hline Correct answer (on both parts) & $25 \%$ \\
\hline Incorrect & $75 \%$ \\
\hline
\end{tabular}

Table 38

Common Errors and Misconceptions: Sixth-Grade Functions, Item 13

\begin{tabular}{|l|r|c|}
\hline \multicolumn{1}{|c|}{ Error/Misconception } & Percent of Responses & Corresponding Reference \\
\hline $\begin{array}{l}\text { Incorrectly interpreting } \\
\text { function }\end{array}$ & $65 \%$ & Kilpatrick et al., 2001 \\
\hline
\end{tabular}


Table 39

Common Errors and Misconceptions: Sixth-Grade Graphing, Item 13

\begin{tabular}{|l|r|c|}
\hline \multicolumn{1}{|c|}{ Error/Misconception } & Percent of Responses & Corresponding Reference \\
\hline $\begin{array}{l}\text { Incorrectly interpreting } \\
\text { graph }\end{array}$ & $65 \%$ & Kilpatrick et al., 2001 \\
\hline
\end{tabular}

Figure 25

Item 14: Sixth-Grade

4 Karen's father ordered outdoor carpeting for a rectangular patio. The carpet he ordered cost $\$ 6.75$ per square yard and measured $8 \frac{1}{4}$ yards wide by $5 \frac{3}{4}$ yards long. ESTIMATE the total cost of the carpet, before tax, to the nearest dollar.

Area of rectangle $=$ length $\times$ width

\section{Show All Work}

\section{Answer $\$$}

How much MORE money will Karen's father need if he has $\$ 250$ ?

Answer \$

(Department of Education, 2007) 
On this item, students are given a problem situation where they must take two mixed numbers representing the dimensions of a rectangular patio in yards and first estimate the area of the rectangular patio and then use that estimate to calculate the total price using a given price per square yard. They are given the formula, area of rectangle = length $\mathrm{x}$ width. Next, students must calculate how much more money they will need if they currently have a given amount of money. Therefore, students must perform three steps to solve this problem. They must estimate the mixed numbers and find their product to obtain the area. Next, they must take the area and multiply it by the price per square yard (decimal). Finally, they must find the difference between the price they obtained as their solution in step two and the amount of money given. Table 40 provides a summary of response types. For this item, the following errors were found: students applied the wrong algorithm when computing fractions (kept common denominator the same when multiplying, but kept as mixed numbers), students selected the wrong operation for the problem (added two sides instead of multiplying), and students incorrectly computed when multiplying decimals. Additionally, $25 \%$ of open-responses were correct with the correct process. Other errors included: adding the whole numbers $(8+4)$ but subtracting fractions $(3 / 4-1 / 4)(5 \%)$, writing 7.00 as the answer for part one and then adding 250 to equal 257 for part two (5\%), writing 300 as an answer for part one with no work shown except a drawing of a rectangle (5\%), writing $6<7<8$ then writing 8.00 for the answer to part one and none for part two $(5 \%)$, and trying to convert one fraction to an improper fraction without success $(5 \%)$. No student attempted to find the perimeter instead of the area. Moreover, some misconceptions and errors identified in the literature were also present on this item. See Table 41 for misconceptions and errors of student responses for 
this item as they relate to the prerequisite content area of numbers and numerical operations.

Table 40

Summary Table: Item 14, Sixth-Grade

\begin{tabular}{|l|c|}
\hline \multicolumn{1}{|c|}{ Response } & Percent of Responses \\
\hline Correct answer and correct process & $25 \%$ \\
\hline Incorrect answer & $75 \%$ \\
\hline
\end{tabular}

Table 41

Common Errors and Misconceptions: Sixth-Grade Numbers and Numerical Operations,

Item 14

\begin{tabular}{|l|r|l|}
\hline \multicolumn{1}{|c|}{ Error/Misconception } & Percent of Responses & Corresponding Reference \\
\hline $\begin{array}{l}\text { Applying the wrong } \\
\text { algorithm when computing } \\
\text { fractions }\end{array}$ & $15 \%$ & Brown and Quinn, 2006 \\
\hline $\begin{array}{l}\text { Selecting the wrong } \\
\text { operation when working } \\
\text { with fractions }\end{array}$ & $20 \%$ & Brown and Quinn, 2006 \\
\hline $\begin{array}{l}\text { Computational error with } \\
\text { multiplication of decimals }\end{array}$ & $15 \%$ & Ashlock, 2006 \\
\hline
\end{tabular}


Figure 26

Item 15: Sixth-Grade

2 Look at the diagram of a cereal box below.

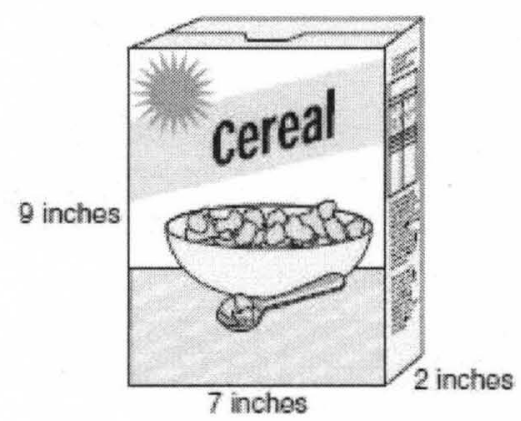

What is the volume, in cubic inches, of the cereal box?

Volume of rectangular prism $=l w h$

$=$ length $\times$ width $\times$ height

Show All Work

Answer cubic inches

(Department of Education, 2007)

On this item, students were given a picture of a box of cereal and the dimensions of the length, width, and height were drawn on the picture. Students were asked to find the volume of this rectangular prism and were given the following formula, volume of rectangular prism $=l w h$ or length $\mathrm{x}$ width $\mathrm{x}$ height. Students generally made two errors they multiplied incorrectly or they added the dimensions instead of multiplying them. Table 42 provides a summary of response types. Overall, 15\% of student responses used 
the wrong operation (adding instead of multiplying), $40 \%$ had computational errors with the multiplication of whole numbers, $25 \%$ had the correct answer and correct process, $10 \%$ had the correct answer but no work shown, $5 \%$ had a transcription error where they copied their answer to the answer line incorrectly, and $5 \%$ only multiplied two instead of all three dimensions.

Table 42

Summary Table: Item 15, Sixth-Grade

\begin{tabular}{|l|c|}
\hline \multicolumn{1}{|c|}{ Response } & Percent of Responses \\
\hline Correct answer and correct process & $25 \%$ \\
\hline Correct answer but no work shown & $10 \%$ \\
\hline Incorrect answer & $65 \%$ \\
\hline
\end{tabular}

Figure 27

Item 16: Sixth-Grade

1 The amount of money Hank earns after working $h$ hours is given by the equation below. Let $m$ equal the amount of money Hank earns.

$$
m=\$ 7 h
$$

How much money would Hank earn after working 35 hours?

Show All Work

Answer \$

(Department of Education, 2007) 
On this item, students were given a one-step two-variable equation and one of the variables to substitute into the equation in order to solve for the other variable. The equation was written with the result first. Solving for the unknown variable did not require students to perform inverse operations. Table 43 provides a summary of response types. Multiplying whole numbers incorrectly, using the wrong operation (adding instead of multiplying), transcription errors, and substituting the wrong value into the equation were the main errors made by students. Overall, $30 \%$ of students had computational errors in their multiplication with whole numbers, $35 \%$ had the correct answer and correct process, $10 \%$ used the wrong operation (they added instead of multiplied), $10 \%$ had transcription errors and copied their correct answer to the answer line incorrectly, and $5 \%$ had an answer of 275 with no work shown. Additionally, $10 \%$ of student responses fit into a misconception identified in the prerequisite content area of algebraic symbolism and letter usage as outlined in Table 44 below. These student responses substituted 7 into the equation instead of 35 .

Table 43

Summary Table: Item 16, Sixth-Grade

\begin{tabular}{|l|c|}
\hline \multicolumn{1}{|c|}{ Response } & Percent of Responses \\
\hline Correct answer and correct process & $35 \%$ \\
\hline Incorrect answer & $65 \%$ \\
\hline
\end{tabular}


Table 44

Common Errors and Misconceptions: Sixth-Grade Algebraic Symbolism and Letter

Usage, Item 16

\begin{tabular}{|l|c|c|}
\hline \multicolumn{1}{|c|}{ Error/Misconception } & Percent of Responses & Corresponding Reference \\
\hline $\begin{array}{l}\text { Substituting the wrong } \\
\text { value into the equation or } \\
\text { expression }\end{array}$ & $10 \%$ & \\
\hline
\end{tabular}

Figure 28

Item 17: Sixth-Grade

7 Conner took 56 seconds to ride his bike a distance of 392 feet.

At what rate, in feet per second. did Conner ride his bike?

Rate $=d \div t$

- distance $\div$ time

Show All Work

Answer ___ leet per second

(Department of Education, 2007)

On this item, students were given the following formula, rate $=$ distance $\div$ time. In a word problem, they were given the time and distance and were asked to find the rate. No units had to be converted. Table 45 provides a summary of response types. On this item, $35 \%$ of open-responses had the correct answer and correct process, $5 \%$ had the correct answer but no work shown, and 5\% added instead of divided. Additionally, $5 \%$ divided correctly then checked their division by multiplying $56 \times 7=392$ and wrote that 
answer on the answer line, $5 \%$ had an answer of 3 with no work shown, and $5 \%$ had an answer of 100 with no work shown. The most common error made, a computational error with the division of whole numbers, was displayed on $40 \%$ of the open-responses. No open-response displayed work where the numbers were substituted incorrectly into the equation.

Table 45

Summary Table: Item 17, Sixth-Grade

\begin{tabular}{|l|c|}
\hline \multicolumn{1}{|c|}{ Response } & Percent of Responses \\
\hline Correct answer and correct process & $35 \%$ \\
\hline Correct answer but no work shown & $5 \%$ \\
\hline Incorrect answer & $60 \%$ \\
\hline
\end{tabular}


Figure 29

Item 18: Sixth-Grade

5 Look at the rectangle below.

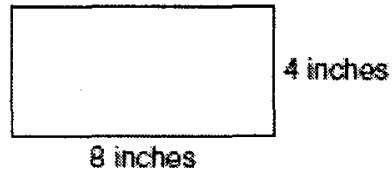

Jeff claims that if he doubles the length and width of the rectangle, the area of the new rectangle will be doubled.

What are the areas, in square inches, of the original rectangle and the new rectangle?

$$
\begin{aligned}
\text { Area of rectangle } & =l w \\
& =\text { length } \times \text { width }
\end{aligned}
$$

\section{Show All Work}

Original rectangle square inches

New rectangle square inches

On the lines below, use the areas of the rectangles to explain how to determine if Jetf's claim is correct.

(Department of Education, 2007)

On this item, students were given a rectangle with dimensions. They were then told that a fictional student believes that if the dimensions are doubled, then the area will be doubled. The student is then asked to find the area of both rectangles (original and doubled dimensions) and explain whether the claim is correct. Table 46 provides a 
summary of response types. Overall, $40 \%$ of student responses had the correct answer and correctly refuted the claim and $15 \%$ had the correct answer but their explanation refuting the claim was incorrect or not complete. On this item, $25 \%$ of:students made the following computational errors: claimed that 128 was 3 multiplied by 32 (instead of 4 ) in explanation (5\%), incorrectly multiplied $16 \times 8(15 \%)$, and incorrectly multiplied $8 \times 4$ (5\%). In addition, $5 \%$ had a transcription error where they copied their correct answer to the answer line incorrectly and another $5 \%$ had $16 \times 8=132$ and $32 \times 2=64$ in their work and wrote 64 as their area for the new rectangle. Other students had misconceptions involving the formula for area of a rectangle including: finding the perimeter for the first rectangle (10\%), finding the perimeter of both rectangles (5\%), writing $4 \times 4=8,8 \times 8=$ 16 , so $8 \times 16=128$ giving answers of 128 for the original and 64 for the new rectangle $(5 \%)$. The total exceeded $100 \%$ because some responses had more than one mistake.

Table 46

Summary Table: Item 18, Sixth-Grade

\begin{tabular}{|l|c|}
\hline \multicolumn{1}{|c|}{ Response } & Percent of Responses \\
\hline Correct answer and correctly refuted claim & $40 \%$ \\
\hline $\begin{array}{l}\text { Correct answer but incomplete or } \\
\text { incorrectly refuted claim }\end{array}$ & $15 \%$ \\
\hline Incorrect answer & $45 \%$ \\
\hline
\end{tabular}


Figure 30

Item 19: Sixth-Grade

1 The grid below contains 100 squares. Shade $\frac{3}{5}$ of the grid.

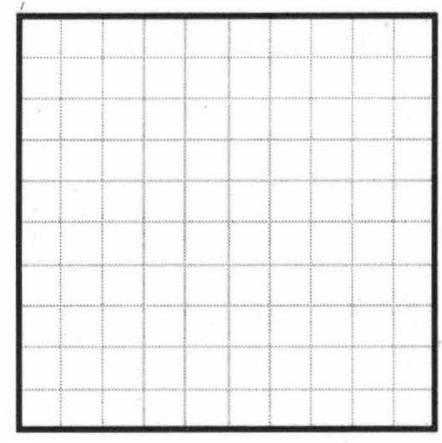

What PERCENT of the grid did you shade?

Answer $\%$

(Department of Education, 2007)

On this item, students were given a hundred square grid and were asked to shade $3 / 5$ of the grid. Then students were asked to state what percent of the grid they shaded. Table 47 provides a summary of response types. Student responses generally fit into one of three categories: correct (35\%), no match between the fraction, grid, and percent (30\%), or the grid and percent matched each other but not the fraction (35\%). A breakdown of portions shaded for the $65 \%$ of open-responses where the shaded amount did not equal the fraction is as follows: 0 hundredths (10\%), 1 hundredth (5\%), 3 hundredths (5\%), 7 hundredths (5\%), 8 hundredths (5\%), 15 hundredths (5\%), 20 hundredths (5\%), 30 hundredths (15\%), 32 hundredths (5\%), 75 hundredths (5\%). See Tables 48 and 49 for connections to the review of literature as this item relates to the 
prerequisite content areas of numbers and numerical operations and ratios and proportions.

Table 47

Summary Table: Item 19, Sixth-Grade

\begin{tabular}{|l|c|}
\hline \multicolumn{1}{|c|}{ Response } & Percent of Responses \\
\hline Correct shading and percent & $35 \%$ \\
\hline Incorrect answer & $65 \%$ \\
\hline
\end{tabular}

Table 48

Common Errors and Misconceptions: Sixth-Grade Numbers and Numerical Operations,

Item 19

\begin{tabular}{|l|r|l|}
\hline \multicolumn{1}{|c|}{ Error/Misconception } & Percent of Responses & Corresponding Reference \\
\hline $\begin{array}{l}\text { Not understanding the value } \\
\text { of a fraction - grid and } \\
\text { percent matched but did not } \\
\text { match fraction }\end{array}$ & $35 \%$ & $\begin{array}{l}\text { Darley, 2009; Wu, 2001, } \\
2005\end{array}$ \\
\hline $\begin{array}{l}\text { Not understanding the value } \\
\text { of a fraction - none of the } \\
\text { representations matched. }\end{array}$ & $30 \%$ & $\begin{array}{l}\text { Darley, 2009; Wu, 2001, } \\
2005\end{array}$ \\
\hline
\end{tabular}

Table 49

Common Errors and Misconceptions: Sixth-Grade Ratios and Proportions, Item 19

\begin{tabular}{|l|r|c|}
\hline \multicolumn{1}{|c|}{ Error/Misconception } & Percent of Responses & Corresponding Reference \\
\hline $\begin{array}{l}\text { Difficulty with the different } \\
\text { ways to write a ratio }\end{array}$ & $65 \%$ & $\begin{array}{l}\text { Hoffer, 1988; Kilpatrick et } \\
\text { al., 2001 }\end{array}$ \\
\hline
\end{tabular}


Figure 31

Item 20: Sixth-Grade

7 On the grid below, plot the ordered pairs $(5,8),(2,2),(3,4),(4,6)$, and $(7,8)$.

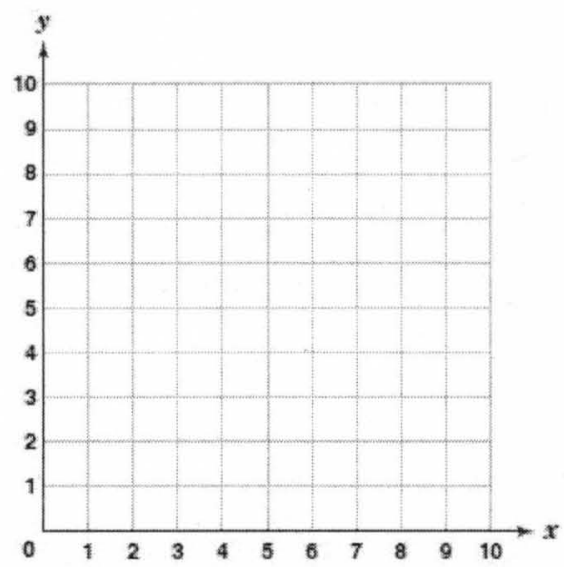

(Department of Education, 2007)

On this item, students were given four ordered pairs to plot on the first quadrant of a coordinate plane. Therefore, all values were positive. Table 50 provides a summary of response types. Some students had difficulty plotting points, often reversing the $x$ coordinate and $y$-coordinate. Several students plotted some of the ordered pairs correctly, but omitted at least one of the ordered pairs (typically the last one). Overall, $35 \%$ of open-responses had all ordered pairs plotted correctly and $10 \%$ omitted one ordered pair but the rest were plotted correctly. In addition, $15 \%$ of students did something other than plotting the ordered pairs including: making bar graphs going up to where the ordered pair would be on the $y$-axis (5\%), making boxes which included some of the ordered pairs $(5 \%)$, and drawing lines in which the top of the line would stop at the $y$-coordinate of the ordered pair (5\%). Additionally, 40\% plotted points incorrectly. Of this $40 \%, 20 \%$ 
reversed the $x$-and $y$-coordinate on at least one of the ordered pairs while the other $20 \%$ plotted at least one point incorrectly (but not by reversing $x$ - and $y$-coordinates). See Table 51 for connections to the review of literature as this item relates to the prerequisite content area of graphing.

Table 50

Summary Table: Item 20, Sixth-Grade

\begin{tabular}{|l|c|}
\hline \multicolumn{1}{|c|}{ Response } & Percent of Responses \\
\hline All ordered pairs correctly plotted & $35 \%$ \\
\hline $\begin{array}{l}\text { At least one ordered pair plotted } \\
\text { incorrectly }\end{array}$ & $65 \%$ \\
\hline
\end{tabular}

Table 51

Common Errors and Misconceptions: Sixth-Grade Graphing, Item 20

\begin{tabular}{|l|r|l|}
\hline \multicolumn{1}{|c|}{ Error/Misconception } & Percent of Responses & Corresponding Reference \\
\hline $\begin{array}{l}\text { Difficulty plotting points - } \\
\text { reversed } x \text { - and } y \text {-coordinate }\end{array}$ & $20 \%$ & $\begin{array}{l}\text { Hadjidemetriou and } \\
\text { Williams, 2001 }\end{array}$ \\
\hline $\begin{array}{l}\text { Difficulty plotting points - } \\
\text { reason other than reversing } \\
x \text { - and } y \text {-coordinate }\end{array}$ & $20 \%$ & \\
\hline
\end{tabular}

\section{Grade Eight}

Twenty-five eighth-grade items were coded and analyzed as they related to the nine prerequisite content areas. First, a figure showing the item is provided. Second, descriptive narrative discussing the process necessary to complete the item and a discussion of the found student misconceptions and errors is provided. Third, a summary table which examines the overall performance of the item from the sample which was received is shown. Fourth, percentage table(s) (where applicable) related to each of the 
nine prerequisite content areas for which identified misconceptions and errors are present are provided.

Figure 32

Item 1: Eighth-Grade

2 The bar graph below shows attendance at a circus over two days.

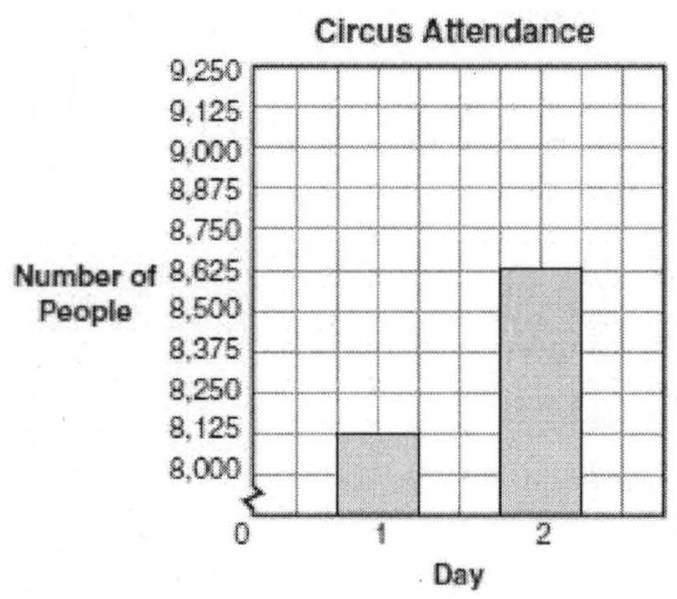

How many MORE people attended the circus on Day 2 than on Day 1 ?

Answer people

On the lines below, explain why it appears that three times as many people attended the circus on Day 2 as on Day 1.

(Department of Education, 2007)

On this item, students were given a double bar graph and asked to find the difference between the $y$-values of the two bars. Then, students were asked to explain 
why it appears that one bar represents three times the number of people than the other bar (because the graph has a break in the scale and is misleading). Table 52 provides a summary of response types. Most students were able to correctly calculate the difference between the heights of the two bars on the graph. However, many students had difficulty fully explaining why it appeared one bar represented three times the amount of the other bar. Overall, $40 \%$ had the correct answer and correct explanation, $50 \%$ had the correct answer and an incorrect or blank explanation, and $10 \%$ had an incorrect answer and an incorrect explanation. For the $50 \%$ who had the correct answer and incorrect or blank explanation there were a variety of explanations including: no explanation (5\%), it (the $y$ axis) increases by small numbers making it looker bigger than big numbers (5\%), the graph is shortened in the corner (5\%), the graph starts at $8,000(15 \%)$, disagrees that it appears that there are three times as many on day two than on day one (5\%), only mentions heights of the bars (5\%), only mentions the increments of $125(5 \%)$, and does not mention the break (5\%). For the $10 \%$ that also had the incorrect answer along with the incorrect explanation the responses incorrectly stated that the $y$-axis increases by increments of 150 (instead of 125) (5\%), and day two was shaded high (5\%). All of these incorrect explanations can be directed back to the fact that the student lacked some understanding or awareness of the discontinuous scale on the $y$-axis. See Table 53 for connections to the prerequisite content area of graphing. 
Table 52

Summary Table: Item 1, Eighth-Grade

\begin{tabular}{|l|c|}
\hline \multicolumn{1}{|c|}{ Response } & Percent of Responses \\
\hline Correct answer and correct explanation & $40 \%$ \\
\hline $\begin{array}{l}\text { Correct answer and an incorrect or blank } \\
\text { explanation }\end{array}$ & $50 \%$ \\
\hline Incorrect answer and incorrect explanation & $10 \%$ \\
\hline
\end{tabular}

Table 53

Common Errors and Misconceptions: Eighth-Grade Graphing, Item 1

\begin{tabular}{|l|r|l|}
\hline \multicolumn{1}{|c|}{ Error/Misconception } & Percent of Responses & Corresponding Reference \\
\hline $\begin{array}{l}\text { Difficulty interpreting } \\
\text { graph- scale. }\end{array}$ & $60 \%$ & $\begin{array}{l}\text { Hadjidemetriou and } \\
\text { Williams, 2001 }\end{array}$ \\
\hline
\end{tabular}


Figure 33

Item 2: Eighth-Grade

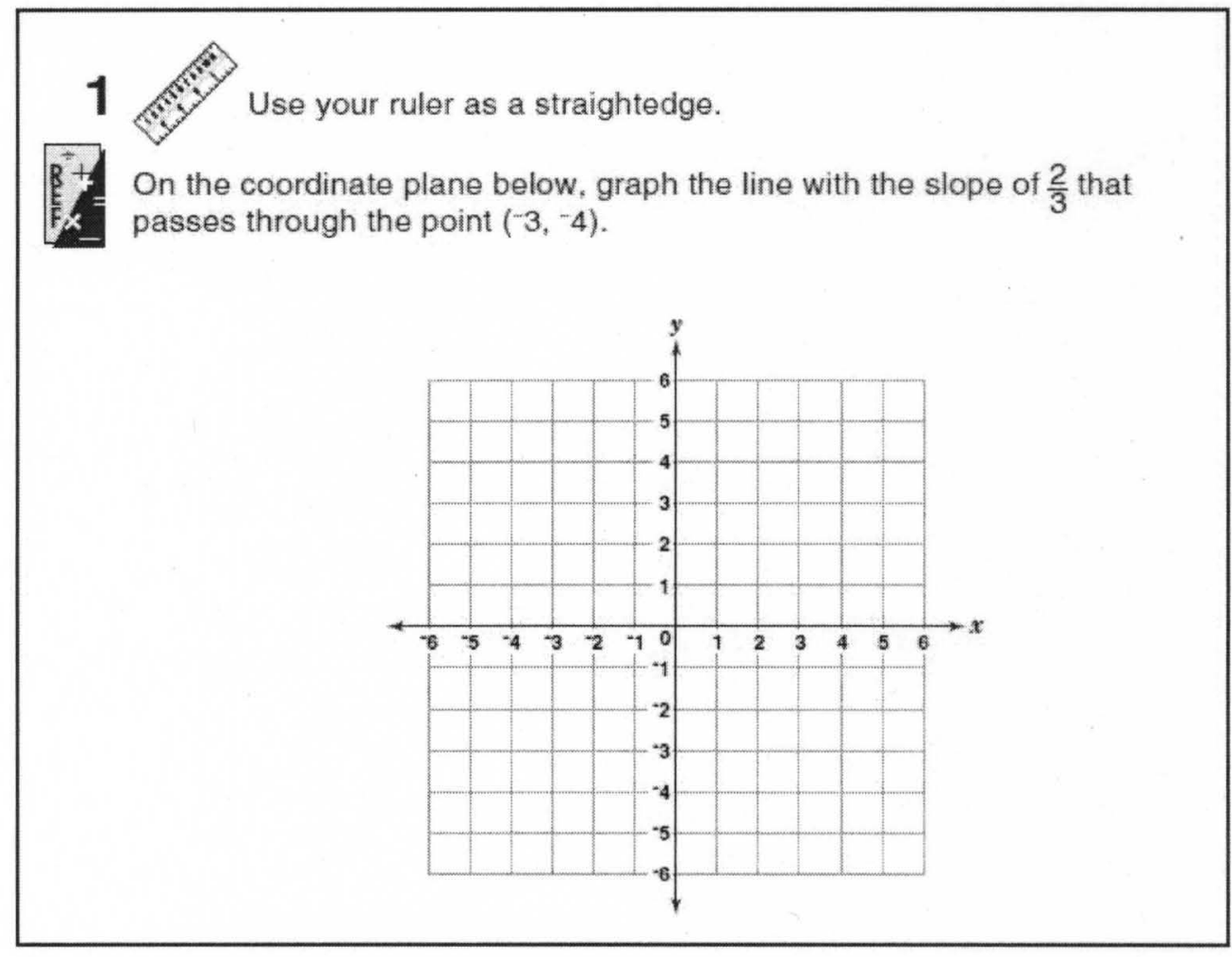

(Department of Education, 2007)

On this item, students were given the slope of a line and an ordered pair including negative integers that passed through the line. Then they were asked to graph the line on a given blank coordinate plane. Table 54 provides a summary of response types. Overall, $25 \%$ of student responses correctly plotted the ordered pair and correctly drew the slope. Another $15 \%$ reversed the $x$ - and $y$-coordinates for the ordered pair but correctly drew the slope from the incorrect ordered pair. A total of $55 \%$ of open-responses incorrectly drew the slope of the line. Of that $55 \%, 10 \%$ drew a vertical line through the point $(-3,-4)$, $10 \%$ drew a slope of $-2 / 3,5 \%$ drew a slope of $-1,10 \%$ did not draw any line, $5 \%$ drew a slope of $7 / 5,5 \%$ drew a slope of $4,5 \%$ drew a slope of $1 / 7$, and $5 \%$ drew a slope of 2 . 
Finally, $5 \%$ plotted the ordered pair incorrectly and drew a curved line with no clear slope. No open-response had a line drawn that did not go through the ordered pair plotted. See Tables 55 and 56 for connections to the review of literature for the prerequisite content areas of functions and graphing.

Table 54

Summary Table: Item 2, Eighth-Grade

\begin{tabular}{|l|c|}
\hline \multicolumn{1}{|c|}{ Response } & Percent of Responses \\
\hline $\begin{array}{l}\text { Correctly plotted ordered pair and correctly } \\
\text { drew the slope }\end{array}$ & $25 \%$ \\
\hline $\begin{array}{l}\text { Correctly drew the slope from an incorrect } \\
\text { point }\end{array}$ & $15 \%$ \\
\hline $\begin{array}{l}\text { Incorrectly plotted the ordered pair and } \\
\text { incorrectly drew the slope }\end{array}$ & $60 \%$ \\
\hline
\end{tabular}

Table 55

Common Errors and Misconceptions: Eighth-Grade Functions, Item 2

\begin{tabular}{|l|r|l|}
\hline \multicolumn{1}{|c|}{ Error/Misconception } & Percent of Responses & Corresponding Reference \\
\hline $\begin{array}{l}\text { Difficulty graphing slope of } \\
\text { line }\end{array}$ & $55 \%$ & $\begin{array}{l}\text { Kalchman and Koedinger, } \\
2005 ; \text { Labato and Ellis, } \\
2010\end{array}$ \\
\hline $\begin{array}{l}\text { Difficulty plotting points - } \\
\text { reversed } x \text {-and } y \text {-coordinate }\end{array}$ & $15 \%$ & $\begin{array}{l}\text { Hadjidemetriou and } \\
\text { Williams, 2001 }\end{array}$ \\
\hline $\begin{array}{l}\text { Difficulty plotting points - } \\
\text { reason other than reversing } \\
x \text {-and } y \text {-coordinate }\end{array}$ & $5 \%$ & \\
\hline
\end{tabular}


Table 56

Common Errors and Misconceptions: Eighth-Grade Graphing, Item 2

\begin{tabular}{|l|r|l|}
\hline \multicolumn{1}{|c|}{ Error/Misconception } & Percent of Responses & \multicolumn{1}{c|}{ Corresponding Reference } \\
\hline $\begin{array}{l}\text { Difficulty graphing slope of } \\
\text { line }\end{array}$ & $55 \%$ & $\begin{array}{l}\text { Kalchman and Koedinger, } \\
2005 \text {; Labato and Ellis, } \\
2010\end{array}$ \\
\hline $\begin{array}{l}\text { Difficulty plotting points - } \\
\text { reversed } x \text { - and } y \text {-coordinate }\end{array}$ & $15 \%$ & $\begin{array}{l}\text { Hadjidemetriou and } \\
\text { Williams, 2001 }\end{array}$ \\
\hline $\begin{array}{l}\text { Difficulty plotting points }- \\
\text { reason other than reversing } \\
x \text { - and } y \text {-coordinate }\end{array}$ & $5 \%$ & \\
\hline
\end{tabular}

Figure 34

Item 3: Eighth-Grade

4 Solve the following equation for $y$

$$
4 y-16=8 x
$$

Equation $y=$

Find the value of $y$ when $x=17$.

Show All Work

Answer $y=$

(Department of Education, 2008)

This item consisted of rewriting an equation given in the form $b y-c=a x$ and asked to create an equivalent equation in the form $y=$, with no specific mention or requirement that the equation must be rewritten in slope-intercept form. The second part 
of this item asked students to substitute a given value in for $x$ and solve for $y$. Table 57 provides a summary of response types. Many open-responses revealed students' difficulties in writing equations in a different, yet equivalent form. While some students were able to substitute a given value for $x$ and obtain the correct answer, they could not symbolically rewrite an equivalent equation correctly in order to solve for $y$. Other students performed the correct process but made computational errors. Overall, $35 \%$ of student responses had both the correct equation and correct answer. Another 5\% of responses had the equation $y=6$ and the answer $y=18-$ with no clear work leading to either response. Other misconceptions and errors overlap by prerequisite content areas (they may be categorized into more than one) and included the following: incorrect use of signs (negative) (5\%), not preserving equivalence when performing inverse operations $(15 \%)$, lack of understanding of algebraic symbolism led to error in equivalence $(5 \%)$, understands the process of solving equations but makes computational error (in division) (10\%), difficulty using inverse operations (15\%), and difficulty moving between equation, table, and graph representations (equation to equation) (40\%). See Tables 58 , 59,60 , and 61 for connections to the review of literature as it relates to numbers and numerical operations, equality, algebraic equations, and functions. Table 57

Summary Table: Item 3, Eighth-Grade

\begin{tabular}{|l|c|}
\hline \multicolumn{1}{|c|}{ Response } & Percent of Responses \\
\hline Correct answer and correct equation & $35 \%$ \\
\hline Incorrect answer and/or equation & $65 \%$ \\
\hline
\end{tabular}


Table 58

Common Errors and Misconceptions: Eighth-Grade Numbers and Numerical

Operations, Item 3

\begin{tabular}{|l|r|c|}
\hline \multicolumn{1}{|c|}{ Error/Misconception } & Percent of Responses & Corresponding Reference \\
\hline Incorrect use of signs & $5 \%$ & Ashlock, 2006 \\
\hline
\end{tabular}

Table 59

Common Errors and Misconceptions: Eighth-Grade Equality, Item 3

\begin{tabular}{|l|r|r|}
\hline \multicolumn{1}{|c|}{ Error/Misconception } & Percent of Responses & Corresponding Reference \\
\hline $\begin{array}{l}\text { Not preserving equivalence } \\
\text { when performing inverse } \\
\text { operations }\end{array}$ & $15 \%$ & Asquith et al., 2007 \\
\hline $\begin{array}{l}\text { Lack of understanding of } \\
\text { algebraic symbolism led to } \\
\text { error in equivalence }\end{array}$ & $5 \%$ & Steinberg et al., 1990 \\
\hline
\end{tabular}

Table 60

Common Errors and Misconceptions: Eighth-Grade Algebraic Equations, Item 3

\begin{tabular}{|l|r|l|}
\hline \multicolumn{1}{|c|}{ Error/Misconception } & Percent of Responses & Corresponding Reference \\
\hline $\begin{array}{l}\text { Understands the process of } \\
\text { solving equations but makes } \\
\text { computational error (but } \\
\text { equation is correct) }\end{array}$ & $10 \%$ & $\mathrm{Wu}, 2001$ \\
\hline $\begin{array}{l}\text { Difficulty using inverse } \\
\text { operations }\end{array}$ & $15 \%$ & $\begin{array}{l}\text { Linchevski and Herscovics, } \\
1996\end{array}$ \\
\hline
\end{tabular}

Table 61

Common Errors and Misconceptions: Eighth-Grade Functions, Item 3

\begin{tabular}{|l|c|l|}
\hline \multicolumn{1}{|c|}{ Error/Misconception } & Percent of Responses & Corresponding Reference \\
\hline $\begin{array}{l}\text { Difficulty moving between } \\
\text { equation, table, and graph } \\
\text { representations (equation to } \\
\text { equation) }\end{array}$ & $40 \%$ & $\begin{array}{l}\text { Kalchman and Koedinger, } \\
2005\end{array}$ \\
\hline
\end{tabular}


Figure 35

Item 4: Eighth-Grade

$$
1 \text { Simplify: } \quad 3(6 x-4)+2(3 x-3)
$$

Show All Work

Answer

(Department of Education, 2008)

This item consisted of a one-variable multi-step expression with two distributive property operations separated by an addition symbol. Students were asked to simplify the expression. Table 62 provides a summary of response types. Most errors students made related to the incorrect use of the negative sign. Some students also made computational errors with positive whole numbers. Overall, $35 \%$ of open-responses had the correct answer and the correct process and 5\% had the correct answer with no work shown. Another 5\% made a computational error when adding like positive $x$ terms, $10 \%$ attempted to perform inverse operations although it was an expression and not an equation, $5 \%$ made a transcription error within the steps of the problem, and $5 \%$ did not simplify completely. Other misconceptions and errors overlapped by prerequisite content areas (they may be categorized into more than one) and include the following: incorrect use of signs (when adding two negatives) (25\%), omitting a negative sign (5\%), difficulty 
combining like terms $(10 \%)$, difficulty with distributive property $(5 \%)$. No

misconceptions or errors were found with regards to the order of operations. See Tables

63 and 64 for connections to the review of literature as it relates to the prerequisite

content areas of numbers and numerical operations and algebraic symbolism and letter

usage.

Table 62

Summary Table: Item 4, Eighth-Grade

\begin{tabular}{|l|c|}
\hline \multicolumn{1}{|c|}{ Response } & Percent of Responses \\
\hline Correct answer and correct process & $35 \%$ \\
\hline Correct answer but no work shown & $5 \%$ \\
\hline Incorrect answer & $60 \%$ \\
\hline
\end{tabular}

Table 63

Common Errors and Misconceptions: Eighth-Grade Numbers and Numerical

Operations, Item 4

\begin{tabular}{|l|r|c|}
\hline \multicolumn{1}{|c|}{ Error/Misconception } & Percent of Responses & Corresponding Reference \\
\hline Incorrect use of signs & $20 \%$ & Ashlock, 2006 \\
\hline Omitting negative signs & $5 \%$ & Ashlock, 2006 \\
\hline
\end{tabular}

Table 64

Common Errors and Misconceptions: Eighth-Grade Algebraic Symbolism and Letter

Usage, Item 4

\begin{tabular}{|l|r|l|}
\hline \multicolumn{1}{|c|}{ Error/Misconception } & Percent of Responses & Corresponding Reference \\
\hline $\begin{array}{l}\text { Difficulty combining like } \\
\text { terms }\end{array}$ & $10 \%$ & $\begin{array}{l}\text { Booth and Watson, 1990; } \\
\text { Booth, 1986; Stacey and } \\
\text { MacGregor, 1997b }\end{array}$ \\
\hline $\begin{array}{l}\text { Difficulty with distributive } \\
\text { property }\end{array}$ & $5 \%$ & $\begin{array}{l}\text { Ding and Li, 2010; Kieran, } \\
1992\end{array}$ \\
\hline
\end{tabular}


Figure 36

Item 5: Eighth-Grade

3 Blanca's aquarium has three types of fish. She has 14 tetras, 7 angelfish, and some mollies. She wants to purchase more mollies to add to her aquarium. If Blanca doubles the number of mollies, she will have a total of 37 fish.

On the line below, write an equation that can be used to determine the number of molies $(m)$ that Blanca had before she purchased more.

\section{Equation}

Now solve the equation you wrote to determine the number of mollies that Blanca had before she purchased more.

Answer mollies

(Department of Education, 2007)

This item consisted of a scenario which could be represented by a one-variable equation. The problem was written in a way that a two-step equation could be efficiently formed from the text of the problem, but any algebraic equation that represented the situation accurately and that was symbolically correct was considered acceptable. After writing an algebraic equation to represent the scenario, students were asked to solve the equation for the unknown variable. Table 65 provides a summary of response types. Most responses that displayed correct algebraic equations also displayed correct answers, which could mean that students at this grade level have more difficulty writing the equation than solving the equation. One other interesting finding was discovered. In the scenario, the language "doubled" was used and could be symbolically represented by multiplying the variable by two in the equation. Some students (with both correct and 
incorrect equations) chose to double the correct answer at the end, resulting in an incorrect answer, or they did not represent the "doubled" in their equation and obtained an incorrect solution of 16 . Overall, $25 \%$ of open-responses had the correct answer and the correct process and 5\% had the correct equation but an incorrect answer of 13 with no work shown (this answer of 13 would not result from incorrect inverse operations so the reason is unclear), and 5\% had a basic computational error when subtracting whole numbers. Additionally, $65 \%$ of open-responses displayed difficulty with writing the equation. Of the $65 \%, 20 \%$ still had the correct answer of $8,30 \%$ gave an answer of 16 (doubled the answer of 8 ), and $15 \%$ had other incorrect answers. Moreover, some of the errors in writing the equation were connected with literature from the prerequisite content area of the order of operations. See Tables 66 and 67 for connections to the review of literature as it relates to the order of operations and algebraic equations. No student had difficulty with inverse operations.

Table 65

Summary Table: Item 5, Eighth-Grade

\begin{tabular}{|l|c|}
\hline \multicolumn{1}{|c|}{ Response } & Percent of Responses \\
\hline Correct answer and correct process & $25 \%$ \\
\hline Correct equation but incorrect answer & $5 \%$ \\
\hline Correct answer but incorrect equation & $20 \%$ \\
\hline Incorrect answer and incorrect equation & $50 \%$ \\
\hline
\end{tabular}


Table 66

Common Errors and Misconceptions: Eighth-Grade The Order of Operations, Item 5

\begin{tabular}{|l|r|l|}
\hline \multicolumn{1}{|c|}{ Error/Misconception } & Percent of Responses & Corresponding Reference \\
\hline $\begin{array}{l}\text { Not using parentheses when } \\
\text { needed }\end{array}$ & $10 \%$ & Booth, 1988 \\
\hline $\begin{array}{l}\text { Belief that commutative and } \\
\text { associative properties are } \\
\text { true for subtraction or } \\
\text { division }\end{array}$ & $10 \%$ & Shifter et al., 2008 \\
\hline
\end{tabular}

Table 67

Common Errors and Misconceptions: Eighth-Grade Algebraic Equations, Item 5

\begin{tabular}{|l|r|l|}
\hline \multicolumn{1}{|c|}{ Error/Misconception } & Percent of Responses & \multicolumn{1}{c|}{ Corresponding Reference } \\
\hline $\begin{array}{l}\text { Difficulty with symbolic } \\
\text { representation of scenario } \\
\text { when writing the equation }\end{array}$ & $65 \%$ & $\begin{array}{l}\text { Booth, 1984; Nathan and } \\
\text { Koedinger, 2000 }\end{array}$ \\
\hline $\begin{array}{l}\text { Understands the process of } \\
\text { solving equations but makes } \\
\text { computational error }\end{array}$ & $5 \%$ & $\mathrm{Wu}, 2001$ \\
\hline
\end{tabular}

Figure 37

Item 6: Eighth-Grade

1 Evaluate the following expression for $y=3$ :

$$
5 y-24 \div y+10
$$

Show All Work

Answer

(Department of Education, 2007) 
This item consisted of a one-variable algebraic expression with subtraction, division, and addition. Students were asked to evaluate the expression for a given value. On this item, students had to substitute a given value into an expression and then use the order of operations to simplify the expression correctly. Table 68 provides a summary of response types. Some students displayed incorrect computation with whole numbers, while others wrote the correct operations in their work but then performed a different operation (such as writing $7+10=70$ ). Overall, $10 \%$ of open-responses had the correct answer and the correct process and $10 \%$ had the correct answer but no work shown. Additionally, $30 \%$ had errors in computation with whole numbers (5\% addition, $15 \%$ subtraction, $10 \%$ division). Transcription errors accounted for $10 \%$ of mistakes with $5 \%$ occurring when working the problem and 5\% wrote their correct answer on the answer line incorrectly. Another 5\% of student responses attempted to use inverse operations although they were working with an expression and not an equation and $15 \%$ had their steps written correctly but then performed the wrong operation $(10 \%$ wrote $7+10=70$ and $5 \%$ wrote $24 \div 3=21$ ). Additional errors and misconceptions which connected to the review of literature can be found in Tables 69 and 70 as they relate to the prerequisite content areas of numbers and numerical operations and the order of operations. The total percentage from above and in the tables below is more than $100 \%$ because some openresponses aligned to more than one misconception or errors. 
Table 68

Summary Table: Item 6, Eighth-Grade

\begin{tabular}{|l|c|}
\hline \multicolumn{1}{|c|}{ Response } & Percent of Responses \\
\hline Correct answer and correct process & $10 \%$ \\
\hline Correct answer but no work shown & $10 \%$ \\
\hline Incorrect answer & $\mathbf{8 0 \%}$ \\
\hline
\end{tabular}

Table 69

Common Errors and Misconceptions: Eighth-Grade Numbers and Numerical

Operations, Item 6

\begin{tabular}{|l|r|c|}
\hline \multicolumn{1}{|c|}{ Error/Misconception } & Percent of Responses & Corresponding Reference \\
\hline Incorrect use of signs & $5 \%$ & Ashlock, 2006 \\
\hline
\end{tabular}

Table 70

Common Errors and Misconceptions: Eighth-Grade The Order of Operations, Item 6

\begin{tabular}{|l|r|l|}
\hline \multicolumn{1}{|c|}{ Error/Misconception } & Percent of Responses & \multicolumn{1}{c|}{ Corresponding Reference } \\
\hline $\begin{array}{l}\text { Performing operations in } \\
\text { order from left to right } \\
\text { instead of using order of } \\
\text { operations }\end{array}$ & $10 \%$ & $\begin{array}{l}\text { Linchevski and Livneh, } \\
1999\end{array}$ \\
\hline $\begin{array}{l}\text { Belief that addition comes } \\
\text { before subtraction or } \\
\text { multiplication before } \\
\text { division }\end{array}$ & $15 \%$ & $\begin{array}{l}\text { Linchevski and Livneh, } \\
1999\end{array}$ \\
\hline
\end{tabular}


Figure 38

Item 7: Eighth-Grade

3 This week, the bakery sold a total of 1,012 muffins.

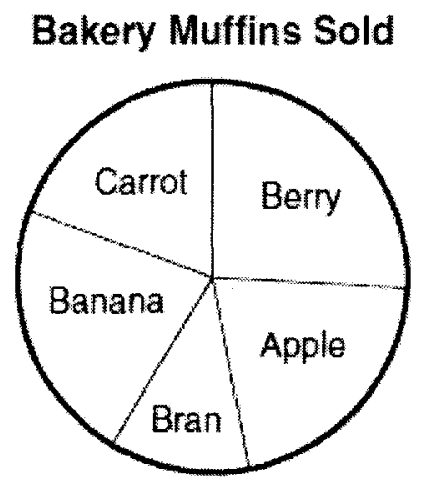

On the lines below, explain how to estimate the total number of berry muffins sold this week. Be sure to include your estimate in your answer.

(Department of Education, 2008)

This item had a pie chart with five different types of muffins sold at a bakery.

Each of the five sections were different sized and were not labeled numerically. A statement told students that there were a total of 1,012 muffins sold. Students were asked to explain how to estimate how many berry muffins were sold (this section was a little more than $1 / 4$ the chart) and to also include their estimate of the total number of berry muffins. The researcher noticed that many students had difficulty explaining how to estimate and arriving at a correct estimation. Table 71 provides a summary of response types. Overall, $40 \%$ had the correct answer and correct explanation and $5 \%$ had the 
correct answer but not a clear explanation. Another $10 \%$ took 1012 × .25 and made an error in multiplying the decimals, $20 \%$ had a correct explanation but then did not state their estimate, and 5\% provided an answer of $\$ 2.50$ instead of 250 with no clear explanation as to why. With regards to the ratios and proportions prerequisite content area, $5 \%$ did not think proportionally and simply tried to find a difference to estimate and $15 \%$ believed each section was equal in size (perhaps confused with fractional pieces). See Tables 72 and 73 for connections to the review of literature as this item relates to the prerequisite content areas of numbers and numerical operations and ratios and proportions.

Table 71

Summary Table: Item 7, Eighth-Grade

\begin{tabular}{|l|c|}
\hline \multicolumn{1}{|c|}{ Response } & Percent of Responses \\
\hline Correct answer and correct explanation & $40 \%$ \\
\hline Correct answer but no clear explanation & $5 \%$ \\
\hline Incorrect answer and incorrect explanation & $55 \%$ \\
\hline
\end{tabular}

Table 72

Common Errors and Misconceptions: Eighth-Grade Numbers and Numerical Operations, Item 7

\begin{tabular}{|c|c|c|}
\hline Error/Misconception & Percent of Responses & Corresponding Reference \\
\hline $\begin{array}{l}\text { Computational error with } \\
\text { multiplication of decimals }\end{array}$ & $10 \%$ & Ashlock, 2006 \\
\hline
\end{tabular}


Table 73

Common Errors and Misconceptions: Eighth-Grade Ratios and Proportions, Item 7

\begin{tabular}{|l|r|l|}
\hline \multicolumn{1}{|c|}{ Error/Misconception } & \multicolumn{1}{|c|}{ Percent of Responses } & \multicolumn{1}{c|}{ Corresponding Reference } \\
\hline Inability to unitize & $5 \%$ & $\begin{array}{l}\text { Behr et al., 1992; Singh, } \\
2000\end{array}$ \\
\hline $\begin{array}{l}\text { Incorrectly viewing portions } \\
\text { as equal sized }\end{array}$ & $15 \%$ & Labato and Ellis, 2010 \\
\hline
\end{tabular}

Figure 39

Item 8: Eighth-Grade

4 Look at the numbers below.

$$
\frac{22}{7} \quad-1.75 \quad \frac{1}{3} \quad-3 \frac{1}{4} \quad \sqrt{16}
$$

Plot each of these numbers on the number line below. Write the number above each point plotted.

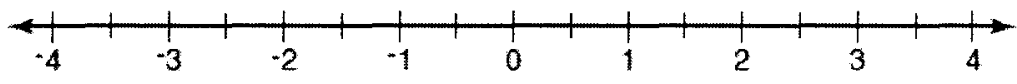

(Department of Education, 2008)

On this item, students were given rational numbers to plot on a number line. The rational numbers included a fraction, improper fraction, negative decimal, negative mixed number, and square root. Table 74 provides a summary of response types. While many responses were correct, some students had specific difficulty plotting the fractional points while other students had trouble with both fractional and decimal points. A few students plotted points at the correct locations on the number line but did not label their points. Overall, $45 \%$ of student-responses had all points plotted and labeled correctly and $15 \%$ 
had all points plotted correctly but they were not labeled. An additional $40 \%$ had fractional points plotted incorrectly with the breakdown as follows: $1 / 3$ plotted incorrectly (25\%), $-3 \frac{1}{4}$ plotted incorrectly (5\%), 22/7 plotted incorrectly (5\%), and all three fractional points plotted incorrectly $(5 \%)$. Of the students who had fractional points plotted incorrectly, $10 \%$ of those also had the decimal point, -1.75 , plotted incorrectly. No errors were found with regards to plotting the square root. Table 75 outlines connections to the review of literature as this item relates to the prerequisite content area of numbers and numerical operations.

Table 74

Summary Table: Item 8, Eighth-Grade

\begin{tabular}{|l|c|}
\hline \multicolumn{1}{|c|}{ Response } & Percent of Responses \\
\hline All points correctly plotted and labeled & $45 \%$ \\
\hline All points correctly plotted but not labeled & $15 \%$ \\
\hline At least one point plotted incorrectly & $40 \%$ \\
\hline
\end{tabular}

Table 75

Common Errors and Misconceptions: Eighth-Grade Numbers and Numerical

Operations, Item 8

\begin{tabular}{|l|r|l|}
\hline \multicolumn{1}{|c|}{ Error/Misconception } & Percent of Responses & Corresponding Reference \\
\hline $\begin{array}{l}\text { Difficulty plotting fractional } \\
\text { points on a number line }\end{array}$ & $40 \%$ & Darley, 2009 \\
\hline $\begin{array}{l}\text { Difficulty plotting decimal } \\
\text { points on a number line }\end{array}$ & $10 \%$ & \\
\hline
\end{tabular}


Figure 40

- Item 9: Eighth-Grade

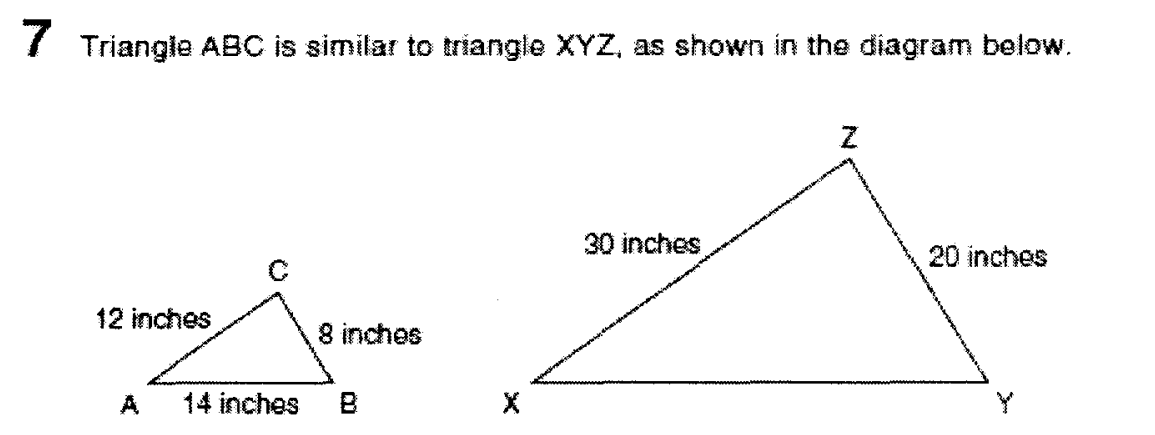

What is the length in inches, of side $\overline{X Y}$ ?

Show All Work

Answer __ inches

(Department of Education, 2007)

On this item, students were given two similar triangles and three side lengths of one triangle and two side lengths of the other. Students were then asked to find the unknown side length. Table 76 provides a summary of response types. Generally, students who did not obtain the correct answer did not approach the problem proportionally or multiplicatively - instead they looked for other patterns (such as additive) or used other incorrect methods to solve for the unknown side length. Overall, $40 \%$ of open-responses had the correct answer and correct process, $5 \%$ had the correct answer and no work shown, and 5\% had the correct answer but the work shown did not clearly lead to that answer. In addition, $10 \%$ placed the decimal point in the incorrect 
place $-5 \%$ when dividing by scale factor of 2.5 and $5 \%$ when multiplying by scale factor of 2.5. Other errors represented students' inability to think proportionally. These $40 \%$ of responses displayed a variety of incorrect methods including: using a combination of division and subtraction (5\%), looking at proportions within a triangle instead of between triangles (5\%), using multiplication but not finding the correct proportion (5\%), using a combination of multiplication and addition (5\%), using subtraction (5\%), using addition $(5 \%)$, using division but did not find the correct proportion (5\%), and thinking the lengths increased by 10 on the bigger triangle $(5 \%)$. Each of these errors was categorized as the inability to unitize. See Tables 77 and 78 for connections to the literature as this item relates to the prerequisite content areas of numbers and numerical operations and ratios and proportions.

Table 76

Summary Table: Item 9, Eighth-Grade

\begin{tabular}{|l|c|}
\hline \multicolumn{1}{|c|}{ Response } & Percent of Responses \\
\hline Correct answer and correct process & $40 \%$ \\
\hline Correct answer but no work shown & $5 \%$ \\
\hline $\begin{array}{l}\text { Correct answer but work shown did not } \\
\text { clearly lead to the correct answer }\end{array}$ & $5 \%$ \\
\hline Incorrect answer & $50 \%$ \\
\hline
\end{tabular}


Table 77

Common Errors and Misconceptions: Eighth-Grade Numbers and Numerical

Operations, Item 9

\begin{tabular}{|l|r|l|}
\hline \multicolumn{1}{|c|}{ Error/Misconception } & Percent of Responses & Corresponding Reference \\
\hline $\begin{array}{l}\text { Placing the decimal in the } \\
\text { incorrect place when } \\
\text { dividing }\end{array}$ & $5 \%$ & Ashlock, 2006 \\
\hline $\begin{array}{l}\text { Placing the decimal in the } \\
\text { incorrect place when } \\
\text { multiplying }\end{array}$ & $5 \%$ & Ashlock, 2006 \\
\hline
\end{tabular}

Table 78

Common Errors and Misconceptions: Eighth-Grade Ratios and Proportions, Item 9

\begin{tabular}{|l|r|l|}
\hline \multicolumn{1}{|c|}{ Error/Misconception } & Percent of Responses & Corresponding Reference \\
\hline Inability to unitize & $40 \%$ & $\begin{array}{l}\text { Behr et al., 1992; Singh, } \\
2000\end{array}$ \\
\hline
\end{tabular}


Figure 41

Item 10: Eighth-Grade

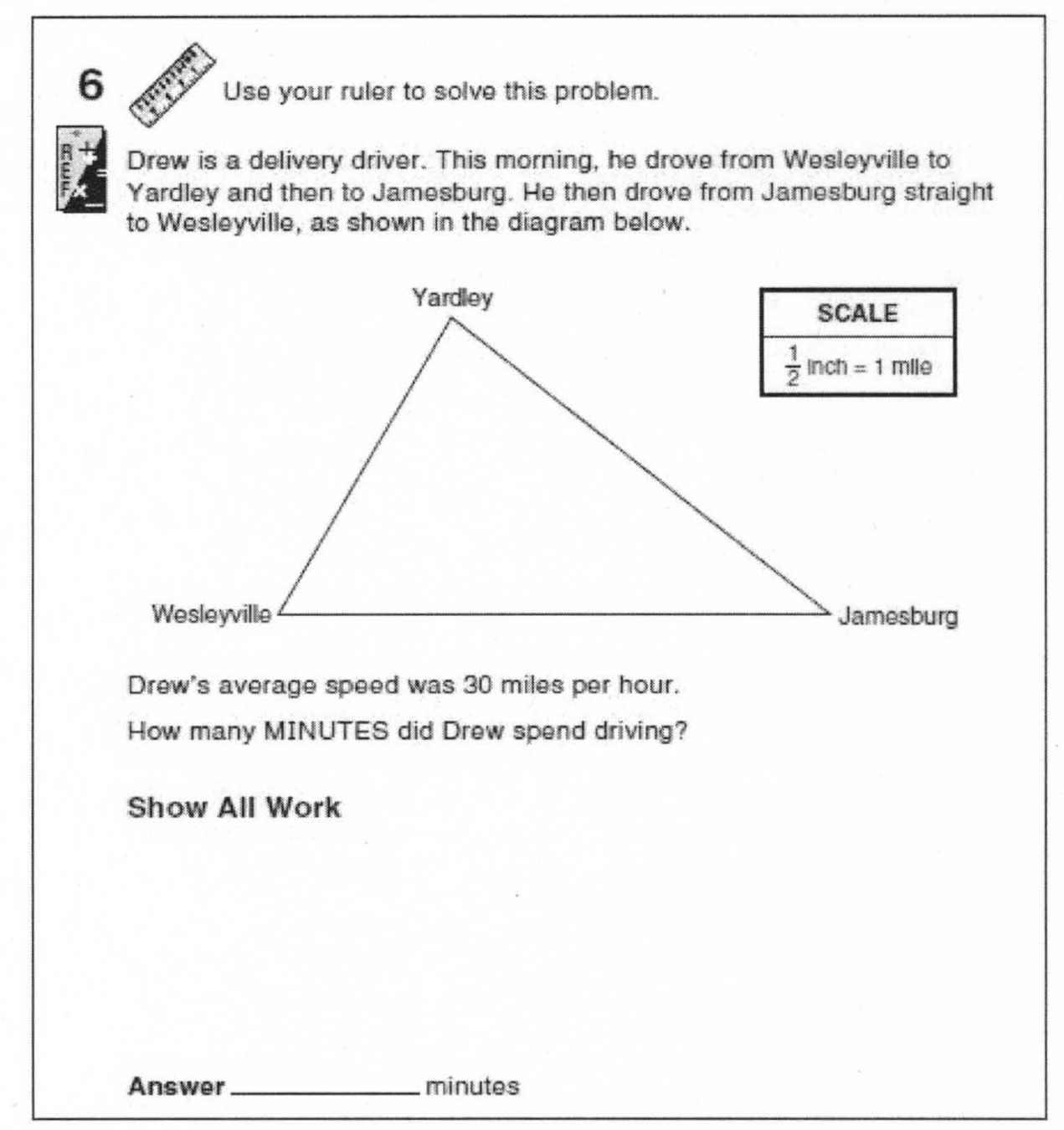

(Department of Education, 2007)

On this item, students were given a triangle with each vertex labeled as a city. A scale was provided (inches to miles) and students were prompted to use a ruler. Students were then asked to calculate the time taken to drive around the triangle (perimeter) to all three cities at a rate of $30 \mathrm{mph}$. In this question students must measure the distances of the three sides in inches, use the scale to convert to miles, and then calculate how many 
minutes are spent driving at a rate of $30 \mathrm{mph}$. Table 79 provides a summary of response types. Overall, $50 \%$ of student responses had the correct answer and correct process, $5 \%$ knew the correct process but made a computational error when doubling $21 / 2$ inches to get 5 miles, and $5 \%$ had an error in their measurement of the three side lengths. The remaining $40 \%$ applied learned procedures and it appeared they did not conceptualize what the question asked. Of this $40 \%, 10 \%$ stopped after finding the number of miles, $10 \%$ added miles and mph, $5 \%$ divided miles and $\mathrm{mph}, 10 \%$ multiplied miles and $\mathrm{mph}$, and $5 \%$ only added the side lengths in inches. See Table 80 for this item's connection to the prerequisite content area of ratios and proportions.

Table 79

Summary Table: Item 10, Eighth-Grade

\begin{tabular}{|l|c|}
\hline \multicolumn{1}{|c|}{ Response } & Percent of Responses \\
\hline Correct answer and correct process & $50 \%$ \\
\hline Incorrect answer & $50 \%$ \\
\hline
\end{tabular}

Table 80

Common Errors and Misconceptions: Eighth-Grade Ratios and Proportions, Item 10

\begin{tabular}{|l|c|c|}
\hline \multicolumn{1}{|c|}{ Error/Misconception } & Percent of Responses & Corresponding Reference \\
\hline $\begin{array}{l}\text { Student applies learned } \\
\text { procedure instead of } \\
\text { adjusting to the scenario }\end{array}$ & $40 \%$ & De Bock et al., 2002 \\
\hline
\end{tabular}


Figure 42

Item 11: Eighth-Grade

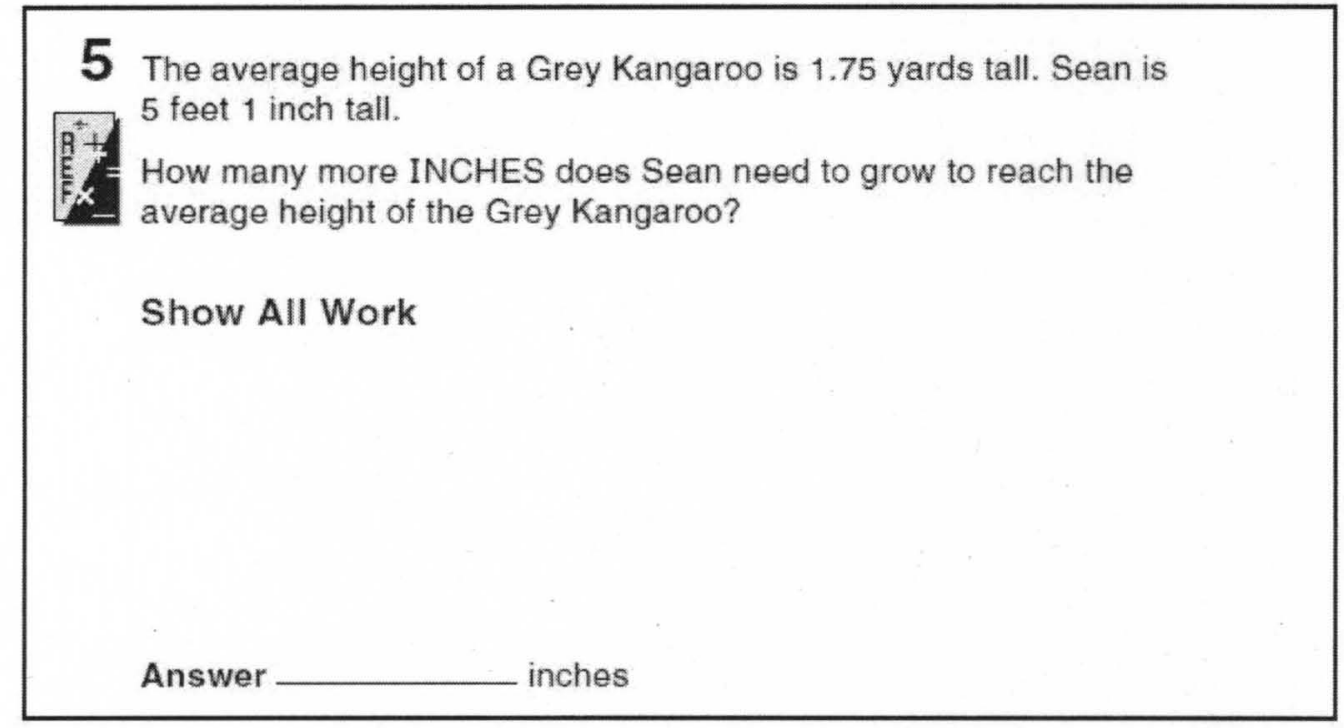

(Department of Education, 2007)

On this item, students were given the height of a kangaroo in yards (decimal).

They were also given the height of a person in feet and inches. Students were then asked to figure out many inches the person must grow in order to reach the height of the kangaroo. Therefore, conversions, computing with decimals, and finding a difference were steps included in solving this problem. Table 81 provides a summary of response types. Several responses demonstrated errors in computing decimals or whole numbers. Surprisingly, one correct response was awarded full credit although their process and work had an incorrect conversion. Overall, $40 \%$ of open-responses had the correct answer and correct process, $5 \%$ had the correct answer but no work shown, $5 \%$ had the correct answer but the work shown did not clearly lead to that answer, and $5 \%$ had a computational error with the subtraction of whole numbers. Another $10 \%$ made a computational error when multiplying decimals and 5\% placed the decimal in the 
incorrect place when dividing. Additionally, $20 \%$ of open-responses displayed difficulty unitizing when converting between inches, feet, and yards. The remaining $10 \%$ included $5 \%$ which thought 5 feet 1 inch was 5.1 inches and 5\% which simply multiplied 1.75 and 5.1. See Tables 82 and 83 for connections to the review of literature for the prerequisite content areas of numbers and numerical operations and ratios and proportions.

Table 81

Summary Table: Item 11, Eighth-Grade

\begin{tabular}{|l|c|}
\hline \multicolumn{1}{|c|}{ Response } & Percent of Responses \\
\hline Correct answer and correct process & $40 \%$ \\
\hline Correct answer but no work shown & $5 \%$ \\
\hline $\begin{array}{l}\text { Correct answer but work shown did not } \\
\text { clearly lead to the correct answer }\end{array}$ & $5 \%$ \\
\hline Incorrect answer & $50 \%$ \\
\hline
\end{tabular}

Table 82

Common Errors and Misconceptions: Eighth-Grade Numbers and Numerical

Operations, Item 11

\begin{tabular}{|l|r|l|}
\hline \multicolumn{1}{|c|}{ Error/Misconception } & Percent of Responses & Corresponding Reference \\
\hline $\begin{array}{l}\text { Placing the decimal in the } \\
\text { incorrect place when } \\
\text { dividing }\end{array}$ & $5 \%$ & Ashlock, 2006 \\
\hline $\begin{array}{l}\text { Computational error with } \\
\text { multiplication of decimals }\end{array}$ & $10 \%$ & Ashlock, 2006 \\
\hline
\end{tabular}


Table 83

Common Errors and Misconceptions - Eighth-Grade Ratios and Proportions, Item 11

\begin{tabular}{|l|r|l|}
\hline \multicolumn{1}{|c|}{ Error/Misconception } & Percent of Responses & \multicolumn{1}{|c|}{ Corresponding Reference } \\
\hline Inability to unitize & $20 \%$ & $\begin{array}{l}\text { Behr et al., 1992; Singh, } \\
2000\end{array}$ \\
\hline
\end{tabular}

Figure 43

Item 12: Eighth-Grade

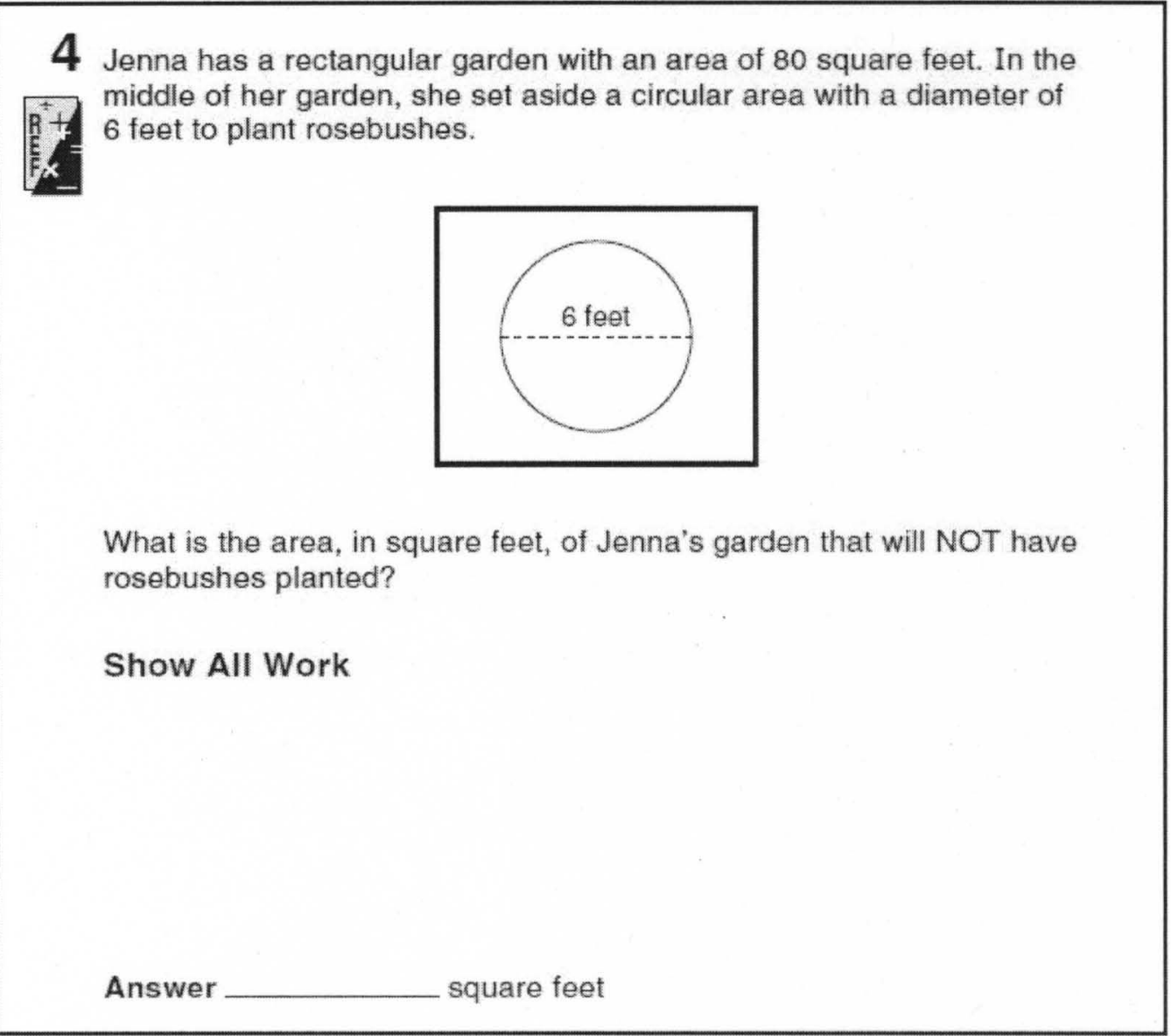

(Department of Education, 2007)

On this item, students were given a diagram of a square with a circle inscribed inside the square. Students were told that the total area of the square is 80 square feet and 
they are given the diameter of the circle as 6 feet. They must find the area of the square, excluding the area of the circle. Therefore, students must find the area of the circle and then subtract it from the total area of the square. They are not given the formula for the area of a circle but can find it on a reference sheet they are allowed to use. Table 84 provides a summary of response types. Overall, $35 \%$ of student responses had the correct answer and correct process, $10 \%$ had the correct answer and no work shown, and 5\% had the correct answer but the work shown did not clearly lead to that answer. An additional $5 \%$ found the sum instead of the difference, $5 \%$ took a difference of 40 (instead of $80-$ the area of the square) and the area of the circle, $5 \%$ made a transcription error when working the steps of the problem, $10 \%$ answered with the area of the circle rather than the difference between the square and circle, $5 \%$ rounded the area of the circle giving an incorrect overall difference, and $5 \%$ took the difference of the area of the square and 6 (diameter of the circle). Finally, 15\% made computational errors with decimals ( $10 \%$ in subtraction and $5 \%$ in multiplication). See Table 85 for literature connections to the prerequisite content area of numbers and numerical operations.

Table 84

Summary Table: Item 12, Eighth-Grade

\begin{tabular}{|l|c|}
\hline \multicolumn{1}{|c|}{ Response } & Percent of Responses \\
\hline Correct answer and correct process & $35 \%$ \\
\hline Correct answer but no work shown & $10 \%$ \\
\hline $\begin{array}{l}\text { Correct answer but work shown did not } \\
\text { clearly lead to the correct answer }\end{array}$ & $5 \%$ \\
\hline Incorrect answer & $50 \%$ \\
\hline
\end{tabular}


Table 85

Common Errors and Misconceptions: Eighth-Grade Numbers and Numerical

Operations, Item 12

\begin{tabular}{|l|r|l|}
\hline \multicolumn{1}{|c|}{ Error/Misconception } & Percent of Responses & Corresponding Reference \\
\hline $\begin{array}{l}\text { Computational error with } \\
\text { addition/subtraction of } \\
\text { decimals }\end{array}$ & $10 \%$ & $\begin{array}{l}\text { Ashlock, 2006; Kilpatrick et } \\
\text { al., 2001 }\end{array}$ \\
\hline $\begin{array}{l}\text { Computational error with } \\
\text { multiplication of decimals }\end{array}$ & $5 \%$ & Ashlock, 2006 \\
\hline
\end{tabular}

Figure 44

Item 13: Eighth-Grade

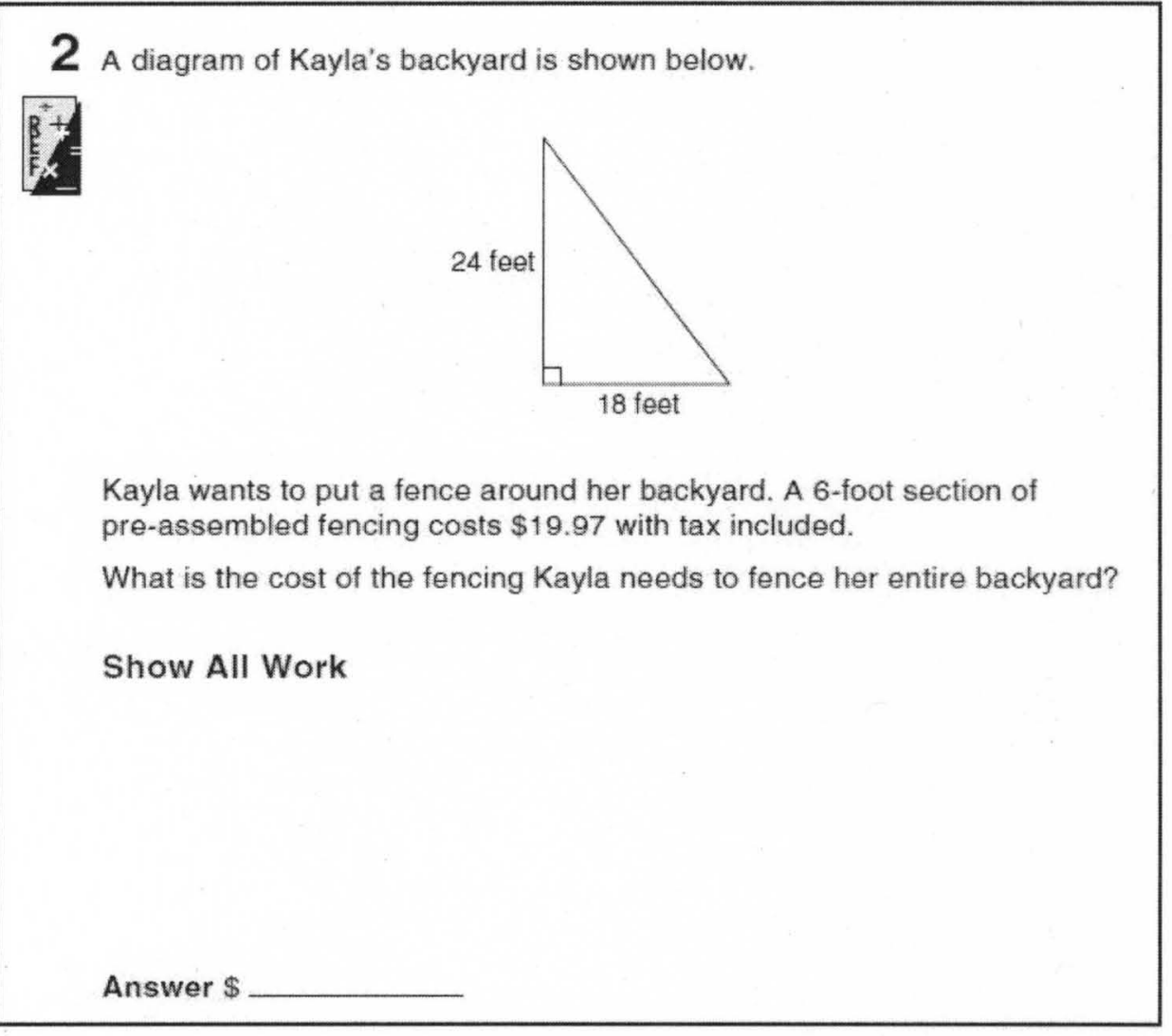

(Department of Education, 2007) 
On this item, students were given a right triangle and the lengths of the two legs were written on the diagram. They must find the hypotenuse and then use the three lengths to calculate how much it would cost to fence the entire perimeter of the triangle. However, students were only given the cost of a 6 - $\mathrm{ft}$ section of fencing and must be able to unitize how many six foot sections are needed on each side. Table 86 provides a summary of response types. While several responses displayed computational errors with multiplying decimals or whole numbers, most students had the correct answer. Overall, $45 \%$ of student responses had the correct answer and correct process, $20 \%$ had the correct answer but work shown did not clearly lead to the correct answer, $10 \%$ had a computational error with whole numbers (adding 6 - $\mathrm{ft}$ sections), and 10\% had a computational error when multiplying decimals. Another $5 \%$ had difficulty symbolically representing the scenario - they did not attempt to use the Pythagorean Theorem. A final $10 \%$ had the correct answer but wrong process - they did not follow the right steps; by chance multiplying the two legs gave the same total as adding all three sides. This does not work for all right triangles, so this process is not mathematically correct - but surprisingly these two students received full credit. It should be noted that no student response displayed work which represented the thinking that the two legs of the triangle were sides of the house. See Tables 87 and 88 for literature connections to the prerequisite content areas of numbers and numerical operations and algebraic equations. 
Table 86

Summary Table: Item 13, Eighth-Grade

\begin{tabular}{|l|c|}
\hline \multicolumn{1}{|c|}{ Response } & Percent of Responses \\
\hline Correct answer and correct process & $45 \%$ \\
\hline $\begin{array}{l}\text { Correct answer but work shown did not } \\
\text { clearly lead to the correct answer }\end{array}$ & $20 \%$ \\
\hline Incorrect answer & $35 \%$ \\
\hline
\end{tabular}

Table 87

Common Errors and Misconceptions: Eighth-Grade Numbers and Numerical

Operations, Item 13

\begin{tabular}{|c|c|c|}
\hline \multicolumn{1}{|c|}{ Error/Misconception } & Percent of Responses & Corresponding Reference \\
\hline $\begin{array}{l}\text { Computational error with } \\
\text { multiplication of decimals }\end{array}$ & $10 \%$ & Ashlock, 2006 \\
\hline
\end{tabular}

Table 88

Common Errors and Misconceptions: Eighth-Grade Algebraic Equations, Item 13

\begin{tabular}{|l|r|l|}
\hline \multicolumn{1}{|c|}{ Error/Misconception } & Percent of Responses & \multicolumn{1}{|c|}{ Corresponding Reference } \\
\hline $\begin{array}{l}\text { Difficulty with the symbolic } \\
\text { representation of scenario }\end{array}$ & $5 \%$ & $\begin{array}{l}\text { Booth, 1984; Nathan and } \\
\text { Koedinger, 2000 }\end{array}$ \\
\hline $\begin{array}{l}\text { Understands the process of } \\
\text { solving equations but makes } \\
\text { computational error }\end{array}$ & $20 \%$ & $\mathrm{Wu}, 2001$ \\
\hline
\end{tabular}


Figure 45

Item 14: Eighth-Grade

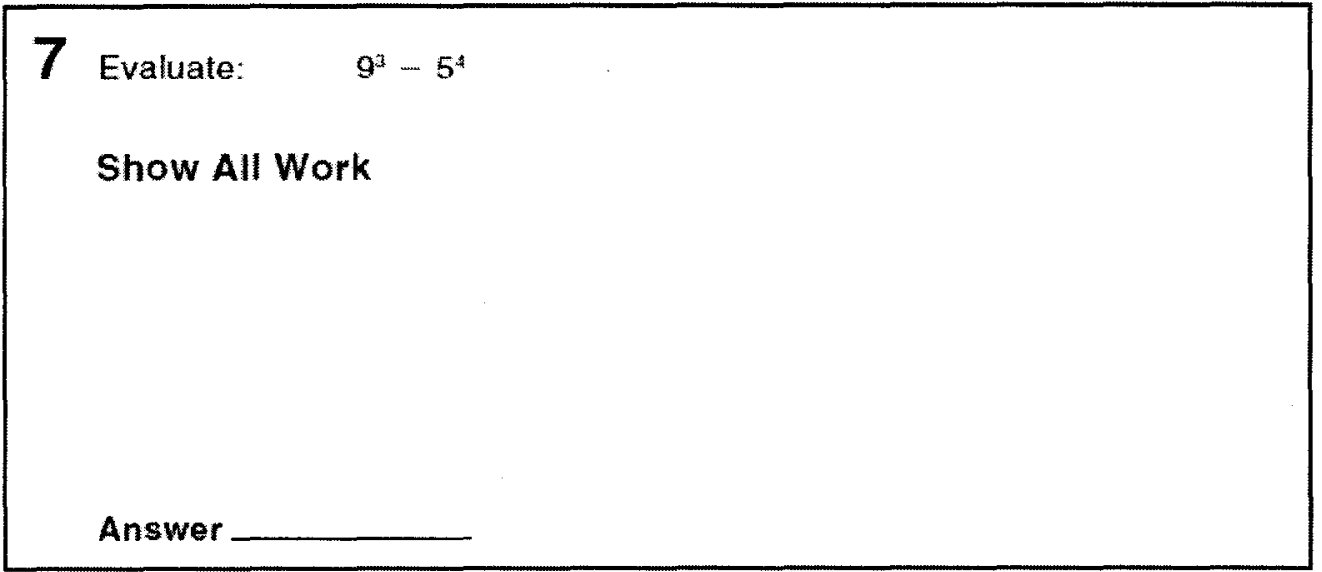

(Department of Education, 2007)

On this item, students were given an expression to evaluate. The expression included exponents and subtraction. Students must use the order of operations to simplify correctly. Table 89 provides a summary of response types. Several students were able to obtain the correct answer, with one response not showing work. Other students either had difficulty computing with whole numbers (but their steps and process were correct) or they incorrectly simplified the exponents (e.g. adding instead of multiplying or other mistakes). Overall, $5 \%$ of student responses had the correct answer and correct process, $5 \%$ had the correct answer and no work shown, and 15\% had transcription errors and copied over their correct answer to the answer line incorrectly. Moreover, $45 \%$ of student responses performed the correct operations but made a computational error. Of this $45 \%$, $20 \%$ made a computational error when multiplying $5 \times 5 \times 5 \times 5,10 \%$ when multiplying $9 \times 9 \times 9,10 \%$ when multiplying both $5 \times 5 \times 5 \times 5$ and $9 \times 9 \times 9$, and $5 \%$ when finding the difference of the two powers. Again, students understood the process for simplifying 
exponents but made a computational error in their multiplication. Conversely, $25 \%$ of open-responses did display a misunderstanding with the definition of an exponent. Of this $25 \%, 5 \%$ took $9 \times 3$ and $5 \times 4,5 \%$ wrote $9 \times 9 \times 9$ and $5 \times 5 \times 5 \times 5$ but then added instead of multiplied, $5 \%$ added $9+9+9$ and $5+5+5+5,5 \%$ took $9+9 \times 9$, and $5 \%$ multiplied $5 \times 5 \times 5 \times 5 \times 5$ (multiplied by a five one extra time). A final misunderstanding found in this item was that in $10 \%$ of open-responses, students took 625-729 (instead of 729-625), which displayed a misbelief that the commutative property is true for subtraction. The total percentage for this item is more than $100 \%$ because some responses displayed more than one misconception or error. See Tables 90 and 91 for connections to the review of literature as they relate to the prerequisite content areas of numbers and numerical operations and the order of operations.

Table 89

Summary Table: Item 14, Eighth-Grade

\begin{tabular}{|l|c|}
\hline \multicolumn{1}{|c|}{ Response } & Percent of Responses \\
\hline Correct answer and correct process & $5 \%$ \\
\hline Correct answer but no work shown & $5 \%$ \\
\hline Incorrect answer & $90 \%$ \\
\hline
\end{tabular}

Table 90

Common Errors and Misconceptions: Eighth-Grade Numbers and Numerical Operations, Item 14

\begin{tabular}{|l|r|r|}
\hline \multicolumn{1}{|c|}{ Error/Misconception } & Percent of Responses & Corresponding Reference \\
\hline $\begin{array}{l}\text { Misunderstanding of the } \\
\text { process for simplifying an } \\
\text { exponent }\end{array}$ & $25 \%$ & \\
\hline
\end{tabular}


Table 91

Common Errors and Misconceptions: Eighth-Grade The Order of Operations, Item 14

\begin{tabular}{|l|c|c|}
\hline \multicolumn{1}{|c|}{ Error/Misconception } & Percent of Responses & Corresponding Reference \\
\hline $\begin{array}{l}\text { Belief that commutative and } \\
\text { associative properties are } \\
\text { true for subtraction or } \\
\text { division }\end{array}$ & & Shifter et al., 2008 \\
\hline
\end{tabular}

Figure 46

Item 15: Eighth-Grade

5 Last Saturday, Rachel shelled walnuts. She was paid $\$ 5.00$ for the day, plus an additional $\$ 0.10$ for each cup of walnuts she shelled.

If Rachel earned a total of $\$ 17.00$, how many QUARTS of walnuts did Rachel shell?

Show All Work

Answer quarts

(Department of Education, 2007)

On this item, students were given a problem scenario which could be represented by a two-step equation. However, students were not asked to write the equation. They were asked to calculate the number of cups and then convert this amount to quarts for their final answer. Decimal computation was used. Table 92 provides a summary of response types. On this item, $25 \%$ of open-responses had the correct answer and correct process, $5 \%$ had the correct answer but no work shown, $15 \%$ had the correct answer but 
work shown did not clearly lead to that answer, and 5\% made a transcription error by copying their correct answer to the answer line incorrectly. Also, $15 \%$ did not complete the last step of converting 120 cups to 30 quarts, $5 \%$ took $17-5=12$ then $12 \div 5$, and $5 \%$ took $17 \div 5$. As far as computational errors, $5 \%$ made a whole number computational error when dividing $120 \div 4,5 \%$ placed the decimal in the wrong place when dividing $120 \div 4$ (they said 300 ), and $5 \%$ placed the decimal in the wrong place when multiplying $12 \times 0.10$. Finally, $15 \%$ of open-responses displayed the inability to unitize correctly when converting between cups and quarts. See Tables 93, 94, and 95 for alignment to the prerequisite content areas of numbers and numerical operations, ratios and proportions, and algebraic equations.

Table 92

Summary Table: Item 15, Eighth-Grade

\begin{tabular}{|l|c|}
\hline \multicolumn{1}{|c|}{ Response } & Percent of Responses \\
\hline Correct answer and process & $25 \%$ \\
\hline Correct answer but no work shown & $5 \%$ \\
\hline $\begin{array}{l}\text { Correct answer but work shown did not } \\
\text { clearly lead to the correct answer }\end{array}$ & $55 \%$ \\
\hline Incorrect answer & $55 \%$ \\
\hline
\end{tabular}


Table 93

Common Errors and Misconceptions: Eighth-Grade Numbers and Numerical

Operations, Item 15

\begin{tabular}{|l|r|l|}
\hline \multicolumn{1}{|c|}{ Error/Misconception } & Percent of Responses & Corresponding Reference \\
\hline $\begin{array}{l}\text { Placing the decimal in the } \\
\text { incorrect place when } \\
\text { multiplying }\end{array}$ & $5 \%$ & Ashlock, 2006 \\
\hline $\begin{array}{l}\text { Placing the decimal in the } \\
\text { incorrect place when } \\
\text { dividing }\end{array}$ & $5 \%$ & Ashlock, 2006 \\
\hline
\end{tabular}

Table 94

Common Errors and Misconceptions: Eighth-Grade Ratios and Proportions, Item 15

\begin{tabular}{|l|r|l|}
\hline \multicolumn{1}{|c|}{ Error/Misconception } & Percent of Responses & Corresponding Reference \\
\hline Inability to unitize & $15 \%$ & $\begin{array}{l}\text { Behr et al., 1992; Singh, } \\
2000\end{array}$ \\
\hline
\end{tabular}

Table 95

Common Errors and Misconceptions: Eighth-Grade Algebraic Equations, Item 15

\begin{tabular}{|l|r|c|}
\hline \multicolumn{1}{|c|}{ Error/Misconception } & Percent of Responses & Corresponding Reference \\
\hline $\begin{array}{l}\text { Understands the process of } \\
\text { solving equations but makes } \\
\text { computational error }\end{array}$ & $15 \%$ & $\mathrm{Wu}, 2001$ \\
\hline
\end{tabular}


Figure 47

\section{Item 16: Eighth-Grade}

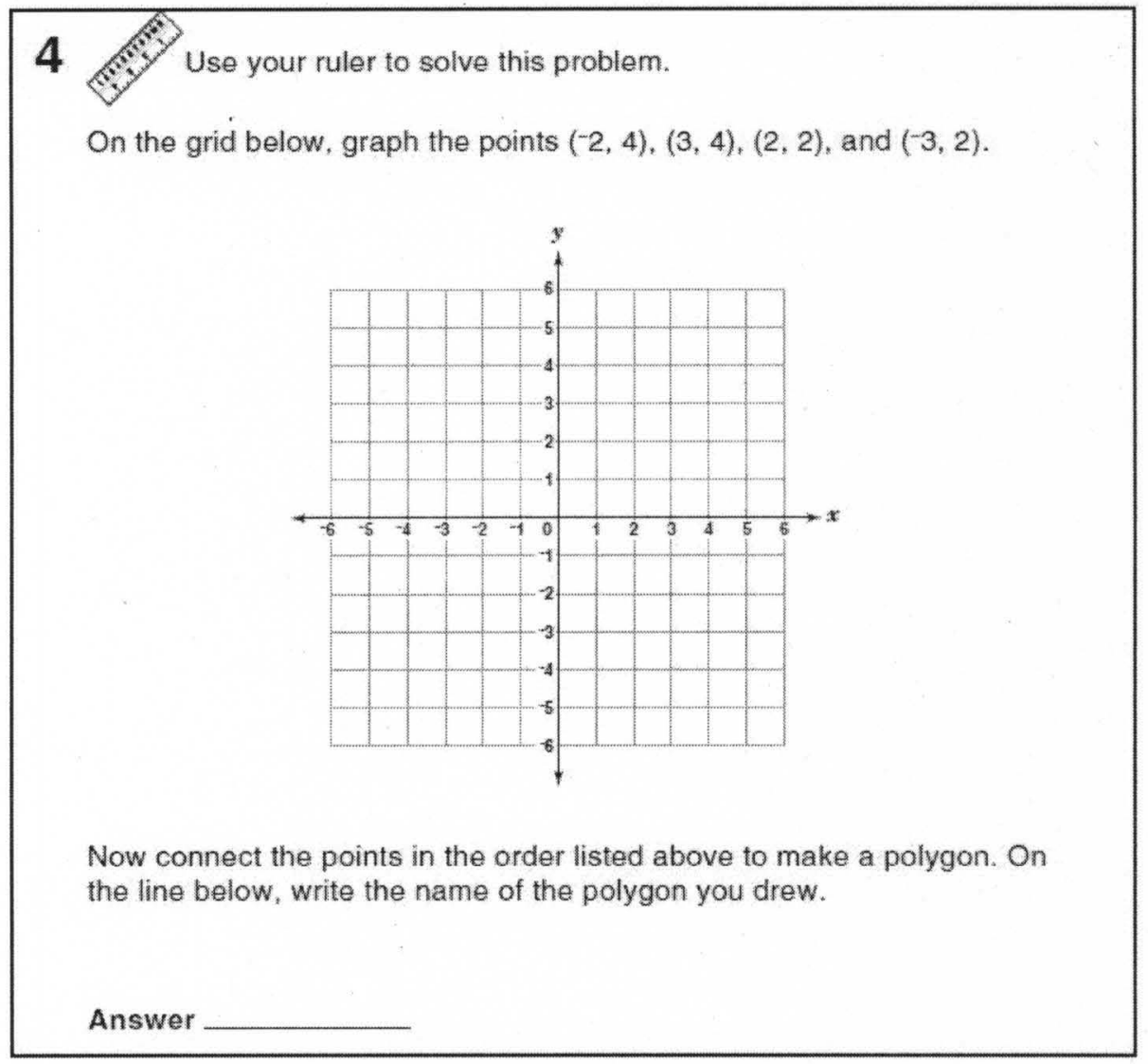

(Department of Education, 2007)

On this item, students were asked to graph four ordered pairs on a coordinate plane. Table 96 provides a summary of response types. While many students correctly plotted the ordered pairs, some students reversed the $x$-coordinate and $y$-coordinate or had other difficulties. Overall, $65 \%$ had all of the ordered pairs plotted and connected correctly. The remaining $35 \%$ had difficulty in plotting points with $25 \%$ reversing the $x$ and $y$-coordinates on some of the ordered pairs, $5 \%$ plotted the ordered pairs $(-2,0),(3$, $0)$, and $(0,4)$, and $5 \%$ plotted the ordered pairs $(2,-1),(4,2),(2,4),(-2,4),(-3,2)$, and ($2,-1)$. It should also be noted that while naming the shape in part two was not related to 
prerequisite algebra skills, $55 \%$ correctly named the polygon either as a quadrilateral or parallelogram while the remaining $45 \%$ named the shape in the following way: rhombus $(5 \%)$, "obtos" $(5 \%)$, triangle $(5 \%)$, trapezoid $(5 \%)$, hexagon $(5 \%)$, rectangle $(5 \%)$, cube (5\%), polygon (5\%), and drew the shape (5\%). See Table 97 for connections to the review of literature for the prerequisite content area of graphing.

Table 96

Summary Table: Item 16

\begin{tabular}{|l|c|}
\hline \multicolumn{1}{|c|}{ Response } & Percent of Responses \\
\hline $\begin{array}{l}\text { All ordered pairs plotted and connected } \\
\text { correctly }\end{array}$ & $65 \%$ \\
\hline Incorrectly plotted at least one ordered pair & $35 \%$ \\
\hline
\end{tabular}

Table 97

Common Errors and Misconceptions: Eighth-Grade Graphing, Item 16

\begin{tabular}{|l|r|l|}
\hline \multicolumn{1}{|c|}{ Error/Misconception } & Percent of Responses & Corresponding Reference \\
\hline $\begin{array}{l}\text { Difficulty plotting points - } \\
\text { reversed the } x \text { - and } y \text { - } \\
\text { coordinates }\end{array}$ & $25 \%$ & $\begin{array}{l}\text { Hadjidemetriou and } \\
\text { Williams, 2001 }\end{array}$ \\
\hline $\begin{array}{l}\text { Difficulty plotting points - } \\
\text { reason other than reversing } \\
\text { the } x \text { - and } y \text {-coordinates }\end{array}$ & $10 \%$ & \\
\hline
\end{tabular}


Figure 48

Item 17: Eighth-Grade

\section{A model boat has a length of 13 inches. One inch on the model boat represents 15 inches on the actual boat.}

What is the length, in inches, of the actual boat?

Show All Work

Answer

(Department of Education, 2008)

On this item, students were given the length of a model boat in inches and were given a scale to the actual boat measurement. They were asked to calculate the length of the actual boat in inches. Basically, students had to multiply the model boat's length by the scale value unit. Table 98 provides a summary of response types. Many students obtained the correct length for the actual boat, although some did not show their work. On this item a total of $40 \%$ had the correct answer and correct process, $15 \%$ had the correct answer but no work shown, $15 \%$ made a computational error with the multiplication of whole numbers ( $15 \times 13)$, and $5 \%$ made a computational error when trying to add 15 thirteen times. Another $15 \%$ displayed the inability to think proportionally and unitize when converting between the model boat and actual boat scale (they used additive thinking). Finally, 5\% incorrectly multiplied $15 \times 15$, and $5 \%$ had no work shown and wrote 15 as their answer. See Table 99 for this item's connections to the review of literature for the prerequisite content area of ratios and proportions. 
Table 98

Summary Table: Item 17

\begin{tabular}{|l|c|}
\hline \multicolumn{1}{|c|}{ Response } & Percent of Responses \\
\hline Correct answer and correct process & $40 \%$ \\
\hline Correct answer but no work shown & $15 \%$ \\
\hline Incorrect answer & $45 \%$ \\
\hline
\end{tabular}

Table 99

Common Errors and Misconceptions: Eighth-Grade Ratios and Proportions, Item 17

\begin{tabular}{|l|r|l|}
\hline \multicolumn{1}{|c|}{ Error/Misconception } & Percent of Responses & Corresponding Reference \\
\hline Inability to unitize & $15 \%$ & $\begin{array}{l}\text { Behr et al., 1992; Singh, } \\
2000\end{array}$ \\
\hline
\end{tabular}


Figure 49

Item 18: Eighth-Grade

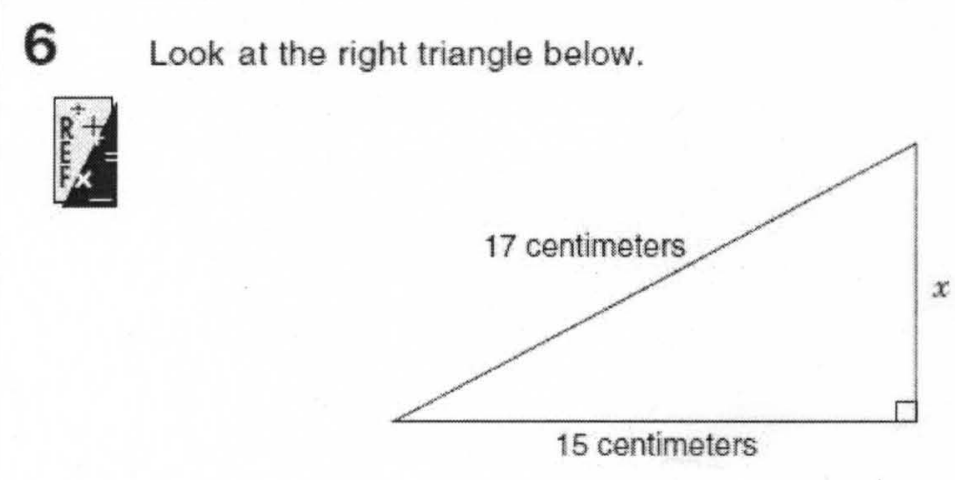

What is the length, in centimeters, of side $x$ of the triangle?

\section{Show All Work}

Answer centimeters

(Department of Education, 2008)

On this item, students were given a right triangle and asked to find the unknown length of one of the legs. Students were not prompted to use Pythagorean Theorem but the formula was provided on their reference sheet which they were allowed to use. Table 100 provides a summary of response types. Students who did not correctly answer this question had trouble setting up the equation (sometimes by substituting the known hypotenuse in for a leg), did not take the square root at the end, or used the wrong operation when using the Pythagorean Theorem. Overall, 25\% had the correct answer and correct process, $10 \%$ had the correct answer but no work shown, and $15 \%$ had the correct 
answer but the work shown did not clearly lead to the correct answer. Additionally, $15 \%$ had difficulty symbolically representing the scenario because they substituted the 17 centimeters in for $b$ instead of $c$ when using the Pythagorean Theorem. Also, 10\% correctly substituted into the Pythagorean Theorem but made an error when performing inverse operations and $10 \%$ had the correct process except they did not take the square root of 64 on the last step. Finally, several other errors were displayed including $5 \%$ which had some correct steps but then wrote 2 as their answer (no clear reason as to why), $5 \%$ subtracted 90 (maybe because it is a right triangle) $-15-57$, and $5 \%$ substituted correctly into the Pythagorean Theorem but then did not solve it or write an answer on the answer line. No student responses displayed evidence of using a formula other than the Pythagorean Theorem. See Table 101 for connections to the prerequisite content area of algebraic equations.

Table 100

Summary Table: Item 18

\begin{tabular}{|l|c|}
\hline \multicolumn{1}{|c|}{ Response } & Percent of Responses \\
\hline Correct answer and correct process & $25 \%$ \\
\hline Correct answer but no work shown & $10 \%$ \\
\hline $\begin{array}{l}\text { Correct answer but work shown did not } \\
\text { clearly lead to the correct answer }\end{array}$ & $15 \%$ \\
\hline Incorrect answer & $50 \%$ \\
\hline
\end{tabular}


Table 101

Common Errors and Misconceptions: Eighth-Grade Algebraic Equations, Item 18

\begin{tabular}{|l|r|l|}
\hline \multicolumn{1}{|c|}{ Error/Misconception } & Percent of Responses & \multicolumn{1}{c|}{ Corresponding Reference } \\
\hline $\begin{array}{l}\text { Difficulty with the symbolic } \\
\text { representation of a scenario }\end{array}$ & $15 \%$ & $\begin{array}{l}\text { Booth, 1984; Nathan and } \\
\text { Koedinger, 2000 }\end{array}$ \\
\hline $\begin{array}{l}\text { Difficulty with inverse } \\
\text { operations }\end{array}$ & $10 \%$ & $\begin{array}{l}\text { Linchevski and Herscovics, } \\
1996\end{array}$ \\
\hline $\begin{array}{l}\text { Failure to take the square } \\
\text { root at the end to solve for } \\
\text { the leg }\end{array}$ & $10 \%$ & \\
\hline
\end{tabular}

Figure 50

Item 19: Eighth-Grade

5 A television station charges $\$ 1,089$ for a sixty-second commercial and $\$ 325$ for a fifteen-second commercial.

The television station also sells 10 minutes of commercial time for a total of $\$ 10,000$.

How much will an advertiser save if they purchase the 10-minute block of commercials instead of 7 sixty-second commercials and 12 fifteen-second commercials?

Show All Work

Answer $\$$

(Department of Education, 2008)

On this item, students have to solve a multi-step problem involving multiplication of whole numbers and finding the difference. Table 102 provides a summary of response types. Mainly, students who obtained an incorrect answer made a mistake in their 
computation. Overall, $25 \%$ of open-responses had the correct answer and correct process, $20 \%$ had the correct answer but work shown did not clearly lead to the correct answer, $20 \%$ made a computational error when multiplying whole numbers, $10 \%$ took the sum instead of the difference between the two options, and 5\% made a transcription error when copying their answer onto the answer line. Other responses included incorrectly taking the difference between 10000 and 3900 (5\%), found the difference in seconds rather than in cost $(5 \%)$, and found the sum $(11,523)$ instead of the difference but wrote 9612.95 on the answer line (5\%). Finally, 5\% of open-responses displayed the incorrect belief that the commutative property is also true for subtraction and reversed the order when finding the difference. See Tables 103 and 104 for literature connections to the prerequisite content areas of numbers and numerical operations and the order of operations.

Table 102

Summary Table: Item 19

\begin{tabular}{|l|c|}
\hline \multicolumn{1}{|c|}{ Response } & Percent of Responses \\
\hline Correct answer and correct process & $25 \%$ \\
\hline $\begin{array}{l}\text { Correct answer but work shown did not } \\
\text { clearly lead to the correct answer }\end{array}$ & $20 \%$ \\
\hline Incorrect answer & $55 \%$ \\
\hline
\end{tabular}


Table 103

Common Errors and Misconceptions: Eighth-Grade Numbers and Numerical

Operations, Item 19

\begin{tabular}{|l|c|c|}
\hline \multicolumn{1}{|c|}{ Error/Misconception } & Percent of Responses & Corresponding Reference \\
\hline $\begin{array}{l}\text { When subtracting - taking } \\
\text { the smaller number subtract } \\
\text { the larger number (reverse } \\
\text { order) }\end{array}$ & $5 \%$ & Ashlock, 2006 \\
\hline
\end{tabular}

Table 104

Common Errors and Misconceptions: Eighth-Grade The Order of Operations, Item 19

\begin{tabular}{|l|c|c|}
\hline \multicolumn{1}{|c|}{ Error/Misconception } & Percent of Responses & Corresponding Reference \\
\hline $\begin{array}{l}\text { Belief that commutative and } \\
\text { associative properties are } \\
\text { true for subtraction or } \\
\text { division }\end{array}$ & $5 \%$ & Shifter et al., 2008 \\
\hline
\end{tabular}


Figure 51

Item 20: Eighth-Grade

3 Lilly and Nina sell cars at the Top Shelf Car Depot. Last week. Lilly's sales total was $\$ 34,000$. Nina's sales total was $40 \%$ more than Lilly's.

The dealership uses the formula below to determine each salesperson's commission (c) based on his or her weekly sales total $(d)$.

$$
c=0.035 d+\$ 55
$$

How much more commission did Nina make than Lilly?

Show All Work

Answer \$

(Department of Education, 2008)

On this item, students were given a two-step two-variable algebraic equation to represent a salesperson's salary based on commission and base pay. Students were given one employee's sales totals and are told that the other employee sold $40 \%$ more. The equation must then be used to determine how much more commission one person made than the other. Therefore, students must find the percent of a number, use the formula for two different givens, and take the difference of the two solutions. Table 105 provides a summary of response types. On this item, $15 \%$ of students had the correct answer and correct process, $15 \%$ had the correct answer but the work shown did not clearly lead to the correct answer, and 5\% made a transcription error when completing steps in their 
work. With regards to computational errors, $25 \%$ made a computational error in the multiplication of decimals when solving for $c$ in the equation and $10 \%$ made a computational error when multiplying decimals when finding $40 \%$ of Lilly's sales. Additionally, $5 \%$ added instead of multiplied when finding $40 \%$ of Lilly's sales and $10 \%$ divided instead of multiplied when finding $40 \%$ of Lilly's sales. Other student responses included: writing .4 (maybe because it is $40 \%$ as a decimal) on the answer line with no clear work leading to that answer (5\%), after finding $40 \%$ of Lilly's sales with an incorrect answer no attempt was made to use the commission formula and 34850 was written on the answer line (5\%), found only Nina's commission (5\%), and found only $40 \%$ of Lilly's sales $(5 \%)$. The overall percentage is more than $100 \%$ because some responses displayed more than one misconception or error. See Table 106 for connections to the review of literature for the prerequisite content area of numbers and numerical operations.

Table 105

Summary Table: Item 20

\begin{tabular}{|l|c|}
\hline \multicolumn{1}{|c|}{ Response } & Percent of Responses \\
\hline Correct answer and correct process & $15 \%$ \\
\hline $\begin{array}{l}\text { Correct answer but work shown did not } \\
\text { clearly lead to the correct answer }\end{array}$ & $15 \%$ \\
\hline Incorrect answer & $70 \%$ \\
\hline
\end{tabular}


Table 106

Common Errors and Misconceptions: Eighth-Grade Numbers and Numerical

Operations, Item 20

\begin{tabular}{|l|c|c|}
\hline \multicolumn{1}{|c|}{ Error/Misconception } & Percent of Responses & Corresponding Reference \\
\hline $\begin{array}{l}\text { Computational error with } \\
\text { multiplication of decimals }\end{array}$ & $35 \%$ & Ashlock, 2006 \\
\hline
\end{tabular}

Figure 52

Item 21: Eighth-Grade

1 Sherry tutors children in computer skills for $\$ 12$ per hour. After spending $\$ 21$ of the money she earned on Monday, she had $\$ 27$ left to put in her savings account.

On the line below, write a linear equation that can be used to determine how many hours $(h)$ Sherry tutored on Monday.

Equation

Now solve the equation you wrote to determine how many hours Sherry tutored on Monday.

Answer _ hours

(Department of Education, 2008)

On this item, students were given a problem situation and were asked to write an algebraic equation to represent the situation. The equation can be written as a one-step linear equation. Table 107 provides a summary of response types. Most students who were able to symbolically write the equation were able to solve for the unknown variable. While a few students made computation or operational errors, more students had trouble 
expressing the equation symbolically. Sometimes when a student could not write an accurate equation, they could still solve for the unknown value using arithmetic skills. Overall, 30\% of student responses had the correct answer and correct process.

Additionally, $5 \%$ displayed the correct process for solving equations but made an error in computation, $40 \%$ could not write a correct symbolic equation, and $10 \%$ made an error when performing inverse operations. Other misconceptions and errors included writing $12+21+27$ as the equation and 60 as the answer (5\%), writing $27+21+12$ as the equation and 56 as the answer (5\%), and writing $21-12+27$ as the equation and 36 as the answer (5\%). See Table 108 for literature connections to the prerequisite content area of algebraic equations.

Table 107

Summary Table: Item 21

\begin{tabular}{|l|c|}
\hline \multicolumn{1}{|c|}{ Response } & Percent of Responses \\
\hline Correct answer and correct process & $30 \%$ \\
\hline Incorrect answer & $70 \%$ \\
\hline
\end{tabular}


Table 108

Common Errors and Misconceptions: Eighth-Grade Algebraic Equations, Item 21

\begin{tabular}{|l|r|l|}
\hline \multicolumn{1}{|c|}{ Error/Misconception } & Percent of Responses & \multicolumn{1}{c|}{ Corresponding Reference } \\
\hline $\begin{array}{l}\text { Difficulty with the symbolic } \\
\text { representation of a scenario }\end{array}$ & $40 \%$ & $\begin{array}{l}\text { Booth, 1984; Nathan and } \\
\text { Koedinger, 2000 }\end{array}$ \\
\hline $\begin{array}{l}\text { Difficulty with inverse } \\
\text { operations }\end{array}$ & $10 \%$ & $\begin{array}{l}\text { Linchevski and Herscovics, } \\
1996\end{array}$ \\
\hline $\begin{array}{l}\text { Understands the process of } \\
\text { solving equations but makes } \\
\text { computational error }\end{array}$ & $5 \%$ & Wu, 2001 \\
\hline
\end{tabular}

Figure 53

Item 22: Eighth-Grade

7 A landscape designer is making a scale drawing of a garden in the shape of a parallelogram, as shown in the diagram below.

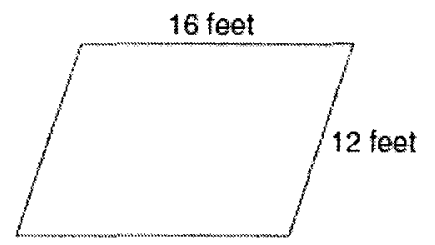

The designer plans to make her drawing using a scale of 1 inch equals 8 feet.

What will be the length and width, in inches, of the scale drawing?

Show All Work

Length inches

Width inches

(Department of Education, 2008) 
On this item, students were given a diagram of a garden in the shape of a parallelogram with dimensions written on the diagram. The dimensions given represented the dimensions of the actual size of the garden, in feet. Students were asked to find the dimensions of a scale drawing of the garden if the scale is 1 inch equals 8 feet. Table 109 provides a summary of response types. Student errors included computational errors when dividing decimals and using the wrong operation to make the conversion. Overall, $30 \%$ of open-responses had the correct answer and correct process, $30 \%$ made a computational error when dividing decimals, and 5\% made a transcription error when copying over the dimensions into the work space. Additionally, $35 \%$ of students had difficulty unitizing - either by multiplying by the scale factor instead of dividing or by not thinking proportionally (thinking additively). No student response used fractions instead of decimals. Table 110 shows connections to the review of literature as it relates to the prerequisite content area of ratios and proportions.

Table 109

Summary Table: Item 22

\begin{tabular}{|l|c|}
\hline \multicolumn{1}{|c|}{ Response } & Percent of Responses \\
\hline Correct answer and correct process & $30 \%$ \\
\hline Incorrect answer & $70 \%$ \\
\hline
\end{tabular}

Table 110

Common Errors and Misconceptions: Eighth-Grade Ratios and Proportions, Item 22

\begin{tabular}{|l|r|l|}
\hline \multicolumn{1}{|c|}{ Error/Misconception } & Percent of Responses & Corresponding Reference \\
\hline Inability to unitize & $35 \%$ & $\begin{array}{l}\text { Behr et al., 1992; Singh, } \\
2000\end{array}$ \\
\hline
\end{tabular}


Figure 54

Item 23: Eighth-Grade

6 Look at the diagram below.

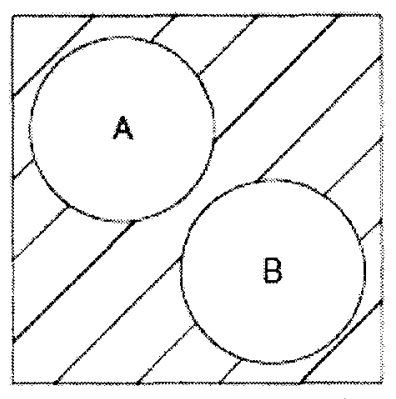

The area of the large square is 100 square units. The area of circle $A$ is 20 square units. Circle $B$ is the image of circle A after a translation.

What is the area, in square units, of the striped portion of the square?

Answer square units

On the lines below, explain how you determined the area of the striped portion of the square.

(Department of Education, 2008)

On this item, students were given a diagram of a square with two circles inscribed inside. Students were also given the total area of the square and the area of one circle. They were also told that Circle B is a translation of Circle A. Students were then asked to find the area of the square excluding the two circles. Therefore, students must know the area of both circles are the same because Circle B is a translation of Circle A and then 
subtract the sum of their areas from the given area of the square. Table 111 provides a summary of response types. Many students answered correctly on this item but several had difficulty explaining how they determined their answer. Overall, $40 \%$ of student responses had the correct answer and correct explanation, $10 \%$ had the correct answer but not a clear or complete explanation, and $15 \%$ made a computational error with whole numbers when finding the difference between the 100 and 40 . Additionally, $5 \%$ had the correct answer but wrote that $40-100=60$ in their explanation which displayed the incorrect use of signs and ordering. Other errors included: subtracting 80 (instead of 40) from $100(5 \%)$, giving an answer of 100 and stating that the strips take up the whole space $(5 \%)$, multiplying $10 \times 10=100$ then $100 \times 20=2000$ then $2000-100=1900$ then $1900 \div 3$ in the explanation (5\%), taking $100 \div 9$ because there are nine strips (but there were really only eight) (5\%), taking $100 \times 20(5 \%)$, and taking $90 \times 4$ because they said they measured $90 \mathrm{~cm}$ then multiplied by $4(5 \%)$. See Table 112 for literature connections to the prerequisite content area of number and numerical operations.

Table 111

Summary Table: Item 23

\begin{tabular}{|l|c|}
\hline \multicolumn{1}{|c|}{ Response } & Percent of Responses \\
\hline Correct answer and correct explanation & $40 \%$ \\
\hline $\begin{array}{l}\text { Correct answer but not a clear or complete } \\
\text { explanation }\end{array}$ & $10 \%$ \\
\hline Incorrect answer & $50 \%$ \\
\hline
\end{tabular}


Table 112

Common Errors and Misconceptions: Eighth-Grade Numbers and Numerical

Operations, Item 23

\begin{tabular}{|l|r|c|}
\hline \multicolumn{1}{|c|}{ Error/Misconception } & Percent of Responses & Corresponding Reference \\
\hline Incorrect use of signs & $5 \%$ & Ashlock, 2006 \\
\hline
\end{tabular}

Figure 55

Item 24: Eighth-Grade

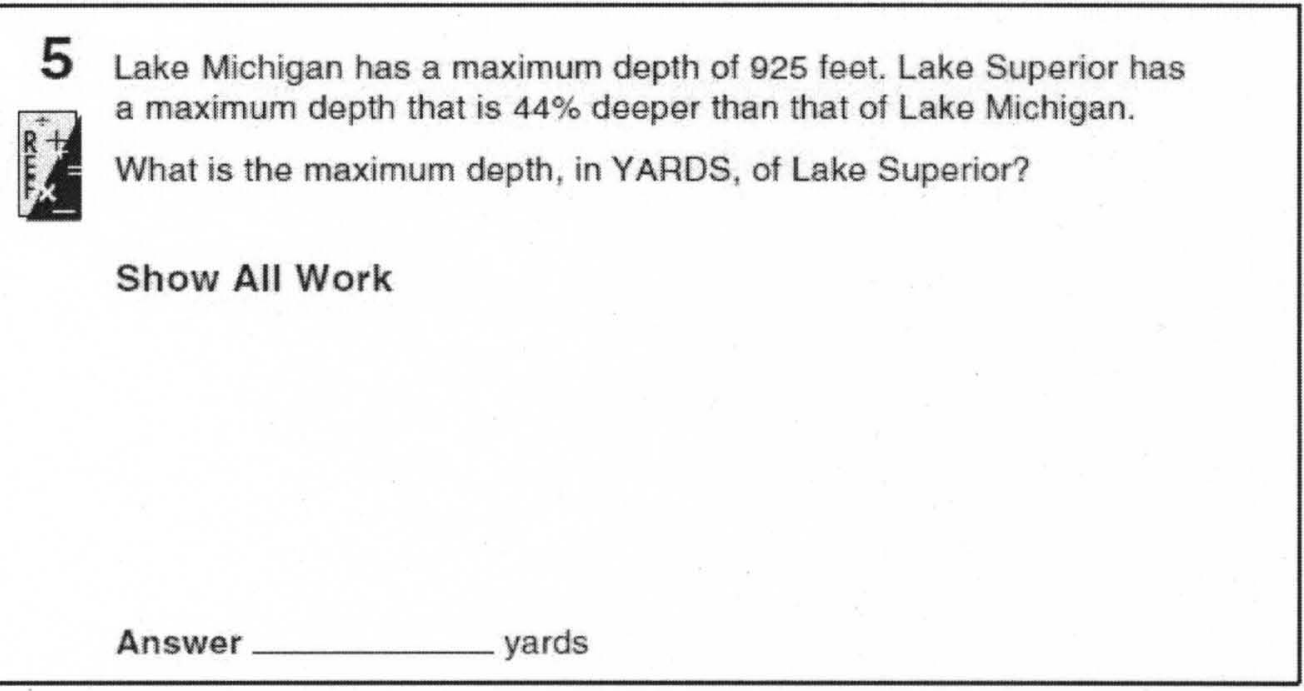

(Department of Education, 2008)

On this item, students were given a maximum depth of a lake in feet. Then they were told that a second lake has a maximum depth that is $44 \%$ deeper than the first lake. Students were asked to find the maximum depth of the second lake, in yards. Therefore, they must find the percent of a number and then convert feet to yards. Students can locate the conversion factor on their reference sheet. Table 113 provides a summary of response types. Student errors included using the wrong operation, placing the decimal point in the wrong location when multiplying or dividing, computational errors when multiplying or 
dividing decimals, and some students struggled with unitizing - they had trouble converting the feet to yards. Overall, $20 \%$ of open-responses had the correct answer and correct process. Additionally, 30\% displayed computational errors in multiplying decimals (but not the placement of the decimal point), $10 \%$ correctly computed when multiplying decimals but placed the decimal in the incorrect place, and 5\% divided with decimals correctly but placed the decimal in the incorrect place. Additionally, $20 \%$ attempted to convert from feet to yards but had difficulty unitizing correctly and $10 \%$ did not convert from feet to yards and left their final answer in feet. Finally, 5\% added instead of multiplied when finding the $44 \%$ and made no attempt to convert their wrong answer to yards, and 5\% only found the $44 \%$ of 925 feet and did not add that to 925 or convert feet to yards. Some student responses displayed more than one misconception or error. See Tables 114 and 115 for connections to the review of literature for the prerequisite content areas of numbers and numerical operations and ratios and proportions.

Table 113

Summary Table: Item 24

\begin{tabular}{|l|c|}
\hline \multicolumn{1}{|c|}{ Response } & Percent of Responses \\
\hline Correct answer and correct process & $20 \%$ \\
\hline Incorrect answer & $80 \%$ \\
\hline
\end{tabular}


Table 114

Common Errors and Misconceptions: Eighth-Grade Numbers and Numerical

Operations, Item 24

\begin{tabular}{|l|r|l|}
\hline \multicolumn{1}{|c|}{ Error/Misconception } & Percent of Responses & Corresponding Reference \\
\hline $\begin{array}{l}\text { Placing the decimal in the } \\
\text { incorrect place when } \\
\text { multiplying }\end{array}$ & $10 \%$ & Ashlock, 2006 \\
\hline $\begin{array}{l}\text { Placing the decimal in the } \\
\text { incorrect place when } \\
\text { dividing }\end{array}$ & $5 \%$ & Ashlock, 2006 \\
\hline $\begin{array}{l}\text { Computational error when } \\
\text { multiplying decimals }\end{array}$ & $30 \%$ & Ashlock, 2006 \\
\hline
\end{tabular}

Table 115

Common Errors and Misconceptions: Eighth-Grade Ratios and Proportions, Item 24

\begin{tabular}{|l|r|l|}
\hline \multicolumn{1}{|c|}{ Error/Misconception } & Percent of Responses & Corresponding Reference \\
\hline Inability to unitize & $20 \%$ & $\begin{array}{l}\text { Behr et al., 1992; Singh, } \\
2000\end{array}$ \\
\hline
\end{tabular}


Figure 56

Item 25: Eighth-Grade

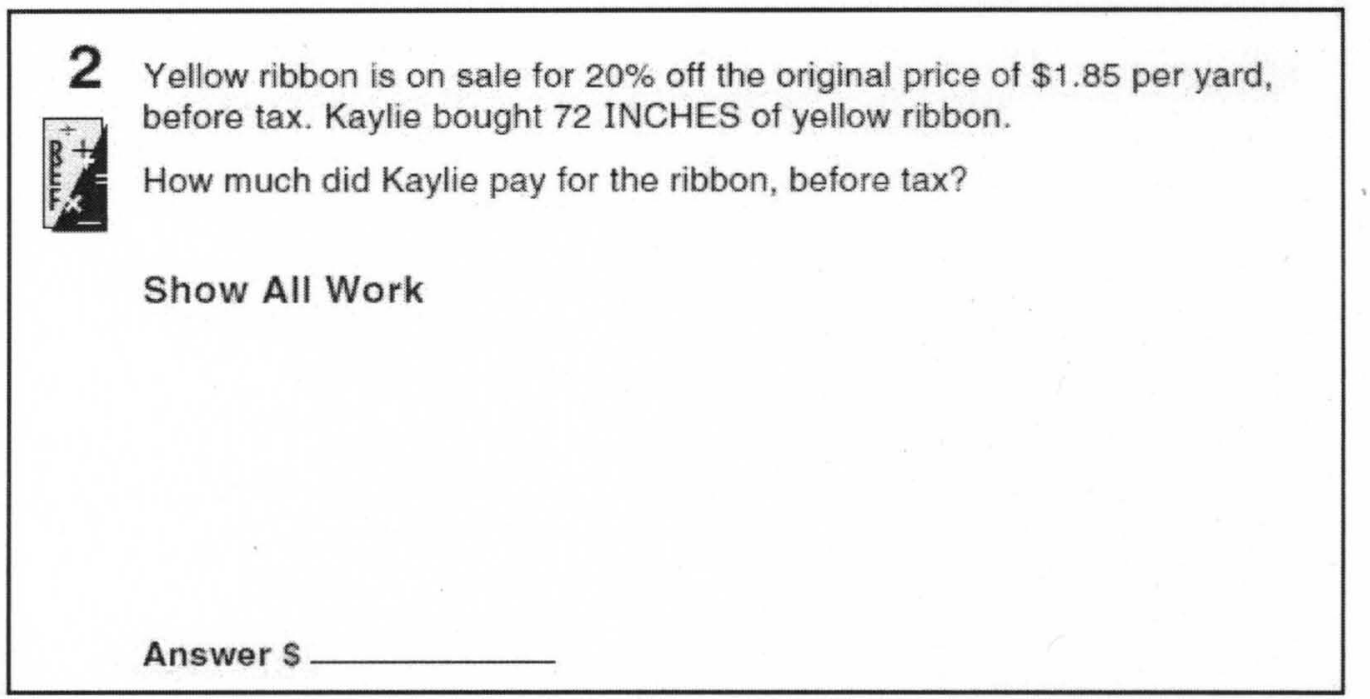

(Department of Education, 2008)

On this item, students must calculate a sale price given a percentage off, and convert yards to inches for their final answer. Table 116 provides a summary of response types. Student responses included errors in computation with addition and subtraction with decimals, multiplication with decimals, the inability to unitize and do the conversion correctly, placing the decimal in the wrong place, and others. Overall, $30 \%$ of openresponses had the correct answer and correct process. With regards to computational errors, $20 \%$ of student responses displayed errors in multiplying decimals (but not the placement of the decimal point), $5 \%$ with the subtraction of decimals, and $10 \%$ with the placement of the decimal point when multiplying decimals. Also, $10 \%$ had difficulty unitizing correctly when converting inches to yards. Other errors included: only finding the amount of discount (5\%), writing 66.6 and 34.15 as their answer with no clear work shown (5\%), only finding the cost of two yards at the original price (5\%), multiplying 
$1.85 \times 72(5 \%)$, rounding .74 (discount) to $.70(5 \%)$, writing $1.85+.15=2.00$ then $200-$ $4=1.96(5 \%)$. Finally, $5 \%$ wrote $.74-3.70$ displaying a misunderstanding with regards to the commutative property. Some student responses displayed more than one misconception or error. See Tables 117,118 , and 119 as they are aligned to the review of literature for this item with regards to the prerequisite content areas of numbers and numerical operations, ratios and proportions, and the order of operations.

Table 116

Summary Table: Item 25

\begin{tabular}{|l|c|}
\hline \multicolumn{1}{|c|}{ Response } & Percent of Responses \\
\hline Correct answer and correct process & $30 \%$ \\
\hline Incorrect answer & $70 \%$ \\
\hline
\end{tabular}

Table 117

Common Errors and Misconceptions: Eighth-Grade Numbers and Numerical Operations, Item 25

\begin{tabular}{|l|r|l|}
\hline \multicolumn{1}{|c|}{ Error/Misconception } & Percent of Responses & \multicolumn{1}{|c|}{ Corresponding Reference } \\
\hline $\begin{array}{l}\text { Placing the decimal in the } \\
\text { incorrect place when } \\
\text { multiplying }\end{array}$ & $10 \%$ & Ashlock, 2006 \\
\hline $\begin{array}{l}\text { Computational error with } \\
\text { multiplication of decimals }\end{array}$ & $20 \%$ & Ashlock, 2006 \\
\hline $\begin{array}{l}\text { Computational error with } \\
\text { addition/subtraction of } \\
\text { decimals }\end{array}$ & $5 \%$ & $\begin{array}{l}\text { Ashlock, 2006; Kilpatrick et } \\
\text { al., 2001 }\end{array}$ \\
\hline
\end{tabular}


Table 118

Common Errors and Misconceptions: Eighth-Grade Ratios and Proportions, Item 25

\begin{tabular}{|l|r|l|}
\hline \multicolumn{1}{|c|}{ Error/Misconception } & Percent of Responses & Corresponding Reference \\
\hline Inability to unitize & $10 \%$ & $\begin{array}{l}\text { Behr et al., 1992; Singh, } \\
2000\end{array}$ \\
\hline
\end{tabular}

Table 119

Common Errors and Misconceptions: Eighth-Grade The Order of Operations, Item 25

\begin{tabular}{|c|c|c|}
\hline \multicolumn{1}{|c|}{ Error/Misconception } & Percent of Responses & Corresponding Reference \\
\hline $\begin{array}{l}\text { Belief that commutative and } \\
\text { associative property are true } \\
\text { for subtraction or division }\end{array}$ & & Shifter et al, 2008 \\
\hline
\end{tabular}

\section{Additional Findings}

In this section, the researcher will discuss additional findings which were discovered during the coding process. First, the researcher noticed some inconsistencies in the scoring of student responses with the expectation of credit given to student work. When an item asked students to "Show All Work," the researcher assumed that meant that the student must show all of their steps and have a correct answer in order to receive full credit. This assumption appears to be true on almost all items. However, on several of the items the researcher noticed that some students would receive full credit on a "Show All Work" item if they had the correct answer - even when they showed little or sometimes no work. To provide a specific example, one three-point item has an openresponse with no work shown which scored a three and another open-response with near complete work which only scored a two. Both responses had correct answers. While this study is not about the scoring of the open-responses, it was an interesting finding. The 
scoring normally worked in favor of the student. This analysis reflects the actual performance of students and is unrelated to the score they received.

On another item that several students showed work and had a correct answer but their process in the work shown was wrong. In other words, given the values in the problem, students were able to use the wrong process (mathematically incorrect because it would not work in all cases) but obtained the correct answer due to the combination of values in the problem (coincidence). These responses were awarded full credit even though the students' work was incorrect.

Calculator use was also of interest to the researcher as an additional observation. A calculator was not permitted on any sixth-grade item. It is apparent that many computational errors were made on student responses at the sixth-grade. For eighthgrade, students were allowed to use a calculator on approximately one half of the items. The "calculator permitted" and "calculator not permitted" items are not always similar, so it would not be valid to make direct statistical comparisons. However, the researcher qualitatively made observations and took notes comparing the number of computational errors made between eighth-grade items where students were allowed to use a calculator compared to items when students are not allowed to use a calculator. No major differences were found. The percentages of computational errors among the items were similar for the calculator and non-calculator items.

\section{Summary of Primary Findings}

To conclude the primary findings of this research, connections to the literature review and other primary findings will now be discussed. Throughout the analysis of the primary data, tables linking the findings with the review of literature were present. As 
previously mentioned, these tables show the frequencies of the misconceptions and errors made on the student responses by item. The tables are aligned to the nine prerequisite content areas (Welder, 2007). Table 120 summarizes the found errors and misconceptions which related to the review of literature. It is organized by the nine prerequisite content areas.

Table 120

Summary of Misconceptions and Errors Related to Welder's Nine Prerequisite Content Areas

\begin{tabular}{|c|c|c|c|c|}
\hline $\begin{array}{l}\text { Prerequisite } \\
\text { Content Area }\end{array}$ & Misconception/Error & Reference & Sixth & Eighth \\
\hline $\begin{array}{l}\text { Numbers and } \\
\text { Numerical } \\
\text { Operations }\end{array}$ & $\begin{array}{l}\text { Determined which } \\
\text { decimal was greater } \\
\text { based on the number of } \\
\text { digits }\end{array}$ & $\begin{array}{l}\text { Ashlock, 2006; } \\
\text { Desmet et al., } \\
\text { 2010; Steinle } \\
\text { and Stacey, 2004 }\end{array}$ & $\mathrm{X}$ & \\
\hline $\begin{array}{l}\text { Numbers and } \\
\text { Numerical } \\
\text { Operations }\end{array}$ & $\begin{array}{l}\text { Not understanding the } \\
\text { value of a fraction }\end{array}$ & $\begin{array}{l}\text { Darley, 2009; } \\
\text { Wu, } 2001\end{array}$ & $\mathrm{X}$ & \\
\hline $\begin{array}{l}\text { Numbers and } \\
\text { Numerical } \\
\text { Operations }\end{array}$ & $\begin{array}{l}\text { Applying the wrong } \\
\text { algorithm when } \\
\text { computing fractions }\end{array}$ & $\begin{array}{l}\text { Brown and } \\
\text { Quinn, 2006 }\end{array}$ & $\mathrm{X}$ & \\
\hline $\begin{array}{l}\text { Numbers and } \\
\text { Numerical } \\
\text { Operations }\end{array}$ & $\begin{array}{l}\text { Selecting the wrong } \\
\text { operation when working } \\
\text { with fractions }\end{array}$ & $\begin{array}{l}\text { Brown and } \\
\text { Quinn, } 2006\end{array}$ & $\mathrm{X}$ & \\
\hline $\begin{array}{l}\text { Numbers and } \\
\text { Numerical } \\
\text { Operations }\end{array}$ & $\begin{array}{l}\text { Placing the decimal in } \\
\text { the incorrect place when } \\
\text { dividing }\end{array}$ & Ashlock, 2006 & & $\mathrm{X}$ \\
\hline $\begin{array}{l}\text { Numbers and } \\
\text { Numerical } \\
\text { Operations }\end{array}$ & $\begin{array}{l}\text { Placing the decimal in } \\
\text { the incorrect place when } \\
\text { multiplying }\end{array}$ & Ashlock, 2006 & & $\mathrm{X}$ \\
\hline $\begin{array}{l}\text { Numbers and } \\
\text { Numerical } \\
\text { Operations }\end{array}$ & Incorrect use of signs & Ashlock, 2006 & & $\bar{X}$ \\
\hline $\begin{array}{l}\text { Numbers and } \\
\text { Numerical } \\
\text { Operations }\end{array}$ & Omitting negative signs & Ashlock, 2006 & & $\mathrm{X}$ \\
\hline
\end{tabular}




\begin{tabular}{|c|c|c|c|c|}
\hline $\begin{array}{l}\text { Numbers and } \\
\text { Numerical } \\
\text { Operations }\end{array}$ & $\begin{array}{l}\text { Difficulty plotting } \\
\text { fractional points on a } \\
\text { number line }\end{array}$ & Darley, 2009 & & $\mathrm{X}$ \\
\hline $\begin{array}{l}\text { Numbers and } \\
\text { Numerical } \\
\text { Operations }\end{array}$ & $\begin{array}{l}\text { When subtracting-- } \\
\text { taking the smaller } \\
\text { number subtract the } \\
\text { larger number (reverse } \\
\text { order) }\end{array}$ & Ashlock, 2006 & & $\mathrm{X}$ \\
\hline $\begin{array}{l}\text { Numbers and } \\
\text { Numerical } \\
\text { Operations }\end{array}$ & $\begin{array}{l}\text { Difficulty ordering } \\
\text { decimals (incorrect, but } \\
\text { not by number of digits) }\end{array}$ & $\begin{array}{l}\text { Desmet et al., } \\
\text { 2010; Steinle } \\
\text { and Stacey, } 2004\end{array}$ & $\mathrm{X}$ & \\
\hline $\begin{array}{l}\text { Numbers and } \\
\text { Numerical } \\
\text { Operations }\end{array}$ & $\begin{array}{l}\text { Computational error with } \\
\text { the addition/subtraction } \\
\text { of decimals }\end{array}$ & $\begin{array}{l}\text { Ashlock, 2006; } \\
\text { Kilpatrick et al, } \\
2001\end{array}$ & $\mathrm{X}$ & $\mathrm{X}$ \\
\hline $\begin{array}{l}\text { Numbers and } \\
\text { Numerical } \\
\text { Operations } \\
\end{array}$ & $\begin{array}{l}\text { Computational error with } \\
\text { the multiplication of } \\
\text { decimals }\end{array}$ & Ashlock, 2006 & $\mathrm{X}$ & $\mathrm{X}$ \\
\hline $\begin{array}{l}\text { Ratios and } \\
\text { Proportions }\end{array}$ & $\begin{array}{l}\text { Student applies learned } \\
\text { procedure instead of } \\
\text { adjusting to the scenario }\end{array}$ & $\begin{array}{l}\text { De Bock et al., } \\
2002\end{array}$ & $\mathrm{X}$ & $\mathrm{X}$ \\
\hline $\begin{array}{l}\text { Ratios and } \\
\text { Proportions }\end{array}$ & Inability to unitize & $\begin{array}{l}\text { Behr et al., 1992; } \\
\text { Singh, 2000 }\end{array}$ & $\mathrm{X}$ & $\mathrm{X}$ \\
\hline $\begin{array}{l}\text { Ratios and } \\
\text { Proportions }\end{array}$ & $\begin{array}{l}\text { Difficulty with the } \\
\text { different ways to write a } \\
\text { ratio }\end{array}$ & $\begin{array}{l}\text { Hoffer, 1988; } \\
\text { Kilpatrick et al., } \\
2001\end{array}$ & $\mathrm{X}$ & \\
\hline $\begin{array}{l}\text { Ratios and } \\
\text { Proportions }\end{array}$ & $\begin{array}{l}\text { Not understanding the } \\
\text { size of a ratio }\end{array}$ & \begin{tabular}{|l|} 
Kilpatrick et al., \\
2001 \\
\end{tabular} & $\mathrm{X}$ & \\
\hline $\begin{array}{l}\text { Ratios and } \\
\text { Proportions }\end{array}$ & $\begin{array}{l}\text { Incorrectly viewing } \\
\text { portions as equal sized }\end{array}$ & $\begin{array}{l}\text { Labato and Ellis, } \\
2010\end{array}$ & & $\mathrm{X}$ \\
\hline $\begin{array}{l}\text { The Order of } \\
\text { Operations }\end{array}$ & $\begin{array}{l}\text { Not using parentheses } \\
\text { when needed }\end{array}$ & Booth, 1988 & & $\mathrm{X}$ \\
\hline $\begin{array}{l}\text { The Order of } \\
\text { Operations }\end{array}$ & $\begin{array}{l}\text { Belief that commutative } \\
\text { and associative properties } \\
\text { are true for subtraction } \\
\text { and division } \\
\end{array}$ & $\begin{array}{l}\text { Shifter et al., } \\
2008\end{array}$ & & $\mathrm{X}$ \\
\hline $\begin{array}{l}\text { The Order of } \\
\text { Operations }\end{array}$ & $\begin{array}{l}\text { Performing operations in } \\
\text { order from left to right } \\
\text { instead of using the order } \\
\text { of operations }\end{array}$ & $\begin{array}{l}\text { Linchevski and } \\
\text { Livneh, } 1999\end{array}$ & $\mathrm{X}$ & $\mathrm{X}$ \\
\hline $\begin{array}{l}\text { The Order of } \\
\text { Operations }\end{array}$ & $\begin{array}{l}\text { Belief that addition } \\
\text { comes before subtraction } \\
\text { or multiplication before } \\
\text { division }\end{array}$ & $\begin{array}{l}\text { Linchevski and } \\
\text { Livneh, } 1999\end{array}$ & & $\mathrm{X}$ \\
\hline
\end{tabular}




\begin{tabular}{|c|c|c|c|c|}
\hline \begin{tabular}{|l} 
Equality \\
\end{tabular} & $\begin{array}{l}\text { Not preserving } \\
\text { equivalence when } \\
\text { performing inverse } \\
\text { operations }\end{array}$ & $\begin{array}{l}\text { Asquith et al., } \\
2007\end{array}$ & & $\mathrm{X}$ \\
\hline Equality & $\begin{array}{l}\text { Lack of understanding of } \\
\text { algebraic symbolism led } \\
\text { to error in equivalence }\end{array}$ & $\begin{array}{l}\text { Steinberg et al., } \\
1990\end{array}$ & & $\mathrm{X}$ \\
\hline \begin{tabular}{|l|} 
Patterning \\
\end{tabular} & $\begin{array}{l}\text { Errors in counting with } \\
\text { patterns }\end{array}$ & $\begin{array}{l}\text { Koellner, et al., } \\
2008\end{array}$ & $\mathrm{X}$ & \\
\hline Patterning & $\begin{array}{l}\text { Difficulty making a } \\
\text { generalization }\end{array}$ & Stacey, 1989 & $\mathrm{X}$ & \\
\hline Patterning & $\begin{array}{l}\text { Not making consistent } \\
\text { generalizations }\end{array}$ & Stacey, 1989 & $\mathrm{X}$ & \\
\hline Patterning & $\begin{array}{l}\text { Difficulty representing a } \\
\text { pattern symbolically }\end{array}$ & $\begin{array}{l}\text { Healy and } \\
\text { Hoyles, 1999; } \\
\text { Radford, 2000 }\end{array}$ & $\mathrm{X}$ & \\
\hline $\begin{array}{l}\text { Algebraic } \\
\text { Symbolism and } \\
\text { Letter Usage }\end{array}$ & $\begin{array}{l}\text { Inability to write a } \\
\text { correct algebraic } \\
\text { expression for a given } \\
\text { situation }\end{array}$ & $\begin{array}{l}\text { MacGregor and } \\
\text { Stacey, } 1997\end{array}$ & $\mathrm{X}$ & \\
\hline $\begin{array}{l}\text { Algebraic } \\
\text { Symbolism and } \\
\text { Letter Usage }\end{array}$ & $\begin{array}{l}\text { The belief that an answer } \\
\text { can only be a number } \\
\text { rather than an expression }\end{array}$ & $\begin{array}{l}\text { Booth and } \\
\text { Watson, 1990; } \\
\text { Booth, 1986; } \\
\text { Kilpatrick et al., } \\
\text { 2001; Stacey and } \\
\text { MacGregor, } \\
\text { 1997b }\end{array}$ & $\mathrm{X}$ & \\
\hline $\begin{array}{l}\text { Algebraic } \\
\text { Symbolism and } \\
\text { Letter Usage }\end{array}$ & $\begin{array}{l}\text { Difficulty combining like } \\
\text { terms }\end{array}$ & $\begin{array}{l}\text { Booth and } \\
\text { Watson, 1990; } \\
\text { Booth, 1986; } \\
\text { Stacey and } \\
\text { MacGregor, } \\
\text { 1997b }\end{array}$ & & $\bar{X}$ \\
\hline $\begin{array}{l}\text { Algebraic } \\
\text { Symbolism and } \\
\text { Letter Usage }\end{array}$ & $\begin{array}{l}\text { Difficulty with } \\
\text { distributive property }\end{array}$ & $\begin{array}{l}\text { Ding and } \mathrm{Li} \text {, } \\
2010 ; \text { Kieran, } \\
1992\end{array}$ & & $\mathrm{X}$ \\
\hline $\begin{array}{l}\text { Algebraic } \\
\text { Equations }\end{array}$ & $\begin{array}{l}\text { Difficulty with the } \\
\text { symbolic representation } \\
\text { of a scenario }\end{array}$ & $\begin{array}{l}\text { Booth, 1984; } \\
\text { Nathan and } \\
\text { Koedinger, } 2000\end{array}$ & $\mathrm{X}$ & $\mathrm{X}$ \\
\hline $\begin{array}{l}\text { Algebraic } \\
\text { Equations }\end{array}$ & $\begin{array}{l}\text { Understands the process } \\
\text { of solving equations but } \\
\text { makes computational } \\
\text { error }\end{array}$ & $\mathrm{Wu}, 2001$ & & $\mathrm{X}$ \\
\hline $\begin{array}{l}\text { Algebraic } \\
\text { Equations }\end{array}$ & $\begin{array}{l}\text { Difficulty using inverse } \\
\text { operations }\end{array}$ & $\begin{array}{l}\text { Linchevski and } \\
\text { Herscovics, } 1996\end{array}$ & & $\mathrm{X}$ \\
\hline
\end{tabular}




\begin{tabular}{|c|c|c|c|c|}
\hline Functions & $\begin{array}{l}\text { Difficulty graphing the } \\
\text { slope of a line }\end{array}$ & $\begin{array}{l}\text { Kalchman and } \\
\text { Koedinger, } \\
\text { 2005; Labato } \\
\text { and Ellis, } 2010\end{array}$ & & $\mathrm{X}$ \\
\hline Functions & $\begin{array}{l}\text { Difficulty moving } \\
\text { between equation, table, } \\
\text { and graph representations }\end{array}$ & $\begin{array}{l}\text { Kalchman and } \\
\text { Koedinger, 2005 }\end{array}$ & & $\bar{X}$ \\
\hline Functions & $\begin{array}{l}\text { Incorrectly interpreting } \\
\text { function }\end{array}$ & $\begin{array}{l}\text { Kilpatrick et al., } \\
2001\end{array}$ & $\mathrm{X}$ & \\
\hline Functions & $\begin{array}{l}\text { Difficulty plotting points } \\
\text { - reversed } x \text { - and } y \text { - } \\
\text { coordinate }\end{array}$ & $\begin{array}{l}\text { Hadjidemetriou } \\
\text { and Williams, } \\
2001\end{array}$ & & $\mathrm{X}$ \\
\hline Graphing & $\begin{array}{l}\text { Difficulty graphing the } \\
\text { slope of a line }\end{array}$ & $\begin{array}{l}\text { Kalchman and } \\
\text { Koedinger, } \\
2005 \text {; Labato } \\
\text { and Ellis, } 2010\end{array}$ & & $\mathrm{X}$ \\
\hline Graphing & $\begin{array}{l}\text { Incorrectly interpreting } \\
\text { graph }\end{array}$ & $\begin{array}{l}\text { Hadjidemetriou } \\
\text { and Williams, } \\
2001 ; \text { Kilpatrick } \\
\text { et al., } 2001\end{array}$ & $\mathrm{X}$ & $\mathrm{X}$ \\
\hline Graphing & $\begin{array}{l}\text { Difficulty plotting points } \\
\text { - reversed } x \text { - and } y \text { - } \\
\text { coordinate }\end{array}$ & $\begin{array}{l}\text { Hadjidemetriou } \\
\text { and Williams, } \\
2001\end{array}$ & $\mathrm{X}$ & $\mathrm{X}$ \\
\hline
\end{tabular}

Overall, there were 22 and 28 identified misconceptions and errors which related to the review of literature for the sixth- and eighth-grade open-response items, respectively. Not only were there more found misconceptions and errors at the eighthgrade level, but they were found more often. Specifically, the most common found misconceptions and errors were the inability to unitize (ratios and proportions), computational errors with decimals (numbers and numerical operations), difficulty with the symbolic representation of a scenario (algebraic equations), and difficulty interpreting functions and graphs (functions and graphing). 


\section{Other Primary Findings}

One surprising and major finding was the number of computational errors found on the open-response items for both grades six and eight. It was expected that students would make errors when computing with fractions, decimals, integers, exponents, and square roots. However, it was surprising the number of computational errors found with whole numbers. Errors were repeatedly found on simple multiplication facts (e.g. $8 \times 8$ ), addition of three-digit whole numbers, division with whole numbers without remainders, etc. Of the 33 items where an error in whole number computation was applicable, approximately $16.5 \%$ of the responses on these items had errors in whole number computation. While the researcher chose to focus on prerequisite algebra skills, perhaps another emphasis should have been placed on basic arithmetic skills. It appears as if students have as much or more difficulty with basic computation of whole numbers as they do with skills aligned to the nine perquisite content areas examined in this study.

When thinking about the nine prerequisite content areas and their presence on the items of the standardized assessment, the researcher noticed that the review of literature aligned more closely with the findings from the eighth-grade items rather than the sixthgrade items. Perhaps this is because eighth-grade is often a student's last year before taking Algebra I, with some students taking Algebra I in the eighth-grade. This could explain why more eighth-grade open-responses related to the literature on prerequisite algebra misconceptions.

The researcher also noticed that four sixth-grade items and seven eighth-grade items gave students clues in all capital letters such as ESTIMATE, MORE, ACTUAL, YARDS, etc. The researcher was interested in whether some open-responses would still 
have answers which represented something different from or the opposite of the clue word given in all capital letters. The researcher found that for the four sixth-grade items, three items did not show any evidence of students ignoring the clue word in all capital letters, and the fourth item displayed $20 \%$ of student responses in which the clue word was ignored (e.g. the clue word was ACTUAL and the open-responses showed that students had calculated an estimate). For the seven eighth-grade items that included a clue word in all capital letters, two items showed no evidence of students ignoring the clue word while the other five items had $10 \%, 10 \%, 15 \%, 10 \%$, and $5 \%$ of student responses in which the clue word was clearly ignored. Overall, the mean for all eleven items where clue words were ignored and thereby caused an error was approximately $6.4 \%$.

In addition to misconceptions and errors made by students, students often lost points for other reasons. The most common reasons found by the researcher included: not showing complete work, not showing any work, omitting a value, or transcription errors. For each item it was determined which of these errors were applicable. Next, for the number of applicable items, the mean percent was calculated for each error. The approximate percentages are as follows: not showing complete work or explanation (7.2\%), not showing any work (4.7\%), omitting a value $(2.5 \%)$, transcription errors when copying over an answer to the answer line (2.1\%), and transcription errors when writing values down and working steps of the problem (1.9\%). Students were often able to obtain a correct solution, but sometimes only received partial credit because only partial work or no work was shown. While this does not represent a misconception or error, this is still a topic of concern for stakeholders. Additionally, sometimes students omitted a value from 
a list - typically the final value after the word "and". For this reason, even if students understood the process and worked correctly with the remaining values, they only received partial credit for their answer. Finally, transcription errors were not uncommon. The two most common transcription errors found included copying a value from the question down incorrectly when doing work or copying over a correct answer incorrectly onto the answer line. While the mistakes discussed in this paragraph are not misconceptions or errors in mathematical understanding, they are problematic. This issue aligns closely with the CCSS mathematical practice, Attend to precision, which addresses students' ability to communicate efficiently and effectively (CCSSO/NGA, 2010).

\section{Secondary Analysis - Connections to Algebra I}

\section{Overview}

This secondary analysis examines Algebra I training papers from the same state. For this Midwestern state, students take a standardized mathematics assessment in grades 3-8 and at the end of their Algebra I course. The primary analysis written above was from grades six and eight, which was taken from part of the bigger grades 3-8 standardized assessment. The Algebra I assessment is created by a different testing company from the block of 3-8 assessments and this assessment serves as the mathematics graduation requirement in this state. Students first take this exam at the end of their Algebra I course, no matter what grade they are currently in when they take Algebra I. If a student does not pass, they have multiple chances to retake the exam up to and including their twelfth grade year. This test is based solely on the Algebra I standards for that state.

This purpose of this secondary analysis is to make general connections from the errors and misconceptions displayed in the sixth- and eighth-grade student responses to 
the errors and misconceptions found on the Algebra I open-responses. After the primary analysis of the sixth- and eighth- grade open-responses, it was determined that 10 of the Algebra I items had potential connections to the sixth- and eighth-grade items. These ten items fit into six loosely defined content categories of Algebra I: graphing equations and inequalities, solving quadratics, solving a system of linear equations, sketching or interpreting graphs, writing and solving linear equations, and one-variable equations. These categories fit with the state's outline of Algebra I topics tested on this standardized assessment. The researcher was given a collection of 20-30 training papers for each of 10 Algebra I items which had authentic student work. More importantly, the items fit into Welder's (2007) nine prerequisite content areas for success in Algebra I in the following way: graphing equations and inequalities (functions and graphing) solving quadratics (numbers and numerical operations), solving a system of linear equations (numbers and numerical operations and algebraic equations), sketching or interpreting graphs (graphing), writing and solving linear equations (algebraic equations), and one-variable equations (numbers and numerical operations, algebraic symbolism and letter usage, and algebraic equations).

It should be noted that not all Algebra I items examined are released items. For this reason, the researcher could not display the items as figures in this chapter. Instead, the items will be discussed through narrative with connections made to the findings from the primary analysis. The ten items will be organized by the six categories listed in the previous paragraph and connected to the nine prerequisite content areas within the analysis for each item. 


\section{Algebra I Findings Related to Literature}

Graphing equations and inequalities. Three of the ten Algebra I items analyzed asked students to graph linear equations or inequalities. Two items gave students an inequality in slope-intercept form and students were asked to graph the inequality. A third item gave students a linear equation in slope-intercept form and students were asked to graph the equation.

For the two linear inequalities, many responses had multiple errors. Steps to solving the problem included: plotting the $y$-intercept, graphing the slope, deciding whether the line should be dashed or solid based on the inequality, and shading the solution area of the graph. Overall, the following errors or misconceptions were found: difficulty in graphing the slope of a line, did not shade, difficulty plotting points $(y$ intercept), or incorrectly dashing or making the line solid. Open-responses in the sixthand eighth-grade displayed both difficulties in plotting points and in graphing the slope of a line. Errors in shading and dashed or solid lines were not applicable on the sixth- and eighth-grade items.

On the item which asked students to graph a linear equation, given in slopeintercept form, students basically made two errors: difficulty plotting points ( $y$-intercept) or difficulty graphing the slope of a line. Only a few open-responses displayed difficulty in correctly plotting the $y$-intercept. Many open-responses had errors in representing the slope. Some of these errors included reversing the rise and run, starting to graph the slope correctly then getting off track, graphing the opposite slope (e.g. positive instead of negative or vice versa), or using the value of the $y$-intercept as the slope. Difficulty 
graphing the slope of a line (issues with rise and run) was also a mistake which was present on the eighth-grade items.

Overall, for the inequalities, errors in slope and shading seem to be the most common. Also, on the inequality that should have been a dashed line (to denote that the points on the line are not included), some students left the line solid (meaning that the points on the line are included). For the equation, difficulty graphing the slope was the most common mistake. The error found in these three items which was also found in the review of literature and on the eighth-grade items was difficulty graphing the slope of a line (Kalchman \& Koedinger, 2005). This error or misconception aligned to both Welder's (2007) functions and graphing prerequisite content area.

Solving quadratics. Two of the ten Algebra I items related to solving quadratics. On both items, students were given a quadratic to solve (they did not have to write the quadratic equation). On one item the quadratic equation was already in standard form and on the other item the $c$ term had to be moved to the left side of the equation in order for the quadratic to be in standard form. Once in standard form, both items were of type $x^{2}+$ $b x+c=0$, meaning that the coefficient on the $a$ term was one. On both items, students could solve the quadratic using any method they choose including factoring, quadratic formula, etc.

For the item that was given in standard form, about half of the student responses showed work where students used the quadratic formula (which would have been on their reference sheet) and the other half used factoring of some type. Several students did not use any method to solve the quadratic and could not obtain a solution other than what appeared to be a random guess. Overall the following errors or misconceptions were 
found: errors in taking the square root of a number, incorrect use of signs, transcription errors, did not simplify completely, did not use a method for solving the quadratic, and computational error with whole numbers. Nearly all of these mistakes, except using a method to solve a quadratic which was not assessed at the sixth- or eighth-grade level, were present on the sixth- and eighth-grade items.

For the second quadratic equation item, about half of the open-responses showed work in which students used the quadratic formula (which would have been on their reference sheet) and the other half used factoring of some type. Several students did not use any method to solve the quadratic and could not obtain a solution other than what appeared to be a random guess. Overall the following errors or misconceptions were found: omitting a negative sign, incorrect use of signs, transcription errors, did not simplify completely, and did not use a method for solving the quadratic. Nearly all of these mistakes were present on the sixth- and eighth-grade items.

Overall, for these two items, the incorrect use of signs and not simplifying completely seem to be the most common mistakes made. Only one student made a computational error with whole numbers, which substantially less than what was present on the sixth- and eighth-grade items. The errors found here which were also found in the review of literature and on the eighth-grade items were the following: omitting a negative sign (Ashlock, 2006) and incorrect use of signs (Ashlock, 2006). Both of these errors can be found under the numbers and numerical operations prerequisite content area.

Solving a system of linear equations. One item asked students to solve a system of linear equations. Both equations were given in standard form. Students were not told what method to use to solve the system, but the problem was set up to easily use the 
elimination method because the coefficients on the $y$ terms would cancel if the two equations were added. The student responses used solving by elimination, substitution, and other student-invented methods. The errors and misconceptions found were the following: subtracted lines instead of adding when using the elimination method, only solving for one instead of both variables, transcription errors, incorrect use of signs, wrong operation used, transposing $x$ and $y$ solutions, and difficulty using inverse operations. All of these mistakes but subtracting lines instead of adding when using the elimination method and only solving for one instead of both variables were present on the sixth- and eighth-grade items.

For this item, only solving for one variable and transcription errors were the most common mistakes present in the student responses. Again, computational errors were not an issue. The errors found here which were also found in the review of literature and on the eighth-grade items for numbers and numerical operations was incorrect use of signs (Ashlock, 2006) and for algebraic equations was difficulty using inverse operations (Linchevski \& Herscovics, 1996).

Sketching or interpreting graphs. Two items related to sketching or interpreting graphs. One item asked students to sketch a graph of a situation and the other item asked students to interpret two separate parts of a graph. For the item that asked students to sketch a graph, students were given three parts to sketch. They were supposed to sketch a person's distance traveled if they walked for a given time, stopped for a given time, then ran for a given time. A graph with axes and intervals labeled was given. Overall, about one-third of the open-responses were correct. Errors students made included: not starting their sketch at a distance and time of zero, not making one or all 
parts of the graph span over the correct amount of time, not making the slope of the running section steeper than the slope of the walking section, and not representing the stop with a horizontal line. Overall, these errors were not related to the errors or misconceptions found on the six- and eighth-grade open-responses because there were no comparable tasks.

The second item asked students to interpret two parts of a graph. The graph represented a car's distance over time. One part of the graph showed a positively sloped segment and the other part of the graph was a horizontal line. Separately, students had to describe the speed of the car for each of these segments. About one-third of the student responses had correct descriptions for both segments of the graph. Other errors included: believing that the car was speeding up when it was traveling at a constant rate, believing that the horizontal line represents a constant speed, and not describing the speed in the response but describing time or distance. About the same amount of errors occurred on descriptions for the positively sloped segment as did for the horizontal line. These errors or misconceptions were not directly related to the sixth- or eighth-grade items, other than the general difficulty with interpreting graphs.

For these two items, students struggled for a variety of reasons for both sketching and interpreting graphs. The errors or misconceptions were neither directly related to the review of literature nor the errors and misconceptions found on the sixth- and eighthgrade open-responses.

Writing and solving linear equations. One item gave students a problem scenario and asked them to first write an equation that represented the scenario. In the problem, students were given two variables to use. The equation they were to write was a 
two-step two-variable equation. Next, students were given the value of one of the variables and asked to solve for the other variable. The open-responses displayed the following misconceptions and errors: wrong operation used, difficulty with the symbolic representation of a scenario, understands the process of solving equations but makes a computational error, omitting one of the two variables, transcription errors, substituting the given for the wrong variable, writing an expression instead of an equation, and other. Nearly all of these errors or misconceptions were also present on the sixth- and eighthgrade items.

For this item, students had the most difficulty with the symbolic representation of a scenario (algebraic equations). The errors found here which were also found in the review of literature and on the sixth- and eighth-grade items for algebraic equations were difficulty with the symbolic representation of a scenario (Booth, 1984; Nathan \& Koedinger, 2000) and understands the process of solving equations but makes a computational error $(\mathrm{Wu}, 2001)$. Unlike the sixth- and eighth-grade items, these openresponses displayed very few computational errors with whole numbers although still present.

Multi-step one-variable equations. One item provided students with a multi-step equation which included distributive property and combining like terms and then showed line-by-line steps to solve the equation. Students were then asked to first describe the error that was made and then resolve the equation correctly. Therefore, the item had two parts with each part being worth one point. Errors or misconceptions in the description or solving process included the following: difficulty combining like terms, omitting a negative sign, difficulty with inverse operations, making computational errors with whole 
numbers, and other. All of these mistakes were present on the sixth- and eighth-grade items.

For this item, combining like terms was the most common error made with errors in inverse operations and omitting negative signs close behind. Only one student made a computational error with whole numbers. The errors found here which were also found in the review of literature and on eighth-grade items for numbers and numerical operations was omitting a negative sign (Ashlock, 2006), for algebraic symbolism and letter usage was difficulty combining like terms (Booth \& Watson, 1990; Booth, 1986; Stacey \& MacGregor, 1997b), and for algebraic equations was difficulty using inverse operations (Linchevski \& Herscovics, 1996).

\section{Summary of Secondary Findings}

To conclude the secondary findings from the Algebra I open-responses, overall connections to the literature review and the sixth- and eighth-grade open-responses will now be discussed. Throughout the analysis of the Algebra I open-responses, connections were made linking common errors and misconceptions present in the sixth- and eighthgrade items and Algebra I items. Specifically, references were made to those errors and misconceptions which were also found in the review of literature. Table 121 outlines the literature connections present on the Algebra I open-responses which were also present on the either or both the sixth-and eighth-grade items. 
Table 121

Literature Connections Found in Algebra I and Sixth-and Eighth-Grade Open-

Responses

\begin{tabular}{|c|c|c|}
\hline Prerequisite Content Area & Misconception/Error & Reference \\
\hline $\begin{array}{l}\text { Numbers and Numerical } \\
\text { Operations }\end{array}$ & Incorrect use of signs & Ashlock, 2006 \\
\hline $\begin{array}{l}\text { Numbers and Numerical } \\
\text { Operations }\end{array}$ & Omitting negative signs & Ashlock, 2006 \\
\hline $\begin{array}{l}\text { Algebraic Symbolism and } \\
\text { Letter Usage }\end{array}$ & $\begin{array}{l}\text { Difficulty combining like } \\
\text { terms }\end{array}$ & $\begin{array}{l}\text { Booth and Watson, 1990; } \\
\text { Booth, 1986; Stacey and } \\
\text { MacGregor, 1997b }\end{array}$ \\
\hline Algebraic Equations & $\begin{array}{l}\text { Difficulty with the symbolic } \\
\text { representation of a scenario }\end{array}$ & $\begin{array}{l}\text { Booth, 1984; Nathan and } \\
\text { Koedinger, } 2000\end{array}$ \\
\hline Algebraic Equations & $\begin{array}{l}\text { Understands the process of } \\
\text { solving equations but makes } \\
\text { computational error }\end{array}$ & $\mathrm{Wu}, 2001$ \\
\hline Algebraic Equations & $\begin{array}{l}\text { Difficulty using inverse } \\
\text { operations }\end{array}$ & $\begin{array}{l}\text { Linchevski and Herscovics, } \\
1996\end{array}$ \\
\hline Functions & $\begin{array}{l}\text { Difficulty graphing the } \\
\text { slope of a line }\end{array}$ & $\begin{array}{l}\text { Kalchman and Koedinger, } \\
2005 \text {; Labato and Ellis, } \\
2010\end{array}$ \\
\hline Graphing & $\begin{array}{l}\text { Difficulty graphing the } \\
\text { slope of a line }\end{array}$ & $\begin{array}{l}\text { Kalchman and Koedinger, } \\
2005 \text {; Labato and Ellis, } \\
2010\end{array}$ \\
\hline
\end{tabular}

The other main finding related to amount of computational errors. It was found that substantially fewer computational errors were present on the Algebra I openresponses than were found on the sixth- and eighth-grade open-responses. Students were allowed to use calculators on approximately one-half of all of the Algebra I items (not able to identify which ones) so it was likely they were able to use a calculator on approximately half of the ten items examined. However, this was also true for the eighthgrade items. It was also found that, in general, the Algebra I items had more steps 
involved for each item. The researcher found more omitted steps in the Algebra I openresponses than were found in the sixth- and eighth-grade items.

\section{Secondary Analysis - Interviews with Key Informants}

As part of a secondary analysis for this study, the researcher conducted interviews with key informants. The key informants included a mathematics specialist at the state's Department of Education office, a sixth-grade mathematics teacher, and an eighth-grade mathematics teacher. Both the sixth- and eighth-grade mathematics teachers are considered master teachers and work in the state where the standardized assessment is administered. They have also taught mathematics in their respective grade level for numerous years. Through the interviews, the researcher hoped to gain additional insight and perspectives regarding the common errors and misconceptions found on algebrarelated open-responses at the middle grades on both the standardized assessment (perspective of the content specialist) and as seen on a daily basis in the classroom (perspective of the sixth- and eighth-grade math teachers).

The first interview conducted was with the mathematics specialist at the state's Department of Education. This interview was conducted over the phone and lasted approximately 55 minutes. The researcher recorded the interview by placing the phone on speaker phone and then recorded the conversation with a digital voice recorder. The second interview was conducted with the eighth-grade mathematics teacher. This interview was also conducted over the phone and lasted approximately 35 minutes. The researcher recorded this interview in the same way. The third interview was conducted with the sixth-grade mathematics teacher in person and lasted approximately 30 minutes. Below is a summary of the three interviews. 
The mathematics content specialist was asked to what extent does the standardized assessment at the sixth- and eighth-grade levels measure students' skills for success in Algebra I and how well the standardized assessment captures students' misconceptions. The content specialist explained that the assessments are aligned to the state standards which have a learning progression. The content specialist stated that the standardized assessment provides a nice snapshot and that one standard in particular, the algebra and function standard, specifically addresses prerequisite algebra skills in addition to other standards such as computation and number sense which would also be helpful to students taking algebra. Furthermore, the content specialist discussed how the holistic rubrics on the open-response questions capture a student's response and where their mistake(s) lie.

All three interviewees were given a group of cards with Welder's (2007) nine prerequisite content areas and were asked questions regarding Welder's nine prerequisite skills for success in Algebra I. When asked which of the nine prerequisite content areas students find particularly challenging, the mathematics content specialist said algebraic equations and functions, the eighth-grade mathematics teacher gave three answers algebraic symbolism and letter usage, numbers and numerical operations, and the order of operations, and the sixth-grade mathematics teacher gave two responses, ratios and proportions and equality. When asked which of the nine prerequisite content areas students perform especially well on, the mathematics content specialist did not feel there was a content area that fit, the eighth-grade mathematics teacher stated algebraic equations, and the sixth-grade mathematics teacher stated order of operations and numbers and numerical operations (not including fractions). The researcher found it 
interesting that there was no clear agreement between the three interviewees and it was particularly interesting that the eighth-grade mathematics teacher felt students had difficulties with the order of operations and numbers and numerical operations while the sixth-grade mathematics teacher considered that a strength of sixth-grade students. Through analysis of the sixth- and eighth-grade open-response items, it was found that numbers and numerical operations are particularly challenging for students while the order of operations ranked towards the bottom.

The researcher asked each of the interviewees to rank order the nine prerequisite content areas according to their presence on the applied skills portion of the standardized assessment (for the mathematics content specialist) or their presence in the curriculum for that grade level (for the sixth- and eighth-grade mathematics teachers). Each interviewee had the nine cards in front of them and physically moved them until they settled on a rank order which they believed to be true. Each interviewee took their time and gave considerable thought on this task. The mathematics content specialist listed them in the following order: algebraic symbolism and letter usage, algebraic equations, and equality as a tie for first, second, and third; functions and graphing as a tie for fourth and fifth, numbers and numerical operations, ratios and proportions, the order of operations, and patterning. The eighth-grade mathematics teacher used this order: numbers and numerical operations and the order of operations tied for first and second, algebraic equations and algebraic symbolism and letter usage tied for third and fourth, graphing, ratios and proportions, functions, equality, and patterning. The sixth-grade mathematics teacher used the following order: numbers and numerical operations, the order of operations, algebraic symbolism and letter usage, algebraic equations, graphing, equality, patterning, 
ratios and proportions, and functions. The researcher found it most interesting that the teachers placed numbers and numerical operations and the order of operations at the top while the content specialist did not. It is also interesting that teachers may emphasize numbers and numerical operations in their classroom but students still struggle with basic computation on the assessment.

The interviewees were also asked to look at each of the nine prerequisite content areas and discuss any student misconceptions and errors that came to their mind. For the numbers and numerical operations prerequisite content area one interviewee mentioned the difficulty with fraction computation. For ratios and proportions two interviewees mentioned that students struggled with the conceptual understanding of ratios. Two interviewees mentioned that when working with the order of operations students would often simplify the parentheses first but then perform operations from left to right. Difficulty writing an algebraic expression or equation from a given scenario was mentioned by two interviewees. One interviewee noted students' difficulty in taking the time to read and determine the context of the problem before trying to form an expression or equation. Another interviewee mentioned that when asked to write an algebraic equation to represent a scenario, students will often write an expression. The third interviewee discussed her difficulty with getting students to be flexible when performing inverse operations. She gave the example that students are comfortable with $x+3=5$ but do not feel comfortable performing inverse operations when the equation is rewritten as 3 $+x=5$. She also said students often do not grasp the benefit of checking their solution when solving an equation. The sixth-grade teacher discussed how difficult it is for students to understand the need to perform inverse operations (to preserve equivalence) 
when beginning to solve algebraic equations. She said students want to continue using arithmetic methods to obtain a solution. Finally, the eighth-grade teacher noted students' struggle with function notation, $f(x)$, and their difficulty understanding the values of the $x$ - and $y$-coordinates of the four quadrants in a coordinate plane. Some of these mentioned misconceptions and errors were found in the primary analysis of this study, particularly, the understanding of a ratio, writing an algebraic expression or equation from a given scenario, and solving equations.

The mathematics content specialist was asked the extent to which students showing their work or complete work factored into their score and stated that "It's huge, it's absolutely huge, it's great how you can see how - look at students' responses and have a very good grasp on what they know." The sixth- and eighth-grade teachers were also asked about students showing their work on the standardized assessment and the eighth-grade teacher mentioned that sometimes they will not show any work or are lazy in providing clear explanations. She mentioned that a student will write a two word explanation when there are four lines available. She did mention that when the test became computerized last year she felt students were more motivated and careful about their work. The sixth-grade teacher felt that students showed work, but maybe not complete work.

When asked about transcription errors, the mathematics content specialist stated that it does happen but only in a small number of responses. The sixth-grade mathematics teacher stated that she has often seen students make transcription errors, specifically when copying the values from the problem or in line-by-line work when solving an algebraic equation. 
When asked about the clue words written in all capital letters, the mathematics content specialist explained that the clue words are determined by teachers involved in item development and that they certainly help students. Both the sixth- and eighth-grade mathematics teachers were unaware that clue words in all capital letters were present on some items and for that reason, had not previously discussed the clue words with their students.

The researcher also asked about the benefit of students using a calculator on some items (at the eighth-grade level). While each interviewee was unsure but interested in the answer to this question, both the sixth- and eighth-grade mathematics teachers acknowledged that students still had to know the concepts and understand the question in order for the calculator to be beneficial. The sixth-grade teacher mentioned that it could help students who work slower because they could benefit from performing computations quicker (as long as they understood the concepts) and the eight-grade teacher noted that students must know how to use their calculator effectively and efficiently, such as for verification or tedious calculations, in order for it to be beneficial.

Finally, the teachers were asked what they did to prepare their students for the standardized assessment. Both teachers said that they work on similar type problems throughout the year, talk about general test taking strategies, and work more practice problems leading up to the date of the standardized assessment. Both teachers also said that they spend extra time emphasizing and practicing how to show work in a neat and organized way and how to provide clear explanations. The mathematics content specialist suggested that throughout the year teachers should use formative assessments daily to 
gauge students' progress, engage students in rich tasks that involve critical thinking, and having a focused curriculum.

In conclusion, the interviews provided the researcher with affirmation regarding some of the common algebra-related misconceptions and errors made by middle school students. It was also interesting that the three interviewees ranked ordered and responded to many questions very differently. It was surprising that the mathematics content specialist believed that some teachers teach their students to look for the clue words in all capital letters while both the sixth- and eighth-grade mathematics teachers did not know clue words in capital letters existed. Finally, it was interesting to hear how the teachers prepare their students for the standardized assessment and to gain the mathematics content specialist's unique perspective through his responses to the questions.

\section{Conclusion}

These findings provide instructional guidance to teacher educators, mathematics curriculum specialists, upper elementary teachers, middle school mathematics teachers, and Algebra I teachers. Chapter V discusses the conclusions and implications of these results as well as the limitations of this study and suggestions for future research. 


\section{CHAPTER V}

\section{DISCUSSION}

\section{Introduction}

Chapter V presents a summary of the study, a summary of the results, and conclusions based on the findings presented in Chapter IV. Additionally, Chapter V includes a discussion of the implications the findings have on teaching. It concludes with limitations of this study and recommendations for future research.

\section{Summary of the Study}

\section{Restatement of Problem Statement}

The importance of examining algebra misconceptions and errors of middle school students stems from our nation's goal to remain mathematically competitive. High school students are encouraged to take more mathematics courses with increased difficulty (NCTM, 2009). Additionally, states are holding students and schools responsible by requiring students to pass graduation tests that demonstrate understanding of algebra (Bottoms, 2003). This pressure places great responsibility on mathematics teachers to teach algebra in ways that help all students in becoming skilled (Capraro \& Joffrion, 2006).

This increase in mathematics accountability has caused mathematics content to be "pushed down" into earlier grades. A significant movement in mathematics education suggests that one element in leading students towards a successful path in algebra is the integration of algebraic thinking skills starting in elementary school and extending into 
the middle grades (Asquith, Stephens, Knuth, \& Alibali, 2007; Baroudi, 2006; Blanton \& Kaput, 2005; Capraro \& Joffrion, 2006; Carraher, Schielmann, Brizuela, \& Ernest, 2006; Erbas, 2005; Falkner, Levi, \& Carpenter, 1999; NCTM, 2000; Warren, 2009). Prealgebra concepts are commonly a curriculum focus for sixth- and seventh-grade, while eighth-grade students often enroll in first-year algebra (Witzel, 2005).

The NCTM states that algebra-related skills should be addressed in the middle grades as documented in their Principles and Standards for School Mathematics (2000). Specifically, this study aligns with the NCTM Algebra content standard for grades 6-8 from Principles and Standards for School Mathematics (NCTM, 2000). The NCTM (2000) supports the belief that teachers should both introduce and continuously build upon algebraic thinking concepts in early grades. For example, the NCTM Curriculum Focal Points states that students in grade six should "...write mathematical expressions and equations that correspond to given situations, they evaluate expressions, and they use expressions and formulas to solve problems" (NCTM, 2006, p. 35). By the time students finish grade eight, the Curriculum Focal Points state that students should "...use linear functions, linear equations, and systems of linear equations to represent, analyze, and solve a variety of problems" (NCTM, 2006, p. 39).

Similarly, the CCSS have an Expression and Equation standard for each of grades six, seven, and eight and a Functions standard for grade eight (CCSSO/NGA, 2010). The CCSS were designed to "...define the knowledge and skills students should have within their K-12 education careers so that they will graduate high school able to succeed in entry-level, credit-bearing academic college courses and in workforce training programs" (CCSSO/NGA, 2010, para.4). Additionally, many more concepts which were 
traditionally Algebra I concepts (such as functions and systems of linear equations) are now addressed in the eighth-grade under the CCSS (CCSSO/NGA, 2010). As of September 2011, 44 states in our nation have already adopted these newly released standards.

\section{Restatement of Purpose and Research Question}

The purpose of this study was to examine and categorize common algebra-related misconceptions and errors of middle school students aligned to Welder's (2007) nine prerequisite content areas in which students should be knowledgeable before entering their first formal algebra course (Algebra I). The research question for this study was the following:

1. What common algebra-related misconceptions and errors exist among students in grades six and eight as identified on student responses on an annual statewide standardized assessment?

\section{Review of Research Methodology}

This research study used qualitative document analysis in order to analyze sixthand eighth-grade student responses on a statewide standardized assessment. A secondary data source consisted of Algebra I student responses on a statewide standardized assessment, a test that also served as the mathematics graduation exam for the state. These Algebra I student responses were also analyzed qualitatively using document analysis. An additional secondary data source included follow-up interviews with key informants.

For the primary analysis of sixth- and eighth-grade student open-responses, data were collected in the form of existing data. The open-responses obtained from the 
publisher of this state's standardized assessment were a collection of student responses from each item which were used to train scorers to accurately score the potential variety of open-responses. A total of 20 student responses were received for each of 45 items which were then aligned to the nine prerequisite content areas for success in Algebra I. These open-responses were received by the researcher in an electronic format in July 2011.

The student responses to the Algebra I items used for a secondary analysis were obtained in a similar way. Although they came from a different testing publisher, the student responses obtained were also the set of open-responses used to train scorers to score the open-response items. These student responses were also received by the researcher in an electronic format in July 2011.

Interviews with key informants were conducted as a secondary analysis. An interview with a mathematics specialist from the state's Department of Education office was conducted over the telephone in August 2011. Interviews with a sixth-grade mathematics teacher (in person) and eighth-grade mathematics teacher (by telephone) were conducted in September 2011.

The primary data, which included the sixth- and eighth-grade open-responses, were analyzed qualitatively by document analysis. Before obtaining the student responses the researcher used the review of literature to establish a set of initial codes for each of the nine prerequisite content areas examined (see Appendix B). Once the data were received, the researcher coded a sample of the data and added additional codes as needed. After establishing inter-rater reliability with two other doctoral students in mathematics education, the researcher finished the coding process. Once all coding of the primary data 
was complete, the researcher made final modifications in the coding list to streamline, clarify, and align the categorizations to the review of literature and Welder's nine prerequisite content areas. See Appendix C for a final list of codes for each of the nine prerequisite content areas. Finally, the researcher reviewed the coding of all items a final time before writing the results section.

\section{Summary of Primary Findings}

The primary purpose of this research was to examine sixth- and eighth-grade student responses from a state's standardized assessment. In this summary, the findings are connected to both the review of literature and additional findings are discussed. In Chapter IV, tables which linked the identified misconceptions and errors to the review of literature were present for each prerequisite content area that aligned to each item.

The following list summarizes the main findings from the sixth- and eighth-grade open-responses.

1. Many errors and misconceptions identified in the review of literature for the Welder's (2007) nine prerequisite content areas were present throughout the sixthand eighth-grade open-responses. Specifically, the inability to unitize (ratios and proportions), computational errors with decimals (numbers and numerical operations), difficulty with the symbolic representation of a scenario (algebraic equations), and difficulty interpreting functions and graphs (functions and graphing) were predominate in the findings. A listing of all connections to the review of literature can be found in Table 120. Twenty-two identified misconceptions and errors were found in the sixth-grade items and 28 were found in the eighth-grade items. When both the number of items which the 
misconception or error was present and percentage it represented within the items for each of the nine prerequisite content areas are taken into account, the evidence of the presence of the prerequisite content areas for the sixth-grade items are ranked as follows (all ties are grouped together): (1 and 2) numbers and numerical operations and ratios and proportions, ( 3 and 4) algebraic equations and graphing, (5 and 6) algebraic symbolism and letter usage and functions, (7) patterning, (8) the order of operations, and (9) equality. For eighth-grade, the ranking of the presence of the prerequisite content areas is as follows (all ties are grouped together): (1,2, and 3$)$ algebraic equations, numbers and numerical operations, and ratios and proportions, (4) graphing, (5) functions, (6) the order of operations, (7 and 8) algebraic symbolism and letter usage and equality, and (9) patterning.

2. Although not specifically one of Welder's (2007) prerequisite content areas for success in Algebra I, basic computational errors with whole numbers were present on approximately $16.5 \%$ of student responses on applicable items. This was unexpected and surprising. However, the state's Department of Education classifies every item on the standardized assessment by one of the following primary mathematics standards that the item examines: number sense, computation, algebra and functions, geometry, measurement, data analysis and probability, and problem solving. It is of significant importance to note that not one of the 20 sixth-grade and not one of the 25 eighth-grade open-response items were classified as computation. Therefore, while students made computational errors, conceptual and deeper knowledge of other mathematics content must still 
be present initially in order to assess and solve each item. In essence, computation was always a secondary skills needed to solve each problem.

3. More misconceptions and errors identified in the review of the literature were present in the eighth-grade items than were found in the sixth-grade items. Twenty-two misconceptions and errors were found in the sixth-grade items and 28 were found in the eighth-grade items which were identified in the review of literature. In addition, the errors and misconceptions found in the eighth-grade items tended to be present on more items. For example, the misunderstanding of the inability to unitize (Behr et al., 1992; Singh, 2000) was present on eight eighth-grade items while it was only present on two sixth-grade items. The eighth-grade items also displayed many more errors and misconceptions within the algebraic equations prerequisite content area likely because more items in the eighth-grade related to algebraic equations.

4. Students often lost points for other reasons. This problematic set of "non mathematical" errors was present on the following percent of student responses (on applicable items): not showing complete work (7.2\%), not showing any work (4.7\%), omitting a value (2.5\%), transcription error when writing answer on answer line (2.1\%), and transcription error when writing down values or working steps in the problem $(1.9 \%)$.

5. While this research validates that the content within Welder's (2007) framework aligns to prerequisite skills for success in Algebra I, some refinement and reorganization of this framework could prove beneficial when using this framework for data analysis purposes. 
a. First, it was found that the numbers and numerical operations prerequisite content area was extremely broad and difficult to use during data analysis because of the sheer number of possible misconceptions and errors found within this single prerequisite content area. In other words, perhaps too much content is contained in the numbers and numerical operations prerequisite content area. The researcher suggests that the numbers and numerical operations prerequisite content area be divided into to two or more separate prerequisite content areas. For example, using the categorization modeled by the newly released CCSS (CCSSO, 2010), perhaps the numbers and numerical operations prerequisite content area could be split into three separate groups. The first two groups would include numbers and operations in base ten and numbers and operations of fractions, as found in the CCSS for grades three through five (CCSSO, 2010). A third group would include other rational numbers in the number system, such as integers and exponents. The number system is a categorization also used by the CCSS beginning in grade six (CCSSO, 2010). Additionally, using a grouping such as this would allow for the much needed inclusion of whole numbers into the framework.

b. Second, other content areas had overlapping codes of misconceptions and errors - such as functions and graphing. The researcher found that many of the same misconceptions and errors fit into both of these prerequisite content areas - which caused overlapped coding. When examining the NCTM's Principles and Standards for School Mathematics (NCTM, 
2000), this study aligns most closely with the Number and Operations and Algebra content strands. It appears that this framework divided the Numbers and Operations content strand into only two prerequisite content areas (numbers and numerical operations and the order of operations). Conversely, the Algebra content strand was divided into the remaining seven prerequisite content areas (ratios and proportions, equality, patterning, algebraic symbolism and letter usage, algebraic equations, functions, and graphing). This division seems disproportionate. For example, functions and graphing could be grouped together although some differences do exist. Overall, the researcher found Welder's framework effective for data analysis but believes it could be improved with these suggested refinements.

\section{Summary of Secondary Findings}

Two secondary or follow-up analyses were conducted as part of this research study. One of the secondary analyses included the examination of open-responses from an Algebra I standardized assessment administered in the same state as the sixth- and eighth-grade assessment. The researcher chose to examine open-responses from the Algebra I assessment in order to see whether students continued to display the same errors and misconceptions in Algebra I as they did in the middle grades. The other secondary analysis included follow-up interviews with key informants.

The following list summarizes the main findings from the Algebra I openresponses. 
1. It was found that some errors and misconceptions which were identified in the review of literature and the sixth- and eighth-grade open-responses were also present on the Algebra I open-responses. Specifically, the following misconceptions and errors were found: incorrect use of signs and omitting negative signs (numbers and numerical operations); difficulty combining like terms (algebraic symbolism and letter usage); difficulty with the symbolic representation of a scenario, understands the process of solving equations but makes a computational error, and difficulty using inverse operations (algebraic equations); and difficulty graphing the slope of a line (functions and graphing).

2. The Algebra I open-responses had substantially fewer computational errors compared to the sixth- and eighth-grade open-responses. This was found to be surprising because it is assumed that students would not have additional instructional time dedicated to the computation of whole numbers between eighthgrade and Algebra I.

3. Students were more likely to omit a step on the Algebra I items. Perhaps this is because $80 \%$ of the Algebra I items examined had three or more steps included in each item.

The interviews conducted with key informants further affirmed some of the misconceptions and errors found on the sixth-and eighth-grade items. Additionally, the interviews helped the researcher gain a perspective from both a teacher point of view at the sixth-and eighth-grade level and from a mathematics content specialist. It was interesting that each of their responses varied greatly. For example, both the sixth- and eighth-grade mathematics teacher ranked numbers and numerical operations and the 
order of operations at the top while the mathematics specialist ranked algebraic symbolism and letter usage, algebraic equations, and equality at the top. When asked about preparing students for the annual standardized assessment, the sixth- and eighthgrade teachers discussed the use of practice test items and an emphasis on good test taking skills while the mathematics content specialist concentrated on the year around use of formative assessments, rich mathematical tasks, and a focused curriculum. Overall, it seems that with this wide range of different priorities, perhaps a focus should be placed on creating a more uniform sense of priorities in order to better align the focus of classroom curriculum and state standardized assessment.

\section{Comparison of Primary and Secondary Findings}

The researcher was interested in the presence and frequency of misconceptions and errors within Welder's nine prerequisite content areas for success in Algebra I. In order to compare the rankings between the primary findings for each sixth- and eighthgrade open-response items, the Algebra I open-response items, and the responses from each of the interviewees, a comparison table was made. All ties are denoted by shaded cells. For example, for the sixth-grade items primary analysis, numbers and numerical operations and ratios and proportions have the same shading because they are tied for first and second. Next, algebraic equations and graphing have the same shading because they are tied for third and fourth, algebraic symbolism and letter usage and functions are

tied for fifth and sixth, patterning is seventh (no tie), the order of operations is eighth (no tie), and equality is ninth (no tie). See Table 122. 
Table 122

Comparison of Findings Related to Welder's Nine Prerequisite Content Areas

\begin{tabular}{|c|c|c|c|c|c|c|}
\hline & $\begin{array}{c}\text { Sixth- } \\
\text { Grade } \\
\text { Items } \\
\text { Primary } \\
\text { Analysis }\end{array}$ & $\begin{array}{l}\text { Eighth- } \\
\text { Grade } \\
\text { Items } \\
\text { Primary } \\
\text { Analysis }\end{array}$ & $\begin{array}{l}\text { Algebra I } \\
\text { Items } \\
\text { Secondary } \\
\text { Analysis }\end{array}$ & $\begin{array}{c}\text { Interview } \\
\text { with } \\
\text { Sixth- } \\
\text { Grade } \\
\text { Teacher }\end{array}$ & $\begin{array}{l}\text { Interview } \\
\text { with } \\
\text { Eighth- } \\
\text { Grade } \\
\text { Teacher }\end{array}$ & $\begin{array}{c}\text { Interview } \\
\text { with Math } \\
\text { Specialist }\end{array}$ \\
\hline 1 & $\begin{array}{l}\text { Numbers } \\
\text { and } \\
\text { Numerical } \\
\text { Operations }\end{array}$ & $\begin{array}{l}\text { Algebraic } \\
\text { Equations }\end{array}$ & $\begin{array}{l}\text { Algebraic } \\
\text { Equations }\end{array}$ & $\begin{array}{l}\text { Numbers } \\
\text { and } \\
\text { Numerical } \\
\text { Operations }\end{array}$ & $\begin{array}{l}\text { Numbers } \\
\text { and } \\
\text { Numerical } \\
\text { Operations }\end{array}$ & $\begin{array}{l}\text { Algebraic } \\
\text { Symbolism } \\
\text { and Letter } \\
\text { Usage }\end{array}$ \\
\hline 2 & $\begin{array}{l}\text { Ratios and } \\
\text { Proportion }\end{array}$ & $\begin{array}{l}\text { Numbers } \\
\text { and } \\
\text { Numerical } \\
\text { Operations }\end{array}$ & $\begin{array}{l}\text { Numbers } \\
\text { and } \\
\text { Numerical } \\
\text { Operations }\end{array}$ & $\begin{array}{l}\text { The Order } \\
\text { of } \\
\text { Operations }\end{array}$ & $\begin{array}{l}\text { The Order } \\
\text { of } \\
\text { Operations }\end{array}$ & $\begin{array}{l}\text { Algebraic } \\
\text { Equations }\end{array}$ \\
\hline 3 & $\begin{array}{l}\text { Algebraic } \\
\text { Equations }\end{array}$ & $\begin{array}{l}\text { Ratios and } \\
\text { Proportion }\end{array}$ & $\begin{array}{l}\text { Algebraic } \\
\text { Symbolism } \\
\text { and Letter } \\
\text { Usage }\end{array}$ & $\begin{array}{l}\text { Algebraic } \\
\text { Symbolism } \\
\text { and Letter } \\
\text { Usage }\end{array}$ & $\begin{array}{l}\text { Algebraic } \\
\text { Equations }\end{array}$ & Equality \\
\hline 4 & Graphing & Graphing & Functions & $\begin{array}{l}\text { Algebraic } \\
\text { Equations }\end{array}$ & $\begin{array}{l}\text { Algebraic } \\
\text { Symbolism } \\
\text { and Letter } \\
\text { Usage }\end{array}$ & Functions \\
\hline 5 & $\begin{array}{l}\text { Algebraic } \\
\text { Symbolism } \\
\text { and Letter } \\
\text { Usage }\end{array}$ & Functions & Graphing & Graphing & Graphing & Graphing \\
\hline 6 & Functions & $\begin{array}{l}\text { The Order } \\
\text { of } \\
\text { Operations }\end{array}$ & N/A & Equality & $\begin{array}{l}\text { Ratios and } \\
\text { Proportion }\end{array}$ & $\begin{array}{l}\text { Numbers } \\
\text { and } \\
\text { Numerical } \\
\text { Operations }\end{array}$ \\
\hline 7 & Patterning & $\begin{array}{l}\text { Algebraic } \\
\text { Symbolism } \\
\text { and Letter } \\
\text { Usage }\end{array}$ & N/A & Patterning & Functions & $\begin{array}{l}\text { Ratios and } \\
\text { Proportion }\end{array}$ \\
\hline 8 & $\begin{array}{l}\text { The Order } \\
\text { of } \\
\text { Operations }\end{array}$ & Equality & N/A & $\begin{array}{l}\text { Ratios and } \\
\text { Proportion }\end{array}$ & Equality & $\begin{array}{l}\text { The Order } \\
\text { of } \\
\text { Operations }\end{array}$ \\
\hline 9 & Equality & Patterning & N/A & Functions & Patterning & Patterning \\
\hline
\end{tabular}


Several conclusions can be drawn from Table 122. First, it verifies that the Algebra I items are more closely related to the eighth-grade items which helps to substantiate the primary finding that more errors and misconceptions were found in the eighth-grade items than were found in the sixth-grade items. Additionally, some alignment can be seen between the rankings of the sixth-grade and the eighth-grade teachers which interestingly do not align well to the ranking of the mathematics content specialist. The sixth-grade teacher only had two out of nine exact matches in ranking (numbers and numerical operations and patterning) when compared to the analysis of data for the sixth-grade items. The eighth-grade teacher had three out of nine exact matches in ranking (numbers and numerical operations, equality, and patterning) when compared to the analysis of data for the eighth-grade items.

For both the sixth- and eighth-grade items, numbers and numerical operations and ratios and proportions were found to rank the highest with regards to identified misconceptions and errors. With regards numbers and numerical operations, this aligns to the perceptions of both the sixth- and eighth-grade teachers, but not the mathematics content specialist. None of the interviewees mentioned ratios and proportions as a high ranking. Additionally, a major emphasis must be placed on algebraic equations at the eighth-grade level because it also ranked at the top for the eighth-grade findings from the analysis of primary data. Both the eighth-grade teacher and mathematics content specialist also had algebraic equations ranking at the top. It appears that the sixth-and eighth-grade teachers should place more of a focus on ratios and proportions (specifically converting units and unitizing) and less of a focus on the order of operations in an effort to better align their curriculum to fit the requirements of the standardized assessment. 
Moreover, there appears to be a disconnect between what students need based on the findings from the open-responses compared to the focus teachers place in the classroom with regards to the nine prerequisite content areas.

\section{Linking Findings to the Literature}

This study was different from other studies because it analyzed student misconceptions and errors related to prerequisite skills for Algebra I on a wide variety of open-response questions which were aligned to the nine prerequisite content areas. As identified through the review of literature, many studies which are related to the nine prerequisite algebra content areas as outlined by Welder (2007) are conducted on a very small scale (e.g. one classroom) (as found in Bastable \& Schifter, 2008; Kaput, 2000; Kaput \& Blanton, 2001 and others) or focus on one specific skill (as found in Brown \& Quinn, 2006; Capraro \& Joffrion, 2006; Falkner et al., 1999; MacGregor \& Stacey, 1997; Stacey \& MacGregor, 1997b; Steinberg et al., 1990; Wollman, 1983 and others).

The finding from both the sixth- and eighth-grade open-responses and the Algebra I open-responses repeatedly aligned to the review of literature. This is displayed in numerous tables for each item aligned to the content areas throughout Chapter IV, summarized in Table 120 for the sixth- and eighth-grade items, and summarized in Table 121 for the Algebra I items. Specifically, the inability to unitize (ratios and proportions), computational errors with decimals (numbers and numerical operations), difficulty with

the symbolic representation of a scenario (algebraic equations), and difficulty interpreting functions and graphs (functions and graphing) were predominate in the findings for the sixth- and eighth-grade items. All three interviewees mentioned the difficulty students have with writing equations given a scenario and with the conceptual understanding of 
ratios and proportions. For the Algebra I items, the incorrect use of signs and omitting negative signs (numbers and numerical operations); difficulty combining like terms (algebraic symbolism and letter usage); difficulty with the symbolic representation of a scenario, understands the process of solving equations but makes a computational error, and difficulty using inverse operations (algebraic equations); and difficulty graphing the slope of a line (functions and graphing) were misconceptions and errors identified in the analysis.

The main disconnect between the review of literature and the findings were the number of basic computational errors with whole numbers found throughout the openresponses on the sixth- and eighth-grade items. While basic computational skills with whole numbers was not aligned to the review of literature for perquisite algebra skills, finding that students make so many errors with the computation of whole numbers raises great concern. However, in many other ways, the findings fit well with the previous research outlined in the review of literature. Identified errors and misconceptions from previous studies were displayed on many of the open-responses on a variety of items examined by the researcher.

The researcher felt that the findings from this study provided a view of identified misconceptions and errors at the middle grades level on prerequisite algebra skills through a wide lens. As previously mentioned, many studies have examined one specific misconception or error. This study examined 45 sixth-and eighth-grade items and 10 Algebra I items on a variety of prerequisite content areas for success in Algebra I. The findings of this study were able to validate the identified misconceptions and errors of many different previous studies discussed in the review of literature and show a link to 
Algebra I misconceptions. Perceptions of mathematics teachers at the sixth- and eighthgrade level and a mathematics content specialist at the Department of Education were also examined.

The findings contribute to the knowledge base by capturing a holistic picture of misconceptions and errors. This study examined student responses on a statewide standardized assessment. Therefore, it captured students' understanding on a variety of skills. Because this test is only administered annually perhaps it captured what students had remembered over time. Additionally, performances on standardized assessments are of highest priority for school districts, schools, teachers, and other stakeholders in mathematics education. It is likely that examining misconceptions and errors through the lens of open-responses on a standardized assessment could be found interesting to such stakeholders.

\section{Conclusions}

\section{Implications for Practice}

The results of this study provided valuable information about common misconceptions and errors students possess on prerequisite algebra skills. The findings revealed common algebra misconceptions and trends that can help guide instruction for middle school mathematics teachers. Overall, the primary audiences for the findings of this study are middle school mathematics teachers, first-year algebra teachers, and upper elementary teachers. The secondary audiences include curriculum specialists, school administrators, and teacher educators.

Each of the findings listed for both the primary analysis and the two secondary analyses have direct implications for the classroom and teacher education. It is widely 
known throughout the mathematics education community that teacher preparation is a potential barrier to the incorporation of early algebra in elementary school and prealgebra concepts in middle school. In 1986, Shulman discussed the specialized knowledge required for teaching. Later, Ball and others (2008) described this pedagogical knowledge specific to mathematics as the Mathematical Knowledge for Teaching (MKT). Many researchers have deemed teacher preparation a significant problem in mathematics (and algebra) education reform (Fennell et al., 2007; Kaput, 2000b; Ma, 1999).

The findings from this research study further confirm the need for strong and knowledgeable teachers of mathematics at the elementary and middle grades because teachers at these grades must be able to help students overcome all of the misconceptions and errors identified in this study. The researcher suggests that schools, both in the state whose standardized assessment was examined as well as other states, use this information to help build awareness of common algebra-related misconceptions and errors in elementary and middle grades mathematics teachers. Informed teachers who know what common misconceptions and errors exist and how to address such misunderstandings hold a great advantage in helping their students move forward in their mathematical understanding.

Teachers at the sixth-grade level should place a focus on the numbers and numerical operations and ratios and proportions prerequisite content areas with the greatest focus placed on computation with decimals and fractions and converting units. Teachers at the sixth-grade level should also start familiarizing students with formal algebraic symbolism, develop good algebraic-based equation solving practices with basic 
one- and two-step equations, and focus on students writing an equation or expression given a scenario. Students should also work on interpreting graphs and plotting ordered pairs.

At the eighth-grade level, teachers should continue to focus on the numbers and numerical operations and the ratios and proportions prerequisite content areas with a continued focus on computation with decimals and fractions and converting units. However, eighth-grade teachers should make helping all students become fluent and efficient in solving equations, examining multiple representations of linear functions, and writing an equation or expression given a scenario a top priority. Additionally, eighthgrade students should be able to plot ordered pairs, draw a slope of a line, and interpret graphs correctly and with conceptual understanding.

Additionally, this study emphasizes the knowledge which a teacher can gain from analyzing their own students' work. While closed-ended question types certainly have their time and place, classroom teachers can gain valuable knowledge from taking the time to examine authentic student work. Examining student work is a useful formative assessment tool that can effectively guide instruction.

Finally, this study lends advice to teachers with regards to test taking strategies. This study found that students often lose points on this standardized assessment because they do not show work, do not show complete work, make transcription errors, or do not look for clue words given in all capital letters. This is a substantial problem that should not be overlooked. 


\section{Limitations of this Study}

There were several limitations to this study. Merriam (2009) pointed out that because the documents, in this case open-response test questions, were not made for research purposes, they may not offer as much information as interviews or observations. For this reason, a follow-up analysis using interviews was conducted. Another limitation is the scope of the content examined. It would be nearly impossible to examine every possible question type related to Welder's (2007) framework for each grade six and eight. Therefore, there was concern to whether the open-response questions captured all of the major algebra misconceptions that really exist. Merriam (2009) would classify this threat as a threat to internal validity - the credibility of the data presented.

Another limitation in this study is the fact that the researcher could not determine whether mistakes made by students represented a misconception or error held by the student. In other words, because the data were existing student work, the researcher only had a snapshot of how individual students each answered one specific question on one specific day. No patterns within each student's performance could be analyzed to determine if the student made an error that they normally do not make, or if their mistake represented a deeply-rooted misconception. Some differentiation can be made in connection to skills as conceptual or procedural, but the analysis was not ideal. Therefore, in this study, misconceptions and errors were viewed as a whole, instead of as two separate entities.

The fact that the data source is an assessment only used in one state is another potential limitation of the study. If another state's standardized assessment had been analyzed instead, the format and types of question could vary greatly. Such analysis 
could lead to different findings. Merriam (2009) pointed out that while generalizability in a statistical sense does not exist in qualitative research, it is important that the findings of the study are generalizable to readers and users of the study. Therefore, this study potentially presents an external validity threat when asked if the findings would be the same with a different population or in a different location.

Finally, the state's Department of Education and testing publisher selected the student responses to be used as the training papers for each question. While these responses are said to be representative of the common responses students make for each question, the researcher has no way to verify that every common student response was represented in the training papers. Furthermore, while the range of the student responses were claimed to be representative of the common responses made by students, this does not mean that the frequency of each type of response is proportionally represented by the training papers.

As with any research study, this study was constrained by its limitations. Specifically, it was constrained by the items which were examined. In other words, if items had existed that asked different types of questions, additional misconceptions and errors may have been identified. For example, perhaps more misconceptions and errors related to patterning would have been identified if more test items related to patterning. The findings of this study could only be based on the items the researcher had access to.

Through reflection on the limitations of the study and the findings from the study, the researcher developed a list of suggestions for future research building from this dissertation. 


\section{Recommendations for Future Research}

The following is a list of ways this research could be extended.

1. Examine one or several of the nine prerequisite content areas of Welder's framework in greater depth - particularly the prerequisite content areas that were most prominent and provide the deepest level of concern. To do this, possibly administer only several of the examined items that fit well within a content area to a large population of students. Another suggestion is to use different items from a different standardized assessment. Using different items could potentially lead to different findings. While the researcher felt that each of the nine prerequisite content areas are worthy of further exploration it would be recommended to focus on the three that ranked the highest which were algebraic equations, numbers and numerical operations, and ratios and proportions.

2. The researcher is interested as to why sixth- and eighth-grade open-responses displayed substantially more errors in whole number computation than the Algebra I items. This was interesting because it is assumed that students would get no additional instruction on whole number computation between grade eight and their Algebra I course (because whole number computation is a focus of the elementary grades). However, the Algebra I items displayed many fewer errors in whole number computations even though whole number computation was used repeatedly when performing inverse operations, factoring, etc. Students were allowed to use calculators on approximately half of each the eighth-grade and Algebra I items so that variable does not explain the difference. The researcher is interested in exploring whether Algebra I students use a calculator more 
effectively, approach problems more carefully, and check their answers more often than middle grades students.

3. This study did not compare groups of students based on demographic variables. The researcher was told that the open-responses received were representative of the range of student responses for each item. No demographic or identification variables were provided with the open-responses. It would be interesting to conduct a similar study but also compare different populations of students to identify groups of students with the greatest need for intervention.

4. The researcher is interested in further research related to the Algebra I findings. In this study, the researcher examined ten Algebra I items in order to make general connections to the findings from the sixth- and eighth-grade open-responses. Another study could place a primary focus on errors and misconceptions found with Algebra I students - on a wide variety of items and a larger number of openresponses for each item.

5. Researchers should further examine student algebra-related misconception and errors from the viewpoint of the classroom teacher. The classroom teacher is the main ingredient in creating change and helping students progress in their understanding of mathematics. While two mathematics teachers were interviewed, it would be interesting to examine what many more middle grades mathematics teachers know about misconceptions and errors on prerequisite algebra concepts and to gain their perspectives on helping students overcome common algebrarelated misconceptions and errors. 


\section{Summary}

This project significantly deepened the knowledge of algebra-related misconceptions and errors made by middle grades students on prerequisite algebra skills in a Midwestern state. It was rewarding that the findings aligned to the review of literature. The most present misconceptions for the sixth- and eighth-grade items included: the inability to unitize (ratios and proportions), computational errors with decimals (numbers and numerical operations), difficulty with the symbolic representation of a scenario (algebraic equations), and difficulty interpreting functions and graphs (functions and graphing). For the Algebra I items, the incorrect use of signs and omitting negative signs (numbers and numerical operations); difficulty combining like terms (algebraic symbolism and letter usage); difficulty with the symbolic representation of a scenario, understands the process of solving equations but makes a computational error, and difficulty using inverse operations (algebraic equations); difficulty graphing the slope of a line (functions and graphing) were the most commonly found misconceptions and errors. Moreover, the additional findings were interesting and provided cause for concern. The sheer number of basic computational errors with whole numbers seen in the openresponses for both sixth- and eighth-grade was alarming. Although the students needed to access other algebraic concepts to succeed on these problems, the computational errors kept students from getting the correct answers. In addition, it was extremely frustrating for the researcher, a former middle school mathematics teacher, to see how many points students lost on questions due to not showing their work, lack of explanation, transcription errors, or other errors that could be avoided. In addition, there are clues 
given on the exam and it is unclear as to whether teachers have been privy to this feature so they can tell their students to use the clues effectively.

The researcher believes that both the review of literature and the findings from both the primary and secondary analyses can serve as a comprehensive guide to teachers, teacher educators, and curriculum specialists. This researcher can now help these stakeholders become aware of the algebra-related misconceptions and errors hindering middle grades students. Additionally, it can help raise awareness of other mistakes students make on standardized tests which can be addressed in the classroom. This can hopefully help students, teachers, and schools in their performance on such assessments and leave no child behind. 


\section{REFERENCES}

Abouchedid, K., \& Nasser, R. (2000). The role of presentation and response format in understanding, preconceptions and alternative concepts in algebra problems.Washington, D.C.: United States Department of Education.

Ainley, J., Bills, L., \& Wilson, K. (2004, July). Constructing meanings and utilities within algebraic tasks. Paper presented at the 28th Conference of the International Group for the Psychology of Mathematics Education, Bergen, Norway.

Ashlock, R., B. (2006). Error patterns in computation: Using error patterns to improve instruction (9 ed.). Upper Saddle Ridge, NJ: Pearson Merrill Prentice Hall.

Asquith, P., Stephens, A. C., Knuth, E. J., \& Alibali, M. W. (2007). Middle school mathematics teachers' knowledge of students' understanding of core algebraic concepts: equal sign and variable. Mathematical Thinking and Learning: An International Journal, 9(3), 249-272.

Ball, D. L., Thames, M. H., \& Phelps, G. (2008). Content knowledge for teaching: What makes it special? Journal of Teacher Education, 59(5), 389-407.

Baroudi, Z. (2006). Easing students' transition to algebra. Australian Mathematics Teacher, 62(2), 28-33.

Bastable, V., \& Schifter, D. (2008). Classroom stories: Examples of elementary students engaged in early algebra. In J. J. Kaput, D. W. Carraher \& M. L. Blanton (Eds.), Algebra in the early grades (pp. 165-184). New York, NY: Routledge. 
Behr, M., Erlwanger, S., \& Nichols, E. (1976). How children view equality sentences. Tallahassee: Florida State University.

Behr, M., Erlwanger, S., \& Nichols, E. (1980). How children view the equals sign. Mathematics Teaching, 92, 13-15.

Behr, M., Harrel, G., Post, T. R., \& Lesh, R. (1992). Rational number, ratio, and proportion. In D. A. Grouws (Ed.), Handbook of research on mathematics teaching and learning (pp. 296-333). Reston, VA: National Council of Teachers of Mathematics.

Blanton, M. L. (2008). Algebra and the elementary classroom: Transforming thinking, transforming practice. Portsmouth, NH: Heinemann.

Blanton, M. L., \& Kaput, J. J. (2005). Characterizing a classroom practice that promotes algebraic reasoning. Journal for Research in Mathematics Education, 36(5), 412446.

Booth, L. R. (1984). Algebra: Children's strategies and errors: A report of the strategies and errors in secondary mathematics project. Windsor, UK: NFER-NELSON.

Booth, L. R. (1986). Difficulties in algebra. Australian Mathematics Teacher, 42(3), 2-4.

Booth, L. R. (1988). Children's difficulties in beginning algebra. In A. F. Coxford \& A. P. Schulte (Eds.), The ideas of algebra: K-12, 1988 Yearbook. Reston, VA: National Council of Teachers of Mathematics

Booth, L. R., \& Watson, J. (1990). Research for teaching: Learning and teaching algebra. Australian Mathematics Teacher, 46(3), 12-14. 
Bottoms, G. (2003). Getting students ready for Algebra I: What middle grades students need to know and be able to do. Atlanta, GA: Southern Regional Education Board.

Braswell, J. S., Lutkus, A. D., Grigg, W. S., Santapau, S. L., Tay-Lim, B., \& Johnson, M. (2001). The nation's report card: Mathematics 2000. Washington, DC: U.S. Department of Education Office of Educational Research and Improvement.

Brenner, M. E., Brar, T., Duran, R., Mayer, R. E., Moseley, B., \& Smith, B. R. (1995, October). The role of multiple representations in learning algebra. Paper presented at the 17th Annual Meeting of the North American Chapter of the International Group for the Psychology of Mathematics Education, Columbus, $\mathrm{OH}$.

Briggs, J., Demana, F., \& Osborne, A. R. (1986). Moving into algebra: Developing the concepts of variable and function. Australian Mathematics Teacher, 42, 5-8.

Brown, G., \& Quinn, R. J. (2006). Algebra students' difficulty with fractions. Australian Mathematics Teacher, 62(4), 28-40.

Capraro, M. M., \& Joffrion, H. (2006). Algebraic equations: Can middle-school students meaningfully translate from words to mathematical symbols? Reading Psychology, 27, 147-164.

Carpenter, T. P., Fennema, E., Franke, M. L., Levi, L., \& Empson, S. B. (1999). Children's mathematics: Cognitively guided instruction Portsmouth, NH: Heinemann, National Council of Teachers of Mathematics 
Carpenter, T. P., Levi, L., \& Farnsworth, V. (2000). Building a foundation for learning algebra in the elementary grades. In Brief 1(2). Washington, DC: Wisconsin University.

Carraher, D. W., \& Schliemann, A. D. (2007). Early algebra and algebraic reasoning. In F. K. Lister (Ed.), Second handbook of research on mathematics teaching and learning (pp. 669-706). Reston, VA: NCTM.

Carraher, D. W., Schliemann, A. D., Brizuela, B. M., \& Ernest, D. (2006). Arithmetic and algebra in early mathematics education. Journal for Research in Mathematics Education, 37(2), 87-115.

Carraher, D. W., Schliemann, A. D., \& Schwartz, J. L. (2008). Early algebra is not the same as algebra early. In J. J. Kaput, D. W. Carraher \& M. L. Blanton (Eds.), Algebra in the early grades (pp. 235-272). New York, NY: Routledge.

Cathcart, W. G., Pothier, Y. M., Vance, J. H., \& Bezuk, N. S. (2003). Learning mathematics in elementary and middle school (3 ed.). Upper Saddle River, NJ: Pearson Education, INC.

CCSSO/NGA. (2010). Common Core State Standards for Mathematics. Council of Chief State School Officers and the National Governors Association Center for Best Practices. Retrieved from http://www.corestandards.org.

Chaiklin, S., Lesgold, S. B., \& Pittsburgh University Learning Research and Development Center. (1984). Prealgebra Students' Knowledge of Algebraic Tasks with Arithmetic Expressions. Pittsburgh, PA: University of Pittsburgh.

Choike, J. R. (2000). Teaching strategies for 'algebra for all'. Mathematics Teacher, $93(7), 556-560$. 
Clement, J. (1982). Algebra word problem solutions: Thought processes underlying a common misconception. Journal for Research in Mathematics Education, 13(1), $16-30$

Clement, J., Lochhead, J., \& Monk, G. (1981). Translation difficulties in learning mathematics. American Mathematical Monthly, 88, 286-290.

Clement, J., Narode, R., \& Rosnick, P. (1981). Intuitive misconceptions in algebra as a source of math anxiety. Focus on Learning Problems in Mathematics, 3(4), 3645.

Corbin, J., \& Strauss, A. (2008). Basics of qualitative research (3 ed.). Thousand Oaks, CA: SAGE.

Creswell, J. W. (2009). Research design: Qualitative, quantitative, and mixed methods approaches ( 3 ed.). Thousand Oaks, CA: Sage.

Darley, J. W. (2009). Traveling from arithmetic to algebra. Mathematics Teaching in the Middle School, 14(8), 458-464.

Davidenko, S. (1997). Building the concept of function from students' everyday activities. Mathematics Teacher, 90(2), 144-149.

Day, R., \& Jones, G. A. (1997). Building bridges to algebraic thinking. Mathematics Teaching in the Middle School, 2(4), 208-212.

De Bock, D., Van Dooren, W., Verschaffel, L., \& Janssens, D. (2002). Improper use of linear reasoning: An in-depth study of the nature and the irresistibility of secondary school students' errors. Educational Studies in Mathematics, 50, 311 334. 
Dede, Y. (2004). The concept of variable and identification its learning difficulties. [Article]. Educational Sciences: Theory \& Practice, 4(1), 50-56.

Department of Education. (2007). Released Items.

Department of Education. (2008). Released Items.

Department of Education. (2009). Program Manual.

Desmet, L., Grégoire, J., \& Mussolin, C. (2010). Developmental changes in the comparision of decimal fractions. Learning and Instruction, 20, 521-532.

Ding, M., \& Li, X. (2010). A comparative analysis of the distributive property in U.S. and Chinese elementary mathematics textbooks. Cognition and Instruction, 28(2), $146-180$.

Edwards, T. G. (2000). Some "big ideas" of algebra in the middle grades. Mathematics Teaching in the Middle School, 6(1), 26-31.

Ellis, A. B. (2009). Patterns, quantities, and linear functions. Mathematics Teaching in the Middle School, 14(8), 482-491.

Erbas, A. K. (2005). Predicting turkish ninth grade students' algebra performance. Mathematics Educator, 15(1), 25-34.

Falkner, K. P., Levi, L., \& Carpenter, T. P. (1999). Children's understanding of equality: A foundation for algebra. Teaching Children Mathematics, 6(4), 232-236.

Fennell, F. (2010, October). RtI math and number sense: What interventions should you consider? We can figure this out. Paper presented at the Regional Meeting of the National Council of Teachers of Mathematics, New Orleans, LA. 
Fennell, F., Faulkner, L. R., Ma, L., Schmid, W., Stotsky, S., Wu, H., \& Flawn, T. (2007). Report of the task group on conceptual knowledge and skills. Washington, DC: National Mathematics Advisory Panel.

Fisher, K. M. (1988). The students-and-professors problem revisited. Journal for Research in Mathematics Education, 19(3), 260-261.

Fosnot, C. T., \& Dolk, M. (2002). Young mathematicians at work: Constructing fractions, decimals, and percents. Portsmouth, NH: Heinemann.

Fosnot, C. T., \& Jacob, B. (2010). Young mathematicians at work: Constructing algebra. Portsmouth, NH: Heinemann.

Gallardo, A. (2002). The extension of the natural-number domain to the integers in the transition of arithmetic to algebra. Educational Studies in Mathematics, 49, 171192.

Graham, A. T., \& Thomas, M. O. J. (2000). Building a versatile understanding of algebraic variables with a graphic calculator. Educational Studies in Mathematics, $41(3), 265-282$.

Hadjidemetriou, C., \& Williams, J. S. (2001). Children's graphical conceptions: Assessment of learning for teaching. Paper presented at the the 25 th Conference of the International Group for the Psychology of Mathematics Education, Utrecht, Netherlands.

Hawes, K. (2007). Using error analysis to teach equation solving. Mathematics Teaching in the Middle School, 12(5), 238-242.

Healy, L., \& Hoyles, C. (1999). Visual and symbolic reasoning in mathematics: Making connections with computers? Mathematical Thinking and Learning, 1, 59-84. 
Herscovics, N., \& Kieran, C. (1980). Constructing meaning for the concept of equation. Mathematics Teacher, 73, 572-580.

Herscovics, N., \& Linchevski, L. (1994). A cognitive gap between arithmetic and algebra. Educational Studies in Mathematics, 27(1), 59-78.

Hiebert, J., Carpenter, T. P., Fennema, E., Fuson, K. C., Wearne, D., Murray, H., . . . Human, P. (2000). Introducing the critical features of classrooms. Making sense: Teaching and learning mathematics with understanding (pp. 1-15). Portsmouth, NH: Heinemann.

Hiebert, J., \& Grouws, D. A. (2007). The effects of classroom mathematics teaching on students' learning. In F. K. J. Lester (Ed.), Second handbook of research on mathematics teaching and learning (pp. 371-404). Reston, VA: National Council of Teachers of Mathematics.

Hiebert, J., Stigler, J. W., Jacobs, J. K., Givvin, K. B., Garnier, H., Smith, M., . . . Gallimore, R. (2005). Mathematics teaching in the United States today (and tomorrow): Results from the TIMSS 1999 video study. Educational Evaluation and Policy Analysis, 27(2), 111-132.

Hoffer, A. (1988). Ratios and proportional thinking. In T. Post (Ed.), Teaching mathematics in grades K-8: Research based methods (pp. 285-313). Boston, MA: Allyn and Bacon.

House, J. D., \& Telese, J. A. (2008). Relationships between student and instructional factors and algebra achievement of students in the United States and Japan: An analysis of TIMSS 2003 data. Educational Research and Evaluation, 14(1), 101112. 
Jacobs, V. R., Franke, M. L., Carpenter, T. P., Levi, L., \& Battey, D. (2007). Professional development focused on children's algebraic reasoning in elementary school Journal for Research in Mathematics Education, 38(3), 258-288.

Kalchman, M., \& Koedinger, K. R. (2005). Teaching and learning functions. How students learn: Mathematics in the classroom (pp. 351-393): National Academies Press.

Kaput, J. J. (2000a). Teaching and learning a new algebra wiih understanding. Dartmouth, MA: National Center for Improving Student Learning and Achievement in Mathematics and Science.

Kaput, J. J. (2000b). Transforming algebra from an engine of inequity to an engine of mathematical power by "algebrafying" the k-12 curriculum. Dartmouth, MA: National Center for Improving Student Learning and Achievement in Mathematics and Science.

Kaput, J. J. (2008). What is algebra? What is algebraic reasoning? In J. J. Kaput, D. W. Carraher \& M. L. Blanton (Eds.), Algebra in the early grades (pp. 5-17). New York, NY: Routledge.

Kaput, J. J., \& Blanton, M. L. (2000). Algebraic reasoning in the context of elementary mathematics: Making it implementable on a massive scale. Dartmouth, MA: National Center for Improving Student Learning and Achievement in Mathematics and Science.

Kaput, J. J., \& Blanton, M. L. (2001, October). Student achievement in algebraic thinking: A comparison of 3rd graders' performance on a state 4th grade assessment. Paper presented at the Annual Meeting of the North American 
Chapter of the International Group for the Psychology of Mathematics Education, Snowbird, UT.

Katz, V. J., \& Barton, B. (2007). Stages in the history of algebra with implications for teaching. Educational Studies in Mathematics, 66(2), 185-201.

Kieran, C. (1980, April). Constructing meaning for non-trivial equations. Paper presented at the Annual Meeting of the American Educational Research Association, Boston, MA. Retrieved fromhttp://search.ebscohost.com/login.aspx?direct=true\&db=eric\&AN=ED18489 $9 \&$ site $=$ ehost-live

Kieran, C. (1981). Concepts associated with the equality symbol. Educational Studies in Mathematics, 12, 318-326.

Kieran, C. (1988, July). The equation-solving errors of novice and intermediate algebra students. Paper presented at the Ninth International Conference for the Psychology of Mathematics Education: Vol 1. Individual Contributions, The Netherlands: State University of Utrecht, Research Group on Mathematics Education and Educational Computer Centre.

Kieran, C. (1992). The learning and teaching of school algebra. In D. A. Grouws (Ed.), Handbook of research on mathematics teaching and learning. Reston, VA: NCTM.

Kieran, C. (2007). Learning and teaching of algebra at the middle school through college levels: Building meaning for symbols and their manipulation. In F. K. Lister (Ed.), Second handbook of research on mathematics teaching and learning (pp. 707-762). Reston, VA: NCTM. 
Kieran, C. (2008). What do students struggle with when first introduced to algebra symbols? Retrieved from http://www.nctm.org/uploadedFiles/Research_News_and_Advocacy/Research/Cli ps_and_Briefs/Brief $\% 20-\% 20$ What $\% 20 \mathrm{Can} \% 20 \mathrm{We} \% 20$ Learn.pdf

Kieran, C., \& Sfard, A. (1999). Seeing through symbols: The case of equivalent expressions. Focus on Learning Problems in Mathematics, 21(1), 1-17.

Kilpatrick, J., Swafford, J. O., \& Findell, B. (2001). Adding it up: Helping children learn mathematics. Washington, DC: National Academies Press

Koellner, K., Pittman, M., \& Frykholm, J. (2008). Talking generally or generally talking in an algebra classroom. [Article]. Mathematics Teaching in the Middle School, 14(5), 304-310.

Küchemann, D. (1978). Children's understanding of numerical variables. Mathematics in School (9), 23-26.

Labato, J., \& Ellis, A. B. (2010). Developing the essential understanding of ratios, proportions and proportional reasoning: Grades 6-8. Reston, VA: National Council of Teachers of Mathematics.

Lamon, S. J. (1999). Teaching fractions and ratios for understanding: Essential content knowledge and instructional strategies for teachers. Mahwah, NJ: Lawrence Erlbaum Associates.

Lannin, J. K. (2003). Developing algebraic reasoning through generalization. [Article]. Mathematics Teaching in the Middle School, 8(7), 343.

Leron, U., \& Hazzan, O. (2009). Intuitive vs analytical thinking: Four perspectives. Educational Studies in Mathematics, 71(3), 263-278. 
Linchevski, L. (1995). Algebra with numbers and arithmetic with letters: A definition of pre-algebra. Journal of Mathematical Behavior, 14, 113-120.

Linchevski, L., \& Herscovics, N. (1996). Crossing the cognitive gap between arithmetic and algebra: Operating on the unknown in the context of equations. Educational Studies in Mathematics, 30(1), 39-65.

Linchevski, L., \& Livneh, D. (1999). Structure sense: The relationship between algebraic and numerical contexts. Educational Studies in Mathematics, 40(2), 173-196.

Liston, D., Borko, H., \& Whitcomb, J. (2008). Conversations in search of a common denominator. Journal of Teacher Education, 59(383), 383-388.

Lockhead, J., \& Mestre, J. (1988). From words to algebra: Mending misconceptions The ideas of algebra, K-12: 1988 Yearbook (pp. 127-135). Reston, VA: National Council of Teachers of Mathematics

Ma, L. (1999). Knowing and teaching elementary mathematics. New York: Routledge. MacGregor, M., \& Stacey, K. (1997). Students' understanding of algebraic notation: 1115. Educational Studies in Mathematics, 33(1), 1-19.

Markovits, Z., Eylon, B. S., \& Bruckheimer, M. (1988). Difficulties students have with the function concept. In A. F. Coxford \& A. P. Schulte (Eds.), The ideas of algebra, K-12. (Vol. 1988 Yearbook, pp. 43-60). Reston, VA: National Council of Teachers of Mathematics.

Maruyama, G., \& Deno, S. (1992). Research in educational settings. Newbury Park, CA: SAGE Publications, Inc. 
Mason, J. (2008). Making use of children's powers to produce algebraic thinking. In J. J. Kaput, D. W. Carraher \& M. L. Blanton (Eds.), Algebra in the early grades (pp. 57-94). New York, NY: Routledge.

Merriam, S. B. (2009). Qualitative research: A guide to design and implementation: Jossey-Bass Inc.

Miles, M. B., \& Huberman, A. M. (1994). Qualitative data analysis (2 ed.). Thousand Oaks, CA: Sage.

Nathan, M. J., \& Koedinger, K. R. (2000). Teachers' and researcher's beliefs about the development of algebraic reasoning. Journal for Research in Mathematics Education, 31(2), 168-190.

Nathan, M. J., \& Koellner, K. (2007). A Framework for understanding and cultivating the transition from arithmetic to algebraic reasoning. Mathematical Thinking and Learning: An International Journal, 9(3), 179-192.

National Council of Teachers of Mathematics. (2000). Principles and standards for school mathematics. Reston, VA: NCTM.

National Council of Teachers of Mathematics. (2006). Curriculum focal points: A quest for coherence. Reston, VA: NCTM.

National Council of Teachers of Mathematics. (2009). Focus in high school mathematics: Reasoning and sense making. Reston,VA: NCTM.

National Council of Teachers of Mathematics. (2010). Focus in high school mathematics: Reasoning and sense making in algebra. Reston, VA: NCTM. 
Novotna, J., \& Hoch, M. (2008). How structure sense for algebraic expressions or equations is related to structure sense for abstract algebra. Mathematics Education Research Journal, 20(2), 93-104.

Panasuk, R. (2010). Three phase ranking framework for assessing conceptual understanding in algebra using multiple representations Education 131(2), 235257.

Panasuk, R., \& Beyranevand, M. L. (2010). Algebra students' ability to recognize multiple representations and achievement. International Journal for Mathematics Teaching and Learning, 1-21.

Patton, M. Q. (2002). Qualitative research and evaluation design (3 ed.). Thousand Oaks, CA: Sage Publications.

Peled, I., \& Carraher, D. W. (2008). Signed numbers and algebraic thinking. In J. J. Kaput, D. W. Carraher \& M. L. Blanton (Eds.), Algebra in the early grades (pp. 303-328). New York, NY: Routledge.

Perrenet, J. C., \& Wolters, M. A. (1994). The art of checking: A case study of students' erroneous checking behavior in introductory algebra. Journal for Mathematical Behavior, 13, 335-358.

Philipp, R. A. (1992a). The many uses of algebraic variables. Mathematics Teacher, $85(7), 557-561$.

Philipp, R. A. (1992b). A study of algebraic variables: Beyond the student-professor problem. Journal of Mathematical Behavior, 11, 161-176.

Pinchback, C. L. (1991). Types of errors exhibited in a remedial mathematics course. Focus on Learning Problems in Mathematics, 13(2), 53-62. 
Post, T. R., Behr, M. J., \& Lesh, R. (1988). Proportionality and the development of prealgebra understandings. In A. F. Coxford \& A. P. Schulte (Eds.), The ideas of algebra, K-12 (Vol. 1988 Yearbook, pp. 78-90). Reston, VA: National Council of Teachers of Mathematics.

Pugalee, D. (2010, October). Extending students' development of proportional reasoning. Paper presented at the Regional Meeting of the National Council of Teachers of Mathematics, New Orleans, LA.

Radford, L. (2000). Signs and meanings in students' emergent algebraic thinking: A semiotic analysis. Educational Studies in Mathematics, 42, 237-268.

Rakes, C. R., Valentine, J. C., McGatha, M. B., \& Ronau, R. N. (2010). Methods of instructional improvement in algebra: A systematic review and meta-analysis. Review of Educational Research, 80(3), 372-400.

Rivera, F. D., \& Becker, J. R. (2009). Algebraic reasoning through patterns. Mathematics Teaching in the Middle School, 15(4), 212-221.

Roberts, C. M. (2004). The dissertation journey: A practical and comprehensive guide to planning, writing, and defending your dissertation. Thousand Oaks, CA: Corwin Press.

Rosnick, P., \& Clement, J. (1980). Learning without understanding: The effect of tutoring strategies on algebra misconceptions. Journal of Mathematical Behavior, 3, 3-27.

Saunders, J., \& DeBlassio, J. (1988). Relating functions to their graphs. In L. R. Booth (Ed.), The ideas of algebra, K-12: 1988 Yearbook (pp. 155-157). Reston, VA: National Council of Teachers of Mathematics. 
Scheuermann, A., \& van Garderen, D. (2008). Analyzing students' use of graphic representations: Determining misconceptions and error patterns for instruction. Mathematics Teaching in the Middle School, 13(8), 471-477.

Schifter, D., Monk, S., Russell, S. J., \& Bastable, V. (2008). Early algebra: What does understanding the laws of arithmetic mean in the elementary grades? In J. J. Kaput, D. W. Carraher \& M. L. Blanton (Eds.), Algebra in the early grades (pp. 413-447). New York, NY: Routledge.

Schwartzman, S. (1996). Some common algebraic misconceptions. Mathematics and Computer Education, 30(2), 164-173.

Shaughnessy, M. (2010, October). NCTM and implementation of the common core state standards. Paper presented at the Regional Meeting of the National Council of Teachers of Mathematics, New Orleans, LA.

Shulman, L. S. (1986). Those who understand: Knowledge growth in teaching. Educational Researcher, 15(2), 4-14.

Silver, E. A. (2000). Improving mathematics teaching and learning: How can "principles and standards" help? Mathematics Teaching in the Middle School, 6(1), 20-23.

Singh, P. (2000). Understanding the concepts of proportion and ratio constructed by two grade six students. Educational Studies in Mathematics, 43(3), 271-292.

Skemp, R. R. (1976/2006). Relational understanding and instrumental understanding. Mathematics Teaching in the Middle School, 12(2), 88-95.

Slavit, D. (2006). Uncovering algebra: Sense making and property noticing. Mathematics Educator, 16(2), 4-13. 
Smith, E. (2008). Representational thinking as a framework for introducing functions in the elementary curriculum. In J. J. Kaput, D. W. Carraher \& M. L. Blanton (Eds.), Algebra in the early grades (pp. 133-160). New York, NY: Routledge.

Sowder, J., \& Wearne, D. (2006). What do we know about eighth-grade achievement? Mathematics Teaching in the Middle School, 11(6), 285-293.

Spielhagen, F. R. (2006a). Closing the achievement gap in math: Considering eighth grade algebra for all students. American Secondary Education, 34(3), 29-42.

Spielhagen, F. R. (2006b). Closing the achievement gap in math: The long-term effects of eighth-grade algebra. Journal of Advanced Academics, 18(1), 34-59.

Stacey, K. (1989). Finding and using patterns in linear generalizing problems. Educational Studies in Mathematics, 20(2), 147-164.

Stacey, K., \& MacGregor, M. (1997a). Building foundations for algebra. Mathematics Teaching in the Middle School, 2(4), 252-260.

Stacey, K., \& MacGregor, M. (1997b). Ideas about symbolism that students bring to algebra. Mathematics Teacher, 90(2), 110-113.

Stacey, K., \& MacGregor, M. (2000). Learning the algebraic method of solving problems. Journal of Mathematical Behavior, 18, 149-167.

Steinberg, R. M., Sleeman, D. H., \& Ktorza, D. (1990). Algebra students' knowledge of equivalence of fractions. Journal for Research in Mathematics Education, 22(2), $112-121$

Steinle, V., \& Stacey, K. (2004). Persistence of decimal misconceptions and readiness to move to expertise. Paper presented at the the 28 th Conference of the International Group for the Psychology of Mathematics Education, Bergen, Norway 
Stephens, A. C. (2005). Developing students' understandings of variable. Mathematics Teaching in the Middle School, 11(2), 96-100.

Stiggins, R. J., Arter, J. A., Chappuis, J., \& Chappuis, S. (2006). Classroom assessment for student learning: Doing it right - using it well. Princeton, NJ: Educational Testing Service.

Stigler, J. W., \& Hiebert, J. (2004). Improving mathematics teaching. Educational Leadership, 61(5), 12.

Swafford, J. O., \& Langrall, C. W. (2000). Grade 6 students' preinstructional use of equations to describe and represent problem situations. Journal for Research in Mathematics Education, 31(1), 89-112.

Swan, M. (2000). Making sense of algebra. Mathematics Teaching(171), 16-19.

Tabach, M., Arcavi, A., \& Hershkowitz, R. (2008). Transitions among different symbolic generalizations by algebra beginners in a computer intensive environment. Educational Studies in Mathematics, 69(1), 53-71.

Tashakkori, A., \& Teddlie, C. (1998). Mixed methodology: Combining qualitative and quantitative approaches (Vol. 46). Thousand Oaks: Sage.

Thorpe, J. A. (1989). Algebra: What should we teach and how should we teach it? In S. Wagner \& C. Kieran (Eds.), Research issues in the learning and teaching of algebra (pp. 11-24). Hillsdale, NJ: Lawrence Erlbaum Associates.

Urbina, S. (2004). Essentials of psychological testing. Hoboken, NJ: John Wiley \& Sons, Inc.

Usiskin, Z. (1987). Why elementary algebra can, should and must be an eighth-grade course for average students. Mathematics Teacher, 80, 428-438. 
Usiskin, Z. (1988). Conceptions of school algebra and uses of variables. In A. F. Coxford \& A. P. Schulte (Eds.), The ideas of algebra, K-12 (Vol. 1988 Yearbook, pp. 819). Reston, VA: National Council of Teachers of Mathematics.

Usiskin, Z. (1995). Why is algebra important to learn? American Educator, 19(1), 30-37. Van Amerom, B. A. (2003). Focusing on informal strategies when linking arithmetic to early algebra. Educational Studies in Mathematics, 54(1), 63-75.

Van de Walle, J. A., Karp, K. S., \& Bay-Williams, J. M. (2010). Elementary and middle school mathematics: Teaching developmentally (7 ed.). New York: Pearson Education.

Van Dooren, W., Verschaffel, L., \& Onghena, P. (2002). The impact of preservice teachers' content knowledge on their evaluation of students' strategies for solving arithmetic and algebra word problems. Journal for Research in Mathematics Education, 33(5), 319-351.

Van Dyke, F., \& Craine, T. V. (1997). Equivalent representations in the learning of algebra. Mathematics Teacher, 90(8), 616-619.

Vlassis, J. (2002). The balance model: Hindrance or support for the solving of linear equations with one unknown. Educational Studies in Mathematics, 49, 341-359.

Vlassis, J. (2008). The role of mathematical symbols in the development of number conceptualization: The case of the minus sign. Philosophical Psychology, 21(4), $555-570$.

Warren, E. (2003). The role of arithmetic structure in the transition from arithmetic to algebra. Mathematics Education Research Journal, 15(2), 122-137. 
Warren, E. (2009). Early childhood teachers' professional learning in early algebraic thinking: A model that supports new knowledge and pedagogy. Mathematics Teacher Education and Development, 10, 30-45.

Weinberg, A. D., Stephens, A. C., McNeil, N. M., Krill, D. E., Knuth, E. J., \& Alibali, M. W. (2004, April). Students initial and developing conceptions of variable. Paper presented at the Annual Meeting fo the American Educational Research Association, San Diego, CA.

Welder, R. M. (2006, January). Prerequisite knowledge for the learning of algebra. Paper presented at the 2006 Hawaii International Conference on Statistics, Mathematics, and Related Fields, Honolulu, HI.

Welder, R. M. (2007). Preservice elementary teachers' mathematical content knowledge of prerequisite algebra concepts (Doctoral dissertation). Availiable from ProQuest Dissertations and Theses database. (UMI No. 3254740).

Welder, R. M. (2010, January). Enhancing mathematical knowledge for teaching prerequisite algebra concepts. Paper presented at the Fourteenth Annual Conference of the Association of Mathematics Teacher Educators, Irvine, CA. Willoughby, S. S. (1997). Activities to help in learning about functions. Mathematics Teaching in the Middle School, 2(4), 214-219.

Witzel, B. S. (2005). Using CRA to teach algebra to students with math difficulties in inclusive settings. Learning Disabilities: A Contemporary Journal, 3(2), 49-60.

Wollman, W. (1983). Determining the sources of error in a translation from sentence to equation. Journal for Research in Mathematics Education, 14, 169-181.

Wu, H. (2001). How to prepare students for algebra. American Educator 25(2), 10-17. 
Wu, H. (2005, April). Key mathematical ideas in Grades 5-8. Paper presented at the annual meeting of the National Council of Teachers of Mathematics, Anaheim, CA. 


\section{APPENDIX A \\ INTERVIEW GUIDE AND INFORMED CONSENT}

\section{A. Introduction}

\section{Interview Guide}

Introduce myself and remind interviewee of my research purpose, topic, and background.

\section{B. Interview Information}

Thank you for volunteering to be interviewed. This interview will last approximately one hour. I will place you on speaker phone and the interview will be tape recorded and later transcribed. Your name will not appear anywhere in my dissertation or resulting publications.

\section{Questions}

Now we will begin the interview questions. During this interview I will frequently refer to the nine content areas of mathematics. Please have those cut out and ready. I really appreciate your insights. Throughout the interview, please visually refer to these nine content areas which were sent to you.

1. What is your opinion on how well the standardized assessment measures students' skills for success in Algebra I? In other words, why do you feel the standardized assessment is (or is not) a good measure of prerequisite algebra skills?

2. How well are state assessments capturing the data on students' misconceptions at the middle grades level?

3. In your opinion, which of the nine content areas do students in grades six-eight find particularly challenging?

4. In your opinion, which of the nine content areas do students in grades six-eight perform especially well on?

5. If you had to rank the nine content areas from having the greatest regular presence to the least regular presence on the standardized assessment for the middle grades, what would this ranking look like?

6. In your opinion, are any of the nine content areas not adequately addressed on the standardized assessment? 
7. Are any overrepresented?

Look at the nine content area strips - I'd like for you to see if there are any you notice that have common misconceptions. Just pick whichever one you'd like to start with and we'll go through each one you feel students have common errors/misconceptions.

8. Number and numerical operation?

9. Ratios and proportions?

10. The order of operations?

11. Equality?

12. Patterning?

13. Algebraic expressions and symbolism?

14. Algebraic equations?

15. Functions?

\section{Graphing?}

17. Is there a category you feel I missed - not in the nine categories?

18. What are some important ideas that teachers should consider when trying to support middle school students' learning to overcome these misconceptions and errors?

19. How does students' showing their work play into the score they receive on each item?

20. Do you believe that students copying over their correct final answer to the answer line incorrectly or students copying the problem down incorrectly (e.g. writing down the numbers accurately from the question) is a significant issue that affects many students?

21. Do you think the overall amount of computational errors decrease on portions of the standardized assessment where students are allowed to use calculators? 


\section{Closing}

Thank you for your time.

(Make sure I get signed copy of consent form)

If you have any questions feel free to email or call me. Thank you. 


\section{Numbers and numerical operations}

Ratios and proportions

The order of operations

Equality 


\section{Patterning}

\section{Algebraic symbolism and letter usage}

\section{Algebraic equations}

Functions

Graphing 


\section{Subject Informed Consent Document \\ Analyzing Common Algebra-Related Misconceptions and \\ Errors of Middle School Students}

IRB assigned number: 10.0623

Investigator(s) name $\&$ address:

PI - Karen Karp

University of Louisville

College of Education and Human Development

Louisville, KY 40292

Doctoral Student: Sarah Bush

Site(s) where study is to be conducted:

Interviews will be conducted over the phone or in person.

\section{Introduction and Background Information}

You are invited to participate in a research study. The study is being conducted by Karen Karp, Ed.D. and Sarah Bush, doctoral candidate. The study is sponsored by the University of Louisville, Department of Teaching and Learning. The study will use existing data and interviews will take place over the phone or in person. Approximately five subjects will be invited to participate in follow-up interviews.

\section{Purpose}

The purpose of this study is to analyze algebra-related misconceptions among middle grades students.

\section{Procedures}

In this study, you will be asked to answer questions related to student algebra-related misconceptions. This interview should last approximately one hour. You may decline to answer any such question that makes you feel uncomfortable. 


\section{Potential Risks}

There are risks associated with interviews. There are no foreseeable risks, although there may be unforeseen risks.

\section{Benefits}

The possible benefits of this study include providing instructional information to mathematics educators and classroom teachers. The information collected may not benefit you directly. The information learned in this study may be helpful to others.

\section{Compensation}

You will not be compensated for your time, inconvenience, or expenses while you are in this study.

\section{Confidentiality}

Total privacy cannot be guaranteed. Your privacy will be protected to the extent permitted by law. If the results from this study are published, your name will not be made public. While unlikely, the following may look at the study records:

The University of Louisville Institutional Review Board and Human Subjects Protection Program Office.

Office for Human Research Protections (OHRP)

Information gathered from interviews will be kept in a password protected computer.

\section{Conflict of Interest}

This study involves a conflict of interest because the investigator will benefit by your participation in the study.

\section{Voluntary Participation}

Taking part in this study is voluntary. You may choose not to take part at all. If you decide to be in this study you may stop taking part at any time. If you decide not to be in this study or if you stop taking part at any time, you will not lose any benefits for which you may qualify.

You will be told about any changes that may affect your decision to continue in the study.

\section{Research Subject's Rights, Questions, Concerns, and Complaints}

If you have any concerns or complaints about the study or the study staff, you have three options. 
You may contact the principal investigator (Karen Karp) at 502-852-1654.

If you have any questions about your rights as a study subject, questions, concerns or complaints, you may call the Human Subjects Protection Program Office (HSPPO) (502) 852-5188. You may discuss any questions about your rights as a subject, in secret, with a member of the Institutional Review Board (IRB) or the HSPPO staff. The IRB is an independent committee composed of members of the University community, staff of the institutions, as well as lay members of the community not connected with these institutions. The IRB has reviewed this study.

If you want to speak to a person outside the University, you may call 1-877-8521167. You will be given the chance to talk about any questions, concerns or complaints in secret. This is a 24 hour hot line answered by people who do not work at the University of Louisville.

This paper tells you what will happen during the study if you choose to take part. Your signature means that this study has been discussed with you, that your questions have been answered, and that you willingly take part in the study. This informed consent document is not a contract. You are not giving up any legal rights by signing this informed consent document. You will be given a signed copy of this paper to keep for your records.

Signature of Subject/Legal Representative Date Signed

Signature of Person Explaining the Consent Form Date Signed (if other than the Investigator)

Signature of Investigator

Date Signed

LIST OF INVESTIGATORS

Karen Karp

Sarah Bush
PHONE NUMBERS

502-852-1654
For IRB Approval Stamp 


\section{APPENDIX B}

\section{PRE-ANALYSIS CODES FROM LITERATURE}

Numbers and Numerical Operations

\begin{tabular}{|c|c|}
\hline Error & Reference \\
\hline $\begin{array}{l}\text { Writing Part/Part relationship instead of Part/Whole relationship } \\
\text { for a fraction }\end{array}$ & Ashlock, 2006 \\
\hline Failure to realize that all parts of a fraction must be equal sized & Ashlock, 2006 \\
\hline $\begin{array}{l}\text { Simply adding/subtracting the numerators and adding/subtracting } \\
\text { the denominators (with no attempt to get common denominator } \\
\text { first) }\end{array}$ & Ashlock, 2006 \\
\hline $\begin{array}{l}\text { Getting a common denominator but failing to change the fractions } \\
\text { into equivalent form - thus not resulting in different numerators }\end{array}$ & Ashlock, 2006 \\
\hline $\begin{array}{l}\text { Incorrectly subtracting mixed numbers by failing to regroup when } \\
\text { needed and instead oversimplify by subtracting the smaller number } \\
\text { from the larger - not realizing that subtraction is not commutative }\end{array}$ & Ashlock, 2006 \\
\hline $\begin{array}{l}\text { Incorrect regrouping - either by incorrectly using base ten or } \\
\text { making some other mistake }\end{array}$ & Ashlock, 2006 \\
\hline $\begin{array}{l}\text { Incorrect cross-multiplying (as if solving a proportion) and then } \\
\text { applying an invented algorithm to get the answers (such as adding } \\
\text { the sum of the two cross multiplications) }\end{array}$ & Ashlock, 2006 \\
\hline $\begin{array}{l}\text { Seeing a whole number, such as } 6 \text {, as } 6 / 6 \text { and multiplying both the } \\
\text { numerator and denominator by six - instead of just the numerator }\end{array}$ & Ashlock, 2006 \\
\hline $\begin{array}{l}\text { Incorrectly dividing fractions by dividing the numerators and then } \\
\text { dividing the denominators (similar to what is correct for } \\
\text { multiplication) }\end{array}$ & Ashlock, 2006 \\
\hline
\end{tabular}




\begin{tabular}{|l|l|}
\hline $\begin{array}{l}\text { Only applying part of the "invert and multiply" algorithm - student } \\
\text { may remember to multiply but forget to invert the second fraction }\end{array}$ & Ashlock, 2006 \\
\hline $\begin{array}{l}\text { Recognizing the different meanings of fractions (coefficients, } \\
\text { constants, slope, proportions, etc.) }\end{array}$ & Wu, 2001 \\
\hline Applying the wrong algorithm for computing fractions & $\begin{array}{l}\text { Brown and Quinn, } \\
2006\end{array}$ \\
\hline Selecting the wrong operation in problems involving fractions & $\begin{array}{l}\text { Brown and Quinn, } \\
2006\end{array}$ \\
\hline Understanding the value of a fraction & $\begin{array}{l}\text { Darley, 2009; Wu, } \\
2001,2005\end{array}$ \\
\hline $\begin{array}{l}\text { Graphing fractional points on a coordinate plane and plotting on a } \\
\text { number line. }\end{array}$ & Darley, 2009 \\
\hline $\begin{array}{l}\text { Determined which decimal was greater simply by the number of } \\
\text { digits }\end{array}$ & Ashlock, 2006 \\
\hline $\begin{array}{l}\text { Not using place value concept to put the decimal in the correct } \\
\text { place in the answer }\end{array}$ & Ashlock, 2006 \\
\hline $\begin{array}{l}\text { When subtracting - not regrouping but instead taking the smaller } \\
\text { number minus the larger (reversing order) }\end{array}$ & Ashlock, 2006 \\
\hline $\begin{array}{l}\text { Placing the decimal point in the incorrect place when multiplying - } \\
\text { multiple reasons }\end{array}$ & Ashlock, 2006 \\
\hline $\begin{array}{l}\text { Placing the decimal point in the incorrect place when dividing - } \\
\text { multiple reasons }\end{array}$ & Ashlock, 2006 \\
\hline Subtraction sign followed by a negative sign & Vlassis, 2008 \\
\hline $\begin{array}{l}\text { Checking answer involving integers by plugging the solution back } \\
\text { into the equation }\end{array}$ & Vlassis, 2008 \\
\hline Omitting negative signs & Vlassis, 2008 \\
\hline $\begin{array}{l}\text { Not knowing what sign to put on the sum involving adding a } \\
\text { positive and negative number }\end{array}$ & Ashlock, 2006 \\
\hline Making the sum of two negatives a positive & Ashlock, 2006 \\
\hline Incorrect uses of signs & Ashlock, 2006 \\
\hline
\end{tabular}


Ratios and Proportions

\begin{tabular}{|l|l|}
\hline \multicolumn{1}{|c|}{ Error } & \multicolumn{1}{|c|}{ Reference } \\
\hline $\begin{array}{l}\text { That a ratio can represent a part/part, part/whole, or whole/part } \\
\text { relationship }\end{array}$ & Hoffer, 1988 \\
\hline Different ways to write a ratio & Hoffer, 1988 \\
\hline Simplifying ratios & Hoffer, 1988 \\
\hline Combining two ratios (as confused with combining two fractions) & Hoffer, 1988 \\
\hline $\begin{array}{l}\text { Student applies a learned procedure instead of understanding the } \\
\text { problem and adjusting as needed for that scenario. }\end{array}$ & $\begin{array}{l}\text { De Bock, Van } \\
\text { Dooren, } \\
\text { Verschaffel, and } \\
\text { Janssens, 2002 }\end{array}$ \\
\hline Inability to unitize & Singh, 2000 \\
\hline
\end{tabular}

The Order of Operations

\begin{tabular}{|l|l|}
\hline \multicolumn{1}{|c|}{ Error } & \multicolumn{1}{|c|}{ Reference } \\
\hline $\begin{array}{l}\text { Performing operations left to right instead of following order of } \\
\text { operations }\end{array}$ & $\begin{array}{l}\text { Linchevski and } \\
\text { Livneh, 1999 }\end{array}$ \\
\hline $\begin{array}{l}\text { Incorrectly believing addition should be performed before } \\
\text { subtraction and multiplication before division (instead of in order } \\
\text { from left to right) }\end{array}$ & $\begin{array}{l}\text { Linchevski and } \\
\text { Livneh, 1999 }\end{array}$ \\
\hline Not using parentheses when needed & Booth, 1988 \\
\hline $\begin{array}{l}\text { The belief that the same value will be obtained regardless of what } \\
\text { order the operations are performed }\end{array}$ & Booth, 1984 \\
\hline $\begin{array}{l}\text { The incorrect belief that the commutative and associative } \\
\text { properties are also true for subtraction or division }\end{array}$ & Shifter et al., 2008 \\
\hline
\end{tabular}


Equality

\begin{tabular}{|l|l|}
\hline \multicolumn{1}{|c|}{ Error } & \multicolumn{1}{|c|}{ Reference } \\
\hline $\begin{array}{l}\text { Believing the equal sign means "and the answer is" when there is } \\
\text { still "more" left to the problem }\end{array}$ & $\begin{array}{l}\text { Ball, et al., 2008 } \\
\text { and many others }\end{array}$ \\
\hline Not preserving equivalence when performing inverse operations & $\begin{array}{l}\text { Asquith et al., } \\
2007\end{array}$ \\
\hline $\begin{array}{l}\text { Understanding the notion of equivalent equations. When you } \\
\text { correctly perform inverse operations the equations remain } \\
\text { equivalent even though they "look different". }\end{array}$ & $\begin{array}{l}\text { Linchevski and } \\
\text { Herscovics, 1996 }\end{array}$ \\
\hline $\begin{array}{l}\text { Not understanding algebraic notation or symbolism which leads to } \\
\text { errors in equivalence. }\end{array}$ & $\begin{array}{l}\text { Steinberg et al., } \\
1990\end{array}$ \\
\hline
\end{tabular}

Patterning

\begin{tabular}{|l|l|}
\hline \multicolumn{1}{|c|}{ Error } & \multicolumn{1}{|c|}{ Reference } \\
\hline Errors in counting with patterns & $\begin{array}{l}\text { Koellner, Pittman, } \\
\text { and Frykholm, } \\
2008\end{array}$ \\
\hline Difficulty making a generalization & Stacey, 1989 \\
\hline Not being consistent in generalizations made & Stacey, 1989 \\
\hline Difficulty expressing the pattern symbolically & $\begin{array}{l}\text { Radford, 2000; } \\
\text { Healy and Hoyles, } \\
1999\end{array}$ \\
\hline Inability to identify the pattern & $\begin{array}{l}\text { Ainley, Bills, and } \\
\text { Wilson, 2004 }\end{array}$ \\
& \\
\hline
\end{tabular}


Algebraic Symbolism and Letter Usage

\begin{tabular}{|c|c|}
\hline Error & Reference \\
\hline Viewing variables as labels & $\begin{array}{l}\text { Asquith et al., } \\
\text { 2007; Clement, } \\
\text { 1982; Stacey and } \\
\text { MacGregor, } \\
\text { 1997b; Usiskin, } \\
1988\end{array}$ \\
\hline $\begin{array}{l}\text { The idea that two different variables (e.g. } \mathrm{x}, \mathrm{y} \text { ) in the same } \\
\text { equation cannot represent the same value }\end{array}$ & $\begin{array}{l}\text { Stephens, } 2005 \\
\text { Swan, } 2000\end{array}$ \\
\hline $\begin{array}{l}\text { Believing the value of a variable has something to do with its } \\
\text { position in the alphabet }\end{array}$ & $\begin{array}{l}\text { Asquith et al., } \\
\text { 2007; Herscovics } \\
\text { and Kieran, 1980; } \\
\text { MacGregor and } \\
\text { Stacey, } 1997\end{array}$ \\
\hline $\begin{array}{l}\text { The inability to understand variables as varying quantities rather } \\
\text { than a missing value }\end{array}$ & $\begin{array}{l}\text { Asquith et al., } \\
\text { 2007; Stacey and } \\
\text { MacGregor, 2000; } \\
\text { Stephens, 2005; } \\
\text { Usiskin, } 1988\end{array}$ \\
\hline Inability to write an algebraic expressions for a given situation & $\begin{array}{l}\text { MacGregor and } \\
\text { Stacey, } 1997\end{array}$ \\
\hline $\begin{array}{l}\text { Inability to simplify an expression correctly because student does } \\
\text { not understand the concept of like terms. }\end{array}$ & $\begin{array}{l}\text { Booth and Watson, } \\
\text { 1990; Booth, } \\
\text { 1986; Stacey and } \\
\text { MacGregor, 1997b }\end{array}$ \\
\hline $\begin{array}{l}\text { The belief that an answer can only be a number (and not an } \\
\text { expression or factor) }\end{array}$ & $\begin{array}{l}\text { Booth and Watson, } \\
\text { 1990; Booth, } \\
\text { 1986; Stacey and } \\
\text { MacGregor, 1997b }\end{array}$ \\
\hline $\begin{array}{l}\text { Incorrectly simplifying as a result of not using distributive property } \\
\text { correctly }\end{array}$ & Kieran, 1992 \\
\hline $\begin{array}{l}\text { With expressions involving subtraction, students would incorrectly } \\
\text { write an expression such as } 4-n \text { instead of } n-4 \text {. }\end{array}$ & $\begin{array}{l}\text { M. M. Capraro and } \\
\text { Joffrion, } 2006\end{array}$ \\
\hline
\end{tabular}


Algebraic Equations

\begin{tabular}{|l|l|}
\hline \multicolumn{1}{|c|}{ Error } & \multicolumn{1}{|c|}{ Reference } \\
\hline $\begin{array}{l}\text { Understands the process of solving the equation but makes an error } \\
\text { in computation (decimals, fractions, whole numbers) }\end{array}$ & Wu, 2001 \\
\hline Error in checking solution & $\begin{array}{l}\text { Perrenet and } \\
\text { Wolters, 1994 }\end{array}$ \\
\hline Difficulty with the symbolic representation of a scenario & $\begin{array}{l}\text { Booth 1984; } \\
\text { Nathan and } \\
\text { Koedinger, 2000 }\end{array}$ \\
\hline Reversal order error & $\begin{array}{l}\text { Lockhead and } \\
\text { Mestre, 1988 }\end{array}$ \\
\hline Incorrect understanding of the meaning of the variable & $\begin{array}{l}\text { Lockhead and } \\
\text { Mestre, 1988 }\end{array}$ \\
\hline Not checking the solution & Wollman, 1983 \\
\hline Errors in using inverse operations & $\begin{array}{l}\text { Linchevski and } \\
\text { Herscovics, 1996 }\end{array}$ \\
\hline Incorrectly simplifying like terms & Ashlock, 2006 \\
\hline Incorrect use or simplification of distributive property & Ashlock, 2006 \\
\hline $\begin{array}{l}\text { Difficulty expressing inverse values (one-half, one-third, etc.) in an } \\
\text { equation }\end{array}$ & $\begin{array}{l}\text { Swafford and } \\
\text { Langrall, 2000 }\end{array}$ \\
\hline Incorrect computation with integers & Vlassis, 2008 \\
\hline
\end{tabular}


Functions

\begin{tabular}{|c|c|}
\hline Error & Reference \\
\hline $\begin{array}{l}\text { Not understanding proportionality or non-proportionality of } \\
\text { functions }\end{array}$ & $\begin{array}{l}\text { Pugalee, } 2010 \\
\text { Van de Walle, } \\
2010\end{array}$ \\
\hline $\begin{array}{l}\text { The understanding that variables can represent varying quantities } \\
\text { (such as in } y=3 x+2)\end{array}$ & $\begin{array}{l}\text { Kieran, 1992; } \\
\text { Usiskin, } 1988 \\
\end{array}$ \\
\hline $\begin{array}{l}\text { Difficulty understanding the algebraic form (equation form rather } \\
\text { than table or graph) of a function. ( } y=m x+b \text { has so many } \\
\text { "letters") }\end{array}$ & Usiskin, 1988 \\
\hline Understanding of slope & $\begin{array}{l}\text { Kalchman and } \\
\text { Koedinger, } 2005\end{array}$ \\
\hline Understanding of independent and dependent variables & $\begin{array}{l}\text { Kalchman and } \\
\text { Koedinger, } 2005\end{array}$ \\
\hline $\begin{array}{l}\text { Difficulty moving between equation, table, and graph } \\
\text { representations }\end{array}$ & $\begin{array}{l}\text { Kalchman and } \\
\text { Koedinger, } 2005\end{array}$ \\
\hline
\end{tabular}

Graphing

\begin{tabular}{|l|l|}
\hline \multicolumn{1}{|c|}{ Error } & \multicolumn{1}{|c|}{ Reference } \\
\hline $\begin{array}{l}\text { Not understanding proportionality or non-proportionality of } \\
\text { functions }\end{array}$ & $\begin{array}{l}\text { Post, Behr, and } \\
\text { Lesh, 1988; } \\
\text { Pugalee, 2010 }\end{array}$ \\
\hline Difficulty identifying the shape of the function & Blanton, 2008 \\
\hline Difficulty with graphing notation & $\begin{array}{l}\text { Scheuermann and } \\
\text { van Garderen }\end{array}$ \\
\hline Understanding of slope & $\begin{array}{l}\text { Kalchman and } \\
\text { Koedinger, 2005 }\end{array}$ \\
\hline Understanding of independent and dependent variables & $\begin{array}{l}\text { Kalchman and } \\
\text { Koedinger, 2005 }\end{array}$ \\
\hline $\begin{array}{l}\text { Difficulty moving between equation, table, and graph } \\
\text { representations }\end{array}$ & $\begin{array}{l}\text { Kalchman and } \\
\text { Koedinger, 2005 }\end{array}$ \\
\hline
\end{tabular}




\section{APPENDIX C}

\section{FINAL CODING SHEETS}

Numbers and Numerical Operations

Grade: Year: Test: Question:

\begin{tabular}{|c|c|c|}
\hline Error & Paper Number & Reference \\
\hline $\begin{array}{l}\text { Writing Part/Part relationship instead of } \\
\text { Part/Whole relationship for a fraction }\end{array}$ & & $\begin{array}{l}\text { Ashlock, } \\
2006\end{array}$ \\
\hline $\begin{array}{l}\text { Failure to realize that all parts of a fraction } \\
\text { must be equal sized }\end{array}$ & & $\begin{array}{l}\text { Ashlock, } \\
2006\end{array}$ \\
\hline $\begin{array}{l}\text { Simply adding/subtracting the numerators } \\
\text { and adding/subtracting the denominators } \\
\text { (with no attempt to get common } \\
\text { denominator first) }\end{array}$ & & $\begin{array}{l}\text { Ashlock, } \\
2006\end{array}$ \\
\hline $\begin{array}{l}\text { Getting a common denominator but failing } \\
\text { to change the fractions into equivalent forms } \\
\text { - thus not resulting in different numerators }\end{array}$ & & $\begin{array}{l}\text { Ashlock, } \\
2006\end{array}$ \\
\hline $\begin{array}{l}\text { Incorrectly subtracting mixed numbers by } \\
\text { failing to regroup when needed and instead } \\
\text { oversimplify by subtracting the smaller } \\
\text { number from the larger }\end{array}$ & & $\begin{array}{l}\text { Ashlock, } \\
2006\end{array}$ \\
\hline $\begin{array}{l}\text { Incorrect regrouping - either by incorrectly } \\
\text { using base ten or making some other } \\
\text { mistake }\end{array}$ & & $\begin{array}{l}\text { Ashlock, } \\
2006\end{array}$ \\
\hline $\begin{array}{l}\text { Incorrect cross-multiplying (as if solving a } \\
\text { proportion) and then applying an invented } \\
\text { algorithm to get the answers (such as adding } \\
\text { the sum of the two cross multiplications) }\end{array}$ & & $\begin{array}{l}\text { Ashlock, } \\
2006\end{array}$ \\
\hline $\begin{array}{l}\text { Seeing a whole number, such as } 6 \text {, as } 6 / 6 \\
\text { and multiplying both the numerator and } \\
\text { denominator by six - instead of just the } \\
\text { numerator }\end{array}$ & & $\begin{array}{l}\text { Ashlock, } \\
2006\end{array}$ \\
\hline
\end{tabular}




\begin{tabular}{|c|c|}
\hline $\begin{array}{l}\text { Incorrectly dividing fractions by dividing } \\
\text { the numerators and then dividing the } \\
\text { denominators (similar to what is correct for } \\
\text { multiplication) }\end{array}$ & $\begin{array}{l}\text { Ashlock, } \\
2006\end{array}$ \\
\hline $\begin{array}{l}\text { Only applying part of the "invert and } \\
\text { multiply" algorithm - student may } \\
\text { remember to multiply but forget to invert the } \\
\text { second fraction }\end{array}$ & $\begin{array}{l}\text { Ashlock, } \\
2006\end{array}$ \\
\hline $\begin{array}{l}\text { Not recognizing the different meanings of } \\
\text { fractions (coefficients, constants, slope, } \\
\text { proportions, etc.) }\end{array}$ & $\mathrm{Wu}, 2001$ \\
\hline $\begin{array}{l}\text { Applying the wrong algorithm when } \\
\text { computing fractions }\end{array}$ & $\begin{array}{l}\text { Brown and } \\
\text { Quinn, } 2006\end{array}$ \\
\hline $\begin{array}{l}\text { Selecting the wrong operation when } \\
\text { working with fractions }\end{array}$ & $\begin{array}{l}\text { Brown and } \\
\text { Quinn, } 2006\end{array}$ \\
\hline Not understanding the value of a fraction & $\begin{array}{l}\text { Darley, } \\
2009 ; \mathrm{Wu} \\
2001,2005\end{array}$ \\
\hline $\begin{array}{l}\text { Difficulty graphing fractional points on a } \\
\text { number line }\end{array}$ & Darley, 2009 \\
\hline $\begin{array}{l}\text { Determined which decimal was greater } \\
\text { based on the number of digits }\end{array}$ & $\begin{array}{l}\text { Ashlock, } \\
2006 ; \\
\text { Desmet et } \\
\text { al., 2010; } \\
\text { Steinle and } \\
\text { Stacey, 2004 }\end{array}$ \\
\hline $\begin{array}{l}\text { Not using place value concept to put the } \\
\text { decimal in the correct place in the answer }\end{array}$ & $\begin{array}{l}\text { Ashlock, } \\
2006\end{array}$ \\
\hline $\begin{array}{l}\text { When subtracting - taking the smaller } \\
\text { number subtract the larger number (reverse } \\
\text { order) }\end{array}$ & $\begin{array}{l}\text { Ashlock, } \\
2006\end{array}$ \\
\hline $\begin{array}{l}\text { Placing the decimal in the incorrect place } \\
\text { when multiplying }\end{array}$ & $\begin{array}{l}\text { Ashlock, } \\
2006\end{array}$ \\
\hline $\begin{array}{l}\text { Placing the decimal in the incorrect place } \\
\text { when dividing }\end{array}$ & $\begin{array}{l}\text { Ashlock, } \\
2006\end{array}$ \\
\hline $\begin{array}{l}\text { Difficulty when there is a subtraction sign } \\
\text { followed by a negative sign }\end{array}$ & $\begin{array}{l}\text { Vlassis, } \\
2008\end{array}$ \\
\hline $\begin{array}{l}\text { Difficulty checking answer involving } \\
\text { integers when plugging the solution back } \\
\text { into the equation }\end{array}$ & $\begin{array}{l}\text { Vlassis, } \\
2008\end{array}$ \\
\hline
\end{tabular}




\begin{tabular}{|l|l|l|}
\hline Omitting negative signs & $\begin{array}{l}\text { Vlassis, } \\
2008\end{array}$ \\
\hline $\begin{array}{l}\text { Not knowing what sign to put on the sum } \\
\text { involving adding a positive and negative } \\
\text { number }\end{array}$ & $\begin{array}{l}\text { Ashlock, } \\
2006\end{array}$ \\
\hline Making the sum of two negatives a positive & $\begin{array}{l}\text { Ashlock, } \\
2006\end{array}$ \\
\hline Incorrect use of signs & $\begin{array}{l}\text { Ashlock, } \\
2006\end{array}$ \\
\hline $\begin{array}{l}\text { Difficulty plotting decimal points on a } \\
\text { number line }\end{array}$ & none \\
\hline $\begin{array}{l}\text { Substituting the wrong value into the } \\
\text { equation }\end{array}$ & & none \\
\hline Difficulty ordering decimals & $\begin{array}{l}\text { Desmet et } \\
\text { al., 2010; } \\
\text { Steinle and } \\
\text { Stacey, 2004 }\end{array}$ \\
\hline Omitted a value & none \\
\hline Transcription error & none \\
\hline Wrong operation used & none \\
\hline $\begin{array}{l}\text { Computational error with the } \\
\text { addition/subtraction of decimals }\end{array}$ & $\begin{array}{l}\text { Ashlock, } \\
2006 ; \\
\text { Kilpatrick et } \\
\text { al., 2001 }\end{array}$ \\
\hline $\begin{array}{l}\text { Computational error with the multiplication } \\
\text { of decimals }\end{array}$ & & $\begin{array}{l}\text { Ashlock, } \\
2006\end{array}$ \\
\hline $\begin{array}{l}\text { Computational error with the division of } \\
\text { decimals }\end{array}$ & none \\
\hline Computational error with whole numbers & & none \\
\hline Correct answer & none \\
\hline Correct answer, no work shown & none \\
\hline $\begin{array}{l}\text { Correct answer but work shown does not } \\
\text { clearly lead to the correct answer }\end{array}$ & none \\
\hline Other & & none \\
\hline
\end{tabular}


Ratios and Proportions

Grade:

Year:

Test:

Question:

\begin{tabular}{|c|c|c|}
\hline Error & Paper Number & Reference \\
\hline $\begin{array}{l}\text { Difficulty with fact that a ratio can represent } \\
\text { a part/part, part/whole, or whole/part } \\
\text { relationship }\end{array}$ & & Hoffer, 1988 \\
\hline $\begin{array}{l}\text { Difficulty with the different ways to write a } \\
\text { ratio }\end{array}$ & & $\begin{array}{l}\text { Hoffer, 1988; } \\
\text { Kilpatrick et } \\
\text { al., } 2001\end{array}$ \\
\hline Difficulty simplifying ratios & & Hoffer, 1988 \\
\hline $\begin{array}{l}\text { Difficulty combining two ratios (as confused } \\
\text { with combining two fractions) }\end{array}$ & & Hoffer, 1988 \\
\hline $\begin{array}{l}\text { Student applies learned procedure instead of } \\
\text { adjusting to the scenario }\end{array}$ & & $\begin{array}{l}\text { De Bock et } \\
\text { al., } 2002\end{array}$ \\
\hline Inability to unitize & & $\begin{array}{l}\text { Behr et al., } \\
1992 ; \text { Singh, } \\
2000\end{array}$ \\
\hline Not understanding size of ratio & & $\begin{array}{l}\text { Kilpatrick et } \\
\text { al., } 2001\end{array}$ \\
\hline Incorrectly viewing portions as equal parts & & $\begin{array}{l}\text { Labato and } \\
\text { Ellis, } 2010\end{array}$ \\
\hline Computational error & & none \\
\hline Correct answer & & none \\
\hline Correct answer, no work shown & & none \\
\hline $\begin{array}{l}\text { Correct answer but work shown does not } \\
\text { clearly lead to the correct answer }\end{array}$ & & none \\
\hline Other & & none \\
\hline
\end{tabular}


The Order of Operations

Grade:

Year:

Test:

Question:

\begin{tabular}{|l|l|l|}
\hline \multicolumn{1}{|c|}{ Error } & \multicolumn{1}{|c|}{ Paper Number } & \multicolumn{1}{|c|}{ Reference } \\
\hline $\begin{array}{l}\text { Performing operations left to right instead of } \\
\text { using order of operations }\end{array}$ & & $\begin{array}{l}\text { Linchevski } \\
\text { and Livneh, } \\
1999\end{array}$ \\
\hline $\begin{array}{l}\text { Belief that addition comes before } \\
\text { subtraction or multiplication before division }\end{array}$ & & $\begin{array}{l}\text { Linchevski } \\
\text { and Livneh, } \\
1999\end{array}$ \\
\hline Not using parentheses when needed & Booth, 1988 \\
\hline $\begin{array}{l}\text { The belief that the same value will be } \\
\text { obtained regardless of what order the } \\
\text { operations are performed }\end{array}$ & & Booth, 1984 \\
\hline $\begin{array}{l}\text { Belief that commutative and associative } \\
\text { properties are true for subtraction or division }\end{array}$ & & $\begin{array}{l}\text { Shifter et al., } \\
2008\end{array}$ \\
\hline Wrong operation used & & none \\
\hline Computational error & none \\
\hline Correct answer & none \\
\hline Correct answer, no work shown & none \\
\hline $\begin{array}{l}\text { Correct answer but work shown does not } \\
\text { clearly lead to the correct answer }\end{array}$ & & none \\
\hline Other & & none \\
\hline
\end{tabular}


Equality

Grade:

Year:

Test:

Question:

\begin{tabular}{|c|c|c|}
\hline Error & Paper Number & Reference \\
\hline $\begin{array}{l}\text { Believing the equal sign means "and the } \\
\text { answer is" when there is still "more" left to } \\
\text { the problem }\end{array}$ & & $\begin{array}{l}\text { Ball, et al., } \\
2008 \text { and } \\
\text { many others }\end{array}$ \\
\hline $\begin{array}{l}\text { Not preserving equivalence when } \\
\text { performing inverse operations }\end{array}$ & & $\begin{array}{l}\text { Asquith et al., } \\
2007\end{array}$ \\
\hline $\begin{array}{l}\text { Difficulty understanding the notion of } \\
\text { equivalent equations. When you correctly } \\
\text { perform inverse operations the equations } \\
\text { remain equivalent even though it "looks } \\
\text { different" }\end{array}$ & & $\begin{array}{l}\text { Linchevski } \\
\text { and } \\
\text { Herscovics, } \\
1996\end{array}$ \\
\hline $\begin{array}{l}\text { Lack of understanding of algebraic } \\
\text { symbolism led to errors in equivalence }\end{array}$ & & $\begin{array}{l}\text { Steinberg et } \\
\text { al., } 1990\end{array}$ \\
\hline $\begin{array}{l}\text { Incorrectly substituting values into the } \\
\text { expression }\end{array}$ & & none \\
\hline Transcription error & & none \\
\hline Wrong operation used & & none \\
\hline Computational error & & none \\
\hline Correct answer & & none \\
\hline Correct answer, no work shown & & none \\
\hline $\begin{array}{l}\text { Correct answer but work shown does not } \\
\text { clearly lead to the correct answer }\end{array}$ & & none \\
\hline Other & & none \\
\hline
\end{tabular}




\section{Patterning}

Grade:

Year:

Test:

Question:

\begin{tabular}{|c|c|c|}
\hline Error & Paper Number & Reference \\
\hline Errors in counting with patterns & & $\begin{array}{l}\text { Koellner et al., } \\
2008\end{array}$ \\
\hline Difficulty making a generalization & & Stacey, 1989 \\
\hline $\begin{array}{l}\text { Not making consistent } \\
\text { generalizations }\end{array}$ & & Stacey, 1989 \\
\hline $\begin{array}{l}\text { Difficulty expressing pattern } \\
\text { symbolically }\end{array}$ & & $\begin{array}{l}\text { Healy and } \\
\text { Hoyles, } 1999 ; \\
\text { Radford, } 2000\end{array}$ \\
\hline Inability to identify the pattern & & $\begin{array}{l}\text { Ainley et al., } \\
2004\end{array}$ \\
\hline Computational error & & none \\
\hline Correct answer & & none \\
\hline Correct answer, no work shown & & none \\
\hline $\begin{array}{l}\text { Correct answer but work shown does } \\
\text { not clearly lead to the correct answer }\end{array}$ & & none \\
\hline Other & & none \\
\hline
\end{tabular}


Algebraic Symbolism and Letter Usage

Grade: Year:

Test: Question:

\begin{tabular}{|c|c|c|}
\hline Error & Paper Number & Reference \\
\hline Viewing variables as labels & & $\begin{array}{l}\text { Asquith et al., } \\
\text { 2007; Clement, } \\
\text { 1982; Stacey } \\
\text { and } \\
\text { MacGregor, } \\
\text { 1997b; } \\
\text { Usiskin, } 1988\end{array}$ \\
\hline $\begin{array}{l}\text { The idea that two different variables } \\
\text { (e.g. } \mathrm{x}, \mathrm{y} \text { ) in the same equation } \\
\text { cannot represent the same value }\end{array}$ & & $\begin{array}{l}\text { Stephens, } \\
2005 ; \text { Swan, } \\
2000\end{array}$ \\
\hline $\begin{array}{l}\text { Believing the value of a variable has } \\
\text { something to do with its position in } \\
\text { the alphabet }\end{array}$ & & $\begin{array}{l}\text { Asquith et al., } \\
2007 \text {; } \\
\text { Herscovics and } \\
\text { Kieran, 1980; } \\
\text { MacGregor } \\
\text { and Stacey, } \\
1997\end{array}$ \\
\hline $\begin{array}{l}\text { The inability to understand variables } \\
\text { as varying quantities rather than a } \\
\text { missing value }\end{array}$ & & $\begin{array}{l}\text { Asquith et al., } \\
\text { 2007; Stacey } \\
\text { and } \\
\text { MacGregor, } \\
\text { 2000; } \\
\text { Stephens, } \\
\text { 2005; Usiskin, } \\
1988\end{array}$ \\
\hline $\begin{array}{l}\text { Inability to write a correct algebraic } \\
\text { expression for a given situation }\end{array}$ & & $\begin{array}{l}\text { MacGregor } \\
\text { and Stacey, } \\
1997\end{array}$ \\
\hline Difficulty combining like terms & & $\begin{array}{l}\text { Booth and } \\
\text { Watson, 1990; } \\
\text { Booth, 1986; } \\
\text { Stacey and } \\
\text { MacGregor, } \\
\text { 1997b }\end{array}$ \\
\hline
\end{tabular}




\begin{tabular}{|c|c|}
\hline $\begin{array}{l}\text { The belief that an answer can only } \\
\text { be a number rather than an } \\
\text { expression }\end{array}$ & $\begin{array}{l}\text { Booth and } \\
\text { Watson, 1990; } \\
\text { Booth, 1986; } \\
\text { Kilpatrick et } \\
\text { al., 2001; } \\
\text { Stacey and } \\
\text { MacGregor, } \\
\text { 1997b }\end{array}$ \\
\hline Difficulty with distributive property & $\begin{array}{l}\text { Ding and } \mathrm{Li} \text {, } \\
2010 ; \text { Kieran, } \\
1992\end{array}$ \\
\hline $\begin{array}{l}\text { With expressions involving } \\
\text { subtraction, student incorrectly } \\
\text { writes an expression such as } 4-n \\
\text { instead of } n-4 \text {. }\end{array}$ & $\begin{array}{l}\text { M. M. Capraro } \\
\text { and Joffrion, } \\
2006\end{array}$ \\
\hline $\begin{array}{l}\text { Substituting in the wrong value into } \\
\text { the equation }\end{array}$ & none \\
\hline Transcription error & none \\
\hline Wrong operation used & none \\
\hline Computational error & none \\
\hline Correct answer & none \\
\hline Correct answer, no work shown & none \\
\hline $\begin{array}{l}\text { Correct answer but work shown } \\
\text { does not clearly lead to the correct } \\
\text { answer }\end{array}$ & none \\
\hline Other & none \\
\hline
\end{tabular}


Algebraic Equations

Grade: Year:

Test: Question:

\begin{tabular}{|c|c|c|}
\hline Error & Paper Number & Reference \\
\hline $\begin{array}{l}\text { Understands the process of } \\
\text { solving equation but makes } \\
\text { computation error }\end{array}$ & & $\mathrm{Wu}, 2001$ \\
\hline Error in checking solution & & $\begin{array}{l}\text { Perrenet and } \\
\text { Wolters, } 1994\end{array}$ \\
\hline $\begin{array}{l}\text { Difficulty with the symbolic } \\
\text { representation of a scenario }\end{array}$ & & $\begin{array}{l}\text { Booth 1984; } \\
\text { Nathan and } \\
\text { Koedinger, } \\
2000\end{array}$ \\
\hline Reversal order error & & $\begin{array}{l}\text { Lockhead and } \\
\text { Mestre, } 1988\end{array}$ \\
\hline $\begin{array}{l}\text { Incorrect understanding of the } \\
\text { meaning of the variable }\end{array}$ & & $\begin{array}{l}\text { Lockhead and } \\
\text { Mestre, } 1988\end{array}$ \\
\hline Not checking the solution & & Wollman, 1983 \\
\hline Difficulty using inverse operations & & $\begin{array}{l}\text { Linchevski and } \\
\text { Herscovics, } \\
1996\end{array}$ \\
\hline Incorrectly simplifying like terms & & Ashlock, 2006 \\
\hline $\begin{array}{l}\text { Incorrect use or simplification of } \\
\text { distributive property }\end{array}$ & & Ashlock, 2006 \\
\hline $\begin{array}{l}\text { Difficulty expressing inverse } \\
\text { values in an equation }\end{array}$ & & $\begin{array}{l}\text { Swafford and } \\
\text { Langrall, } 2000\end{array}$ \\
\hline $\begin{array}{l}\text { Incorrect computation with } \\
\text { integers }\end{array}$ & & Vlassis, 2008 \\
\hline Difficulty transforming equations & & none \\
\hline Computational error & & none \\
\hline Correct answer & & none \\
\hline Correct answer, no work shown & & none \\
\hline $\begin{array}{l}\text { Correct answer but work shown } \\
\text { does not clearly lead to the correct } \\
\text { answer }\end{array}$ & & none \\
\hline Other & & none \\
\hline
\end{tabular}


Functions

Grade:

Year:

Test:

Question:

\begin{tabular}{|c|c|c|}
\hline Error & Paper Number & Reference \\
\hline $\begin{array}{l}\text { Not understanding proportionality } \\
\text { or non-proportionality of functions }\end{array}$ & & $\begin{array}{l}\text { Pugalee, } 2010 \\
\text { Van de Walle, } \\
2010\end{array}$ \\
\hline $\begin{array}{l}\text { Difficulty understanding that } \\
\text { variables can represent varying } \\
\text { quantities (such as in } y=3 x+2 \text { ) }\end{array}$ & & $\begin{array}{l}\text { Kieran, 1992; } \\
\text { Usiskin, } 1988\end{array}$ \\
\hline $\begin{array}{l}\text { Difficulty understanding the } \\
\text { algebraic form (equation form } \\
\text { rather than table or graph) of a } \\
\text { function. }\end{array}$ & & Usiskin, 1988 \\
\hline Difficulty graphing slope of a line & & $\begin{array}{l}\text { Kalchman and } \\
\text { Koedinger, } \\
\text { 2005; Labato } \\
\text { and Ellis, } 2010\end{array}$ \\
\hline $\begin{array}{l}\text { Difficulty understanding } \\
\text { independent and dependent } \\
\text { variables }\end{array}$ & & $\begin{array}{l}\text { Kalchman and } \\
\text { Koedinger, } \\
2005\end{array}$ \\
\hline $\begin{array}{l}\text { Difficulty moving between } \\
\text { equation, table, and graph } \\
\text { representations }\end{array}$ & & $\begin{array}{l}\text { Kalchman and } \\
\text { Koedinger, } \\
2005\end{array}$ \\
\hline Difficulty plotting points & & $\begin{array}{l}\text { Hadjidemetriou } \\
\text { and Williams, } \\
2001\end{array}$ \\
\hline Incorrectly interpreting function & & $\begin{array}{l}\text { Kilpatrick et } \\
\text { al., } 2001\end{array}$ \\
\hline Wrong operation used & & none \\
\hline Computational error & & none \\
\hline Correct answer & & none \\
\hline Correct answer, no work shown & & none \\
\hline $\begin{array}{l}\text { Correct answer but work shown } \\
\text { does not clearly lead to the correct } \\
\text { answer }\end{array}$ & & none \\
\hline Other & & none \\
\hline
\end{tabular}


Graphing

Grade:

Year:

Test:

Question:

\begin{tabular}{|c|c|c|}
\hline Error & Page Number & Reference \\
\hline $\begin{array}{l}\text { Not understanding proportionality } \\
\text { or non-proportionality of } \\
\text { functions }\end{array}$ & & $\begin{array}{l}\text { Post, et al., } \\
1988 \text {; Pugalee, } \\
2010\end{array}$ \\
\hline $\begin{array}{l}\text { Difficulty identifying the shape of } \\
\text { the function }\end{array}$ & & Blanton, 2008 \\
\hline Difficulty with graphing notation & & $\begin{array}{l}\text { Scheuermann } \\
\text { and van } \\
\text { Garderen, } 2008\end{array}$ \\
\hline Difficulty graphing slope of line & & $\begin{array}{l}\text { Kalchman and } \\
\text { Koedinger, } \\
\text { 2005; Labato } \\
\text { and Ellis, } 2010\end{array}$ \\
\hline $\begin{array}{l}\text { Difficulty understanding } \\
\text { independent and dependent } \\
\text { variables }\end{array}$ & & $\begin{array}{l}\text { Kalchman and } \\
\text { Koedinger, } \\
2005\end{array}$ \\
\hline $\begin{array}{l}\text { Difficulty moving between } \\
\text { equation, table, and graph } \\
\text { representations }\end{array}$ & & $\begin{array}{l}\text { Kalchman and } \\
\text { Koedinger, } \\
2005\end{array}$ \\
\hline Difficulty plotting points & & $\begin{array}{l}\text { Hadjidemetriou } \\
\text { and Williams, } \\
2001\end{array}$ \\
\hline Incorrectly interpreting graph & & $\begin{array}{l}\text { Hadjidemetriou } \\
\text { and Williams, } \\
2001 \text {; } \\
\text { Kilpatrick et } \\
\text { al., } 2001\end{array}$ \\
\hline Omitted ordered pair & & none \\
\hline Computational error & & none \\
\hline Correct answer & & none \\
\hline Correct answer, no work shown & & none \\
\hline
\end{tabular}




\begin{tabular}{|l|l|l|}
\hline $\begin{array}{l}\text { Correct answer but work shown } \\
\text { does not clearly lead to the correct } \\
\text { answer }\end{array}$ & none \\
\hline Other & & none \\
\hline
\end{tabular}




\title{
CURRICULUM VITAE
}

\author{
Sarah B. Bush \\ Bellarmine University \\ 2001 Newburg Rd. \\ Louisville, KY 40205 \\ Work Phone: 502-272-8135 \\ Email: sbush@bellarmine.edu
}

\section{Education}

2011 Doctor of Philosophy, Curriculum and Instruction: Mathematics Education University of Louisville

4.0 GPA

Dissertation Title: Analyzing Common Algebra-Related Misconceptions and Errors of Middle School Students

2008 Master of Education, Indiana Wesleyan University

4.0 GPA

2005 Bachelor of Science in Secondary Education Mathematics, Indiana University Southeast

4.0 GPA

University Teaching Experience

Assistant Professor of Mathematics Education, Bellarmine University (2011present)

Elementary Mathematics Methods (EDUC 336) (2011-present)

- Taught P-5 mathematics methods to pre-service undergraduate level elementary teacher candidates

Middle Mathematics Methods (EDUC 336) (2011-present)

- Taught 5-9 mathematics methods to pre-service undergraduate level middle school teacher candidates 
Teaching Mathematics in the Middle School (MAT 580) (2011-present)

- Taught 5-9 mathematics methods to pre-service graduate level middle school teacher candidates

Teaching Mathematics in the Secondary School (MAT 582) (2011-present)

- Taught 8-12 mathematics methods to pre-service graduate level high school teacher candidates

\section{University Supervisor of Middle School Mathematics Student Teachers} (2011-present)

- University supervisor to 5-9 undergraduate teacher candidates during their student teaching experience

\section{University Supervisor of Secondary Mathematics Student Teachers (2011-present)}

- University supervisor to 8-12 undergraduate teacher candidates during their student teaching experience

Doctoral Student, University of Louisville (2009-2011)

Elementary Mathematics Methods (EDTP 604), Co-Teacher (2010)

- Taught P-5 mathematics methods to pre-service graduate level elementary teacher candidates

Summer Portfolio Institute Leader (EDAP 611) (2010)

- Taught a group of graduate level teachers in developing curriculum and planning for a course that integrates mathematics, writing, science, and technology

- Engaged teachers in developing critical thinking for students in elementary and middle grades

\section{K-12 Teaching Experience}

\section{Mathematics Teacher, Highland Hills Middle School, Georgetown, Indiana (2005-} 2011)

- Taught middle school mathematics grades 7-8, Pre-Algebra, Algebra I, and Geometry as well as summer school for grades 5-6

- Adapted and implemented curriculum for students with special needs, traditional, honors, and gifted/talented students

- Developed curriculum for intervention summer camp

- Served on curriculum mapping council and assisted teachers in creating curriculum maps

- Experience teaching in an inclusive environment with a special education coteacher

- Served on Algebra I Task Force 
Mathematics Teacher, Indiana Virtual Academy, Versailles, Indiana (2007- present)

- Conducted distance learning instruction for Pre-Algebra, Algebra I, Geometry, Algebra II, Pre-Calculus, and Economics

- Piloted credit recovery program

- Created Pre-Algebra course assessments

Student Teacher, Jeffersonville High School, Jeffersonville, Indiana (2005)

- Taught Algebra I, Integrated Algebra II, and Honors Pre-Calculus

\section{Publications}

\section{$\underline{\text { Peer Reviewed Articles }}$}

Bush, S. (2010, September). Unfolding the solution of linear systems. Mathematics Teacher. 104(2), 160.

Ronau, R., Rakes, C., Bush, S., Driskell, S., Niess, M., \& Pugalee, D. (2011, September). Research Brief: Using Calculators for Teaching and Learning Mathematics. National Council of Teachers of Mathematics Research Brief

Bush, S., McGatha, M., \& Bay-Williams, J. Invest in financial literacy! Mathematics Teaching in the Middle School. (accepted)

Bush, S., Brown, E. T., Washburn, S. Teachers on the Hunt for Problem-Based Instruction. Middle Ground. (accepted)

Bush, S., \& Karp, K. (2011). Hunger games: What are the chances? Mathematics Teaching in the Middle School. (accepted)

\section{Submitted Publications}

Ronau, R., Rakes, C., Niess, M., Bush, S., Pugalee, D., Driskell, S. (2011) Nature and Quality of Mathematics Education Technology Research.

\section{In Progress Publications}

Bush, S., Pugalee, D., Driskell, S., Niess, M., Rakes, C. \& Ronau, R. (2011). What Have We Learned (or Failed to Learn) About the Use of Technology in Mathematics Education from 40 Years of Research. 
Rakes, C., Pugalee, D., Ronau, R., Driskell, S., Bush, S., \& Niess, M. (2011).

Technology Use in Mathematics Education: A Crosswalk Through a Comprehensive Database of Research, Theory, and Practice: 1968-2009.

Ronau, R., Niess, M., Bush, S., Pugalee, D., Rakes, C., Driskell, S. (2011). A Systematic Study of Dissertations in Mathematics Educational Technology and its Implications for Doctoral Programs.

Ronau, R., Niess, M., Driskell, S., Rakes, C., Pugalee, D., Bush, S. (2011). Teacher Knowledge in Mathematics Educational Technology: An Investigation into Research Quality, Scope, and Impact.

Rakes, C., Driskell, S., Ronau, R., Niess, M., Bush, S., Pugalee, D. (2011). An Examination of the Moderating Effect of Research Quality on the Measured Impact of Technology on Student Outcomes in Mathematics.

Choi, N., Bush, S., English, A., \& Truitt, T. (2011). Factorial validity of the scores from the TIMSS 2007 mathematics attitude scale.

\section{Peer-Reviewed Presentations}

Ronau, R., Rakes, C., Bush, S. (2012, April). Using Research in Mathematics Educational Technology to Inform Classroom Teaching. Presentation to be given at the Annual Meeting of the National Council of Teachers of Mathematics. Philadelphia, PA.

Bush, S. (2012, April). Analyzing Middle School Students' Algebra-Related Misconceptions and Errors. Presentation to be given at the Annual Meeting of the National Council of Teachers of Mathematics. Philadelphia, PA.

Rakes, C., Ronau, R., Bush, S., Driskell, S., Niess, M., Pugalee, D. (2012, January). A Structured Inquiry of Research in Mathematics Educational Technology: Findings and Implications. Presentation to be given at the Annual Meeting of the Association of Mathematics Teachers Educators. Fort Worth, TX.

Popelka, L., \& Bush, S. (2011, November). Developing Your Interdisciplinary Murder Mystery. Presentation to be given at the Annual Meeting of the National Middle School Association. Louisville, KY.

Driskell, S., Ronau, R., Rakes, C., Bush, S., Niess, M., Pugalee, D. (2011, October). Research in Mathematics Instructional Technology: Current Trends and Future Demands. Presentation to be given at the $33^{\text {rd }}$ Annual Conference of the North American Chapter of the International Group for the Psychology of Mathematics Education. Reno, NV. 
Bush, S., \& English-Hunter, A. (2011, October). Analyzing Middle School Students' Algebra-Related Misconceptions and Errors. Presentation to be given at the Regional Meeting of the National Council of Teachers of Mathematics. St. Louis, MO.

English-Hunter, A. \& Bush, S. (2011, October). Technology, Transformations, $2 D$ Animation, and Treasures-Making Geometry Come Alive! Presentation to be given at the Regional Meeting of the National Council of Teachers of Mathematics. St. Louis, MO.

Choi, N., Bush, S., English, A., \& Truitt, T. (2011, April). Factorial Validity of the Scores from the TIMSS 2007 Mathematics Attitude Scale. Presentation given at the Annual Meeting of the American Education Research Association. New Orleans, LA.

Higgins, R., English, A, \& Bush, S. (2011, April). Geometry and the Real WorldBudget Math Trips. Presentation given at the Annual Meeting of the National Council of Teachers of Mathematics. Indianapolis, IN.

Rakes, C., Ronau, R., Driskell, S., Niess, M., Pugalee, D., \& Bush, S. (2011, January). Research in Mathematics Instructional Technology: Current Trends and Future Demands. Presentation given at the Annual Meeting of the Association of Mathematics Teacher Educators. Irvine, CA.

Bush, S. (2010, October). Dollars and Sense! Developing Financially Literate Students. Presentation given at the Regional Meeting of the National Council of Teachers of Mathematics. New Orleans, LA.

Bush, S., \& English, A. (2010, October). Technology, Transformations, and Treasures. Presentation given at the Annual Meeting of the Kentucky Council of Teachers of Mathematics. Somersville, KY.

English, A., \& Bush, S. (2010, October). Implementing a Technologically Efficient Middle School Response to Intervention (RTI) Program. Presentation given at the Annual Meeting of the Kentucky Council of Teachers of Mathematics. Somersville, KY.

Bush, S. \& English, A. (2009, October). Dollars and Sense! Developing Financially Literate Students. Presentation given at the Annual Meeting of the Kentucky Council of Teachers of Mathematics. Bourbon, KY.

\section{Grants}

Horseshoe Foundation Grant (2011). Horseshoe Foundation of Floyd County: Technology (SMARTboard) Grant for Sixth Grade Classrooms, $\$ 16,000$

Graduate Student Travel Award (2011). University of Louisville: American Education Research Association Conference, \$231 
Great Classroom Teacher Grant (2011). New Albany-Floyd County Education Foundation: SmartPAL Classroom Set, \$187

Research and Faculty Development Grant (2010). University of Louisville: Analyzing Common Algebra-Related Misconceptions and Errors Among Middle School Students, $\$ 1,000$

Graduate Student Council Travel Grant (2010). University of Louisville: Association of Mathematics Teachers Educators Conference, $\$ 350$

Horseshoe Foundation Grant (2010). Horseshoe Foundation of Floyd County:

Technology (SMARTboard) Grant for Mathematics Department, $\$ 16,000$

Great Classroom Teacher Grant (2010). New Albany-Floyd County Education

Foundation: Mathematics-Related Children's Literature Books, \$233

Donors Choose Grant (2008). Classroom Technology and Manipulatives, private donor, approx. $\$ 390$

Donors Choose Grant (2007). Scientific Calculators Classroom Set, private donor, $\$ 500$

\section{National Service}

Program Chairperson, National Council of Teachers of Mathematics Regional Meeting, Louisville, KY, 2013

Mathematics Teaching in the Middle School - Manuscript Reviewer (2009 - present)

Journal for Research in Mathematics Education - Manuscript Reviewer (2011-present)

\section{Local Service}

President-Elect, Greater Louisville Council of Teachers of Mathematics, 2011-2013

Membership Chair, Greater Louisville Council of Teachers of Mathematics, 2010-Present

\section{University Service}

First Generation College Student Faculty Committee, Bellarmine University (2011present)

Teacher Representative, Secondary Education Advisory Group, Indiana University Southeast (2004-2010) 
Teacher Representative, Indiana Science Technology Engineering and Mathematics (ISTEM) Committee, Indiana University Southeast (2008)

\section{K-12 Service}

Strategic Planning Task Force, New Albany-Floyd County Schools (2011)

Leadership Academy, New Albany-Floyd County Schools (2011)

School-Wide Positive Behavior Support Plan Committee, Highland Hills Middle School (2010-2011)

Response to Intervention (RTI) Committee, Highland Hills Middle School (2009-2011)

Practicum Student Host, Highland Hills Middle School for Indiana University Southeast students (2006-present)

Curriculum Mapping Council, New Albany-Floyd County Schools (2008-2010)

Student Council Co-Sponsor, Highland Hills Middle School (2006-2010)

Responsible for coordinating dances, fundraisers, charity drives, red ribbon week, student/teacher of the month, teacher appreciation events, representative and officer elections, mix-it-up day, and spirit week

Algebra I Essential Map Task Force, New Albany-Floyd County Schools (2009)

Summer Camp Curriculum Task Force, New Albany-Floyd County Schools (2009)

Information and Analysis Committee, Highland Hills Middle School (2005-2007)

Chicago Chaperone Volunteer, Highland Hills Middle School (2006-2007)

Math Basic Skills Packet Curriculum Developer, Highland Hills Middle School (2006)

Success Skills Day Curriculum Committee, Highland Hills Middle School (2005)

\section{Professional Development/Consulting Experience}

Consultant for Transition to Common Core State Standards for Mathematics, Grades 5-8, New Albany-Floyd County Schools, (2011-present) 


\section{Other Professional Experience}

Indiana Department of Education Educator Learning Link Ambassador (2011)

IMAST Cut Score Setting Committee, Indiana Department of Education (2010)

Diagnostic Teacher Assessment in Mathematics (DTAMS) Trained Scorer (2009)

\section{Professional Affiliations}

Association of Mathematics Teacher Educators - Member

Greater Louisville Council of Teachers of Mathematics - President-Elect, Executive

Board, Membership Chair

Kentucky Council of Teachers of Mathematics - Member

National Council of Teachers of Mathematics - Member

\section{Scholarships, Honors, Awards}

Samuels Fellowship, University of Louisville (2011 fall)

Samuels Fellowship, University of Louisville (2011 summer)

Samuels Family Scholarship, University of Louisville (2011 spring)

Tribute to Excellence Annual Award, Highland Hills Middle School (2010)

Samuels Family Scholarship, University of Louisville (2010 fall)

Samuels Family Scholarship, University of Louisville (2010 summer)

Samuels Family Scholarship, University of Louisville (2010 spring)

Education Scholarship Award, University of Louisville (2009 fall)

Full Scholarship Award, University of Louisville (2009 summer)

Graduated with Highest Distinction, Indiana University Southeast (2005)

Chancellor's List (8 semesters), Indiana University Southeast (2001-2005)

Outstanding Practicum Student, Indiana University Southeast (2005) 
Kappa Delta Pi Outstanding Junior Award, Indiana University Southeast (2004)

Pearson Pi Lambda Theta Scholarship, Indiana University Southeast (2004)

Alpha Chi Honors Society, Indiana University Southeast (2004)

Pi Lambda Theta Education Honor Society, Indiana University Southeast (2004)

Outstanding Student Initiate Award, Phi Eta Sigma, Indiana University Southeast (2003)

Phi Eta Sigma Freshman Honor Society, Indiana University Southeast (2002)

Professional Licensures

Indiana Teacher License in Mathematics 5-12 (2005-present)

Indiana Teacher License in Economics 5-12 (2005-present) 